OECD Local Economic and Employment Development (LEED) Papers 2012/12

\title{
Skills Development Pathways in Asia
}

\section{Cristina Martinez-} Fernandez,

Kyungsoo Choi 


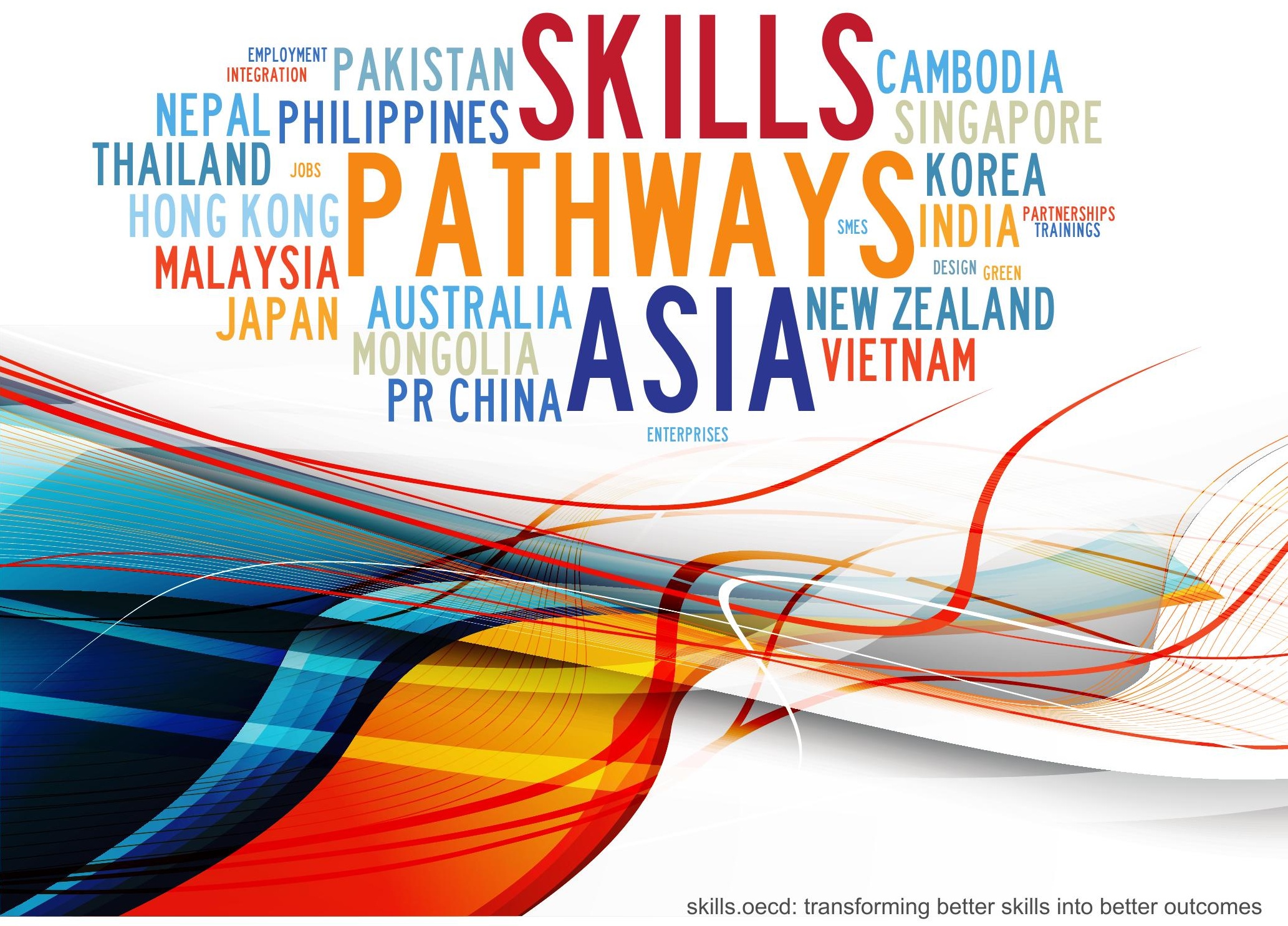

skills.oecd: transforming better skills into better outcomes

\section{Skills Development Pathways in Asia}
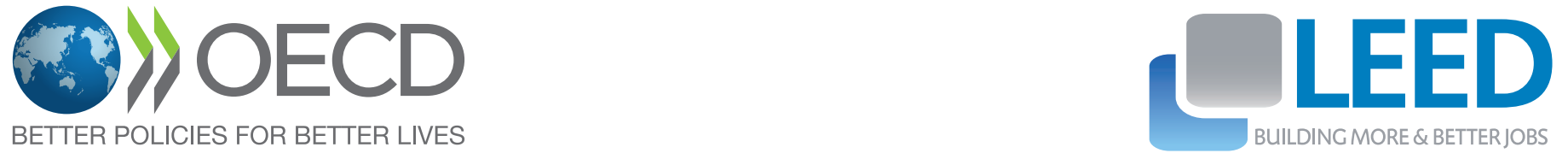



\section{About the OECD}

The Organisation for Economic Co-operation and Development (OECD) is a unique forum where the governments of 34 market democracies work together to address the economic, social and governance challenges of globalisation as well as to exploit its opportunities. The OECD's way of working consists of a highly effective process that begins with data collection and analysis and moves on to collective discussion of policy, then decision-making and implementation. Mutual examination by governments, multilateral surveillance and peer pressure to conform or reform are at the heart of the OECD's effectiveness.

Much of the material collected and analysed at the OECD is published on paper or online: from press releases and regular compilations of data and projections to one-off publications or monographs on particular issues; from economic surveys of each member country to regular reviews of education systems, science and technology policies or environmental performance. For more information on the OECD, please visit www.oecd.org/about.

\section{About LEED}

The OECD Programme on Local Economic and Employment Development (LEED) has advised government and communities since 1982 on how to respond to economic change and tackle complex problems in a fast-changing world. Its mission is to contribute to the creation of more and better quality jobs through more effective policy implementation, innovative practices, stronger capacities and integrated strategies at the local level. LEED draws on a comparative analysis of experience from the five continents in fostering economic growth, employment and inclusion. For more information on the LEED Programme, please visit www.oecd.org/cfe/leed.

\section{About the ESSSA initiative}

The initiative on Employment and Skills Strategies in Southeast Asia (ESSSA) facilitates the exchange of experiences on employment and skills development. Its objectives are to guide policy makers in the design of policy approaches able to tackle complex cross-cutting labour market issues; to build the capacity of practitioners in implementing effective local employment and skills development strategies; and to assist in the development of governance mechanisms conducive to policy integration and partnership at the local level. For more information on the ESSSA initiative, please visit www.oecd.org/cfe/leed/employment/esssa. 



\section{Foreword}

Skills and educational development for inclusive and sustainable growth are becoming significant drivers in OECD countries. Asian countries are not lagging behind on the challenge; on the contrary, they are working towards developing integrated pathways of skills and employment.

This report focuses on current efforts in 15 countries in the Asian region: Australia, Cambodia, China, Hong Kong, China, India, Japan, Korea, Malaysia, Mongolia, Nepal, Pakistan, the Philippines, Singapore, Thailand and Viet Nam. Together, these countries represent one of the most dynamic regions in the world, with steady growth, even during the recent financial crisis.

The strategic and policy pathways Asian countries are developing do not duplicate the approaches we can observe in other OECD countries: a different model is emerging from their efforts and vision. Skills development pathways in Asia have a significant focus on developing skills infrastructure in an integrated way with physical infrastructure and therefore taking greater advantage of the synergies of capital investment and industry growth for the large infrastructure projects that the majority of these countries are undertaking. Much can be learned for the experiences in the region. This report is an initial insight into the skills challenges ahead for Asian economies but also of the originality of the approaches and the pathways they are choosing.

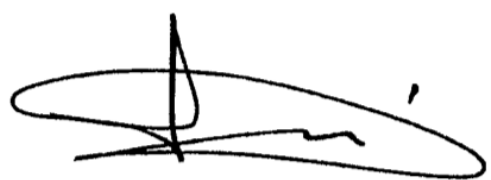

Sergio Arzeni

Director, Centre for Entrepreneurship, SMEs and Local Development 


\section{Acknowledgements}

This report presents a summary of the discussions held at the annual meetings of the Employment and Skills Strategies in Southeast Asia initiative (ESSSA) in Tokyo (2010) and Shanghai (2011) in relation to policies and programmes for skills development approaches in Asian countries. The report was edited and prepared by Dr. Cristina Martinez-Fernandez and Dr. Kyungsoo Choi of the OECD LEED Programme. Dr. Sylvain Giguere, Head of the LEED Division, provided valuable guidance and comments. The report is largely based on the original contributions from the following 15 countries: Australia, Cambodia, China, Hong Kong, China, India, Japan, Korea, Malaysia, Mongolia, Nepal, Pakistan, the Philippines, Singapore, Thailand and Viet Nam. We are grateful to the contributors and government departments who collaborated on this report (see list in Annex A).

We are also grateful to the comments received from experts participating in the meetings and particularly to Mr. Paul Baker, Senior Manager, Education System Strategy, Ministry of Education, New Zealand; Mr. Robert Strauss, Head of Employment Analysis in the European Commission's Directorate General for Employment, Social Affairs and Inclusion; and Ms. Noela Eddington, Director of VET Strategy and Research, Department of Education and Training in Queensland, Australia. Our gratitude to Ms. Shiho Ono, International Affairs Division, Ministry of Health, Labour and Welfare, Japan for her revisions.

This work has been undertaken under the Employment and Skills Strategies in Southeast Asia initiative supported by the European Commission. Research assistance was provided by Dr. Tamara Weyman (consultant) and Ms. Elisa Campestrin of the OECD LEED Trento Centre. Mr. François Iglesias of the OECD LEED assisted with the editorial process. Ms. Elisa Campestrin designed the cover. Ms. Jennifer Allain edited the report for publication. 


\section{Table of contents}

Chapter 1 An overview of skills development pathways in Asia by Cristina MartinezFernandez and Kyungsoo Choi..................................................................................................... 13

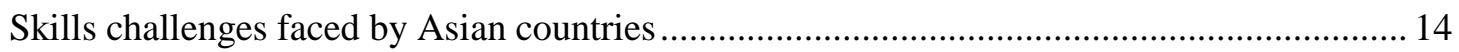

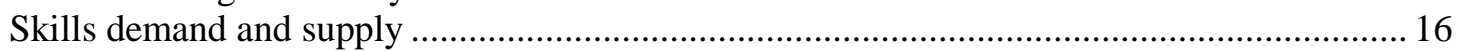

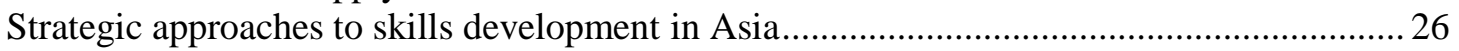

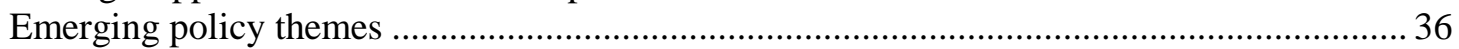

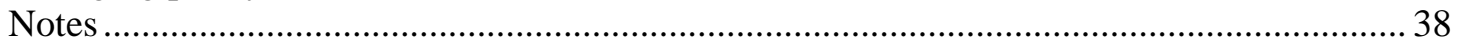

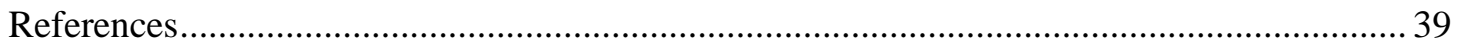

Part I The challenges for skills development in Asia ..................................................................... 41

Chapter 2 Lessons for skills policy frameworks by Shanti Jagannathan ................................. 43

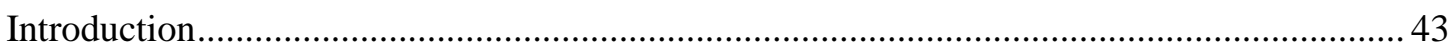

Priorities and preoccupations of developing countries in skills training and TVET ............... 43

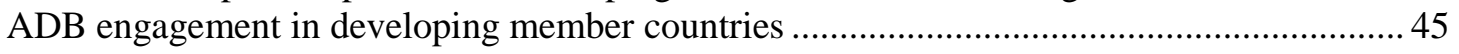

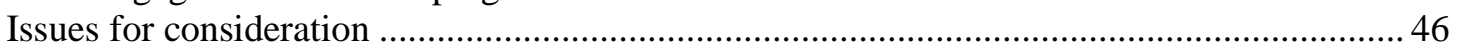

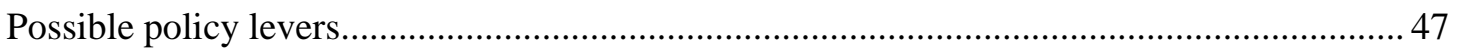

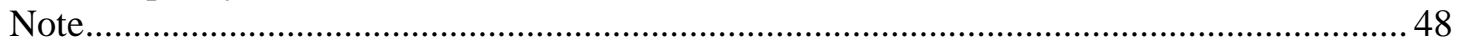

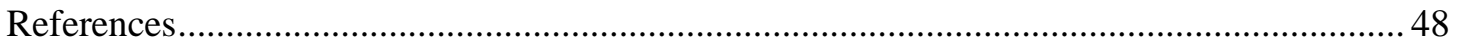

Chapter 3 Integrating skills, employment and local development by Randall Eberts ........... 49

Integrating skills development for sustained growth .................................................................. 49

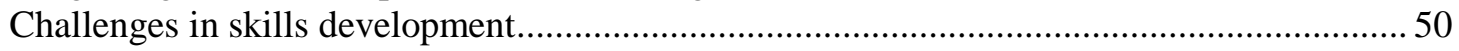

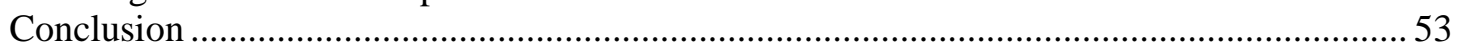

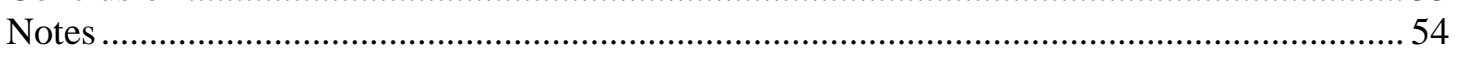

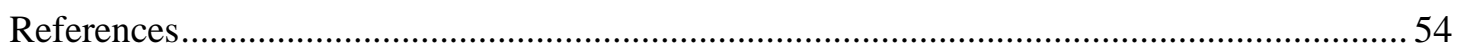

Chapter 4 Building effective local partnerships for skills development by Graham Larcombe .................................................................................................................................................................... 55

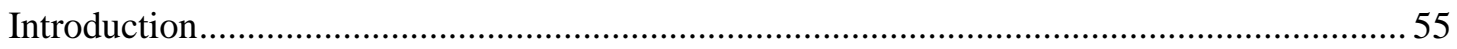

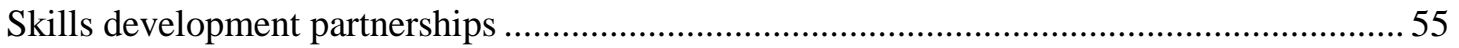

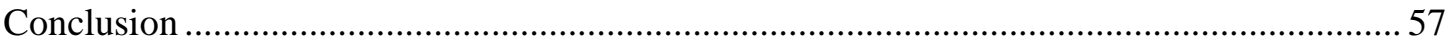

Part II Developing skills systems for growth ..............................................................................59

Chapter 5 Skills development to support rebalancing employment growth in China

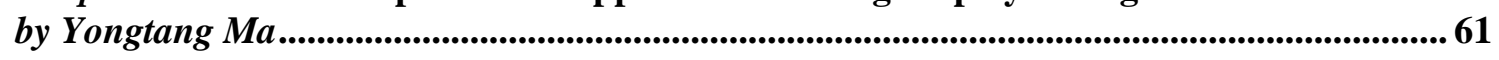

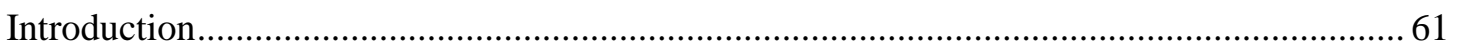

Special vocational training programmes responding to the impact of the global

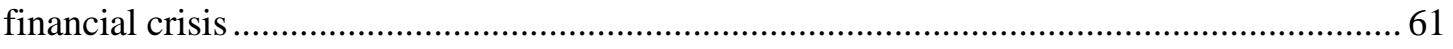

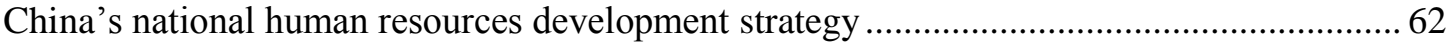


Chapter 6 Mainstreaming skills training: Malaysia's skills and the future by Ghazlan Ghazali

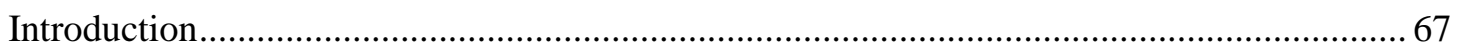

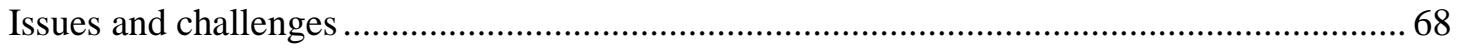

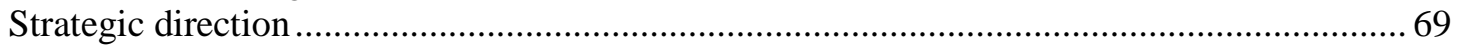

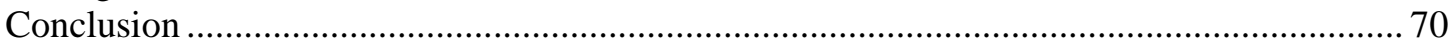

Chapter 7 Integrated skills: an approach for strengthening the Technical and Vocational Education Program (STVEP) in the Philippines by Milagros Campos

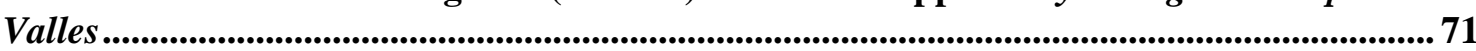

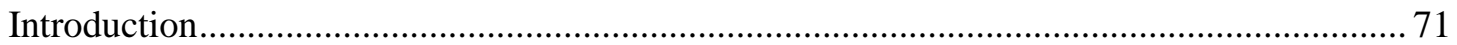

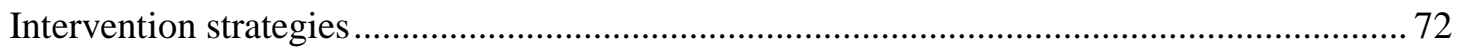

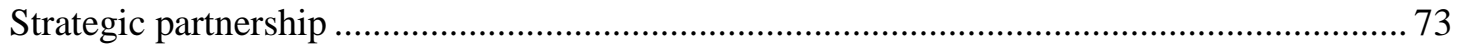

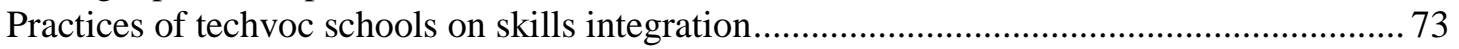

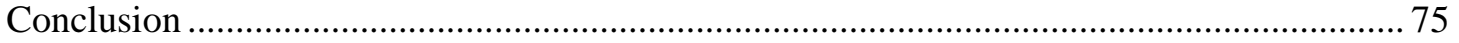

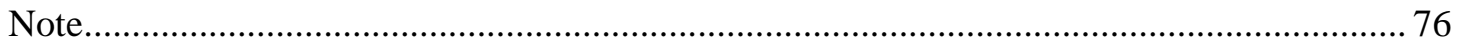

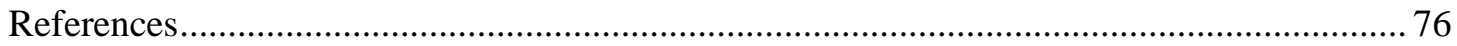

Chapter 8 Vocational training in large companies and SMEs in Korea by Kyetaik Oh ....... 77

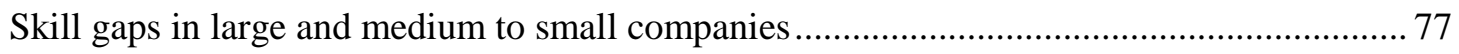

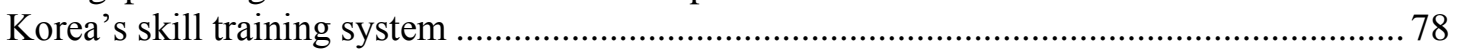

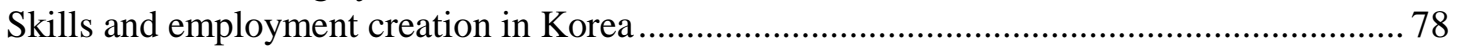

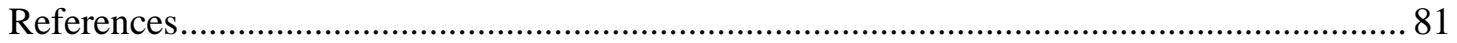

Chapter 9 Measures for skills development and employment in Viet Nam by Hoang

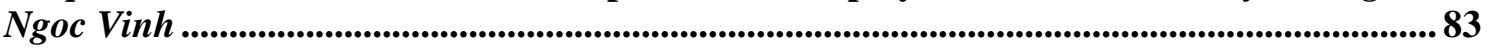

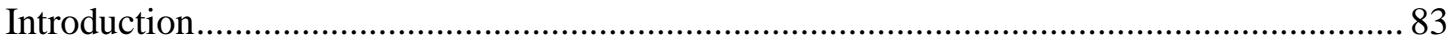

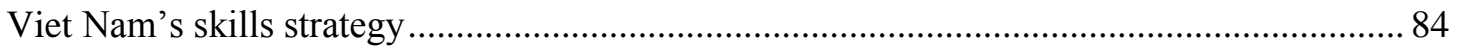

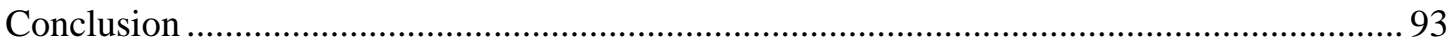

Chapter 10 Thailand's skills strategy by Dhida Wiwaha ............................................................... 95

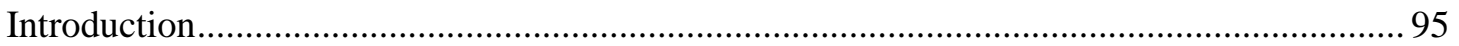

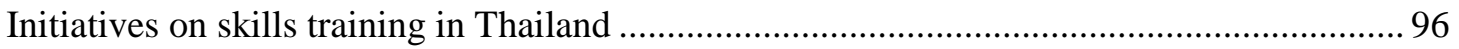

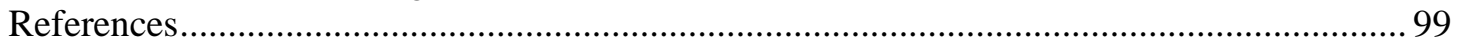

Chapter 11 Cambodia's technical education system in high schools by Vuthy Va ............. 101

Technical education in high schools ................................................................................... 101

Strategies to expand technical and vocational education ........................................................ 102

Chapter 12 Skills policy framework for the next decade in China by Jing Dong ................. 105

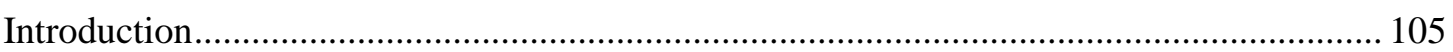

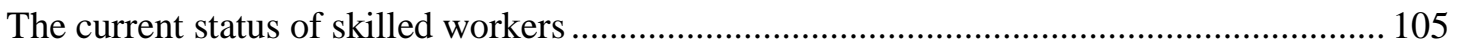

The policy framework for skilled workers in the next decade............................................ 106

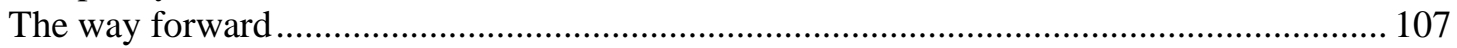

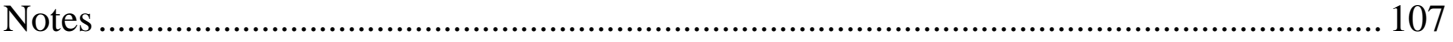


Chapter 13 "Skilling Pakistan": National Skills Strategy by Sajid Manzoor Asadi............. 109

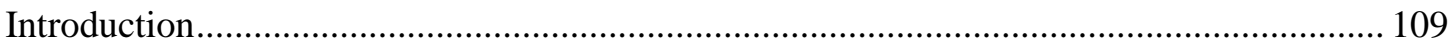

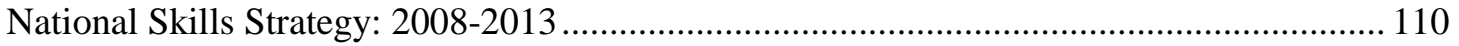

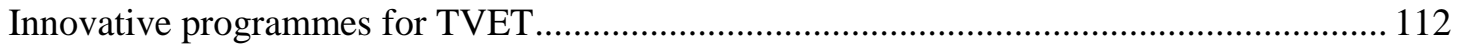

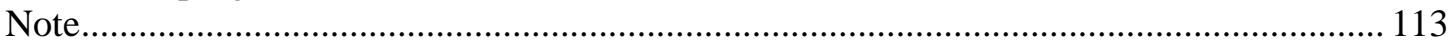

Chapter 14 Integrating skills, employment and economic development: the south

Asian context by Ranabhat Baburam ................................................................................................... 115

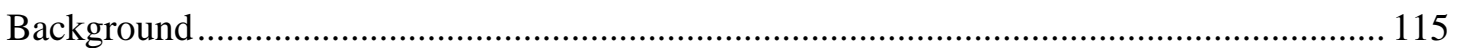

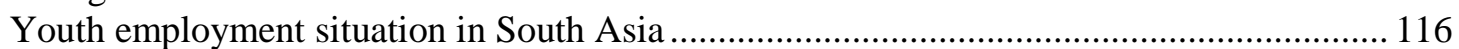

Challenges for the government and policy makers ................................................................ 117

The way forward and policies for employment generation ................................................. 117

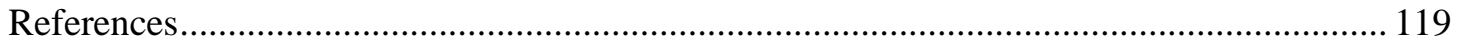

Chapter 15 Public Vocational Training Framework in Japan by Doui Yasuhiro ................ 121

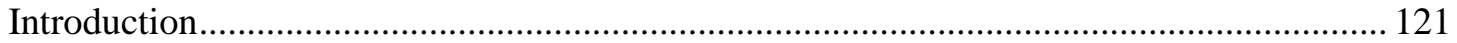

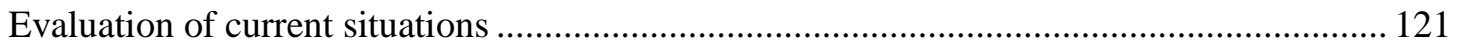

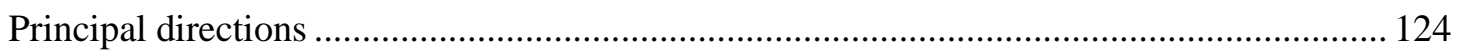

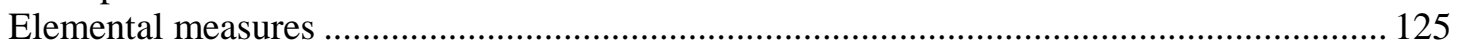

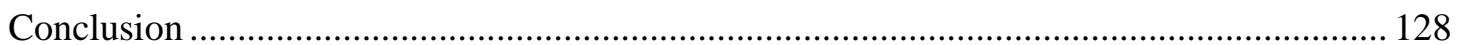

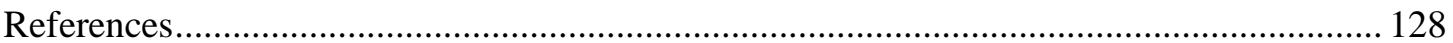

Chapter 16 Introduction to employment and social welfare policies and programmes in Mongolia by Amartugs Tsenddavaa .............................................................................................. 129

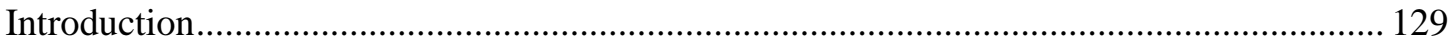

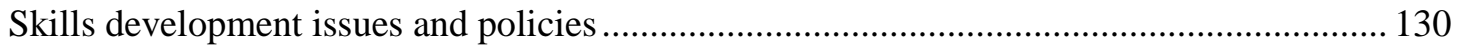

Chapter 17 SMEs' important role in creating jobs in the post-crisis by Yasuhiko Yoshida ................................................................................................................................................... 133

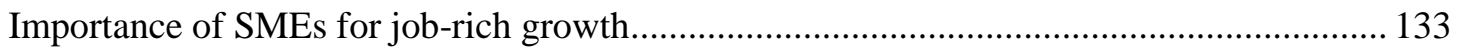

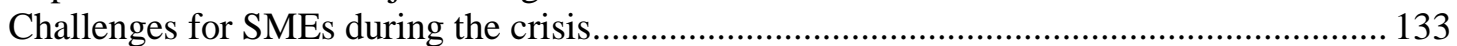

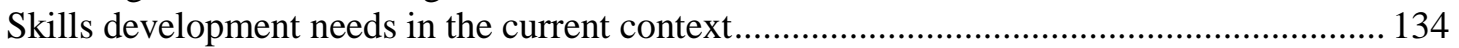

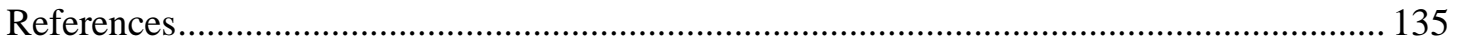

Part III Workplace training and local ecosystems ....................................................................... 137

Chapter 18 Shanghai's talent development strategy for becoming an international financial centre by Kouqing $\mathrm{Li}$...................................................................................................... 139

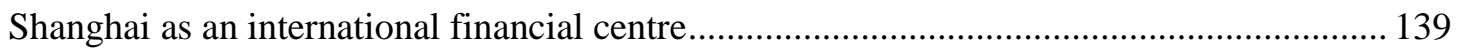

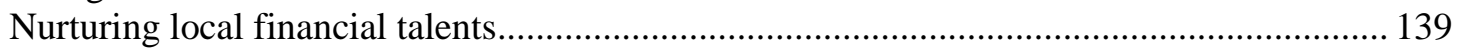

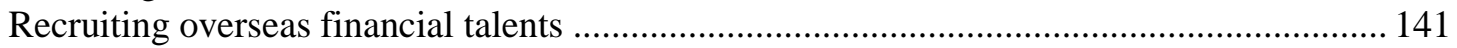

Improving the development environment for financial talents in Shanghai ......................... 141

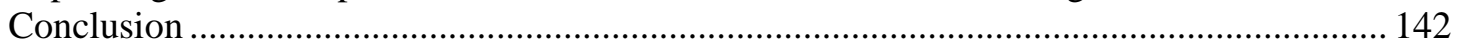

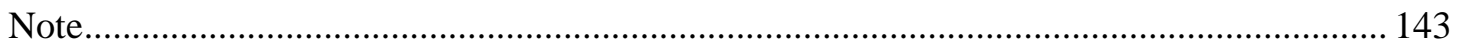

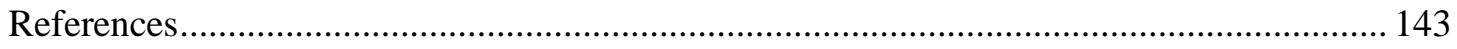


Chapter 19 Hong Kong Qualifications Framework: A platform for skills development and responding to changing market needs by Bing Hung Pang ................... 145

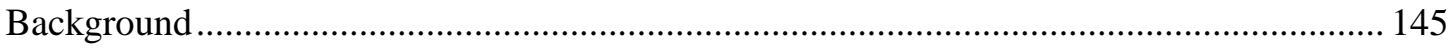

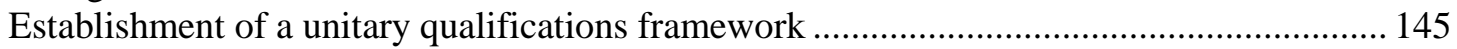

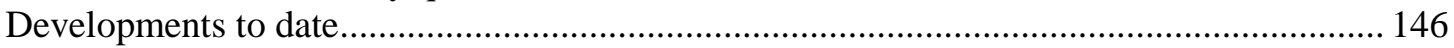

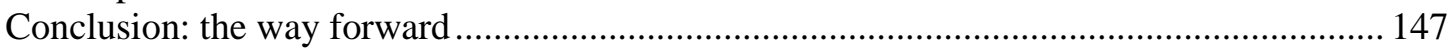

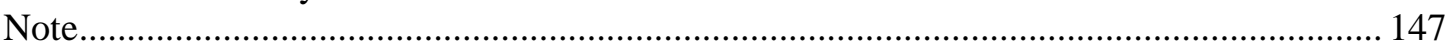

Chapter 20 Skills development for SMEs and micro enterprises in the Philippine by Marissa Grasparil Legaspi ................................................................................................ 149

MSMEs in the Philippines and the impact of the crisis ...................................................... 149

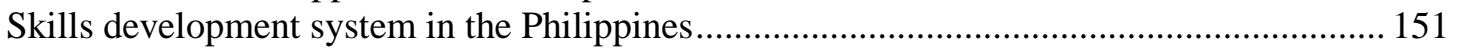

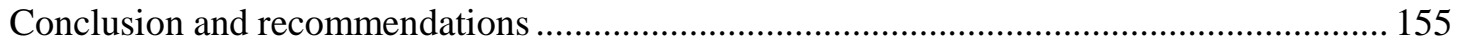

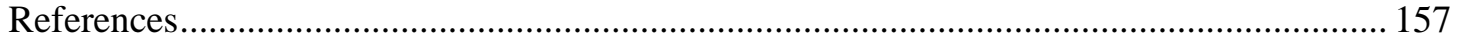

Chapter 21 An area-based approach to skills development in Australia by Caroline

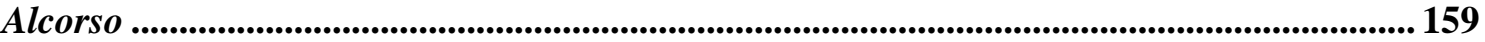

Post-school education participation and government targets........................................... 159

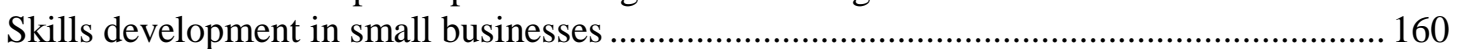

How can we better connect small businesses with formal and structured training? .............. 165

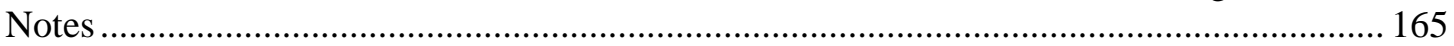

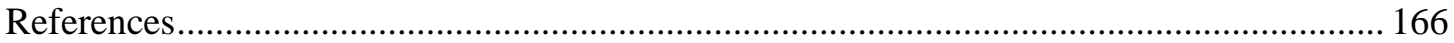

Chapter 22 Challenges and strategies in the local partnership approach to training in Japan by Yoko Nitta ......................................................................................................................... 167

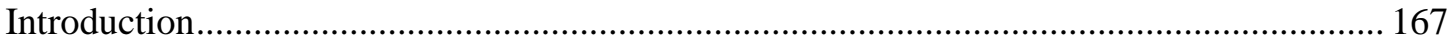

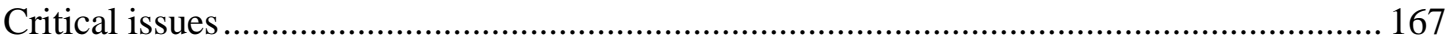

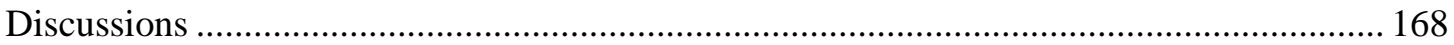

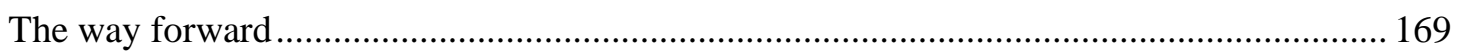

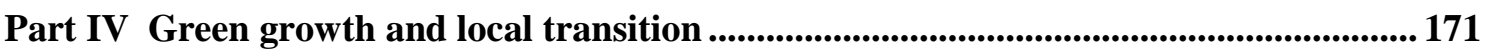

Chapter 23 Green job creation in Korea: issues and policies by Seung Teak Kim and Kyungsoo Choi............................................................................................................................................... 173

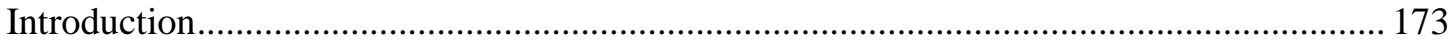

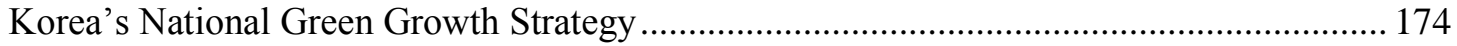

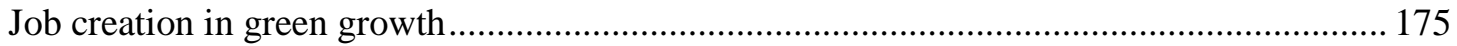

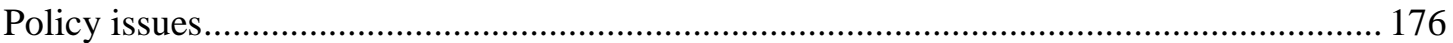

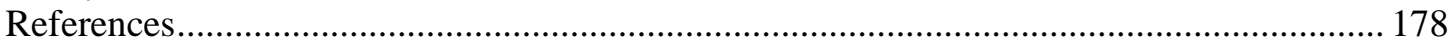

Chapter 24 Skills development for green jobs in Singapore by Bhavani Prakash and

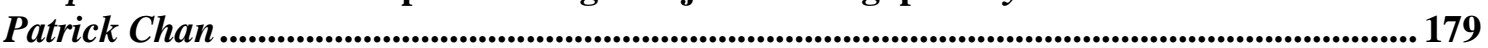

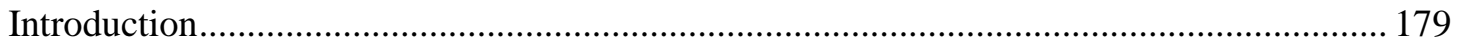

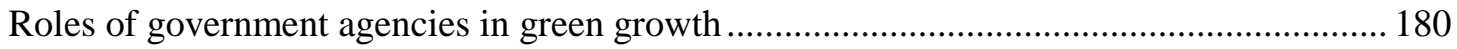

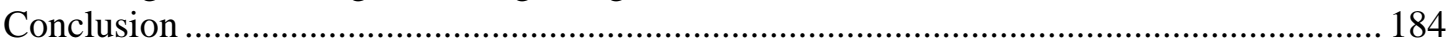

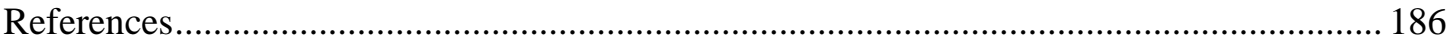


Chapter 25 Educating for sustainability: Australian green skills initiatives and employment services by Sally Sinclair ............................................................................................ 189

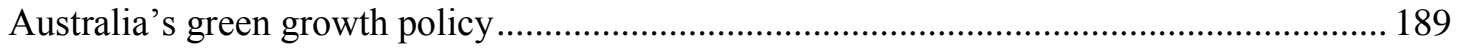

The role of employment services providers ....................................................................... 190

\section{Chapter 26 Skills for low-carbon growth: an Indian perspective by Sunita Sanghi and}

Jeevan Sharma ............................................................................................................................................... 191

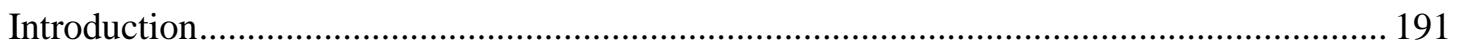

Challenges and priorities for low-carbon growth and skills response ................................ 192

Challenges for skills development and skills strategy ....................................................... 197

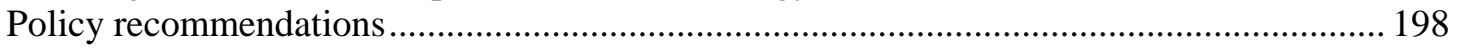

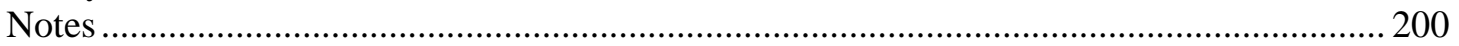

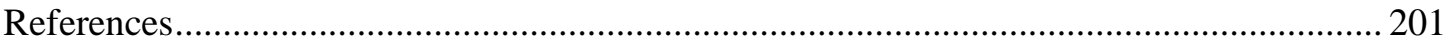

Chapter 27 Skills development and green jobs in Thailand by Silpa Archa Nakorn........... 203

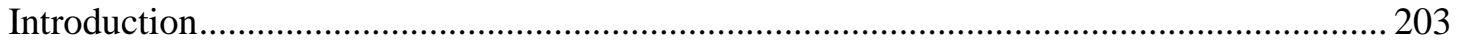

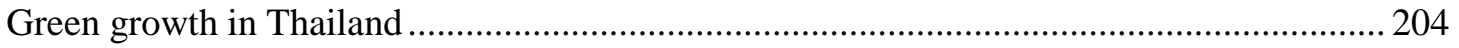

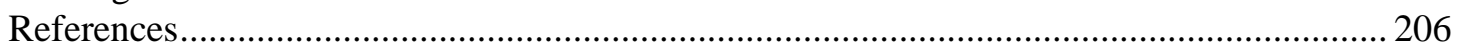

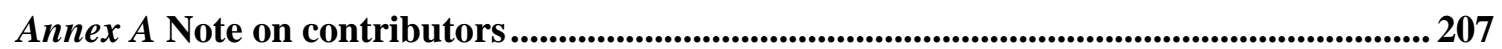

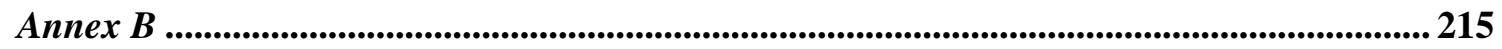

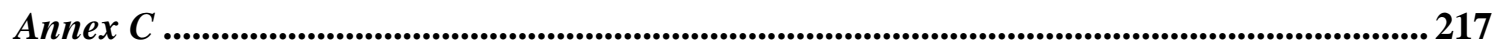

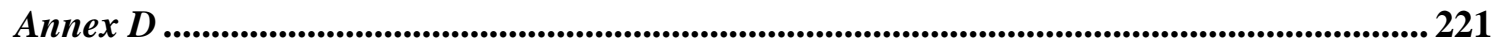

\section{Tables}

Table 9.1. Trained personnel for 2010, 2015 and 2020 and percentage of labour force....... 88

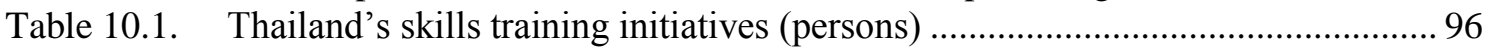

Table 10.2. Public and private sector skills training (persons) ................................................. 97

Table 10.3. Composition of the Department of Skill Development's training areas ............... 97

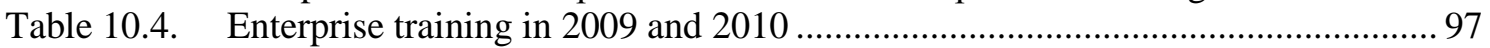

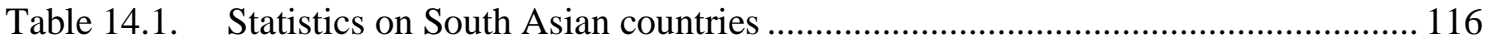

Table 21.1. Use of the VET system and provision of training in the last 12 months by employer size, 2009................................................................................ 160

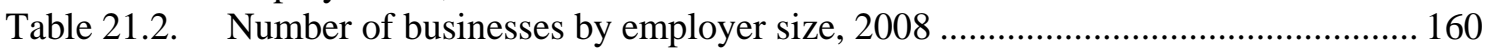

Table 21.3. Adequacy of employee skills by employer size, 2005* ................................. 161

Table 21.4. Innovation activity by business size, 2008-2009............................................ 163

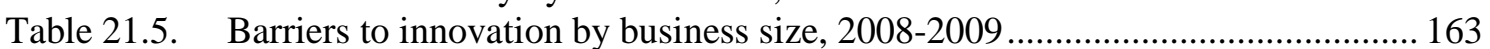

Table 21.6. Sources of innovation by business size, 2008-2009 ........................................... 164

Table 23.1. Expected employment effect from the United Kingdom's renewable

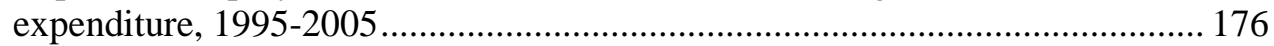

Table 26.1. India's National Action Plan on Climate Change .............................................. 193

Table C.1. Educational attainment by labour force (age cohort), 2008 ............................... 217

Table C.2. Ratio of total graduates to labour force by field of education (\%) ...................... 218 


\section{Figures}

Figure 1.1. Skills demand in Asia: employment by aggregated sector in 2000 and 2010 ......

Figure 1.2. Shares of high-, medium- and low-skilled occupations in total

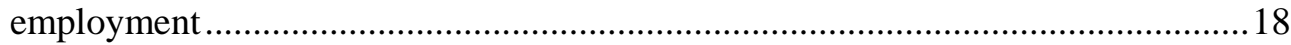

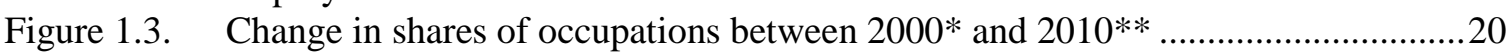

Figure 1.4. Educational attainment by labour force (age cohort), 2008 ..................................23

Figure 1.5. Broad field of education (tertiary) as a ratio to total graduates ..............................24

Figure 1.6. Science and engineering graduates as a \% of the labour force, 2009......................25

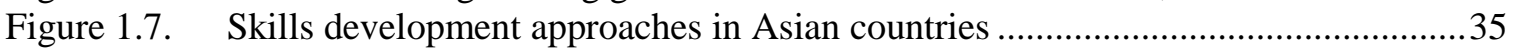

Figure 4.1. Relationship between central and local education authorities................................57

Figure 8.1. Compositions of occupations by firm size .......................................................... 77

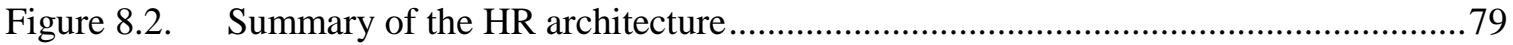

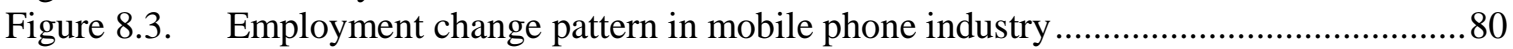

Figure 8.4. Employment change pattern in automobile industry .............................................. 80

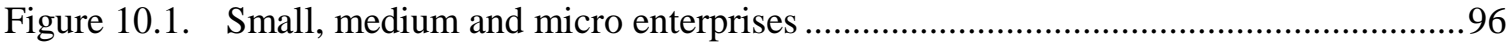

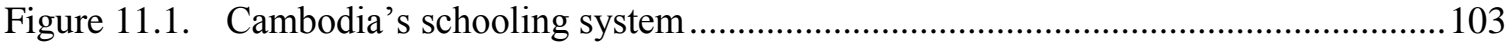

Figure 14.1. Conceptual framework for participative planning ................................................. 118

Figure 14.2. Workforce development for foreign employment ................................................119

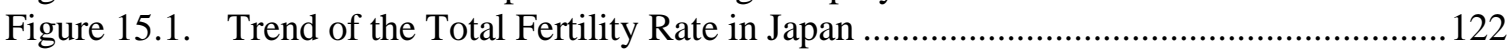

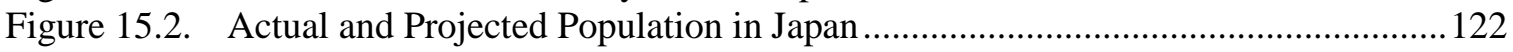

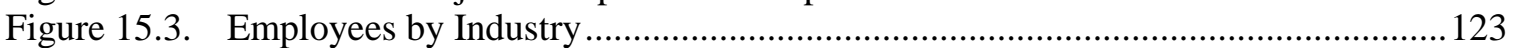

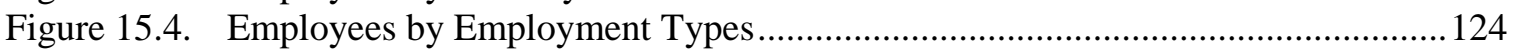

Figure 21.1. National Skill Ecosystem Program: a broader approach to skills .......................... 164

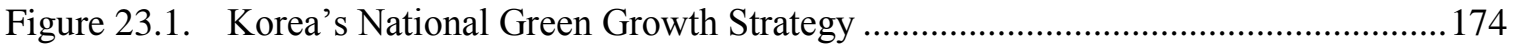

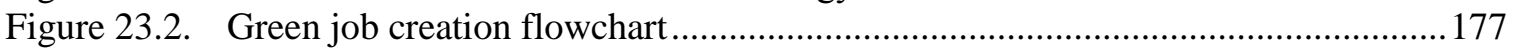

Figure B.1. Shares of higher-skilled occupations in employment.........................................215

Figure B.2. Shares of medium-skilled (trade and machine operators/assemblers) occupations in employment ..............................................................................2216

Figure B.3. Shares of agricultural and elementary occupations in employment ......................216

Figure C.1. Broad field of education (tertiary) as a ratio to total graduates ............................2.219 


\title{
Chapter 1
}

\section{An overview of skills development pathways in Asia}

\author{
by \\ Cristina Martinez-Fernandez \\ and Kyungsoo Choi
}

Skills development is high on the sustainable growth agenda of developing Asian countries. Those Asian countries which depended on their cheap labour force and exports for economic growth, are increasingly finding that their growth is being limited by the deteriorating terms of trade and vulnerability to other countries' troubles. This was made clear by the recent global financial crisis and the ongoing economic recession in many advanced countries. In the wake of the global financial crisis, developing Asian economies are now adapting their development strategies and taking up the challenge of "rebalancing growth" towards greater reliance on domestic and regional demand (OECD/International Labour Office, 2011). These countries are making adjustments to their labour market and social policies for a job-rich and sustainable recovery, albeit to different degrees and within their country-specific situation.

It is in this context that most developing Asian countries are endeavouring to upgrade the skills of their labour force for sustained growth and further job creation, as skill development is a way for these countries to continue their growth and move from a middle-income country to a high-income country. For large economies, such as China or India, this means rebalancing their growth strategy from being dependent on foreign demand towards a greater reliance on domestic and regional demand. But for smaller economies, the prime objective is to move into newly growing industries. Each country has different objectives and adopts different strategies to attain them.

Asian countries are among the most dynamic economies in the world. As a result of their rapid growth, several countries are experiencing skill shortages in higher skilled manufacturing. As a response, they have ambitious plans for increasing vocational education and training as part of their national development plans. However, it remains to be seen how these plans will be implemented at the local level.

This report discusses inputs and conclusions from two experts' meetings of the "Skills and Employment Strategies in Southeast Asia Initiative" (ESSSA) held in Tokyo in 2010 and Shanghai in 2011 on integrating skills development strategies. ${ }^{1}$ It includes brief country-specific chapters of skills development strategies and policies from the following 15 countries: Australia, Cambodia, China, Hong Kong, China, India, Japan, Korea, Malaysia, Mongolia, Nepal, Pakistan, Philippines, Singapore, Thailand and Viet Nam. The analysis and emerging policy themes are based on the original contributions. 
This introductory chapter is divided into three sections: $i$ ) skills challenges faced by Asian countries; ii) strategic approaches to skills development in Asian countries; and iii) emerging policy themes.

\section{Skills challenges faced by Asian countries ${ }^{2}$}

The challenges faced by Asian countries are diverse as is their stages of economic development. Asian countries are faced with the following skills challenges:

1. Building up a system for training or creating a training market. Many countries have an outdated system and lack sufficient facilities and equipment or qualified instructors. Several ways for building up the training system are being pursued, such as creating additional training academies, imposing skill levies, and using apprenticeship models. A common element is that increasingly involvement of the private sector.

2. Reducing skills mismatches and increasing the links between training and industry needs. As the industry skill demand is quickly upgrading, growing economies are faced with a widening gap between skill supply and demand. Several approaches are taken in this regard. One is the "train the trainers" model. When private sector initiative in providing new skills training is deficient, the public sector traning for instructors can be most efficient way in propogating new skills. The cost is charged to companies in some cases. A second model is to give subsidies to a leading technology company to provide training not only to their own workers but also to the unemployed or workers from other small to mediumsized companies. For example, Mongolia subsidies on-the-job training in enterprises for the unemployed with its Employment Promotion Fund. The Philippines seeks to strengthen industry education and training linkages with a focus on an enterprise-based training system. Thailand provides incentives to companies such as income tax breaks via the Skill Development Promotion Act (2002) and has a National Vocational Training Co-ordination Committee to co-ordinate with the private sector.

3. Upgrading outdated training systems and under-qualified instructors. There is need to assure the quality of skills training and create vocational pathways for high school leavers. In countries such as Cambodia, Indonesia, Lao People's Democratic Republic, Mongolia, the Philippines and Viet Nam, despite the high unemployment rate among college graduates, vocational training paths are not chosen and high school graduates and their parents value academic studies over vocational studies and aim at white collar jobs unrelated to industry demands. To improve the status of vocational training and attract youth to where there is demand, competency based training is needed. A National Qualification System (NQS) needs to be constructed. Quality assurance and industry ownership in training is often absent in developing countries and administrative problems or conflicts between authorities exist. For example, Pakistan plans to streamline the existing fragmented training system with a focus on centres of excellence. China is setting up a national system of honours and rewards for skill masters in an effort to improve the public's perception of skill training.

4. Increasing industry participation and ownership. One of the major weaknesses in developing Asian countries' skill development system is lack of industry participation and ownership in training. The vast majority of firms are small and 
medium sized ones and their investment in training is insufficient as they lack the required resources or they have a short planning horizon. On the other hand public sector training provision are often supply-oriented with weak links to demands. There are examples of private sector leadership. Indonesia's Malang Migrant Workers Training Centre is a privately owned training centre for female migrant workers, specialising in domestic works in Hong Kong, China and Singapore. The company that runs the centre has branches nationwide and offers training services for prospective migrants to the electronics sectors of neighbouring Malaysia (mostly men) as well. In this case, training is an integral part of the company's service provision. Unfortunately, the vast majority of firms (SMEs) do not have such well-established training systems.

Some examples of national strategies for skills development are presented in Box 1.1.

\section{Box 1.1. Examples of national skills plans}

Pakistan's National Skill Strategy (2008-2013) sets the following four goals:

1. streamline policy making;

2. build centres of excellence;

3. enhance the role of the private sector in policy making, designing and setting standards in training;

4. improve apprenticeship training systems and provide more flexibility in industries' selection of trainees and the structure of the training.

Malaysia's Tenth Five-Year Plan (2011-2015), technical and vocational education part:

1. improve the perception of technical and vocational education and training (TVET) and attract more trainees;

2. develop highly effective TVET instructors;

3. improve and align the quality of TVET curriculum with industry needs;

4. streamline the delivery of TVET.

China's $12^{\text {th }}$ Five-Year Plan for National Economic and Social Development:

1. increase upskilling and on-the-job training of skilled workers;

2. accelerate the development of tertiary industry skilled workers - IT, service sector, etc.;

3. low-carbon and green industry sector skilled workers.

Source : OECD (2010)

These challenges are interrelated and cannot be addressed in isolation. In practice, this creates the challenge of integrating skills strategies, which requires a dedicated dialogue among different ministries and departments for policy cohesion and co-ordination. The issues of skills demand and supply, analysed in the next section, allow greater understanding the context to which these challenges apply. 


\section{Skills demand and supply ${ }^{3}$}

The Asian economies have experienced a sustanined productivity growth since 1991, driven mostly by East Asia, see box 1.2 (ILO, 2012) Despite the sustained growth, the weak global demand for export-oriented products is predicted to affect the region, decelerating economic and job growth in the manufacturing sector.

Other variables also impact the supply and demand for skills, especially within East Asia where the population is ageing rapidly, and according to the ILO (2012), this would result in flat labour force growth during the next decade. Vulnerable employment within the South-East Asia and the Pacific region remains a signficant challenge, and although progress has been made to reduce working poverty, this decline has slowed considerably in recent years (between $2008-11$ ).

\section{Box 1.2. Asia accounts for all of the catch-up in productivity levels between the developing and developed regions}

"The three Asian regions, in contrast, have seen tremendous productivity growth and have been on a strong path of convergence with the developed economies, albeit from very low initial productivity levels. The Asian regions have therefore accounted for all of the catch-up in levels of labour productivity between thedeveloping and developed regions between 1991 and 2011. This, in turn, was driven largely by productivity growth in East Asia, where output per worker stood at 20 per cent of the level in the developed economies in 2011, against only 6 per cent in 1991 . This figure is projected to climb to 26 per cent in 2016. The figure for South Asia increased from 6 per cent of the level in the developed economies in 1991 to 11 per cent in 2011 and is projected to rise to13 per cent in 2016. In South-East Asia and the Pacific, output per worker stood at 14 per cent of the level in the developed economies, up from 10 per cent in 1991 . The level is projected to rise only slightly to 15 per cent in 2016. The relatively weak productivity growth in much of the developing world outside of Asia is one key factor explaining the persistence of working poverty."

Source: ILO (2012), p.40.

\section{Skills demand by aggregated sector}

Employment trends by aggregated sector (agriculture, industry, and services) highlight the sectors where net skills are in demand, stable or in decline (see Figure 1.1). Agriculture is still a significant part of the economy but services dominate greatly over industry, which is the least intense sector.

Agriculture. Five of the countries have large agriculture sectors, accounting for over $50 \%$ of employment: Cambodia (72.2\% in 2008), India (51.1\% in 2010), Myanmar (62.7\% in 1998), Nepal (76.1\% in 2001) and Viet Nam (51.7\% in 2006). Large declines in agricultural employment were experienced in Viet Nam (-13.6\% from 2000-2006), China (-10.4\% from 2000-2008) and Mongolia (-8.6\% from 2000-2009).

Industry. Countries with large shares of employment in industry include China (27.2\% in 2008), Japan (25.3\% in 2010) and Malaysia (27\% in 2009). The country with the lowest share of employment in industry is Cambodia (8.6\% in 2008). Changes in the shares of employment in industry fluctuate between countries: large declines were experienced in Korea (-11.1\% between 2000-2010), Hong Kong, China (-7.9\% from 2000-2009), Japan (-5.9\% from 2000-2010) and Malaysia (-5.2\% from 2000-2009). 
Specific areas of industry decline were in manufacturing, especially in Australia, Korea, Malaysia, New Zealand and Singapore. However, Viet Nam experienced a large bound in industry skills (7.8\% from 2000-2006), especially in manufacturing and construction, with industry growth also occurring in China $(4.7 \%, 2000-2008)$ and Pakistan $(2.1 \%$, 2000-2008).

Services. Most developed countries have a heavy reliance (over 70\%) on service skills including: Australia (75.5\% in 2009), Hong Kong, China (87.4\% in 2009), Korea (76.4\% in 2010) and New Zealand (72.5\% in 2009). Cambodia relies the least on services skills (19.2\% in 2008). Generally, in the past decade (2000-2010) there has been an overall rise in service employment, with major increases occurring in Korea $(15.2 \%$ between 2000-2010), Malaysia (10.0\% from 2000-2009) and Hong Kong, China (8.0\%, 2000-2009). The share of employment in services grew significantly in China, Mongolia, Thailand and Viet Nam over the last decade.

Figure 1.1. Skills demand in Asia: employment by aggregated sector in 2000 and 2010

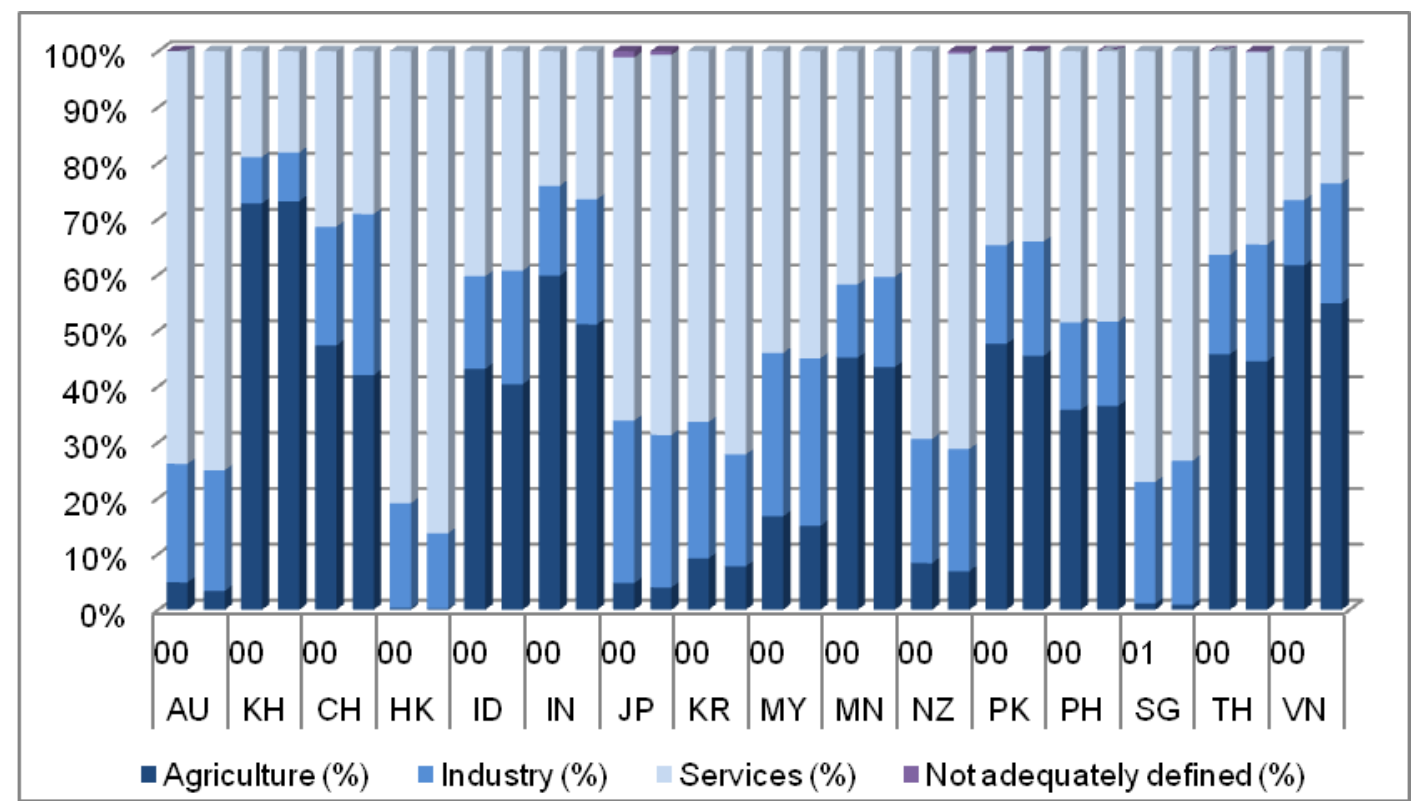

Note: Australia (AU); Cambodia (KH); China (CH); Hong Kong, China (HK); India (IN); Indonesia (ID); Japan (JP); Korea (KR); Malaysia (MY); Mongolia (MN); New Zealand (NZ); Pakistan (PK); Philippines $(\mathrm{PH})$; Singapore (SG); Thailand (TH); and Viet Nam (VN). Data for Singapore from 2001. Data for Viet Nam from 2006; Cambodia, China and Pakistan for 2008; Australia, Hong Kong, China, Malaysia, Mongolia, New Zealand, the Philippines, Singapore and Thailand for 2009.

Source: Based on ILO (2011), Key Indicators of the Labour Markets (KILM), $7^{\text {th }}$ edition, ILO, Geneva.

\section{Skills demand by occupation}

Examining skills demand by occupation shows that, generally, the more developed the country is, the more highly skilled occupations are available, compared to developing countries which seem to rely on lower skilled occupations. The higher skilled occupations such as professionals, technicians, associate professionals and clerks are significantly advanced in the developed countries of Australia, Hong Kong, China, New Zealand and Singapore. Cambodia, Pakistan and Viet Nam are struggling to supply these types of skills (see Figure 1.2 and Annex B for more detail). Figure 1.2 illustrates the supply of 
craft/related trades, and plant/machine operators and assemblers skills, occupations that could be labelled "medium-skilled". Operators and assemblers are generally in the manufacturing sector and industrialised countries have more of these jobs. Both high- and low-skilled workers can be found in the craft and trades category, with a high share not only in Australia but in low-skilled countries as well such as Pakistan and Viet Nam. Faigure 2 also shows the share of low-skilled agricultural and elementary occupations available. As classification into occupations is not always compatible across countries, the shares are given as the sum of the two occupations. Several countries in the region are in a state of low-skill equilibrium. There is a high share of low-skilled workers in Cambodia, Mongolia, Pakistan, the Philippines and Viet Nam. These countries need to are faced with skills development demands for upskilling.

Figure 1.2. Shares of high-, medium- and low-skilled occupations in total employment

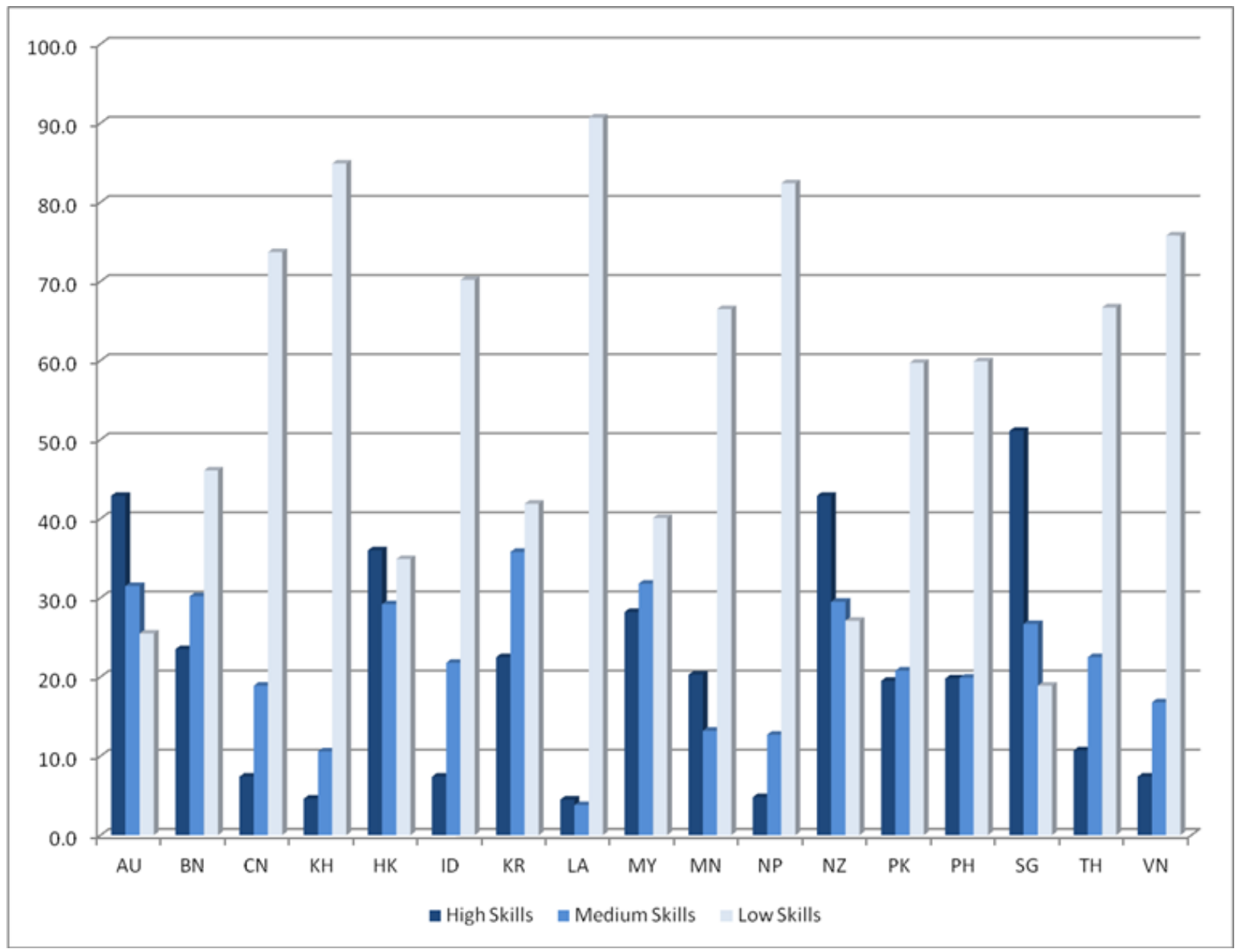

Note: Australia (AU); Brunei Darussalam (BN); China (CH); Cambodia (KH); Hong Kong, China (HK); Indonesia (ID); Korea (KR); Lao People's Democratic Republic (LA); Malaysia (MY); Mongolia (MN); Nepal (NP); New Zealand (NZ); Pakistan (PK); Philippines (PH); Singapore (SG); Thailand (TH); and Viet Nam $(\mathrm{VN})$.

Japan is not included due to classification issues with the ISCO 68.

Data for Brunei Darussalam and Nepal is for 2001; China for 2005; Lao People's Democratic Republic for 1995; Malaysia for 2009; and Viet Nam for 2004. For ISCO 88: higher skilled (legislators, senior officials and managers; professionals; technicians and associate professionals); medium skilled (clerks; craft and related 
trade workers, plant and machine operators and assemblers); low skilled (skilled agricultural and fishery workers, elementary occupations, service workers and shop and market sales workers).

Source: Based on ILO (2011), Key Indicators of the Labour Markets (KILM), $7^{\text {th }}$ edition, ILO, Geneva.

Occupational structures show the level of skills a country has. The demand for skills training is derived from the need to align skills supply with demand. The change in shares of occupation shows the direction and the magnitude of the shifts in skills demand. Figure 1.3 shows changes in shares of occupations during the last decade for countries for which data are available. Pakistan and Viet Nam have growing demands for craft/trade and production workers. On the other hand, demands for agricultural workers and elementary occupations have declined. This shift in demand means that these countries need to train unskilled workers from rural areas to become production workers. Demand for production occupations has increased in other countries such as Cambodia, Indonesia, Nepal and Thailand with diverse patterns, as shown. For example, in Thailand demand for services occupations has grown more rapidly than production occupations, but in Viet Nam growth in the demand for services labour has been weak during the last decade. All of the countries have experienced a reduction in agricultural employment.

In the more industrialised parts of Asia, the shares of medium-skilled occupations (craft/trades and operator/assembler workers) have declined by a large margin in a number of countries including: Australia, Japan, Hong Kong, China, Korea, Malaysia and Singapore. The share of skilled agricultural employment has also declined, although the decrease is modest or insignificant in Korea and Malaysia as they already had low shares. In these countries, the shares of more highly skilled jobs such as professionals and associate professionals have increased. Countries in which the shares of professional and technician / associate professional workers has risen by the largest margin include Hong Kong, China, Korea, Malaysia and Singapore, albeit to varying degrees. However, the increase in these highly skilled jobs does not account for the entire decline in production jobs. In all countries, the shares of the least skilled, elementary occupations have increased. There are diverse patterns among the service and sales and clerks, which show that the skills training demands for these countries are quite different from the previous set of countries.

During the last decade, Mongolia and the Philippines have experienced a reduction of both agricultural jobs and production jobs. Instead, the shares of elementary occupations has increased. These countries are facing demands for skills training for a wide range of unskilled workers. 
Figure 1.3. Change in shares of occupations between 2000* and 2010**

Viet Nam (2000-2004)

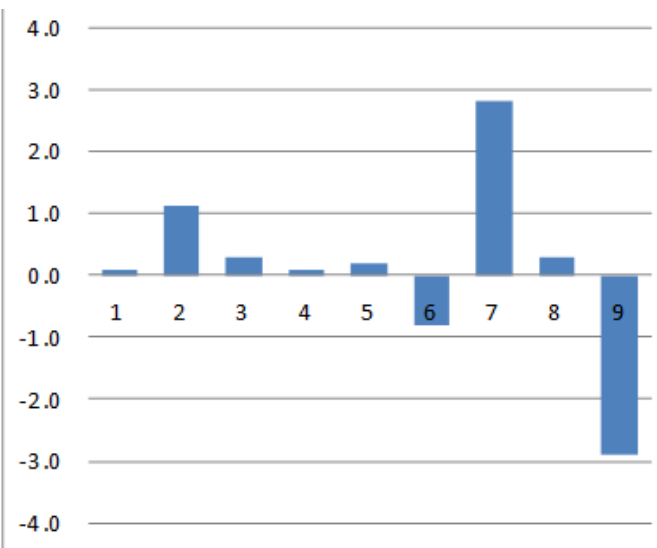

Nepal (1999-2001)

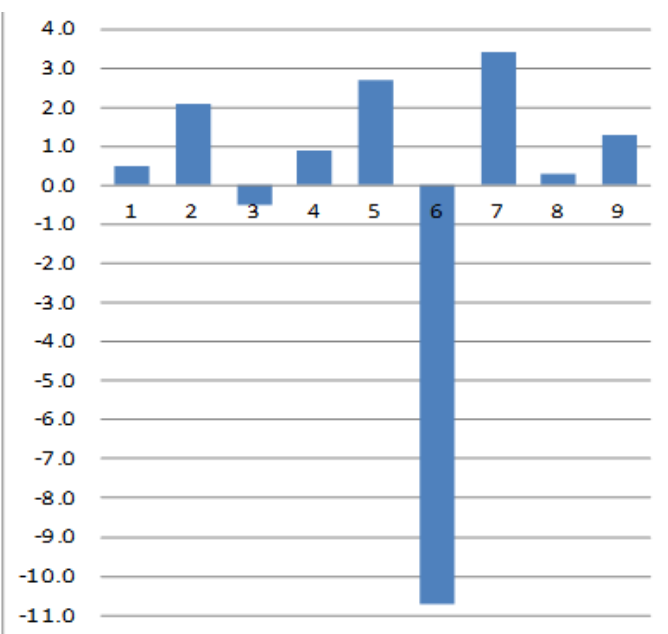

Thailand (2001-2007)

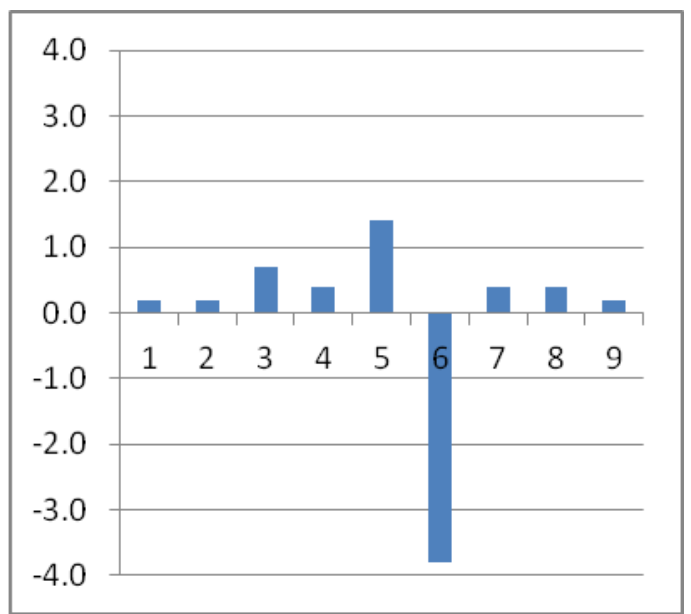

Pakistan (2001-2008)

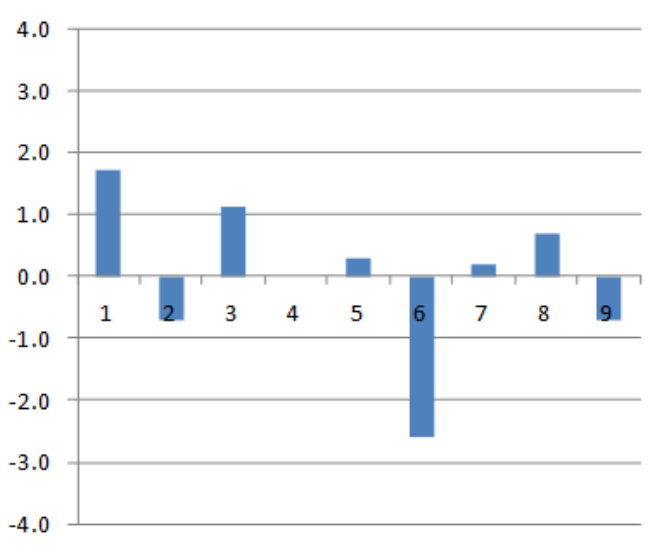

Indonesia (1999-2007)

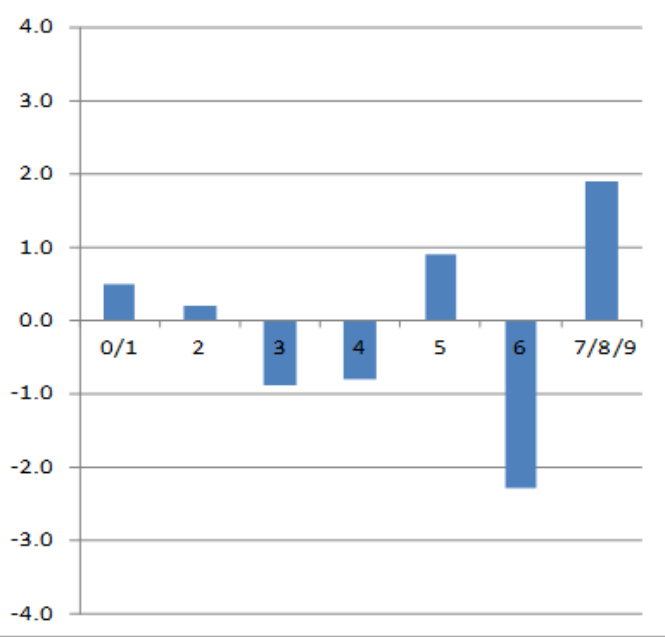

Cambodia (2000-2008)

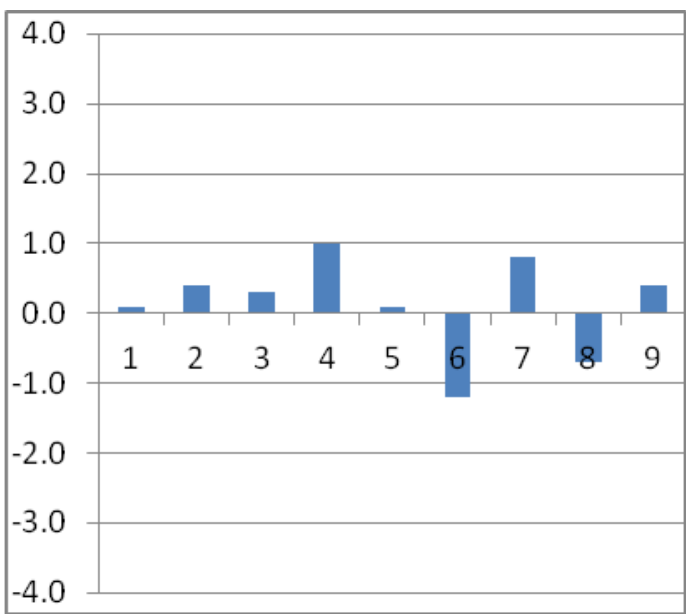


Figure 1.3. Change in shares of occupations between 2000* and 2010** (cont'd)

Singapore (2000-2008)

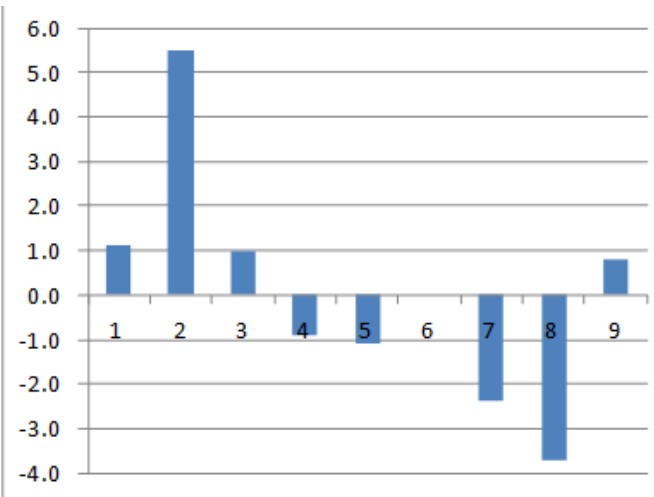

Korea (2000-2008)

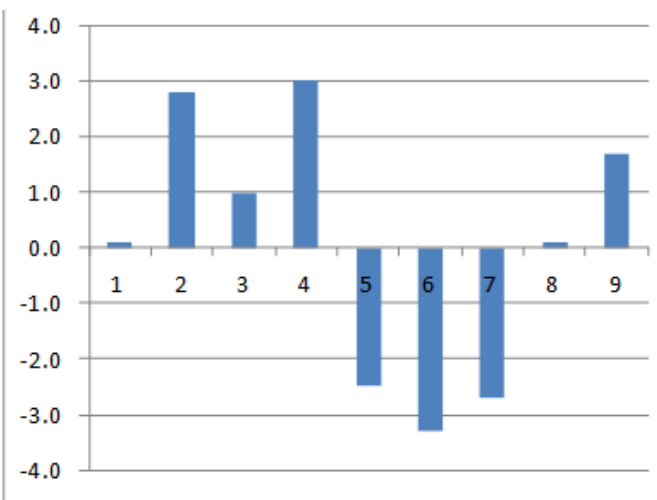

Japan (2000-2008)

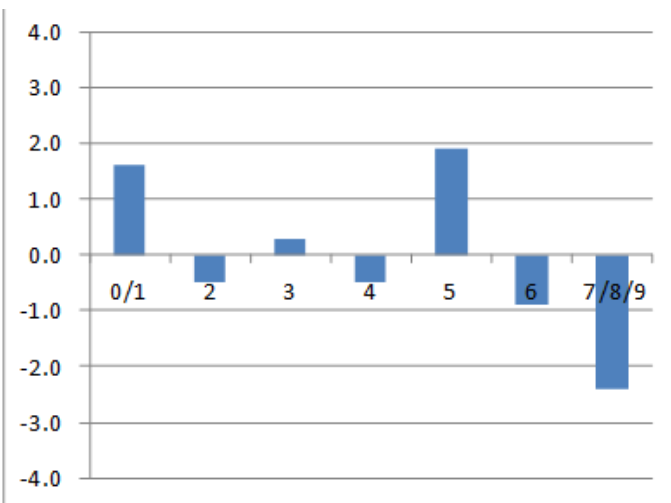

Australia (2000-2008)

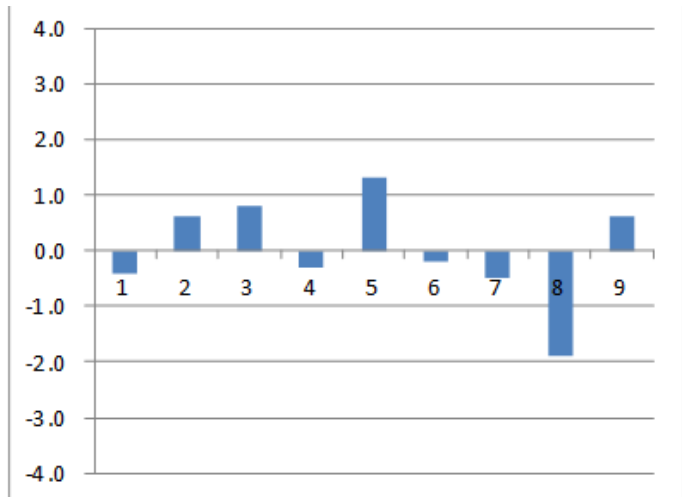

Malaysia (2001-2009)

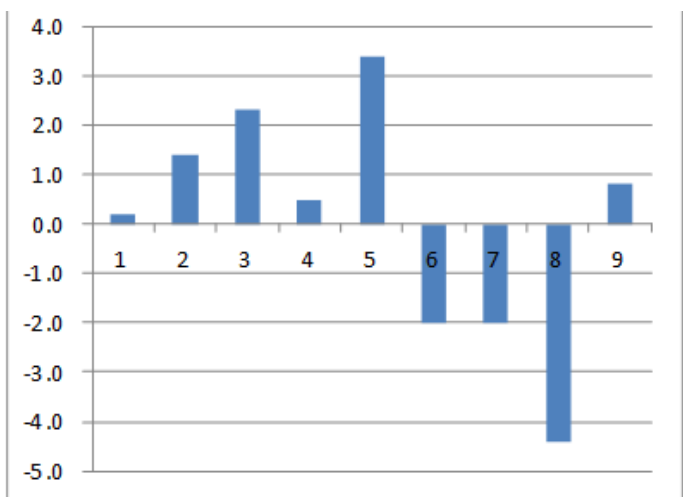

Hong Kong, China (2000-2008)

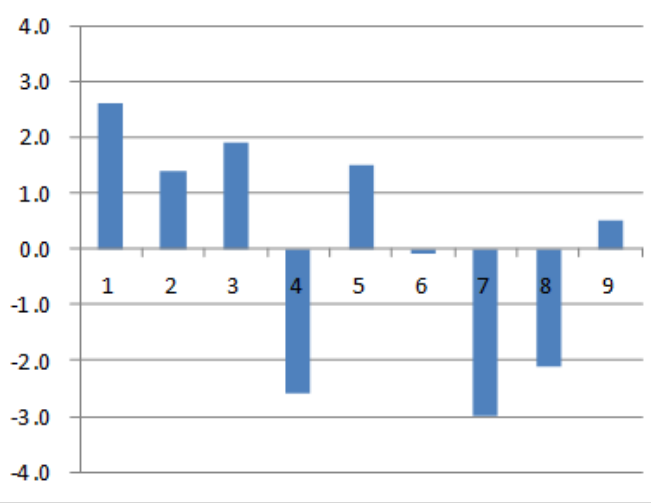


Figure 1.3. Change in shares of occupations between 2000* and 2010** (cont'd)

Philippines (2001-2008)

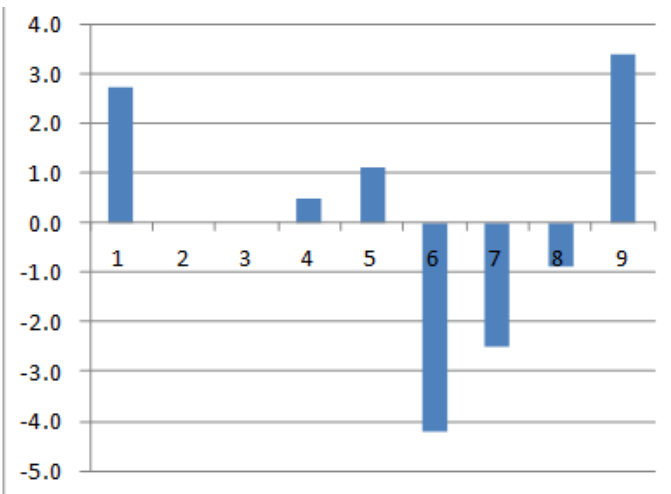

Mongolia (2000-2008)

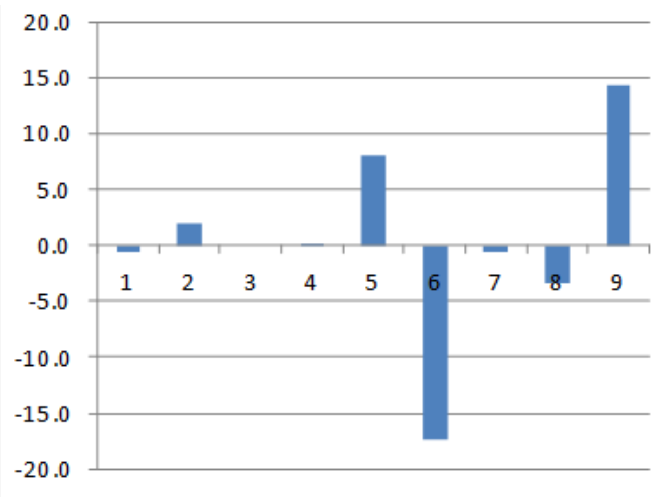

Notes: ISCO-88 occupation categories: 1. legislators, senior officials and managers; 2. professionals; 3. technicians and associate professionals; 4. clerks; 5. service workers and shop and market sales workers; 6. skilled agricultural and fishery workers; 7. craft and related trades workers; 8. plant and machine operators and assemblers; and 9. elementary occupations.

Data for Indonesia and Japan are in ISCO-68 occupation categories as follows: 0/1. professional, technical and related workers; 2. administrative and managerial workers; 3. clerical and related workers; 4. sales workers; 5. service workers; 6 . agricultural, forestry, fishermen; 7/8/9. production and related workers.

Source: Based on ILO (2011), Key Indicators of the Labour Markets (KILM), $7^{\text {th }}$ edition, ILO, Geneva.

\section{Skills supply}

Looking at the labour force by educational attainment (primary, secondary and tertiary) among the youth (15-29 years old) and adults (30+ years) highlights the areas where a more educated workforce is required. Figure 1.4 shows the level of educational attainment (2008) of the age cohorts of youth and adults.

Primary education. Figure 1.4 (see Table C.1 in Annex C) illustrates the level of educational attainment of the labour force in 2008. The countries with the highest percentage of the labour force with only a primary education include Indonesia and Pakistan; these countries have a significantly high percentage of labourers with either less than one year or only pre-primary education. These countries have a definite demand for a more educated labour force. All countries have experienced a decline in primary education as the highest level of educational attainment of their workforce (1998-2008), indicating that workforce education and skills development are increasing. Developed countries that generally experience lower levels of primary education only include Australia, Hong Kong, China, Korea, Japan (before 2002 when primary and secondary education levels were combined), Malaysia and New Zealand. Generally, the higher percentage of primary education only occurs in the adult age group, more significantly in Indonesia (75.1\%), Pakistan (65.6\%) and the Philippines (41.8\%). Indonesia (61.3\%) and Pakistan $(59.0 \%)$ experienced the highest levels of primary education only within their youth (15-29 years old) labour force.

Secondary education. As Figure 1.4 illustrates, the countries with the highest level of secondary education attainment by their labour force include: Australia, Hong Kong, China, Korea, Malaysia and New Zealand. Countries that are struggling with 
secondary educated labour force skills include Indonesia and Pakistan; however, these countries are generally experiencing an increase in secondary education attainment. The youth labour force dominates secondary educational attainment in all countries, most significantly in Singapore (63.5\%) and Malaysia (63.0\%).

Tertiary education. As illustrated in Figure 1.4, all countries are experiencing an increase in tertiary educational attainment within the workforce, some more prominently than others. Indonesia has the lowest percentage of its labour force with a tertiary education, while Australia, Korea, Japan and New Zealand have the highest percentage, indicating a highly skilled workforce. Generally, the youth have higher ratios of tertiary educational attainment, indicating the rising skills levels within these countries. Korea $(52.7 \%)$ has a majority of young adults within the labour force with a tertiary education, followed by Japan (51.0\%), Hong Kong, China (35.6\%), New Zealand (29.8\%), Singapore (28.9\%) and Australia (25.9\%).

Figure 1.4. Educational attainment by labour force (age cohort), 2008

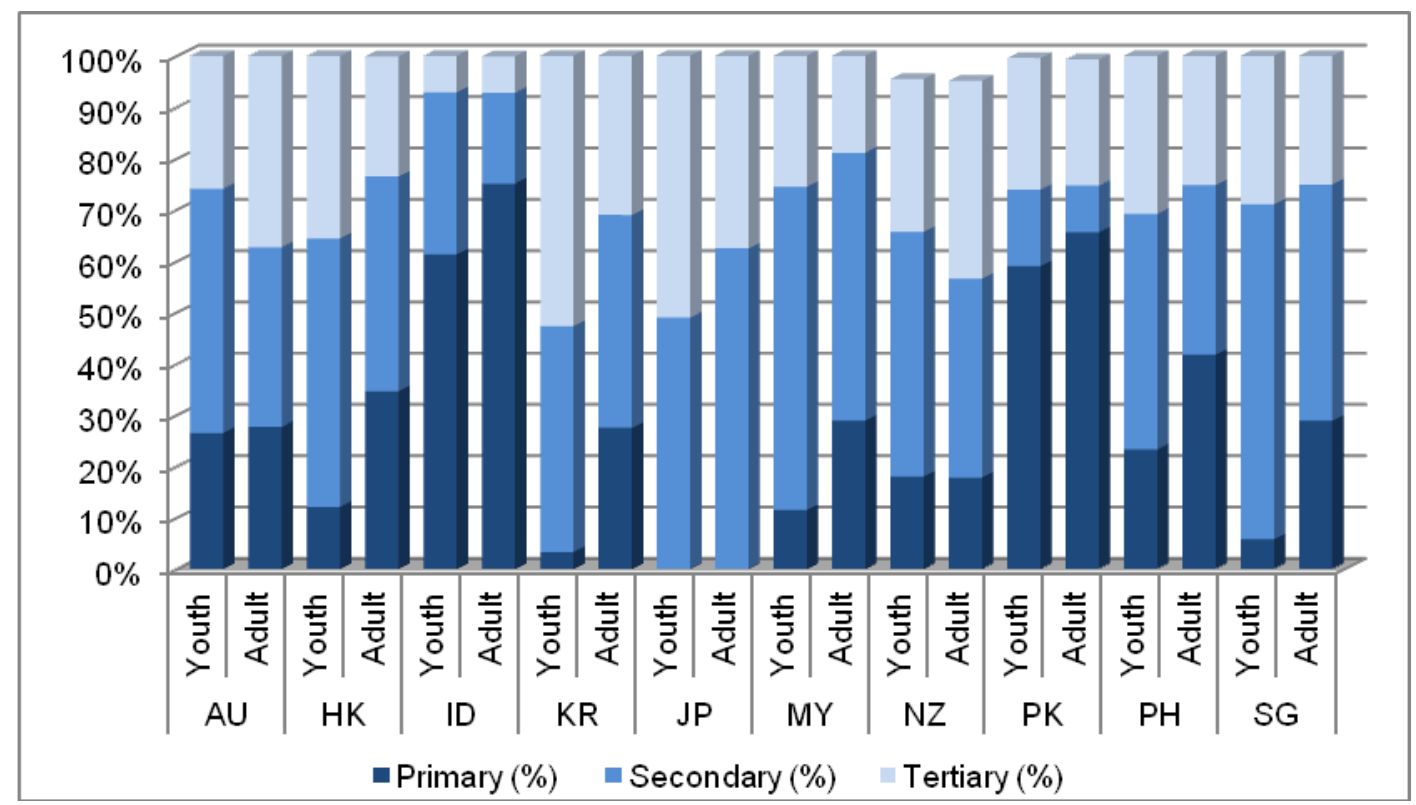

Notes: Australia (AU); Hong Kong, China (HK); Indonesia (ID); Japan (JP); Korea (KR); Malaysia (MY); New Zealand (NZ); Pakistan (PK); Philippines (PH); Singapore (SG). The "youth" category is aged 15-29 and "adult" aged 30 and over, except for Japan and Singapore where youth is 15-35 years old and adult is 35 and over, and for Australia where adult is 30-64. ILO's Key Indicators of the Labour Markets (KLIM) primary level includes ISCED-97 level 1) basic education, and 2) lower secondary education; secondary level includes 3) upper secondary, and 4) post-secondary non-tertiary; and tertiary includes 5) first-stage tertiary, and 6) second-stage tertiary education. For Japan, "primary" includes secondary. Data for Korea is for 2007.

Source: Based on ILO (2011), Key Indicators of the Labour Markets (KILM), $7^{\text {th }}$ edition, ILO, Geneva.

The skills supply is also examined through the ratio of graduates by broad field of education (tertiary). As the size of tertiary education fluctuates across countries, graduates by field of education are also examined as ratios to the total size of the country's labour force (see Table C.2 in Annex C). The ratios can be interpreted as approximate measures of the importance of new high-skill supplies to the existing labour force. As illustrated in Figure 1.5, the latest available data show that social sciences, business and law have the greatest number of graduates with high percentages in Australia (44.9\% in 2008), 
Cambodia (66.2\%) and Mongolia (41.4\% in 2010). Education also has a relatively high percentage of graduates in Brunei Darussalam (42.3\%), Nepal $(25.5 \%)$ and Viet Nam $(27.5 \%)$. The lowest percentage of the labour force with a graduate degree is in agriculture followed closely by services (excluding general programmes and unspecified programmes). It should be noted that although there are a high number of graduates in some broad fields of education, that does not mean that these graduates obtain employment within that field or country. High shares of education and social sciences may be due to the low cost of education, regardless of demand side conditions.

Figure 1.5. Broad field of education (tertiary) as a ratio to total graduates

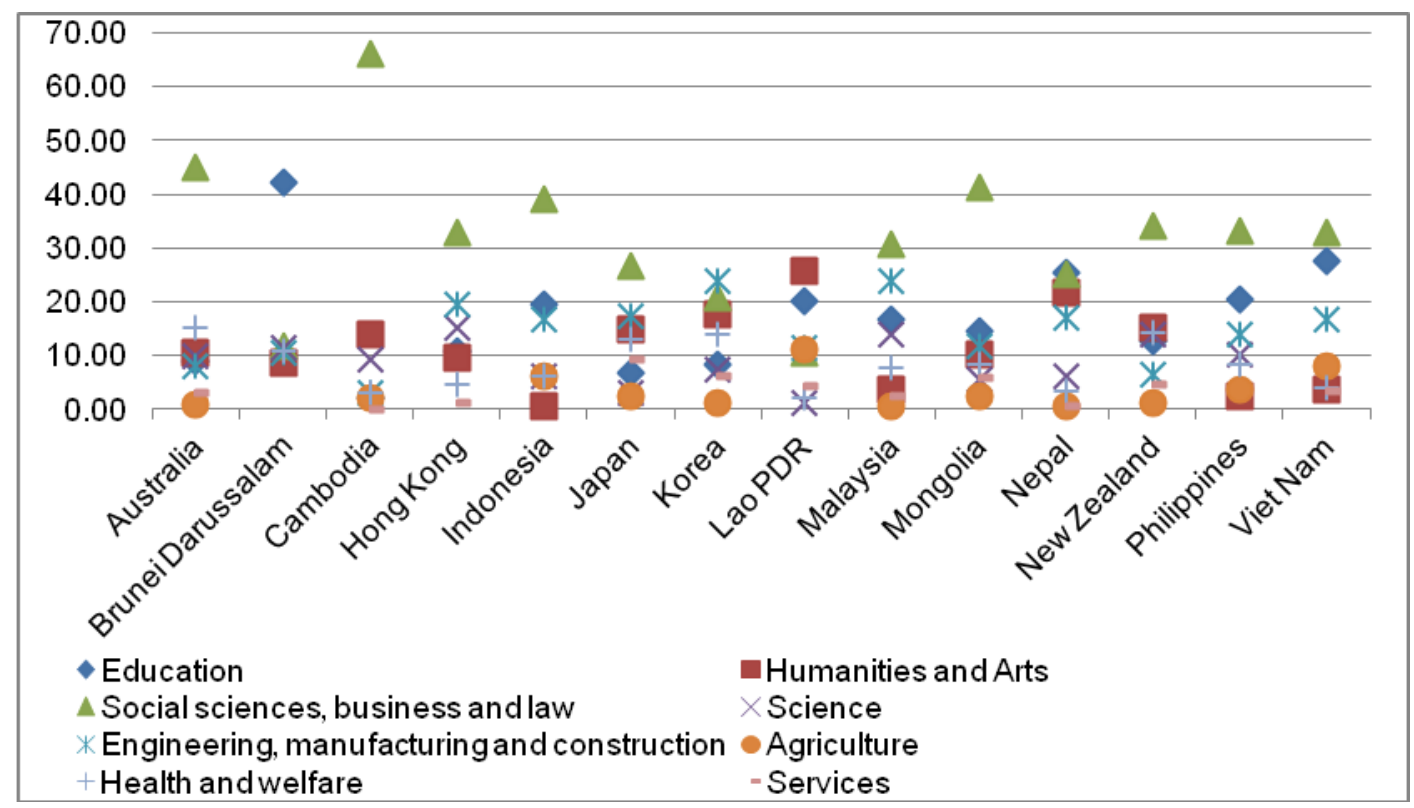

Note: Latest data available: 2004 (Philippines), 2006 (Hong Kong, China, Lao PDR), 2008 (Australia, Cambodia), 2009 (Japan, Korea, Malaysia, New Zealand), 2010 (Brunei Darussalam, Indonesia, Mongolia, Nepal, Viet Nam).

Source: Based on UNESCO, Institute for Statistics (graduate statistics).

As the number of tertiary education graduates varies across countries, high shares of science and engineering graduates do not always equate to an ample supply of new skills in the labour force. Figure 1.6 compares the number of science and engineering graduates as a percentage of the total labour force. In Australia, Korea, Malaysia, Mongolia and New Zealand, it is around $0.4 \%$ of the total labour force. But in Cambodia, Lao People's Democratic Republic, Nepal and Viet Nam, the inflow of this type of knowledge into the labour force is insufficient, as their colleges and universities do not produce sufficient numbers of graduates in these fields. Countries need to increase the supply of science and technology personnel given their importance to innovation processes, particularly in advanced manufacturing and services industries. All science and technology workers can be considered "knowledge workers" and calculating their number is a useful way of examining and interpreting the knowledge dynamics of a region (Sharpe and MartinezFernandez, 2007). 
Figure 1.6. Science and engineering graduates as a \% of the labour force, 2009

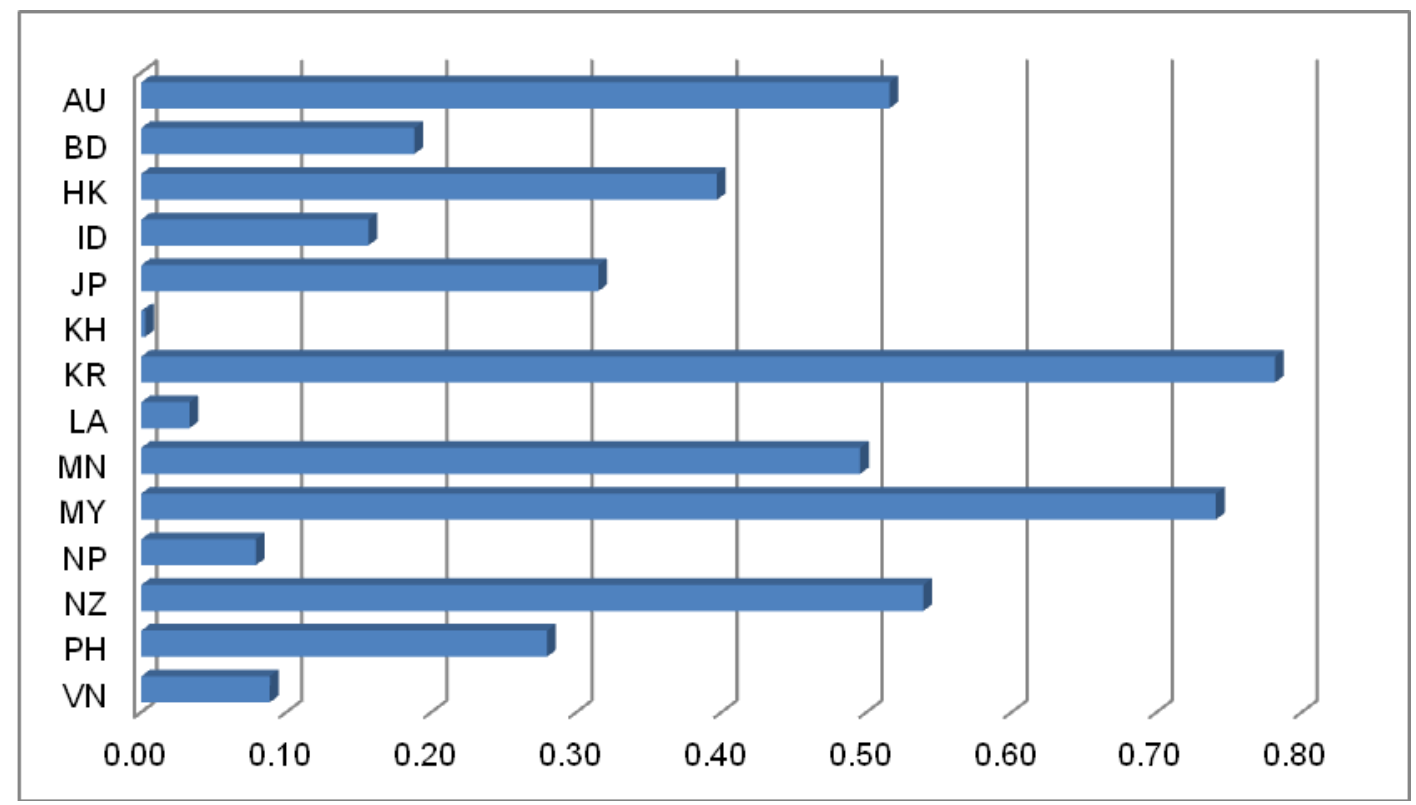

Notes: Australia (AU); Brunei Darussalam (BN); Cambodia (KH); Hong Kong, China (HK); Indonesia (ID); Japan (JP); Korea (KR); Lao People's Democratic Republic (LA); Malaysia (MY); Mongolia (MN); Nepal (NP); New Zealand (NZ); Philippines (PH); and Viet Nam (VN). Data for Australia and New Zealand for 2006; Hong Kong, China for 2004; Viet Nam and the Phillipines for 2008; Nepal for 2010.

Source: Based on graduate statistics from UNESCO, Institute for Statistics, and labour force statistics from ILO (2011), Table 1a.

\section{Summary}

The challenges faced by Asian countries relate to the pathways of their sectoral development and the ways they are moving into the secondary and tertiary industries and the knowledge economy. As their economies change, four challenges have been identified for sustaining growth: $i$ ) building a system for training or creating a training market; ii) reducing skills mismatches and better aligning training and industry needs; iii) upgrading outdated training systems and training instructors; iv) increasing industry participation and ownership.

The analysis of skills demand by sector and occupation and skills supply in the 15 Asian countries included in this report indicate diverse development with a dual development pathway. While some of the countries such as China, Hong Kong, China, Malaysia, Myanmar and Singapore already have a quite well-developed service economy, other countries such as Cambodia, Lao People's Democratic Republic, Nepal and Viet Nam have large amounts of their workforce in agriculture. Skills are almost a mirror of sector development and those countries with large agriculture sectors lack the higher skilled workforce and present large pools of unskilled workers in need of training. At the same time, the supply of skills in those fields more related to innovation processes (science and technology and engineering) is clearly insufficient to promote sustainable and inclusive growth. 


\section{Strategic approaches to skills development in Asia}

There is a mix of approaches to skills development. Most countries are strengthening basic training (including general education). This approach is largely driven by public institutions; however, it needs greater investment. More workplace training is needed for high-skilled workers, but above all transition economies in Asia lack the needed market system. Large economies, such as China, have large-scale investments in home-grown technology; India has developed sophisticated high-value technology services significantly leveraging its science and technology systems. At the same time, there are local initiatives for specialised technologies and services such as financial talents in Shanghai or SME entrepreneurs' managerial skills in Japan that foster skills and training ecosystems in particular places. Other countries are focusing on the skills development needs of the transition to a green growth economy with policies and initiatives that try to integrate other areas of workforce development and education at the same time. This section discusses four approaches that are further explored in the country cases in Parts II, III, and IV (see Figure D.1 in Annex D): $i$ ) strengthening technical and vocational education and training (TVET) systems; ii) fostering knowledge intensity through workplace training; iii) developing local skills ecosystems; and $i v$ ) integrating skills and technologies for green growth.

\section{Strengthening TVET systems}

A strong vocational skill can be built upon a solid general primary education. Hence, in Asian countries where primary education is not universal, expanding it to the whole population is one of the primary goals of their human resources development. For example, China views general primary education as a key strategy for achieving equality, and has extended a universal, free compulsory nine-year education nationwide, giving priority to rural areas, outlying poor areas, and ethnic minority regions to reduce the gap between urban and rural areas and between different regions. China invests in human capital on a large scale. As of 2008, its investment in human capital amounted to $11 \%$ of total GDP. China also provides financial aid to students in higher education to raise participation: $90 \%$ of secondary vocational school students and 20\% of university students receive some type of financial support.

Expanding vocational education at the stage of secondary education is one of the key elements in skills development strategies in Asian countries. Since many youths do not complete secondary education, vocational education is considered a desirable way of expanding the skills supply for the labour force and also a way of achieving equality in the population. But a common hindrance in expanding vocational education is the negative perception of vocational education as secondary education and the consequently low participation rate. One of the reasons for the low participation is the weak link between vocational education and labour market employment. Asian countries are enacting diverse policy measures to overcome this perception and provide incentives for their youth to choose vocational education.

In Cambodia, technical and vocational education (TVE) is a strategy for integrating the youth, especially in rural areas and poverty areas, and having them contribute to the social and economic development of the country. The nationwide enrolment rate in basic education is $94.8 \%$ but the enrolment rate is just $31.9 \%$ and $19.4 \%$ at the lower and upper secondary levels, respectively. The dropout rate is also high at the secondary education level, standing at $18.8 \%$ and $11.3 \%$ in the lower and upper secondary level, respectively. Expanding technical and vocational education at the secondary educational level is an 
objective stated in the Education Strategy Plan of the Ministry of Education, Youth, and Sport for 2009-2013. Cambodia believes that expanding TVE with a solid link to labour markets will contribute to social stability and inclusion, poverty reduction, and sustainable economic growth. But its high cost and the perception of TVE as second-class education are challenges. To resolve these problems Cambodia is seeking a diversified provision of TVE including private provision, employer investment, and multi-lateral involvement, with a gradual expansion schedule. To change the low public perception and low demand for TVE, several steps are being taken, including institutional capacity building and improving quality before increasing quantity.

Pakistan is faced with a similar problem. In Pakistan, compared to general education, vocational training has been relatively neglected and is fragmented and supply-oriented. As Pakistan is trying to transform itself from a middle-income to a high-income country through a human capital development strategy entitled "Skilling Pakistan", it is facing the following issues and challenges to reform its TVET system: $i$ ) due to the low perception and low quality of training education, students do not consider training as a viable and mainstream alternative, and enter the labour market with low skills; $i i)$ industries' general perception of the quality of technical/skills education is low and a shortage of skilled labour is listed as one of the major constraints for investment; and iii) employees' low expectations of the prospects of technical/skills education courses and hence their low take-ups.

The South Asian countries of Bangladesh, Nepal, Pakistan and Sri Lanka have particularly high youth unemployment, despite the surge of the region's economic growth in the last decade. In these countries, overseas employment is an important option for the youth. In order to prepare them for gainful foreign employment, a skill development programme targeted at the unemployed youth is needed, with a systematic planning, foreign market surveys, knowledge of foreign employment systems, and identification of needed skills.

Malaysia focuses on quality improvement as the key element in increasing enrolment in technical education and vocational training (TVET). Malaysia adopted the following four strategies in its Tenth Economic Plan (2011-2015) to broaden access to quality TVET: $i$ ) improve the perception of TVET and attract more trainees; ii) develop highly effective TEVT instructors; iii) upgrade and align TVET curriculum with industry needs; and iv) streamline the delivery of TVET.

Thailand has the policy goal of "No youth entering the labour market without proper skills training by 2020 ". The country has a large-scale training system for the youth. As of 2007, about 1.5 million students were in diverse training institutions managed by the Ministry of Education.

\section{Fostering knowledge intensity through workplace training}

The other problem faced by Asian countries is increasing knowledge intensity and skills development in the workplace. Asian countries commonly have a large share of unskilled and semi-skilled workers. To move out of a middle income trap to a higher value-added production and towards a sustained growth path, workplace training is becoming a key agenda item. Skill shortages are becoming an impediment for their sustained growth and countries are seeking to upskill their labour force through workplace training. 
A common problem in promoting workplace training is the low skill investment of the industries. To overcome this problem, countries are introducing incentives including tax exemptions for training costs to promote workplace training.

Malaysia is using the Tenth Plan period (2011-2015) to revamp its educational system to significantly raise students' skills to increase their employability. Currently, the workforce in Malaysia remains relatively unskilled, with $77 \%$ of the labour force with only 11 years of education, and only $28 \%$ of the jobs are in the higher skill bracket. The Economic Planning Unit projects that this share will reach $32 \%$ by 2020 . For Malaysia to be on par with high-income regional peers such as Korea, Singapore and Taiwan, this target would need to be increased to $35 \%$. The government aims to increase this share to $33 \%$ by 2015 and to $50 \%$ by 2020 . Achieving this goal requires greater involvement of the private sector. The government will expand the coverage of the Skills Development Fund to promote upskilling and retraining workers. The coverage will be extended beyond school leavers to include existing workers and preferential loans will be provided to pay for workers' costs incurred in skills upgrading. The Recognition of Prior Learning (RPL) programme will be expanded. It grants the Malaysian Skills Certificate to workers who do not have any formal certification but who have obtained relevant knowledge, experience, and skills in the workplace to enhance their career prospects as well as to encourage and reward lifelong learning among the workforce.

In the case of Viet Nam, although it is an export-oriented economy and its exports have been hit by the global financial crisis, the impact has been modest. The GDP growth rate decreased slightly from $6.2 \%$ in 2008 to $5.3 \%$ in 2009 , and but there was not any major political or social instability. However, Viet Nam faces enormous training demands. Among its approximately 50 million person labour force, 33 million (65\%) are unskilled workers. The addition of 5 million jobs in industry and the services sector between 2005 and 2009 barely affected the rural area primary sector. The share of the primary sector in production has remained at around $20 \%$ during the last decade with a labour force of 24 million. Along with structural development, workforce training constitutes a key element in the country's employment growth strategy. Viet Nam is taking a two-pronged approach: higher education reform to mitigate the shortage of skilled professional workers and a workforce vocational training programme to create jobs. The government approved training programmes, which cover 1 million trainees annually during 2010-2015, target youth, textile and garment industry workers, and women. For higher education reform, the programme focuses on improving the quality of universities. The reform programme aims at more autonomy, more accountability, and improved funding for universities, as well as training 20000 faculty members up to doctoral level qualifications through 2020.

In Thailand, the very large agricultural sector accounted for $41.5 \%$ of its workforce in 2010. Employment in industry is $19.5 \%$ but signs of manufacturing sector adjustment in labour-intensive industries have already begun to appear as employment growth is stagnant in that sector. In response, the government plans to support higher technology skill training in order to facilitate the industrial transition. However, a great majority of the country's enterprises are SMEs with a high employment share but with a small output share and without a proper capacity for providing training. About 5 million workers are in training programmes managed by the Ministry of Labour, along with 1 million workers in other ministries' programmes. The business sector accounts for about 5.3 million places or $74 \%$ of total training. The Thai Government issued the Skill Development Promotion Act in 2002 to promote workplace training with a combination of compulsory measures and incentives. The act encourages enterprises to establish themselves as training 
providers and conduct skills training in the workplace. An income tax exemption is provided to cover the cost of the training. In 2010, about 2.4 million workers were enrolled in enterprise training programmes.

Mongolia has been faced with a widening mismatch between the training provided by existing public training institutions and the industry skills demand. The existing public training institutions lack resources and capacity, while skills demand is rapidly upgrading. Small and medium-sized enterprises are often unable or unwilling to provide their workers with sufficient training. To make up for the deficient skills training and to facilitate a flexible and quick upgrading of skills under a competitive market environment, the Mongolian Government encourages and subsidises on-the-job training in enterprises for the unemployed with its Employment Promotion Fund. Trainees are provided with four months of production site training paid for by subsidies that cover the training expenses. For the employers who offer the on-the-job training for the unemployed, the training cost is reimbursed. In the construction industry, 3000 unemployed were trained and $80 \%$ of them landed jobs in 2009. The services sector and entrepreneurship training is conducted in business centres.

The skills demand in Cambodia's is for low-skilled workers, and this demand reinforces the current low skills equilibrium in the country. Besides boosting economic growth, the Royal Government Cambodia (RGC) may well need to help firms move upmarket in terms of product market strategy, technology uptake, innovation and skill need and usage, in order to break the current low-skill equilibrium. For example, the garment industry currently requires new technology to underpin its longer term sustainability. The focus on demand-side skills and labour market issues are designed to support the skills upgrading and utilisation processes that are required in Cambodia in order to underpin the Supreme National Economic Council's (SNEC) pending industry development policy. The industry development policy should strengthen economic growth by providing the right business environment and incentivising local industry to grow through adopting higher order product market strategies and sound business improvement practices. Business improvement practices must address optimal development and deployment of labour as such behaviour is the essence of demand-side skills and labour strategies. Integrated and balanced skills and labour strategies could include: $i$ ) mobilising national initiatives; ii) supporting local skills upgrading and employment initiatives; and iii) dealing with infrastructure for employment and training programmes (Eddington, 2012).

In Japan, SMEs employ $74 \%$ of total manufacturing employees but job creation is not active. Under the current global business environment, not only large multi-national corporations but local SMEs as well are increasingly influenced by the sophisticated global value chains helped by information technology (IT) and free trade agreements (FTAs), including economic partnership agreements (EPAs). Many multi-national corporations' FDI destinations are geared towards where there are reliable supporting industries, which are mostly made up of SMEs. And in such cases, specialised SMEs can readily make up a part of the global value chains. Furthermore, in rapidly growing middle class markets in Asia and other emerging economies, product specifications need to be strategically defined, in which specialised SMEs can be better integrated into the global value chains. In addition, SMEs are less affected by the impact of the crisis and can serve as an important job creation engine in such situations. Just after the financial crisis hit the world, what most countries witnessed was an evaporation of liquidity for financing SME business activities. Therefore, securing access to financing (working capital as well as capital for investment) for SMEs are crucial. In the past, to facilitate growth and 
innovation, government policy for supporting SMEs' access to financing tended to focus on investment capital. However, amid the current crisis, not only investment capital but also working capital is essential for their survival. More specifically, the current crisis epitomises that SMEs need to know how to secure capital, especially working capital, under a tight capital market. SMEs tend to lack reliable documents for financing purposes, not to mention detailed business plans and future projections, etc. In this context, SMEs need to be equipped with knowledge on financing, and this should be included in the skills list needed for SMEs.

The share of micro, small and medium-sized enterprises (MSMEs) is large in the Philippines, accounting for $70 \%$ of total employment, $30 \%$ of total sales and value-added in manufacturing, and $25 \%$ of total exports. The demand for training in the Philippines is two-fold: the existing and potential entrepreneurs need business skills and knowledge to be competitive in the world market, particularly in financing, marketing, technology, and human resources development; and the MSME workers need to be trained for skills required in technology intensive industries and for improving productivity. The needs are even higher for smaller MSMEs. However, employer-provided training is very limited and the following are the following constraints have been cited: insufficient access to finance, poor information on training needs, low perception of formal training, and lack of training facilities. The government and the education and training institutions, both public and private, are the major providers of the needed skill training for the MSMEs, in which the Technical Education and Skills Development Authority (TESDA) is the lead government agency for managing TVET.

Developing Asian countries commonly face a lack of skills development in SMEs, especially internal training, a focus which is not well developed by donor agencies either, whose efforts tend to focus much more on physical infrastructure development (Usui and Martinez-Fernandez, 2011). However, lack of training in SMEs is not confined to developing countries, and many OECD countries face similar problems (OECD, forthcoming). In Australia, small firms with less than 20 employees constitute the vast majority of businesses, and nearly two-thirds of them are very small, microbusinesses with 1 to 4 employees. They collectively employ nearly half of the workforce (48\% in June 2009), with another $23 \%$ of employed people working in medium-sized businesses with 20-199 employees. But small businesses are less likely to use formal (nationally accredited) and structured training than larger firms, and more likely not to train their staff at all. Small businesses tend to respond that their staff already have adequate skills or more skills than needed, indicating that many small businesses are not seeking growth or change. However, even in small firms, training is often associated with innovation, growth or restructuring, and training programmes need to be tailored so that they favour and engage the demands of small businesses. Small and medium-sized businesses are more likely to report skill shortages as a factor hampering innovation than larger ones. As small businesses are more likely to be locally owned, they are less able to draw on expertise from outside. Recently, small and medium-sized innovating firms are reporting more difficulties accessing suitable skills compared to larger firms. The gap on this issue is larger than for any other barriers such as access to funds for innovation, and it appears to have widened during the last decade. In order to better connect small businesses with formal and structured training and to link them with innovation, Australia undertook the National Skill Ecosystem Programme in the early 2000s which was based on firms in an industry or region working together on a skill and workforce issue. In the programme, businesses take more responsibility for the training and development of their 
own workforces, but also they work with outside experts such as research and educational institutes for new ideas and approaches.

China's long term human resources development strategy in the new century puts a great emphasis on high quality science and technology personnel. China plans to produce an enormous amount of high quality and professional science and technology human resources as outlined in several of its national plans for the 2000s, such as the Tenth FiveYear Plan for National Economic and Social Development (2001), The Guidelines on National Medium- and Long-term Program for Scientific and Technological Development, 2006-2020 (2006), The National Outline for Medium and Long-term Talent Development, 2010-2020 (2010), and The National Plan for Medium and Longterm Education Reform and Development, 2010-2020 (2010). To become an innovation led economy, China has launched various high-tech R\&D and basic science research programmes and centres at the national level, and established science and research foundations. In addition, the government invests in upgrading technical professionals. In 2008, China had about 2 million R\&D personnel, three times the number in 1991.

\section{Developing local skills ecosystems ${ }^{4}$}

Local skills ecosystems include organisations, institutions and firms in a certain local area or labour market that constitute area-based partnerships for training and skills development (OECD, forthcoming). There are many advantages in putting more emphasis on devolving more responsibility and resources for partnership development to the local level. In addition, in Asia there is an increased need for flexibility and adaptability in skills development and the changing modes of skill acquisitions. Skills have traditionally been acquired through schools and vocational education systems and passed on through family or community networks. However, increasingly more skills are acquired from multiple sources including workshops, short courses, online, on-the-job and learning by doing. Skills are increasingly developed through face-to-face communication, particularly taking into account local cultural and socio-economic characteristics. Hence, local skills partnerships are not just for providing skills, they are for knowledge exchange as well. Local partnerships in training have advantages in that local agents are better able to develop skills that meet their specific needs, increase knowledge flows and information within communities, drive local innovation through new ideas, utilise local knowledge, develop capabilities and skills and common ownership, increase transparency and accountability, and supplement limited resources of the formal education and training system.

However, there are many challenges in designing and promoting local partnerships. More trust has to be consolidated in market relationships, and it has to be sustainable as the returns tend to be over the longer term. The objectives for local partnerships have to be clear from the start, and co-operation and the balance of power has to be secured. In many ways, the role of centralised agencies is increased through local partnerships. For example, in education and training, central agencies can contribute by providing the policy, regulation, and planning framework for local initiatives, by supporting local partners with information and forecasts, curriculum development, quality and accreditation assessment, evaluation and monitoring, and funding for the local partners to meet the agreed funding criteria.

As an example, Thailand's skills training strategy emphasises local initiatives. Thailand's regional offices are equipped with the capacity for designing and developing training curricula and the network for training, and training can be provided more 
efficiently thanks to the flexibility they are granted. Budgets for partnerships are given as a lump sum according to the regulations of the authority.

A more integrated and robust example of fostering local skills ecosystems is the decision of the Chinese Government in 1992 to speed up the process of developing Shanghai into an international financial centre in response to increasing economic globalisation and global financial competition. However, lack of competent financial talents in the city created a serious bottleneck. To resolve the manpower problem, the municipal Government of Shanghai decided to invest in the following areas, to: i) develop local financial talents, ii) recruit high-level overseas financial talents, and iii) improve the environment for the talents. To nurture local financial talents, Shanghai built a sound system for developing financial talent including improved curricula at universities, high-end professional training, and internal training within financial institutions. In 2010, four top-notch universities were designated as training bases by the city and financial institutions are advised to co-operate with them for training. Shanghai built high-level financial training bases with international standards relying upon foreign universities and financial institutions. Firms are encouraged to train their employees abroad. The knowledge and capabilities of existing executives at financial institutions were updated through participation in executive MBA programmes in top business schools, outbound programme training, and knowledge updating programmes.

To facilitate the recruitment of high-level overseas talents, the Shanghai municipal Government launched programmes for attracting 10000 overseas Chinese talents in 2003, the Shanghai Pujiang Talent Programme in 2005, and the Young Talent Returning Programme in 2008. Shanghai co-operates with many overseas Chinese organisations for recruiting financial talents. The municipal government recommends recruiting overseas talents at senior or key positions, and supports system change favourable to overseas talents. City officials make regular visits and communication with the overseas talents to better meet their needs.

Finally, to create a comfortable living and working environment for the financial "talents", Shanghai provided them with career development opportunities, preferential policies, and services and cultural/living facilities. The municipal government made efforts to invite Chinese and foreign financial institutions to locate their headquarters or regional headquarters in Shanghai. Many preferential policies were enacted in terms of healthcare, education and credential handling procedures for their children, and their residential and taxation status.

As a result of the city's efforts, the number of workers in the financial industry in Shanghai jumped from 130000 in 2000 to 231900 in 2010. The financial industry has now expanded beyond the banking area to securities, insurances, futures and trust. In the Chinese Academy of Social Science's global financial centre rankings of 2011, Shanghai is ranked as the fifth most competitive among the 75 global financial centres along with Tokyo, following London, New York, Hong Kong, China and Singapore.

\section{Integrating skills and technologies for green growth $^{5}$}

Asian countries perceive the move towards a green economy both as a new challenge and a new opportunity. Several countries in the region have very large carbon dioxide footprints, and the transition dictates a revision of their planned growth path. However, they also aim to become one of the world's hub countries in new technology and innovations and an advent of new technologies offers them an opportunity to join the technology leading countries in the world. 
Many Asian countries are setting up ambitious targets and responding proactively to the transition. Korea announced its National Strategy for Green Growth in 2009, which set up an ambitious goal of raising the share of new and renewable energy from $2.7 \%$ of 2009 to $2.8 \%$ by 2013 and to $6.1 \%$ by 2020 . It aims to join the World's 7 Green Powers by 2020. Singapore has set up a carbon emission reduction goal of $7 \%$ to $11 \%$ from the BAU (business-as-usual) level by 2020, which can be extendable to $16 \%$ if a global agreement is reached. Singapore developed a national framework for sustainable growth in 2008, documented in the "Sustainable Singapore Blueprint," according to which energy efficiency will be raised by 35\% from its 2005 level by 2030. The Energy Conservation Act is expected to take effect in 2013, and will require companies with large energy consumption to appoint an energy monitor officer and report energy use to the National Environment Agency (NEA) and submit improvement plans to improve energy efficiency.

Australia demonstrated its commitment to build a stronger and greener economy by developing policies that will boost green collar jobs, such as energy efficiency strategies for buildings and industry; rapid expansion of clean energy infrastructure; structural reform of emission-intensive industries; a cleaner vehicle fleet and public transport infrastructure plan; and targeted regional investment and industry planning.

Aside from such national level issues, achieving a green economy requires a diverse range of workers with broad skill sets, not only technology and R\&D professionals, but also workplace skilled workers who can cope with the skilled demand shifts.

Singapore is focusing on green technology personnel: the Building and Construction Authority estimates that at least 18000 to 20000 "green specialists" are required by 2030 in the building sector. The Environment and Water Industry Programme has an allocation of SGD 470 million to promote research and development in the water sector as well as to develop manpower, and commercialisation of technology. The Singapore Business Federation predicts an increasing market demand for sustainability professionals like engineering or audit professionals and is working with universities and research institutes to address the skills demands.

In Australia, the move to a low-carbon economy is expected to create thousands of extra jobs, as well as the re-creation of hundreds of thousands of existing jobs. The reskilling, cross-skilling, and upskilling of new work practices and workers are needed, and this can provide a window of opportunity for the disadvantaged group. But to take advantage of this opportunity, educating communities should be able to ensure candidates obtain the training necessary to gain sustainable employment in the green collar sectors. Australia tries to achieve this through integration of the school system, VET system, trade colleges and universities. The National Green Skills Agreement between the federal, state and territory governments seeks to build up the capacity of the VET sector to deliver the skills required in the workplace and to enable individuals, business and communities to adjust to and prosper in a sustainable, low-carbon economy. Included in the agreement is the review and revision of training packages to incorporate skills for sustainability, development of national standards of sustainability practice and teaching in vocational training, the upskilling of VET practitioners so that they could offer quality in skills.

In Korea, the green growth strategy is also a part of the economic stimulus programme to overcome the effects of the worldwide recession. Out of the total USD38 billion stimulus package, $80 \%$ was assigned to environmental projects such as fresh water, waste control, energy efficient buildings, renewable energy, low-carbon vehicles, and rail network systems. In the medium term, the government is focusing on 
public credit guarantees for green technologies and industries and introducing a carbon emission trading system and tax incentives for energy saving. The total budget for the green initiative was set at 2\% of GDP for 2009-2013. On the human resources and social policy side, the transition requires human resources development for green technology $\mathrm{R} \& \mathrm{D}$, re-training existing workers for green technology, and a new system of active labour market programmes for displaced workers as well as a new social safety net for them.

For the less-developed economies, green growth is a challenge in their development path because it could mean a widening knowledge gap and slowdown in growth as the introduction of mass production becomes harder. The implication of not catching up with the green growth trend could be increased poverty and job insecurity. Countries such as India and Thailand feel the need for a more proactive policy and public and private investment expansion to close the skill gap and to monitor progression in low-carbon technologies.

On the training side, the transition to low-carbon growth raises two challenges: the countries do not have sufficient skilled manpower for green jobs, and they have demands for retraining for those affected by shifts in skills demand. Thailand attaches more importance to promote training in green jobs, understanding that green growth would intensify skills demands in the area; and the green training would become crucial in future human development activities. For policy implementation, it extensively uses the Skill Development Promotion Act of 2002 which covers the cost of private enterprises' green training by means of corporate income tax reduction. In parallel with training expansion, Thailand is also seeking measures and mechanisms for extending the social safety net.

India has incorporated the sustainable growth process as a focus area in its growth strategy plan within the $12^{\text {th }}$ Five-Year Plan 2012-2017. The strategy covers areas of agriculture, waste management, energy, transport, and services, and addresses mapping of skills, creating a registry of skills, infrastructure for skill development, and involvement of the private sector and civil society in skill building. India's policy focus is on a sustainable and inclusive growth strategy, as the adoption of greener technology would affect the labour market in terms of change in occupational structure as well as associated skill levels. Low-carbon growth is expected to create millions of (green) jobs in India in different sectors, requiring different skill sets and competency levels which may or may not exist in the current skill structure. However, no comprehensive training plan has been elaborated. Lower level skill training is carried out by local governments, but industry linkages with the training institutes are weak and efforts are underway to upscale the initiatives through sector skill councils. Although new higher level skills in relation to new green occupations are not yet available, they are being developed at diverse universities and research institutes with government financial support.

\section{Summary}

Asian countries are utilising different strategic approaches to skills development (see Figure 1.7): $i$ ) strengthening technical and vocational education and training (TVET) systems; ii) fostering knowledge intensity through workplace training; iii) developing local skills ecosystems; and $i v$ ) integrating skills for green growth. 
Figure 1.7. Skills development approaches in Asian countries

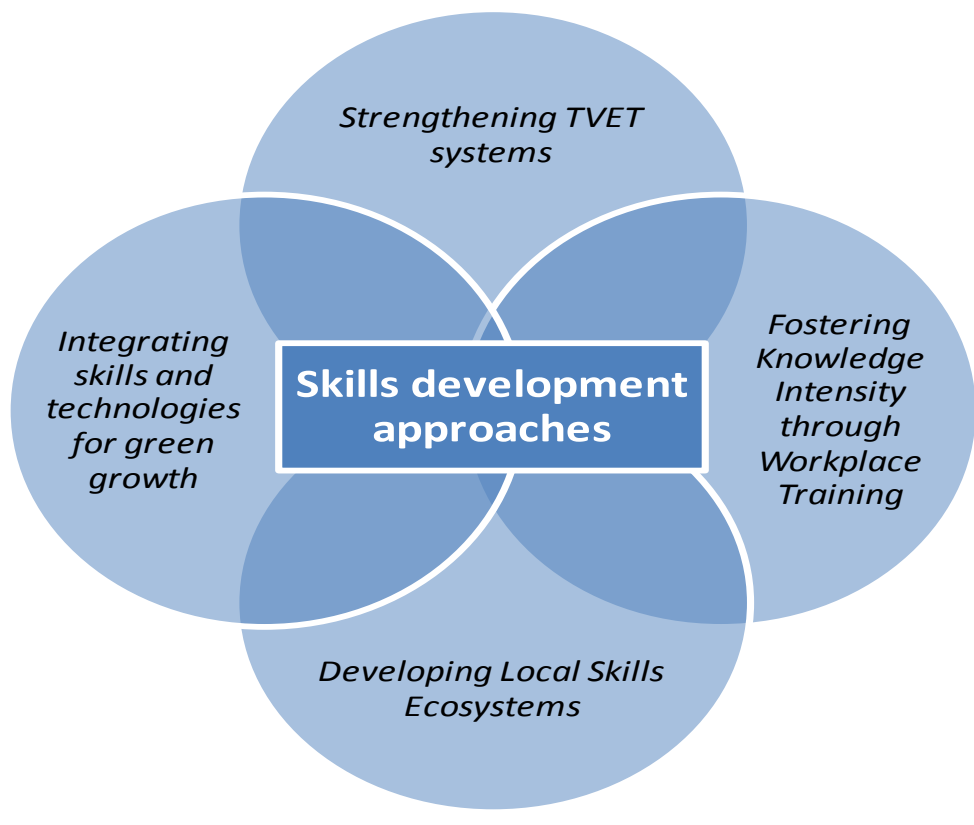

Strengthening TVET and secondary education systems requires a shift from curriculabased approach to competency-based training and creating a demand-driven training system which is responsive to industry needs. Corrective measures are needed, among others: $i$ ) streamlining policy making and reorganising the current procedural overlaps among institutions; ii) setting up sector-specific centres of excellence, located in proximity to relevant industries; and iii) institutionalising industry's role in policy making.

Workplace training in most Asian countries lacks a well-developed training infrastructure at the institutional level. Therefore, developing firms' capacity as training partners or training organisations is a pathway that can be faster and more sustainable for increasing the level of skills and the level of knowledge intensity in firms. In particular, SMEs are suffering the most from the struggle on skills development and the skills gaps they experienced. Ultimately, increasing firms' level of knowledge intensity increases innovation and productivity for innovation and commercialisation which pushes workforce skills development internally and is directly related to the production pathway of the firms (Martinez-Fernandez et al., 2011).

Local skills and training ecosystems can provide a network mechanism for vocational training co-ordination by involving more industry in training, better placing trainees in firms and providing improved incentives for training that better respond to the market in terms of satisfying employers' changing demands. The impact of developing local skills ecosystems and fostering local skills initiatives is less known in Asian countries but some examples of integrated strategies driven by national authorities have had successful results, e.g. Shanghai finance skills strategy.

Green growth has become an opportunity for many Asian countries to integrate their skills strategies and connect into global development networks for new technologies and the development of green sectors. Not all countries can invest at the same level. For some countries, just raising awareness among their training systems and firms is the most 
feasible strategy; for others, strong investments in their science and technology systems and skills and training systems are linked to job creation and sustainable development.

\section{Emerging policy themes}

The skills development programmes and policies analysed in this report indicate four levels of policy concern for a more integrated approach to skills development. The first level refers to "skills infrastructure and governance". The second level refers to "the composition of the skills and jobs" as they relate to current employment. The third level refers to "the knowledge intensity in the workplace". And the fourth level refers to "integrating skills strategies at the local level".

\section{More investment in skills infrastructure and governance...}

Asian countries face common challenges of building up skills infrastructure for creating a training market with quality suppliers, reducing skills mismatches, improving links between training and industry needs, upgrading outdated training systems and increasing industry participation.

Agriculture is still a significant part of many Asian economies but services dominate greatly over industry which is the least-intense sector. Five countries have large agricultural sectors, which account for over 50\% of employment: Cambodia, India, Myanmar, Nepal and Viet Nam. Services employment shares have grown significantly in China, Mongolia, Thailand and Viet Nam during the last decade.

If public training systems are outdated and the elements of a training market are weak, the transition to the knowledge economy and the higher value-added to the dominant sectors will happen at a slower pace. Including those in the non-formal sector is also more difficult if governance of the skills system is not clear or well articulated in partnership with the private sector.

\section{...while addressing the composition of skills and jobs,}

Not much attention has been devoted to the development of knowledge workers in Asia. The higher skilled occupations such as professionals, technicians, associate professionals and clerks are significantly advanced in the developed countries of Australia, Hong Kong, China, New Zealand and Singapore while Cambodia, Pakistan and Viet Nam are struggling to supply these types of skills. Several countries in the region are in a state of low-skill equilibrium, particularly in Cambodia, Mongolia, Pakistan, the Philippines and Viet Nam. These countries are faced with skills development demands for upskilling. The shares of more highly skilled jobs such as professional and associate professionals have increased in most countries but the share is larger in Korea, Hong Kong, China, Malaysia and Singapore.

The countries that have the highest percentage of their labour force with a primary education only include Indonesia and Pakistan; these countries have a significantly high percentage of labourers with either less than one year or only pre-primary education. These countries have a definite demand for a more educated labour force. The countries with the highest level of secondary educational attainment by their labour force include: Australia, Hong Kong, China, Korea, Malaysia and New Zealand. Countries that are struggling with insufficient secondary educated labour force skills include Indonesia and Pakistan; however, these countries are generally experiencing an increase in secondary educational attainment. Indonesia has the lowest share of labour force with science, 
technology, engineering and mathematics (STEM) tertiary education, while Australia, Japan, Korea and New Zealand have the highest percentage of labour force with a tertiary education, indicating a highly skilled workforce. In Australia, Korea, Malaysia, Mongolia and New Zealand, the STEM percentage is around $0.4 \%$ of the total labour force. But in Cambodia, Lao People's Democratic Republic, Nepal and Viet Nam the inflow of these types of knowledge into the labour force is insufficient, as their colleges and universities do not produce sufficient numbers of graduates in these fields.

\section{...promoting more knowledge intensity in the workplace}

Private sector development, both in the formal and non-formal sectors, strongly depends on raising the skills of the large share of unskilled and semi-skilled workforce. To move to higher value-added production and towards a sustained growth path, increasing the level of workplace training and the quality of training is becoming a key issue. A common problem in promoting workplace training is the low skill investment of the industries. Less is known about how to increase knowledge intensity in the workplace as a way to address the needs of skilling professionals, firms and clusters in high-growth enterprises and industries. This is an urgent need both in countries in high-skill equilibrium and in countries presenting low-skill equilibrium so as to support those firms and sectors that are already embedded in global value chains and technological innovation networks.

A particularly notable case is the need of the SME sector to know how to secure capital, especially working capital, in a tight capital market situation. SMEs tend to lack reliable documents for financing purposes, not to mention detailed business plans and future projections. In this context, SMEs need to be equipped with knowledge of sophisticated financing, and this should be built in in different ways for firm training. There are alternative ways for skills development and knowledge-intensive service activities already well utilised in OECD countries (OECD, forthcoming) but how they relate to developing countries has still not been investigated.

\section{...and integrating skills strategies at the local level}

Asian countries are developing skills plans as national statements and frameworks. In most cases there is little specification of how the plans will be implemented at the local level where they need to reach the workforce, firms and organisations. Some countries are now realising the advantages of developing local skills ecosystems and therefore integrating the local implementation into policies and programmes. However, this focus is more often stated in the most advanced countries.

Skills development for transition to a green growth economy presents a useful example because for green growth, strategies for local skill development can be separated from the higher dimension national level policy. On a national level, it is about setting the right prices and guiding the direction of investment (OECD, 2009), but on the local level it is about training and job placement in a changing environment (MartinezFernandez et al., 2010). The cases of Korea and Thailand show the importance of the establishment of national strategic policy related to sustainable development and climate change. Without such strategic direction and investment, and without adjusting to the "right" prices, small and medium-sized enterprises tend to hold back on "greening" activity, reporting that they do not know what to do or how to proceed, as is the case in Australia. For a "green" jobs skilling initiative, multiple stakeholders are involved in establishing industry development and skills development plans. The latter is essential to 
ensure that demand for new "green" skills and supply are balanced and strategically timed. Skills are wasted if they are supplied before industry is ready to use them, a situation which could lead to skill migration from the region.

For the local training dimension, collaboration and flexibility are critical. As in other skills development, "green" skill development must add value to workforce capacity in a meaningful way, and it seems to work best when a regional/cluster approach is taken that fosters collaboration amongst multiple stakeholders. Investment is less effective when skills are provided in an isolated policy silo so facilitating skills and training ecosystems at the local level provides an invisible skills infrastructure that largely reaches stakeholders in connected activities to build capacities in human capital.

\section{Notes}

1. See www.oecd.org/cfe/leed/employment/esssa for more information.

2. We are grateful to Mr. Paul Baker, Senior Manager, Education System Strategy, Ministry of Education, New Zealand, for his valuable contribution to this section.

3. Dr. Tamara Weyman provided valuable inputs and research assistance for this section.

4. We would like to thank Mr. Graham Larcombe of Strategic Economics for his contribution to this section.

5. We would like to thank Noela Eddington, Vet Strategy and Research, Department of Education and Training (Australia) for her contribution to this section. 


\section{References}

Eddington, Noela (2012), "Skills labour market policy in Cambodia", a report for the OECD ESSSA Initiative, unpublished.

ILO (2012), Employment Trends 2012, International Labour Office, Geneva.

ILO (2011), Key Indicators of the Labour Markets (KILM), $7^{\text {th }}$ edition, ILO, Geneva.

Martinez-Fernandez, C., C. Hinojosa and G. Miranda (2010), "Green jobs and skills: the local labour market implications of addressing climate change", 8 February, working document, CFE/LEED, OECD, Paris, www.oecd.org/dataoecd/54/43/44683169.pdf?c onte $n t I d=44683170$.

Martinez-Fernandez, C., I. Miles and T. Weyman (2011), The Knowledge Economy at Work: Skills and Innovation in Knowledge Intensive Service Activities, Edgar Elgar, United Kingdom.

OECD (2009), Green Growth: Overcoming the Crisis and Beyond, OECD Publishing, Paris, http://dx.doi.org/10.1787/9789264083639-en.

OECD (forthcoming), Innovation in Skills and Training in SMEs, Local Economic and Employment Development (LEED), OECD Publishing, Paris.

OECD/International Labour Office (2011), Job-Rich Growth in Asia: Strategies for Local Employment, Skills Development and Social Protection, Local Economic and Employment Development (LEED), OECD Publishing, Paris, http://dx.doi.org/10.178 7/9789264110984-en.

Sharpe, S. and C. Martinez-Fernandez (2007), "Measuring regional knowledge resources: what do occupations have to offer?", Innovation, Management, Policy and Practice, September, 9(3-4): 262-275.

The Ministry of Education, Youth and Sports, Cambodia (2010), The Education Strategic Plan for 2009-2013, http://www.moeys.gov.kh/en/policies-and-strategies.htm

The State Council, The People's Republic of China (2001). The Tenth Five-Year Plan for National Economic and Social Development, http://www.gov.cn/english/official/200507/29/content_18334.htm

The State Council, The People's Republic of China (2006). The National Plan for Medium and Long-term Scientific and Technological Development of 2006-2020, http://www.gov.cn/english/2006-02/09/content_184426.htm

The Central People's Government of the People's Republic of China (2010a). The National Outline for Medium and Long-term Talent Development (2010-2020).

The Central People's Government of the People's Republic of China (2010b). The National Plan for Medium and Long-term Education Reform and Development (20102020). 
Usui, K. and C. Martinez-Fernandez (2011), "Low-carbon green growth opportunities for SMEs", Asia-Pacific Tech Monitor Journal, Special Feature: Environmentally Sustainable Low-Carbon Technologies, Nov-Dec 2011,www.techmonitor.net/tm/imag es/8/8c/11nov_dec_sfl.pdf. 


\section{Part I}

\section{The challenges for skills development in Asia}

This part provides an overview of the key challenges for skills development in Asia: building skills policy frameworks; integrating skills, employment and local development; and building effective local partnerships for skills development. 



\title{
Chapter 2
}

\section{Lessons for skills policy frameworks}

\author{
by \\ Shanti Jagannathan ${ }^{1}$
}

\section{Introduction}

Skills policies are increasingly occupying centre stage in the economic growth priorities of Asian countries. As countries take steps to increase their competitiveness in world markets and to enhance employment opportunities, designing and delivering effective skills policy frameworks is crucial for attaining inclusive and equitable growth. Asian economies have achieved remarkable growth rates. The ADB report Asia 2050: Realizing the Asian Century (ABD, 2011), projects that if Asia continues to grow on its present trajectory, by 2050 it could account for 51\% of world GDP (compared to 27\% in 2010), with a six-fold increase in per capita income, reaching current European levels. Seven countries - China, India, Indonesia, Japan, Korea, Malaysia and Thailand - are projected to account for $87 \%$ of GDP growth in Asia and almost 55\% of global GDP growth between 2010 and 2050. However, sustained productivity increases are required to maintain and accelerate growth rates. With global technological frontiers advancing constantly, the extent of sufficient technology absorption of products and services will also determine Asia's competitiveness. It is essential for skills development initiatives to incorporate these priorities to ensure a workforce that contributes to competitiveness.

Skills training systems can influence not only countries' economic strength but improve human development levels and strengthen human capital as well. The priorities of government policies are evident in terms of the share of GDP allocated for skills development, the importance of the sector in national development plans, and the innovative strategies to boost the quality of training for better and more sustainable jobs.

\section{Priorities and preoccupations of developing countries in skills training and TVET}

Raising the bar on skills development and creating a highly skilled workforce. Developing countries are highly preoccupied with "upskilling" their workforce in order to remain competitive in world markets and increase the value-added of their products and services. Most Asian governments' plans and policies have a prominent focus on developing a cadre of "highly skilled" workers. A number of shifts, particularly in the context of globalisation and technological progess, require skilled workforce and higher levels of educational attainment. 
Addressing the mismatch between skills and employment and promoting the development of relevant skills. A major priority for developing countries is to redress poor employment outcomes of skills training. Recent trends reveal that while economic growth has rebounded well, employment rates have not picked up. Both developed and developing countries alike are concerned with improving employment outcomes of skills training. However, given the importance of the anticipated increase in the working age population in developing countries, there is a much larger challenge of creating productive jobs. Structural unemployment needs to be tackled.

Steering skills development towards increasing the productivity of the workforce. While skills shortages in general have become more acute in the region, skills development for emerging industries is putting pressure on their education systems. Analysts have argued that further growth impetus will be derived largely from productivity gains. Therefore, planners in developing countries are looking to ensure that skills training systems address more output per worker and increase the efficiency by which training translates into actual skills of the workplace.

Advancing skills development for structural transformation. As countries attempt to move up in the value chain from resource-intensive growth to knowledge-based growth, there is an obvious pull towards creating a highly skilled workforce to support high-technology industries. The shift of employment and output from agriculture to manufacturing and services necessitates changes in the skills mix of the workforce. Emerging, higher technology industries require modern skills and an adaptable workforce.

Establishing competency based training and national qualification frameworks. In the quest for quality, acceptability and portability of skills, policy makers are engaged in developing and implementing national qualification frameworks (NQF). Over 100 countries are either implementing or planning national qualification frameworks (Allais, 2010). Competency based training and skills metrics have become crucial for certification and accreditation of skills training - for both students and trainers. Even though there is not yet any compelling evidence that NQFs lead to improved quality or greater acceptance by employers, there are major initiatives to establish them in the pursuit of making skills relevant to the job market.

Meeting global standards in skills training and global recognition of qualifications. Globalisation and labour mobility across borders has given rise to preoccupations of how national training systems can take cognisance of workforce qualifications and worker mobility.

Increasing private sector participation in financing and providing skills training. The mobilisation of the private sector is a priority for ensuring market relevant training, particularly in new and emerging industries. The private sector is expected to have an extensive and potentially growing role not only in financing but in providing skills training as well. In addition, business and industry associations will have a vital role to play in redefining workplace training and re-orientating existing workers to new occupational standards. Creating appropriate regulatory environments and policy instruments to augment private sector participation are important priorities for governments.

Improving the image and prestige of technical and vocational education and training (TVET). Education planners are grappling with the task of correctly positioning technical and vocational education and training in the education spectrum. TVET is often 
considered below par in comparison with degree programmes and similar tertiary level education opportunities. In some countries, there is insufficient uptake of additional opportunities created for technical and vocational education courses. It has become imperative to enhance the prestige of TVET as well as its outcomes in well-paid jobs.

\section{ADB engagement in developing member countries}

$\mathrm{ADB}$ has an extensive and growing portfolio of projects in the technical and vocational education and training and skills sector across the region. There are many ongoing skills projects in Southeast Asian countries as well as new projects planned by the ADB.

The main objectives and priorities of ADB's support to the skills and TVET sector could be summarised as:

- Improving access to skills training as a lever for poverty reduction and inclusive growth: ADB projects aim to invest in strengthening the human capital endowments in order to enhance opportunities for productive jobs and decent incomes.

- Expanding the provision of skills training, including upgrading infrastructure and equipment: ADB projects support government initiatives to expand training services through modernised facilities and equipment and strengthening physical training infrastructure for student and faculty development.

- Enhancing the quality of skills training for better outcomes, particularly increased employment: one of the key outcomes expected from investing in skills and training is increased job opportunities and the acquisition of skills relevant to the market. Projects include interventions to strengthen the link between skills training and the world of work.

Thrust areas of ADB support include:

- Improving access to skills training in general and more specifically affirmative action for assuring access to the disadvantaged: ADB projects focus on improving the access of girls, ethnic minorities and students from poor communities to skills training and technical and vocational education. This is promoted through scholarships, stipends and skill vouchers.

- Enhancing the quality of vocational and technical education and training: an overarching component of ADB projects is to enhance the quality of TVET by improving the quality of: trainers, training institutions and trainees. Typical interventions include developing minimum professional standards for trainers and instructors; minimum service delivery standards (through accreditation of courses and curriculum) for training institutions, and competency based skill standards for trainees.

- Strengthening capacity and regulatory frameworks: ADB projects provide assistance for improving the capacity of key institutions, regulatory bodies and quality assurance agencies and promoting public-private partnerships to improve the overall skills sector. 


\section{Issues for consideration}

\section{Skills in the education continuum}

It has become increasingly apparent that skills training connects with both lower and higher levels of education. Good quality secondary education provides the foundation needed to participate in further training. Tertiary education trains trainers and provides opportunities for upgrading skills. Policy makers need to consider flexible pathways between different levels and types of education.

\section{Responsive and diversified skills training systems}

While earlier institutional skills training was considered to be the main method of skills delivery, recent times have demonstrated that industry participation in particular has led to different ways of delivering skills training. Formal, informal and workplace training models have been developed. TVET institutions need to develop mechanisms by which they can be responsive to industry specific needs - high-, medium- and low-level skills.

\section{Flexible and modular approaches to skills}

The rapid pace of transformation in Asian economies signals the need for a more adaptable approach to curriculum maintenance and renewal in skills training. With technological progress, the level and types of skills required are also evolving and TVET institutions need to keep track of these. An important area in which continuous renewal is required concerns "soft" skills, which are acknowledged as increasingly important for success in the workplace. As workplace requirements are constantly evolving, skills training needs to become more modular with opportunities for refreshing training and lifelong learning.

\section{Youth aspirations}

Many Asian countries have large youth populations. Trends indicate that unemployment and weak labour force participation is more of a challenge for youth than for adults. Youths have high aspirations of the expected outcomes from training in terms of job quality. Skills training systems are challenged to connect up with quality jobs that meet youth aspirations. Vocationalisation of secondary and tertiary education and enhancing the image of TVET are also important considerations.

\section{Improving market signals for jobs}

Many countries have developed and implemented labour market information systems, such as surveys and tracking studies of vocational training graduates. Tools must be refined in order to capture market trends for jobs and industry's requirements for skills in a more timely manner, and to improve training institutions' alignment with them as well.

\section{Indicators for productivity of the workforce}

Adequate attention has not yet been given to assessing whether training results in higher outputs. Training systems need to strengthen employment outcomes while at the same time enhance outputs per worker, particularly for workplace-based training. 


\section{Vulnerability and informality of employment}

Asia has large informal labour markets consisted of unskilled and poorly skilled workers. Lack of appropriate training impedes their chances of getting jobs in the formal labour market with contracted employment and social security. Adequate skills are also needed for informal markets to ensure that productivity and returns increase. The small and medium-sized enterprises sector also requires specific types of training. While there are several good examples and good practices of training for informal markets, it is crucial to advance further ideas for developing and implementing specific strategies for training that are directly relevant for SMEs and informal labour markets.

\section{Possible policy levers}

\section{National qualification frameworks}

Most Asian countries are concerned with establishing and implementing national qualification frameworks (NQFs). Governments in an estimated 100 countries are designing or implementing qualification frameworks. Such widespread international interest stems from concerns regarding the relevance, flexibility and portability of skills and training, and the employment outcomes expected from them. NQFs serve as a potential tool for policy reform in technical and vocational education and training (TVET) and in higher education. Despite such extensive interest and work in this area, there is not yet any compelling evidence of the benefits of NQFs. A recent 16-country study by the International Labor Organization (ILO) on the impact of NQFs concluded that there is little evidence that they have substantially improved communication between education and training systems and labour markets. However, NQFs can play a valuable role in quality assurance and accountability and help to improve the transparency of information on learning outcomes. It is equally important to recognise and acknowledge the caveats and what NQFs can and cannot do - they cannot alone make the entire TVET system more effective.

\section{Matching skills development priorities with economic and industrial policies}

Effective skills training can help create a workforce that enhances a country's economic competitiveness. As Asian countries are rapidly pushing forward the technology frontier, a highly skilled and adaptable workforce can facilitate further technology adoption. However, Asian countries need to align skills and training policies with economic and industrial policies for sustainable growth, productivity and competitiveness. Studies have shown that countries such as Hong Kong, China, Korea, Singapore and Viet Nam ensured appropriate planning, policies and interventions to co-ordinate education and training so that skilled workers are available in the labour market when employers need them. This helped these countries to guarantee that investing in skills development attracted investment in high value-added industries and helped them to move up the value chain by increasing their competitiveness and exports. Policy makers thus need to consider skills development strategies in the context of the economy's overarching economic growth plans.

\section{Alternative models for private sector participation}

It is now fairly well established that the private sector can add considerable value and relevance to skills training. The private sector is increasingly financing skills training. While many countries have developed public-private partnerships for skills training, it is 
also necessary to develop a range of opportunities for private sector participation, such as training academies, skill levies, apprenticeship models to increase the effectiveness of skills training. A "light" regulatory framework is also crucial for the private sector to participate in national plans for skills development.

\section{Labour market and social protection interventions}

Countries in Asia are aspiring to advance inclusive growth and skills training is one of the instruments for doing so. However, if skills development initiatives are to advance inclusive growth, it is essential that they are buttressed with appropriate labour market and social protection policies. The prevalence of large and informal labour markets is one reason that opportunities for skills training should be accessible to the poor and disadvantaged populations and why those populations are able to translate this opportunity into higher employment prospects.

\section{Note}

1. The views expressed in this paper are those of the author and do not necessarily reflect the views and policies of the Asian Development Bank (ADB) or its Board of Governors or the governments they represent.

\section{References}

Allais, Stephanie (2010), The Implementation and Impact of National Qualifications Frameworks: Report of a Study in 16 Countries, International Labor Organization, Geneva.

Asian Development Bank (2011), Asia 2050: Realizing the Asian Century, ABD, Singapore. 


\title{
Chapter 3
}

\section{Integrating skills, employment and local development}

\author{
by \\ Randall Eberts
}

\section{Integrating skills development for sustained growth}

Integrating skills, employment and economic development in developing countries and the desire to rebalance growth strategies are gaining momentum in Asia. The proposition is that rebalancing growth strategies towards a greater reliance on domestic and regional demand rather than on export-oriented growth can help regions and countries mitigate the effects of global economic crises, weather global business cycles, and achieve a more sustained and job-rich recovery and long-term growth path. Certainly, the recent global financial crisis, which in the United States is referred to as the "Great Recession," has forced everyone to take a closer look at their past economic strategies to see what can be done to avoid such a catastrophic event from happening in the future. Of course, most national governments have implemented some type of stimulus package to make up for the lack of demand in the private sector and provided financial support to help resuscitate a trauma-stricken banking sector.

In many cases, countries that depend on a large export sector for economic growth found that they were vulnerable to the economic malaise of other countries - such as those who exported to the United States or the European Union - and understandably wanted to find a way to avoid that dependency. However, some countries such as Australia found that exporting natural resources and other products to China helped shelter it from the global recession. Germany, where exports account for 39\% of GDP, has experienced greater growth coming out of this recession than its EU neighbours. On the other hand, for the United States, dependence on the domestic market (US exports are $8 \%$ of GDP) did not make it less resilient to the recession nor did it lead to a more robust recovery, particularly with respect to employment growth. It is interesting to note that there is a growing consensus among US policy analysts that the United States must rely more on exports to reset its economic trajectory (Istrate et al., 2010). They also emphasise that future export growth will increasingly target emerging markets, such as China and India. So, balanced growth has merit.

One of the risks of pursuing a domestic-oriented strategy is to avoid it from becoming a protectionist strategy. Often we see this happening in the form of higher import tariffs, in response to the fear that foreign workers are taking domestic jobs. This is a typical populist reaction after economic crises. It is important not to become too inward looking with respect to the export sectors. Export sectors have many advantages. They link a country to the global economy with respect to cutting-edge technologies, best business 
practices, and information sharing. Exporting firms are larger, more productive, more skill- and capital-intensive, offer better career opportunities, and pay higher wages than non-exporting firms (Bernard, 2007). In the case of developing countries, it has been found that firms actually become more productive after beginning to export. Productivity is improved in those domestic-oriented firms that are in competition with exporting firms as well (Clerides, 1998). Furthermore, exporting firms typically establish extensive supply chains, comprised largely of domestic companies, which supply exporting firms with services like distribution, transportation, advertising - activities that are also intensive in skilled labour. It is also found that much of the growth attributable to the export sector comes from the expansion of domestic firms that supply exporting firms. So there is already a strong linkage between the export sector and the domestic sector (Feenstra and Wong, 2007).

Regardless of whether it is the export sector, the domestic supply chain supporting exports, or domestic firms selling to their own local markets, the key to future growth is the skills development of workers. Skills are required for competitiveness in the global economy and for increasing workers' wages and their household's standard of living. On the other side of the equation, employers must be in a position to benefit from a readily available skilled workforce by creating jobs that take full advantage of the skills available. Otherwise, educated workers in developing countries might leave in search of higher returns for their skills in developed countries and firms and regions (countries) may squander the opportunity to improve the welfare of their workers.

\section{Challenges in skills development}

The question is how to develop an integrated skills development strategy that contributes to re-balanced and sustainable growth and to identify the challenges, particularly within the context of developing or emerging countries. There are four challenges:

1. Diversity of emerging economies, primarily the division between the high-skill export sector, the medium-skill domestic sector, and the low-skill informal sector and the gaps that exist between these sectors.

2. Increased access to skills training for workers from all sectors, including new arrivals from rural areas.

3. Shift the focus from national policy, particularly one that targeted specific industries, to an emphasis on local integration of the skills strategy across many sectors, particularly across the three broad sectors (high-skill export sector, medium-skill domestic sector, and low-skill informal sector).

4. Foster a culture of partnership and co-operation in order to achieve successful integration of skills.

The first challenge is the diverse nature of emerging economies. There are at least three sectors: high-skill export sector, medium-skill domestic sector, and low-skill informal sector. Because these sectors are fairly distinct, particularly in the earlier stages of development, the challenge is to bridge the gaps between them, with respect to skills requirements and worker mobility, particularly the ability to move up into higher pay and higher skill positions. The fear, or course, is that most of the jobs are created at the low end and that there are few opportunities for workers to move up the career ladder. Studies show there is a distinct division between firms that export and those that only serve local 
markets. These studies show that only a small percentage of firms in a country export. For example, of the 5.5 million firms operating in the United States in 2000, just $4 \%$ were exporters. Among these exporting firms, the top $10 \%$ accounted for $96 \%$ of total US exports. Even for the manufacturing, mining, and agricultural sectors, which produce tradable goods and are typically associated with exporting (even though services are now exporting more), only 15\% were exporters (Bernard et al., 2007). For some developing countries, the share is around $10 \%$ (e.g. Colombia, Morocco and Mexico, see Clerides et al., 1998). However, it must be recognised that the development of an export sector also stimulates the development of a supply chain, which also requires skilled jobs. So, including the supply chain as part of an export cluster can help to tie these sectors more closely together.

It appears that economic and demographic forces are already moving these sectors closer together and integrating them, but still within a global context. For example, forecasts call for burgeoning growth in emerging market cities. Today, there are 717 emerging market cities with populations currently greater than 500000 . By 2030, the number is expected to increase by 371 to nearly 1100 . One-third of the world's population (2.6 billion) lives in emerging market cities, with another 1.3 billion expected to by 2030. In contrast, it is anticipated that the population in developed market cities will increase by only 0.1 billion during that same time period. Consequently, emerging market cities claim $62 \%$ of world GDP growth and will continue to do so. Along with population growth is growth in the middle class. In only five years, the middle-class population is projected to increase by $70 \%$, with an increase in the consumption of tradable and non-tradable goods. Already, $37 \%$ of the world's cars are purchased in emerging market cities, and projections call for an expanding need for services and even prestigious and luxury goods (Boston Consulting Group, 2010).

The growth in domestic markets and the growth in the middle class provide opportunities for larger companies (chains) to enter domestic markets replacing "mom-and-pop" operations (many of which make up the informal economy) with larger, more globally integrated companies such as Wal-Mart and consumer financial institutions. As the convergence towards a middle ground between large export firms and larger (than mom-and-pop) domestic firms continues, pay differentials within and across sectors should narrow as domestic economies become increasingly attractive to larger, global companies.

This leads to the second challenge: how to increase access to skills training for workers from all sectors and to bridge the gap between the types of skills businesses need and the type of training that is offered to workers and those about to enter the workforce. In addition, because of the importance of SMEs in serving domestic markets, and in becoming part of the supply chains, it is also necessary to ensure that they have the technical training and expertise to best use the available skills so to produce high value-added products and services.

The diversity of emerging economies across these three sectors and the emergence of a more sophisticated "middle economy" (middle-class households and domestic firms serving this population) require programmes to help develop skills, such as training, as well as to provide technical assistance to smaller firms on how to best use the available skills. It also requires the ability to communicate by using a common language of worker 'qualifications' among all partners across various sectors. More specifically: 
1. The workforce development system needs to reorient its focus to make business more of a primary customer. Local workforce development agencies should provide demand-driven training (including customised incumbent training programmes and on-the-job training), customised skills assessments, onsite job analysis, and specialised human resource services. In addition, the workforce development programme should partner with economic development agencies and business and engineering schools in local universities to provide technical assistance to local businesses facing workforce and technical production challenges. For example, customised training programmes could be combined with programmes to provide technical services to businesses to improve productivity and human resource practices, such as the Manufacturing Extension Partnership (MEP) programme provides to manufacturing firms in the United States. Training programmes could also be combined with job creation tax credits and other job creation incentives.

2. Workforce programmes should target services that keep workers in jobs. Training should be extended to incumbent workers, not just those who are out of work, to upgrade their skills so that they can improve their career opportunities (though career ladders). This minimises the cost of worker displacement to workers, families, and employers, and the cost to society. The skills training should also be focused on the needs of employers in order to help companies be more productive and better able to gain a foothold in the local economy. Businesses should be given incentives (such as a lower unemployment insurance contribution rate, or a wage subsidy when training is provided) to invest in workplace innovations focused on career ladders in the same way they are granted to companies that invest in research and development.

3. Workforce programmes should provide assistance throughout a worker's learning and working career. First, the national government should provide financial assistance to support workers engaged in re-training activities, since clearly there will be considerable displacement across the various sectors. Second, the national government should help establish a common language that provides all parties - workers, businesses, workforce development agencies, educational institutions - with a better understanding of job requirements and a person's qualifications to meet them. Third, the workforce system should be more of an advocate for workers who need guidance about career opportunities, help navigating between programmes, and assistance in dealing with work issues. Fourth, national programmes should recognise that some displaced workers, particularly older ones, may not benefit from training, and thus income support is needed to help them transition into retirement. Finally, the national government should develop modern workforce information systems and platforms to provide better information to workers, firms, and workforce (and partnering agency) staff as a way to bridge the gap among the three (or more) sectors.

The third challenge is to move from a focus on national policy, particularly those that targeted specific industries, to an emphasis on local integration of the skills strategy. It makes sense that local agents (e.g. government, civil society and the private sector) who have a "grounds eye" view are better able to assess the economic opportunities and challenges of their community, are more cognizant of the community's priorities, and better positioned to mobilise local resources to ensure the initiative sustains its impact beyond the period of the project (OECD, 2011 ). These markets typically vary with respect to industrial composition and worker skills, and a one-size-fits-all approach to 
national policies is typically not appropriate for framing and meeting the needs of workers and businesses. Furthermore, increased globalisation has placed greater emphasis on local markets and has blurred the lines between national ones. This not only has important ramifications for addressing these issues locally instead of nationally but it also offers lessons from the private sector with respect to the importance of networks in delivering services.

\section{Conclusion}

The global economy is rapidly transforming into a myriad of networks of enterprises that transcend national boundaries. In most instances, they are more closely linked to local industrial clusters than they are to the confines of national borders. Thus, as the world moves more towards a landscape without borders, the role of nation states as producers of goods and services is being replaced by networks of industrial clusters as the predominant economic entities. Furthermore, the globalisation of trade creates pressure to harmonise a wide variety of laws and policies across regions within countries. It also puts pressure on national governments to equalise the different economic situations across regions that result from global networks favouring one industrial cluster over another. Public workforce development and economic development organisations increasingly need to recognise that the old paradigm of centralised decision making and service delivery makes it more difficult to serve the needs of workers and businesses that are competing within this global arrangement.

Lessons learned from efforts to achieve greater integration of skills development points to accomplishing the following key steps: attention to customers, the balance between accountability and flexibility, appropriate mechanisms and incentives, performance-based monitoring, strategic planning and goal setting, alignment, strong leadership, competent staff, and trust among partners. ${ }^{1}$ The most important lesson, and perhaps greatest challenge, however, is that it will not be achieved through a simple restructuring of government, but rather it requires a cultural transformation among management, staff, and policy makers. Partnerships and co-operation happen at the local level, and each of the 1100 cities mentioned earlier has its own circumstances, industrial composition, leadership base, pre-existing levels of co-operation, and competencies. Each must find the right approach and engage the right leadership to bring together the appropriate partners and bring about the co-ordinated efforts to link workforce programmes with economic development programmes with educational institutions. National governments can provide resources, foster alignment among national agencies, and offer flexibility to local governments, but establishing a culture of co-operation at the local level is ultimately up to the local leadership. 


\section{Notes}

1. Criteria based on evaluations of WIRED and Michigan Regional Skills Alliances, conducted by the Upjohn Institute as reported in Eberts (2009) and Eberts and Hollenbeck (2009).

\section{References}

Bernard, Andrew, J. Bradford Jensen, Stephen J. Redding and Peter Schott (2007), "Firms in international trade", Journal of Economic Perspectives, 21(3): 105-130, Summer.

Boston Consulting Group (2010), Winning in Emerging-Market Cities: A Guide to the World's Largest Growth Opportunity, Boston Consulting Group, Boston.

Clerides, Sofronis, Saul Lach and James Tybout (1998), "Is learning by exporting important? Micro-dynamic evidence from Columbia, Mexico and Morocco", Quarterly Journal of Economics, 113(3): 903-47.

Eberts, Randall W. (2009), "The role of labour market policy in horizontal co-ordination", in Sylvain Giguere and Francesca Froy (ed.), Flexible Policy for More and Better Jobs, Local Economic and Employment Development (LEED), OECD Publishing, Paris, 2009, http://dx.doi.org/10.1787/9789264059528-7-en.

Eberts, Randall and Kevin Hollenbeck (2009), "Michigan regional skills alliances: a statewide initiative to address local workforce needs", in Francesca Froy, Sylvain Giguere and Andrea Hofer, Designing Local Skills Strategies, OECD, 2009, http://dx.doi.org/10.1787/9789264066649-5-en.

Feenstra, Robert and Chang Wong (2007), "China's exports and employment", NBER Working Paper, No. 13552, October.

Istrate, Emilia, Jonathan Rothwell and Bruce Katz (2010), "Export nation: how U.S. metros lead national export growth and boost competitiveness," Metropolitan Policy Program, Brookings Institution, September.

OECD/International Labour Office (2011), Job-rich Growth in Asia: Strategies for Local Employment, Skills Development and Social Protection, Local Economic and Employment Development (LEED), OECD Publishing, Paris, http://dx.doi.org/10.1787/9789264110984-en 


\title{
Chapter 4
}

\section{Building effective local partnerships for skills development}

\author{
by \\ Graham Larcombe
}

\section{Introduction}

The global financial crisis and the ongoing economic malaise in advanced economies raise questions about developing Asia's economic future. Is the global financial crisis over or are major developed economies slipping back into recession? Alternatively, is growth in developing Asia strong enough to withstand further downturns in developed economies? There are significant risks and uncertainty in relation to economic prospects, both in the short and medium term.

The growing complexity of economic systems and supply chains, the increasing importance of knowledge in economic and social activities, as well as constant improvements in information and communications technologies, underline the importance of continuous learning and upgrading of skills. This age of uncertainty increases the need for flexibility and adaptability. This is where local partnerships involving businesses, households, educational and training organisations, and local government can play an important role. Local partnerships create more opportunities for local innovation, and they can utilise the skills and tacit knowledge of specific communities. In this environment, the central role of the formal education and training system is increasingly being supplemented by continuously upgrading skills at the local level in businesses, households and communities.

\section{Skills development partnerships}

The skills of economies evolve all the time, whether they are in developed or developing countries. Skills are traditionally acquired through schools and the vocational education system, or passed on through family and community networks. Increasingly, however, skills are acquired from multiple sources including workshops, short courses, online, on-the-job and learning by doing.

Partnerships are a cost-effective way of promoting local employment and learning. Face-to-face interaction at a local level has many advantages. People develop skills through face-to-face communication, particularly taking into account distinctive local cultural and socio-economic characteristics. Individuals and organisations working together at the local level can complement each others' skills and learn from each other. They may also have different expertise and responsibilities and they mobilise resources 
for projects from different sources. This is why they benefit from flexibility, taking account of rapidly changing economic circumstances. Ongoing interaction between partners promotes continuous learning, which is often the source of local innovation and can lead to a virtual cycle of development. Hence, partnerships for skills are not just about providing training opportunities. They are also about knowledge exchange.

To be effective, local partnerships need to break down the barriers that separate different organisations. For example, industry, education and training organisations, local government, employment and training agencies, and households need greater local autonomy and resources to be able to collaborate and implement local projects.

In looking to strengthen local partnerships, stakeholders need to recognise the distinctive features of the local skills system. An important feature of the global economy is that skills are not just acquired through the formal education and training system. In many countries of developing Asia, skills are often developed through family and kinship networks. On the other hand, in many industry sectors, innovation and competition drives constant change and skills. In many cases, "learning by doing" within the firm is a better way to develop skills. Many firms, particularly multinationals, have their own internal training programmes, which they rely on to develop the skills of their workforce. Groups working together on local employment-related projects can maximise skills outcomes through knowledge sharing in practical ways.

In designing and promoting local partnerships to expand job and skills opportunities, it needs to be emphasised that building partnerships has many challenges. They require more trust than in market relationships, and returns tend to be longer term. Prospective partners have different missions and priorities. Groups need to be clear from the start what they are expecting from the local partnership. Of course, there are always issues when people work together. Some may work harder than others to make the partnership work. Free riders can quickly undermine partnerships. Power imbalances - where one group brings more resources or is more articulate - can raise major problems, particularly when partnerships aim to provide more job and skills opportunities for locals with few resources. They need mechanisms to resolve conflicts. There is also the ongoing challenge of the relationship between experts and the community. Other challenges include the long-term sustainability of partnerships and how to expand the partnership with new entrants. Many partnerships start with minimum seed resources, but need to continually mobilise resources if they are to be successful in the long run. The best way to address some of these challenges is to invest in partnership building and management.

One of the most important relationships in a decentralised system is the relationship between central government agencies and local partners. In many ways, the role of centralised agencies is enhanced. In relation to education and training, the contribution of central agencies many include:

- $\quad$ providing the policy, regulation and planning framework for local initiatives;

- $\quad$ supporting local partners with strategic industry intelligence and occupational forecasts;

- co-ordinating skills strategies as part of comprehensive local/regional development strategies, which may include infrastructure, industry, environmental strategies;

- curriculum development, quality and assessment where accredited outcomes are involved;

- $\quad$ establishing criteria for funding (inclusive, quality, participatory) and providing funding to partnerships that meet the agreed criteria; 
- evaluation and monitoring.

Figure 4.1 shows how the relationship works where education authorities are involved. The provincial education and training system works within the parameters established by the central government and its agencies, particularly associated with the implementation of curricula, funding, and monitoring and evaluation. But interaction between the provincial education and training system and local stakeholders is nurtured as a matter of policy. Continuous interaction between agencies at the local level provides the local education and training authorities with a better understanding of the needs and dynamics of local industries and households. Some scope is available at the local level for flexibility and adaptability. This might include providing customised training within enterprises, organising flexible learning delivery with time scarce households and enterprises, and providing cultural specific programmes for local communities. Feedback is provided from the local level to the central level and this informs policy and programme development. External links are encouraged directly from the local level to enhance understanding on relevant learning models being implemented elsewhere.

Figure 4.1. Relationship between central and local education authorities

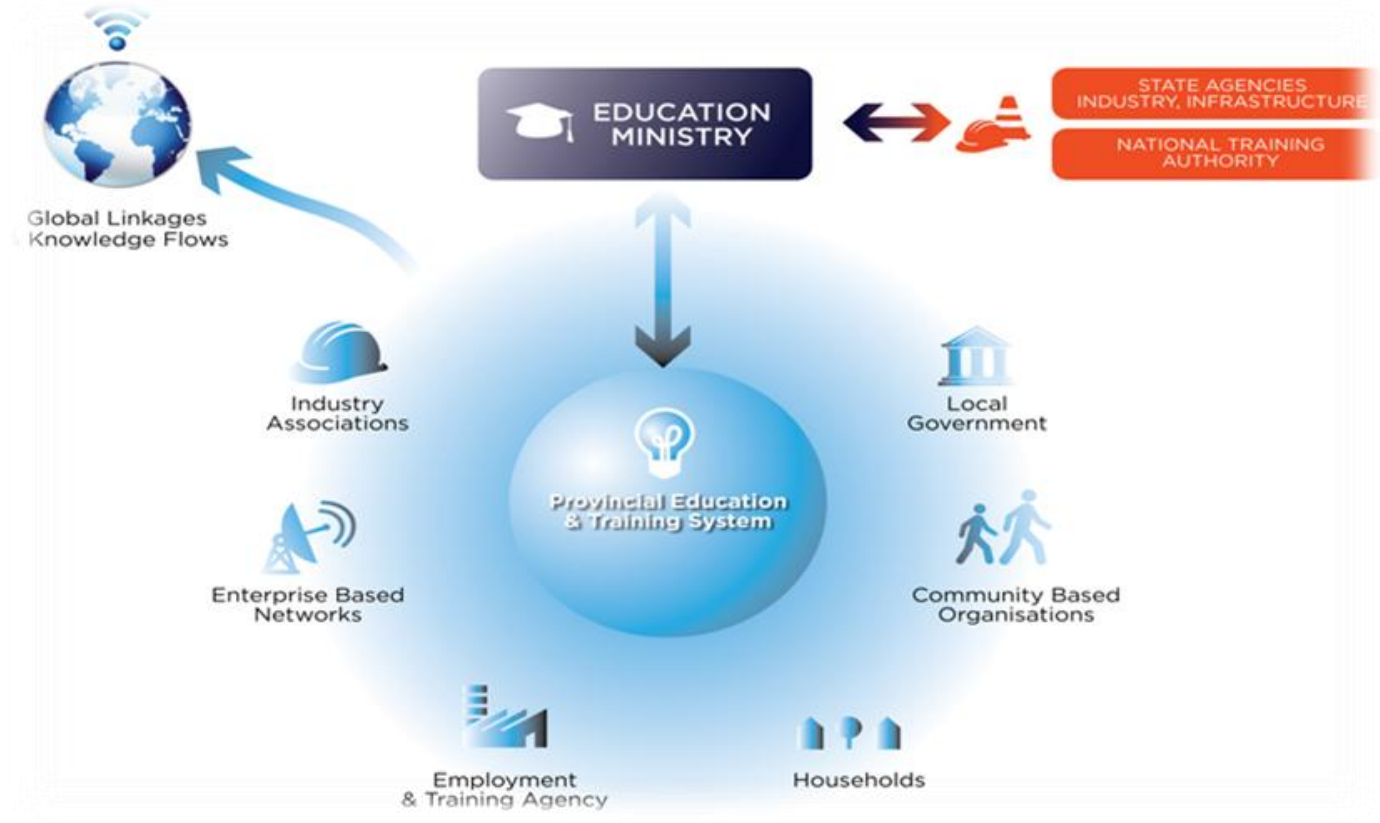

\section{Conclusion}

The advantages in putting more emphasis on devolving greater responsibility and resources for partnership development at the local level are diverse and include:

- local agents are better able to develop strategies that meet their specific needs;

- increasing knowledge flows and information within communities;

- driving local innovation through new ideas;

- utilising local knowledge;

- developing capabilities/skills and common ownership; 
- $\quad$ increasing transparency and accountability;

- $\quad$ supplementing the limited resources of the formal education and training system. 


\section{Part II}

Developing skills systems for growth 



\title{
Chapter 5
}

\section{Skills development to support rebalancing employment growth in China}

\author{
by \\ Yongtang Ma
}

\section{Introduction}

China is a developing country with the largest population in the world. By the end of 2009, China's total population was 1.335 billion, with a labour force of 1.069 billion (112.67 million more than in 2000). The number of employees had reached 779.95 million (an increase of 59.1 million from the year 2000), 311.2 million of which were urban employees (an increase of 79.69 million compared with the year 2000).

The global financial and economic crisis has had, and is still having, grave effects on China's employment. According to data from the Chinese Ministry of Human Resources and Social Security, China's registered urban unemployment rate stood at $4.3 \%$ at the end of 2009, with 9.21 million people unemployed. There were 24 million people, including 6.3 million new college graduates and 6 million high school graduates, who entered the labour market, but only 12 million jobs were available for job-seekers. At the same time, as industrial restructuring accelerates, the demand for skilled workers is great, but employers have trouble finding qualified skilled workers, even with higher wages. There were 4 million skilled job vacancies across the country at the end of 2009.

\section{Special vocational training programmes responding to the impact of the global financial crisis}

To overcome the impact of the global financial crisis on the Chinese economy and employment, and to meet the demands of different groups of people in finding jobs and preparing them for different types of careers, the Chinese Government has carried out various special vocational training programmes. These programmes took place from 2009 to 2010, organising on-the-job trainings for workers in enterprises in difficulty, practical skills training for rural migrant works, employability training for the unemployed, and preparative training for new labour force and free vocational training for demobilised soldiers. These training activities were based on vocational schools' and various vocational training institutions' efforts and made use of training subsidy policies. This experience proved that such special vocational training programmes are highly necessary for improving job-seekers' employability, increasing their salary, extending the duration of paid work and improving the quality of the jobs available. 
The On-the-Job Training Program encourages enterprises in difficulty to carry out in-service training, on-the-job training and new job transferring training for their workers in enterprise-run training centres and other training institutions. The training costs are covered by the enterprises' Workers Education and Training Fund and if that is not sufficient, may be subsidised by the government's Special Funds for Employment Promotion. However, the maximum amount of the subsidy can be no more than $50 \%$ of the total training costs. In the first half of 2010, 500000 workers in enterprises in difficulty and 1.1 million rural migrant workers participated in such training activities.

The Practical Skills Training Program is designed to upgrade the skills level of migrant workers without jobs who are returning home from urban areas. This training is focused on the skill demand created by local industrial restructuring, technological upgrading and the newly state-sponsored construction projects, such as railways, highways, electricity and building construction. It is carried out by the related government departments and social organisations. Moreover, entrepreneurship training stressing project development, guidance on starting and operating a business, small loans, follow-up support and one-stop services - is also organised for migrant workers who want to start their own small businesses. The funds for such training are subsidised by the government's Special Funds for Employment Promotion and other special training funds. In the first half of 2010, 2.76 million rural migrant workers participated in such training.

The Employability Training Program was designed for the urban unemployed. However, it is not only conducted for the urban unemployed, but for registered unemployed college graduates and rural migrant workers who are seeking jobs in cities and towns as well. The employability training courses usually last three to six months, and focus specifically on local third industrial sectors and community services. Entrepreneurial training activities are also provided to help those who have aspirations to run their own small businesses. The training costs can be subsidised by the government's Special Funds for Employment Promotion and the Unemployment Insurance Fund. In the first half of 2010, 2.35 million urban unemployment persons participated in such re-employment training, of which 200000 were registered unemployed college graduates; 490000 people participated in entrepreneurial training.

The Preparative Training or Pre-Employment Training Program is carried out for junior and senior high school graduates who failed to gain admission to higher education in a bid to help them master vocational skills or obtain a professional certification before they begin seeking work. Such training courses are usually held in technical schools in co-operation with enterprises and last from 6 to 12 months. The training costs can be partially subsidised by the government's Special Funds for Employment Promotion. In the first half of 2010, 500000 participants had already been trained under this programme.

Thanks to these efforts, 11 million urban jobs were created in 2009; the employment rate of college graduates reached $87.4 \%$; over 5 million laid-off workers found new jobs; and over 1.5 million people with difficulty in finding jobs were re-employed.

\section{China's national human resources development strategy}

China has always devoted a lot of attention to national human resources development. In the new century, China made a major decision to rejuvenate the nation through human resources development, aiming to train thousands of millions of high-quality workers, hundreds of millions of professionals and a large group of top-notch innovative 
personnel, and to set up a large-scale and rationally structured contingent of high-caliber personnel. In 2001, the Chinese Government incorporated this strategy into the Five-Year Plan for National Economic and Social Development. It has intensified efforts since 2006 in the sphere of top-level design and systematic planning of human resources development. It formulated the Outline of the National Plan for Medium- and Long-term Scientific and Technological Development (2006-2020), the Outline of the National Plan for Medium- and Long-term Human Resources Development (2010-2020), and the Outline of the National Plan for Medium- and Long-term Educational Reform and Development (2010-2020), focusing on prioritising human resources development in the course of economic and social development. The plans formed the country's guidelines on the overall development of human resources in urban and rural areas, among different regions, industries and trades, and among the public and private sectors, ensuring that everyone has an equal opportunity to benefit from related policies and participate in human resources development, and striving to realise co-ordinated development of all types of human resources.

\section{Developing highly skilled personnel}

To meet the need of establishing an innovative nation, the Chinese Government has launched, among others, the National High-tech R\&D Program (863 Program), the National Key Basic Research Program (973 Program), the National Key Technology R\&D Program and the National Natural Science Foundation. It has also built the National Engineering Research Center and the National Engineering Laboratory, implemented the Skills Training Plan of the "Hundred-Thousand-Ten Thousand Project", Changjiang Scholars Program and some other major human resources-related programmes. In addition, it has increased investments in science and technology and implemented the Project on Upgrading the Knowledge of Technical Professionals. As a result, it has trained a large number of highly qualified scientific and technical professionals and attracted high-caliber personnel from abroad. In 2008, the number of full-time R\&D personnel nationwide had reached 1965 400, some 2.9 times the 1991 figure. Among these there were 1593400 full-time scientists and engineers, 3.4 times the 1991 figure. A total of 2146 centres for post-doctoral studies and 1642 post-doctoral workstations were set up, and the number of post-doctoral researchers exceeded 70000.

To meet the needs of industrialisation and for optimising and upgrading the industrial structure, the Chinese Government has implemented the National Plan for Developing Skilled Personnel, set up public training bases and national demonstration bases for training highly skilled personnel, and striven to create a contingent of skilled personnel for different industries. Following the "high-skill training project" and "three-year 500000 new technician training programme", the structure of skilled workers has been upgraded. By the end of 2007, China had a total of 98.9 million skilled workers, of which 4.29 million technical masters and senior technical masters, accounting for $4.3 \%$ of the total skilled workers, and 18.1 million highly skilled workers, accounting for $18.3 \%$ of the total skilled workers.

The state has made great efforts to train people with practical skills for the countryside, implemented a plan to enhance their quality of life, and tried to improve the scientific and technical attainment, vocational skills and business capabilities of this population. It has also trained teachers, doctors and agricultural technicians to meet the urgent needs of rural development, and encouraged and guided personnel with different qualifications to work in the countryside. 


\section{Promoting equity in general education for all teenagers nationwide}

Free nine-year compulsory education is now available to all children, urban or rural, throughout China. Since 2006, the Chinese Government has reformed and adjusted the mechanism for ensuring funding for compulsory education in rural areas; and since 2008 urban students in compulsory education have been exempted from tuition and other fees. Nine-year compulsory education has been fully incorporated into the national financial security system.

China has been active in promoting balanced compulsory education. The government has given priority to rural areas, outlying poor areas and regions inhabited by ethnic minority groups in allocating public resources for education, and implemented programmes such as the National Compulsory Education in Poor Areas, Building Boarding Schools in Western China's Rural Areas, Modern Distance Education for Elementary and Middle Schools in Rural China, Renovating Junior Middle Schools in Central and Western China and the Plan for Special Education in Central and Western China, so as to narrow the gap between urban and rural areas and between different regions and to guarantee that disadvantaged groups have access to education.

The financial aid system has been improved. The Chinese Government has a national scholarship system, student subsidy system and national student loan system applicable to regular higher learning institutions and vocational schools. It has provided more financial aid to ensure that students from families with financial difficulties can continue their studies. By the end of 2009, $90 \%$ of students from secondary vocational schools and $20 \%$ of university students had received financial aid (for a total of 43.06 million students). Since 2009 , students from poor rural families studying at secondary vocational schools and students studying agriculture-related subjects in such schools have been exempted from tuition.

In 2008, China's invested $10.75 \%$ of GDP in human capital. In 2009, the state treasury spent CNY 198.139 billion on education, an increase of $84.1 \%$ from 2007 .

\section{Strengthening vocational training projects for different groups in different sectors}

The Chinese Government has put cadre education and training in a prominent place. The state has drawn up and issued the Regulations on the Work of Cadre Education and Training, the National Plan for Cadre Education and Training (2006-2010) and the Opinions on the Implementation of Cadre Training Work on a Large Scale (2008-2012). With a focus on the requirements of major government work and civil service posts, the government has conducted initial training, post-related training, professional training and in-service training; carried out training plans geared to the needs of the posts; promoted formal training; and sent cadres on secondment, thus effectively developing the human resources of the civil service and promoting career development for civil servants.

Through the Project on Upgrading the Knowledge of Technical Professionals, the Chinese Government has carried out special training programmes on new theories, knowledge, technologies and methods for middle- and high-level professionals in fields that are important for economic, social, scientific and technological development. Altogether, between 2005 and 2009, 3 million professionals participated in such training programmes. The government has worked hard to build a continuing education system for technical specialists with clear levels and categories. The system is gradually forming a demand-driven, continuing education mechanism characterised by a combination of 
government leadership and employer initiative, with individuals carrying out their vocational training and academic work on their own initiative. In 2009, professionals involved in continuing education throughout China reached 30 million person/times.

To meet the demands of different groups for finding employment, and geared to different stages of careers, the government has conducted vocational training programmes, set up a vocational training system with technical schools as the mainstay and vocational training institutions as the supplement, and given an important role to trade unions, Communist Youth League, women's federations, and other mass and social organisations. By the end of 2009 there were over 6000 technical schools and employment training centres, over 20000 privately-run vocational training institutions, and over 260000 demonstration bases of science and technology for women, providing different education and training programmes for women on 120 million occasions and enhancing women's capability for self-development. For junior and senior high school graduates who have failed to gain higher education, the government offers pre-job training courses to help them master a vocational skill or obtain a professional certificate before hunting for a job. For the unemployed, the government offers re-employment training courses that are relevant, practical and effective, so as to better prepare them for re-employment. For urban and rural workers who want to start their own business and who have the qualifications, the government offers entrepreneurship training courses. For surplus rural workers who want to transfer to non-agricultural fields and urban areas, the government offers vocational training and carries out special programmes such as the Sunshine Project, Training Plan for the Transfer of Rural Labor Force, Spark Technical Training and Yulu Plan, to enhance their abilities to find employment in new sectors.

Since 1994, in order to comprehensively improve the quality of the workforce and strengthen workers' chances of finding jobs and performing their jobs well, China has established a professional qualification certificate system. By the end of 2009, a total of 18.433 million professionals in various fields throughout the country had obtained the required qualifications, and over 100 million qualification certificates for workers of different skill levels were issued.

\section{A national system of honours and rewards}

The Chinese Government believes in combining morale boosting with material rewards, with a focus on the former, and has therefore set up a national system of honours and rewards which is constantly being improved.

The state awards workers who have made major contributions to national development with the honorary titles of "National Model Worker" and "National Outstanding Worker" - the former for workers, farmers and managerial personnel of enterprises, and the latter for personnel of government departments and public institutions. Since 1989, the Chinese Government has held a national conference once every five years to award such titles to model and outstanding workers from all walks of life. So far 14578 people have received one of these titles.

The state honours citizens and organisations that make brilliant contributions to scientific and technological development with the Science and Technology Award. Since 2000, a total of 27772 people have won this award, among them 16 prominent scientists won the State Preeminent Science and Technology Award of China. China has two titles for academicians, granted following an assessment and selection process: member of the Chinese Academy of Sciences, the highest title in the field of science and technology, and member of the Chinese Academy of Engineering, the highest title in the 
field of engineering and technology. By the end of 2009 there were 1143 academicians of the Chinese Academy of Sciences and 861 academicians of the Chinese Academy of Engineering. Since 1990, China also has a system of special government allowances. In addition to the certificates granted to experts, scholars, technicians and highly skilled personnel who have made important contributions to their fields, the government gives them special government allowances. By 2009, 158000 people had received such allowances. In addition, the state has put in place a national system for rewarding outstanding professionals. Since 1999, a total of 200 people have won the title of "National Outstanding Professional". Since 1995, a total of 120 people have won the state's "Grand Skill Award of China" and 2976 have won the "National Technical Expert" award. These individuals are role models of high-skilled workers in China. The government has also established a national system to reward prominent personnel from rural areas, and 160 people have been commended under this system since 2000 .

\section{Long-term efforts in human resources development to support rebalancing employment growth}

By implementing a long-term strategy of human resources development and an active employment policy, China has re-employed over 30 million workers laid off by stateowned enterprises, and incorporated subsistence allowances of laid-off workers into their unemployment insurance. From 2005 to 2009, over 50 million new jobs were provided in urban areas, and nearly 45 million surplus rural workers were transferred to nonagricultural sectors.

Efforts made in human resources development have also optimised the employment structure. The proportion of those employed in primary industry has dropped significantly while those in tertiary industry has risen greatly. In 2009, the proportion of employment in primary, secondary and tertiary industries changed to $38.1 \%, 27.8 \%$, and $34.1 \%$ from $50 \%, 22.5 \%$ and $27.5 \%$, respectively in 2000 . 


\title{
Chapter 6
}

\section{Mainstreaming skills training: Malaysia's skills and the future}

\author{
by \\ Ghazlan Ghazali
}

\section{Introduction}

Malaysia's 50 years of nationhood have witnessed many milestones in its economic development. Following independence, Malaysia was highly reliant on tin and rubber and more than half of the population lived in poverty. Today, Malaysia has a broad-based and diversified economy. It is the $19^{\text {th }}$ largest trading nation in the world, with trade in excess of MYR 1 trillion in 2007. Malaysia continues to enjoy political stability with a diverse, yet united, population. At the same time, per capita income has increased 26 times to MYR 20841 and the incidence of poverty has been reduced to less than $6 \%$. The course of Malaysia's development was shaped by the vision, ideas and efforts of many of the country's great leaders and thinkers, as enshrined in the Constitution and as encapsulated in the three key national policy frameworks: the New Economic Policy (NEP) 1971-1990; the National Development Policy (NDP) 1991-2000; and the National Vision Policy (NVP) 2001-2010. Each of these policy frameworks was based on a profound understanding of the needs and challenges of the time, as well as the responses required to tackle them. Equally important, these frameworks captured the country's collective aspirations, which culminated in the launch of Vision 2020 in 1991, outlining the aim of attaining developed nation status by the year 2020 .

Human capital lies at the core of innovation and a productive high-income economy. It is the most important investment a country makes. No economy can succeed without a highly skilled talent base that is able to rapidly respond creatively to economic changes, and that is centered on developing and utilising knowledge. To achieve Malaysia's aspirations, it is imperative to develop, attract and retain a first-world talent base. The talent base and workforce of high-income countries have a number of key characteristics, specifically around higher education qualifications to promote knowledge generation and innovation, high skill levels in both technical and professional fields, and high productivity. Regarding these characteristics, Malaysia has a long way to go and will need to concentrate efforts to catch up with a first-world skill and talent base by 2020 .

The workforce remains relatively unskilled, $77 \%$ are only educated up to 11 years of basic education at the Malaysian Certificate of Education (SPM) level or equivalent, and only $28 \%$ of Malaysian jobs are in the higher skilled bracket. Talent shortages are almost certain to become more acute in intensifying global competition where the best global talent is drawn across borders to the most attractive global opportunities. Asian countries 
such as Korea and Singapore have propelled themselves into the group of developed nations within a generation as a result of precise, deliberate and purposeful prioritisation of certain sectors for their economies, whilst concentrating on developing, upskilling and delivering the talent required to drive growth in these specific sectors. For Malaysia, the development of a first-world talent base requires nothing less than a comprehensive, all-inclusive national effort from the public and private sectors as well as civil society, to elevate the quality of the nation's human capital. The development of human capital in Malaysia requires the collaboration of multiple ministries and the private sector to address all segments of the population. It requires a holistic set of measures that supports the development needs of every Malaysian at every stage of their lives.

\section{Issues and challenges}

Malaysia faces several key challenges in its efforts to become a high-income economy by 2020. Malaysia's growth is between that of fast-growing high-income economies and that of developing ones. However, given the current economic climate, it will be challenging to achieve the required high growth rates to transition into a high-income economy. Malaysia will therefore need to change its economic industry structure. It will also need to significantly improve its labour productivity, which is currently lagging behind regional peers. In order to do so successfully, it will need to upskill its existing, mostly semi-skilled, workforce as well as improve educational levels of new workers entering the labour market.

Multiple human capital recommendations and programmes have been implemented in recent years to improve the quality of the workforce. However, several key issues remain:

- A high number of students enter the workforce with low skills levels as technical/skills education is not considered a viable and mainstream option due to quality and perception issues. Even though Malaysia offers a wide range of affordable higher education pathways to its youth, more than 100000 SPM leavers (approximately 25\%) enter the workforce each year without pursuing further education. This group of students may not be academically inclined or have sufficient grades to meet entry requirements into universities. However, technical/skills education, which generally has much lower entry requirements, is not regarded to be a viable alternative by these students. This type of education has become mainstream in all developed countries but in Malaysia it is still perceived by many students and parents as a last resort. Many prospective students are also not fully aware of the various skills training courses that are offered by various providers. For others, the benefits of further technical/skills education - higher pay or a quicker promotion period - are not apparent.

- Industry's perception that technical/skills education is of a generally low quality jeopardises Malaysia's goal of becoming a high-income economy by 2020. Malaysian employers continue to identify skilled labour shortages as the leading investment climate constraint. According to Economic Planning Unit's baseline occupational planning scenario, $32 \%$ of all jobs will fall in the skilled category in 2020. However Malaysia might need to target even a higher figure of about 35\% to be on par with highincome regional peers such as Korea, Taiwan and Singapore. 
- Employees will also profit from further education as this will enable them to move on to higher level jobs and wages. Expected qualification requirements for various job levels are based on the National Occupational Skills Standards (NOSS). Managerial level jobs in trade-related occupations require at minimum a SKM level 3 certificate. For example, one year of additional training is required for a SKM 2 certificate holder to upgrade to an SKM 3 certificate, which would lead to almost double the salary.

- Despite the clear benefits of further technical/skills education to both employees and employers, the actual take up of this type of education is still low. This can be partly explained by the very low participation in technical, vocational and skills education at upper secondary level. Only around $10 \%$ of all upper secondary level students were enrolled in vocational training in 2006. This low figure stands in sharp contrast to European countries such as Germany and the Netherlands, as well as Australia, where the majority of upper secondary level students are enrolled in skills education. Based on these figures, Malaysia should set ambitious targets to at least double the level of upper secondary students enrolled in technical/skills education. Moreover, post-secondary skills education is concentrated in the lower levels as approximately $90 \%$ of SKM certificates are for level 1 and 2 graduates. However, if Malaysia wants to advance to a high-income economy it needs to stimulate enrolment in higher skills levels.

\section{Strategic direction}

For Malaysia, the development of a first-world talent base requires nothing less than a comprehensive, all-inclusive national effort from the public and private sectors as well as civil society, in improving the quality of the nation's human capital. It requires a holistic set of measures that supports the development needs of every Malaysian at every stage of their lives. During the Tenth Plan period (2011-2015), the government will adopt an integrated human capital and talent development framework. This approach will nurture and develop Malaysians throughout their entire life cycle, from early childhood education, basic education, tertiary education, all the way to their adult working lives, specifically by:

- revamping the education system to significantly improve student outcomes;

- raising the skills of Malaysians to increase employability; and

- reforming the labour market to transform Malaysia into a high-income country.

The second and third strategies are directly related to skills development and training as discussed in the following sections.

\section{Raising the skills of Malaysians to increase employability}

Given the rapid pace at which Malaysia will need to develop its human capital to achieve high-income nation status, it is necessary to radically raise the skills of Malaysians to increase their employability. One of the strategies to do this is by mainstreaming and broadening access to quality technical education and vocational training. Malaysia must significantly increase enrolment in technical education and vocational training (TEVT) and improve overall training quality to upskill its workforce. The purpose of TEVT is to increase the skilled human capital base in Malaysia by providing quality education to learners who possess keen interest, ability and talent in the technical and vocational fields. TEVT aims to provide skills that will be immediately applicable in the labour market. TEVT has become a mainstream education option in 
many developed countries. In Malaysia, only $10 \%$ of students enrol in upper secondary technical and vocational education, whereas the average enrolment rate for OECD countries is $44 \%$. Improving the availability, access and quality of TEVT for the technical pathway is equally as important as the academic pathway of tertiary education.

During the Tenth Plan period, the following four strategies will be adopted to mainstream and broaden access to quality TEVT:

- improving the perception of TEVT and attracting more trainees;

- developing highly effective TEVT instructors;

- upgrading and aligning TEVT curriculum quality with industry requirements; and

- $\quad$ streamlining the delivery of TEVT.

\section{Reforming the labour market to transform Malaysia into a high-income nation}

Currently, only $28 \%$ of the total Malaysian workforce is employed in the higher skilled jobs bracket, reflecting the low level of educational attainment among a large segment of the workforce. There is an urgent need to upgrade and re-skill the existing workforce, to move the economy up the value chain. The government aims to have $33 \%$ of the workforce employed in the higher skilled jobs bracket by 2015 , and up to $50 \%$ by 2020. This will require greater involvement of the private sector.

The coverage of the Skills Development Fund will be expanded to promote upskilling and retraining the workforce. It will be extended beyond school leavers to include existing workers. Recognising that not all workers have enough funds to pay for their own training, preferential loans will be provided by the fund to pay for training costs incurred in skills upgrading.

The Recognition of Prior Learning (RPL) programme will be expanded with the goal of formally recognising the experience and expertise of workers, as well as of encouraging and rewarding lifelong learning among the workforce. The programme will enhance the career prospects of the workforce by conferring the Malaysian Skills Certificate on workers who do not have any formal certification, but who have obtained relevant knowledge, experience and skills in the workplace.

\section{Conclusion}

Human capital development is an economic imperative and lies at the foundation of transforming Malaysia from a middle-income to a high-income country. Achieving a globally competitive and innovation-led economy requires a systematic and comprehensive approach to nurturing, attracting and retaining top talent for the country. Malaysia must close the gap to achieving a first-world talent base. The government will undertake a reform spanning the entire life cycle of human capital development, from upgrading early childhood education right through to upskilling the existing adult workforce. Achieving a first-world talent base for Malaysia requires nothing less than consistent, co-ordinated and concentrated efforts to leverage diversity internationally as well as to nurture, attract and retain top talent in Malaysia. 


\title{
Chapter 7
}

\section{Integrated skills: an approach for strengthening the Technical and Vocational Education Program (STVEP) in the Philippines}

\author{
by \\ Milagros Campos Valles
}

\section{Introduction}

One of the recommendations of the revised Technical and Vocational Education and Training report (UNESCO-ILO, 2001) is that as general technical and vocational studies in schools have a great importance in the orientation and education of the youths, there should be an appropriate balance between theoretical and practical work. This implies that programme curricula should be designed in collaboration between the professional community and those responsible for technical vocational education.

Anchored on this concept and recognising that technical and vocational education is the key to sustainable development, in 2007 the Department of Education (DepEd) implemented the Strengthened Technical and Vocational Education Program (STVEP) in 282 public secondary schools in the 16 regions of the country. The move to implement the STVEP is also in line with the objectives of the Education for All (EFA) global movement, the Philippine Millennium Development Goals (MDG) and the 10-point Agenda of the Philippine Government. The strengthening of the technical and vocational education (TVE) programme is also based on the result of the first National Career Assessment Examination (NCAE) conducted in the 2006-2007 school year (NETRC), which revealed that out of the 1.3 million graduating high-school students in public and private high schools, 58.03\% have an inclination for entrepreneurship and areas of TVET.

The main objective of the STVEP is to provide high-school graduates with opportunities to acquire certifiable vocational and technical skills that would allow more options in pursuing their post-secondary career ranging from a college education, shortterm technical courses, entrepreneurship to apprenticeship leading to eventual formal employment. In order to attain this objective, the Department of Education has worked closely with relevant stakeholders including the academe, TVET institutions and industry to ensure that the programme can produce a new generation of highly skilled workforce and at the same time equip students with relevant skills and competencies, foundation skills, and qualifications needed for their entry to higher learning, field of work or venture into entrepreneurship. 


\section{Intervention strategies}

In order to ensure the efficient and effective implementation of the STVEP in the 282 techvoc schools, DepEd is continuously providing the schools with the following financial assistance and intervention strategies in close collaboration with relevant partner agencies:

- Development of a competency based curriculum and instructional materials: through a series of consultation workshops, the competency based curriculum (CBC) of the STVEP was prepared and packaged by an ad hoc committee composed of tech/voc practitioners, experts from academe, representatives from the Bureau of Secondary Education, TESDA experts, and representatives from industry. The CBC is now utilised as the basis of the development of instructional/learning materials, teaching strategies, and learning assessments, among others, needed for the operationalisation of the STVEP. It consists of basic, common and core competencies or learning outcomes which are integrated in the 21 techvoc specialisations in the areas of arts and trades, agriculture and fishery. These are vital in the development of middle level skilled individuals ready to be absorbed in the field of work.

- Capability building programmes: this includes the skills development/ enhancement programme designed for techvoc school administrators, teachers, and other stakeholders. Training is financed solely by DepEd; however, technical assistance in the form of resource persons and trainers are provided by TESDA, academe, and industry in terms of specific skills or specialisations in arts and trades, agriculture, fishery, ICT, etc. Training venues with the appropriate facilities for skills enhancement were co-shared by some relevant institutions, e.g. polytechnic colleges, state universities, techvoc institutions (KorPhil, Meralco Foundation).

- Provision of tools and equipment: provided by DepEd through the allocation of funds to the schools to support laboratory activities or hands-on skills training. The purchase of tools and equipment was based on the specialisations offered by the schools.

- Provision of infrastructure/facilities' support: funding assistance provided by DepEd for the rehabilitation of old laboratory workshops and the construction of new multipurpose laboratory facilities. It provides opportunities for students to apply what they have learned in the classroom.

- Provision of competency assessment subsidy: financial support given by DepEd to subsidise the skills assessment of graduating students to acquire national certification in their chosen specialisations. This covers the provision of supplies and materials, TESDA assessors' fee, transport expenses, and equipment rentals. Through partnership with local and small-scale industries, some techvoc schools graduates who have been awarded with National Certification (NC 1 and 2) were already employed in occupations that are not covered under the Philippine Labour Code Law (as they are only 16 or 17 years old). The law prohibits individuals under 18 years of age to work under certain provisions of the labour code. 
- Provision for additional teacher plantilla ${ }^{1}$ items: the allocation of teacher plantilla items for techvoc schools is based on a 1:20 teacher-student ratio. Techvoc teachers are required to have national certification for certain specialisations. Schools with insufficient teachers with specific Techvoc specialisations are allowed to tap the services of experts from universities or other technical learning institutions.

- Provision for increased maintenance and other operating expenses (MOOE): the schools also received MOOEs higher than some schools in the general secondary education.

\section{Strategic partnership}

DepEd, recognising the importance of skills integration, expertise, and other needed resources in the implementation of STVEP, has signed Memorandums of Understanding with various agencies using the following mechanisms: co-financing, co-sharing of resources/expertise, consortium, scholarship programmes and training activities, Adopt-a-School or Adopt-a-Student Program, among others. The following are some agencies with which DepEd has entered into partnership:

- Southeast Asian Ministers of Education Organization Regional Center for Educational Innovation and Technology (SEAMEO INNOTECH) - facilitated the conduct of a school survey to assess the preparedness of the secondary schools to implement the STVEP. SEAMEO INNOTECH also helped carry out benchmarking activities for key officials designed to generate best practices/models on the implementation of the STVEP from Canada, Germany and other Asian countries.

- Technical Education and Skills Development Authority (TESDSA) - provided technical assistance in curriculum development, skills training, and competency assessment. TESDA is the official agency mandated to spearhead the provision of TVE skills development in the Philippines and also the agency responsible for packaging the Industry-Based Training Regulations and Standards (TRS) in close consultation with the industry and business sectors in the country. Consequently, the TRS serves as guide in the development of industry-based curriculum, training programmes, skills assessment, learning materials, etc.

- Technical and vocational institutions, universities and colleges offering techvoc specialisations - were tapped to provide skills enhancement training for techvoc teachers teaching subjects/courses in arts and trades, agriculture and fishery. These institutions are also often the venues for training and skills assessment as they have the tools/equipment and laboratory facilities needed to carry out the training and assessments.

- Local government units, non-government, private institutions, business sector provide learning interventions and financial assistance through the on-the-job training (OJT), apprenticeship programmes, scholarship grants, and Adopt-a-School/Student programme. These institutions also provide or donate equipment and tools, laboratory workshops, and other provisions to support students' hands-on activities.

\section{Practices of techvoc schools on skills integration}

As mentioned earlier, an integral component of the STVEP is an inter-agency partnership, particularly with the industries. This approach has been cascaded down to the 
school level where sharing resources through the provision of scholarship programmes, co-sharing facilities, equipment/tools, technologies, and expertise during the skills training were explored. This process is vital in acquiring synchronised competencies, providing a well-balanced education and relevant job skills in the workplace for employability and work mobility. The industry linkage is also an avenue for the provision of scholarship programmes, OJT or industry exposure thus facilitating the desired skills integration and honing the talents of students. It provides the opportunity to link the knowledge acquired in the classroom to the real world of work (theoretical versus practical). This will also give them an edge for employment and prepares them to become efficient workers. The following are sample integration skills approaches used by some techvoc schools in the Philippines:

- Skills Training and Industry Exposure through Strong Linkage with Industries and Universities - Bataan School of Fisheries (BSF)

The Bataan School of Fisheries has played a pivotal role in the human resource development of it students by providing them with a quality education that caters not only to their academic development but by engaging in skills training designed to prepare them for gainful employment and/or entrepreneurship. In order for the school to ensure that skills in demand by industries are integrated, students were provided with the opportunity to do on-the-job training in relevant industries such as Subic Bay Metropolitan Area for linkage with Subic Bay Apparel Corporation, Jollibee Balanga, Chowking Balanga, Max Restaurant, Crown Royale Hotel, Bureau of Fisheries and Aquatic Resources, National Integrated Fisheries Technology Development Center, National Marine Fisheries Development Center at Sangley Point, Cavite City, and Pawikan Cente, Morong Bataan.

For the dressmaking course, students are sent to Subic Bay Apparel to undergo their OJT. The student trainees receive an allowance for the duration of their training. After the training period, the students were hired as regular employees (as sewers of coats or pants). Students enrolled in food and beverages service (NC 11) were sent to Jollibee, Chowking, Max Restaurant, Crown Royale Hotel. In most cases, the trainees of the food and beverages service were hired by the establishment that trained them. Students who specialised in aqua culture were sent to the National Integrated Fisheries Technology Development Center of the Bureau of Fisheries and Aquatic Resources for a one-month hands-on training on water analysis, bangus hatchery, and other aquaculture activities. The center also hired some of the graduates.

- OJT with industry for the STVEP: Key to Linkages in Entering Higher Education, World of Work and Entrepreneurship - Siniloan National High School (SNHS), Laguna

The most remarkable result that SNHS obtained by implementing OJT with industry partnership/linkages in close co-ordination with other relevant stakeholders is scholarships granted to deserving students who are pursuing higher education. The students are provided with free room and board with a modest allowance and the guarantee of a job after graduation. Another advantage of the partnership approach is that the school received various equipment, machineries and buildings from partner agencies such as the Department of Agriculture, the Rotary Club Laguna Chapter, and the World Bank. 
- Advocacy and Partnership with Local Government and Industry Sector for Skills and Resource Generation - Subangdaku Technical and Vocational High School (SVHS), Mandaue City

The Aboitiz Foundation, Inc., Cebu, Philippines is one of the industry partners of the Subangdaku Technical and Vocational High School. The foundation has provided the school with laboratory facilities for their welding and food trades courses. As the foundation has specific skills requirements, additional competencies were integrated in SVHS' curriculum, particularly in the welding courses. In order to implement the curriculum as the Aboitiz Foundation desired, it provided laboratory facilities and trainers to train the teachers who will teach the subjects. On-the-job training is also a vital component of the linkage. SCHS students are sent to the Metaphil and Aboitiz Group of Companies to apply for a job or practice what they have learned in the classroom. At the same time they are acquiring practical knowledge of their vocational specialisation, students are also earning money as they are provided with allowances and other benefits. Some of those who underwent training were now employed as workers in Metalphil and the Aboitiz Group of Companies.

- Adopt-a-School Program - Muntinlupa Business High School (MBHS)

The Petron Foundation, Inc. adopted a school that offers a pilot programme on forecourt, entrepreneurship and food and beverages service. In line with this, TESDA, through its Qualification and Standard Office, facilitated the development of competency-standard and competency based curriculum for those specialisations (qualifications). Currently, the MBHS benefits from the Adopt-a-School Program as students who underwent OJT at the Petron Foundation were employed in the different companies as forecourt or food and beverage attendants; while those who took up entrepreneurship were given seed capital to start a small business.

\section{Conclusion}

There is a real need to develop diverse links and mutually beneficial strategic partnerships with the industries and other partners to enhance technical skills advancement towards integrated skills, develop talents, and upskill and multi-skill graduates for employment, venture into entrepreneurship, workforce mobility or prepare them for a higher level of education.

DepEd has utilised varied approaches to integrate skills into the STVE Program which is now recognised as a revitalised basic education programme that aims to provide opportunities for employment by providing skills for enhancing the employability and mobility of high school vocational graduates, including: $i$ ) creating an inter-agency ad hoc body to develop a competency based curriculum; ii) signing Memorandums of Understanding with relevant industries for on-the-job training/industry exposure for students, provision of scholarships, and placement of graduates; iii) establishing a co-sharing mechanism with industries for the provision/utilisation of facilities and sharing expertise; iv) the Adopt-a-School/Student Program; v) industry linkages for skills and resource generation such as laboratory equipment and tools; vi) advocacy and partnership for entrepreneurship and employment of graduates, among others.

The partnership established with relevant agencies was beneficial not only to the Department of Education and the 282 tech/voc schools but even more so to the students 
as they are exposed to the actual technical aspects of their tech/voc specialisation and the latest products/technology produced in the industry. It also provides them with the opportunity to explore careers or make contact with potential employers for future employment.

In addition, the industries also benefit from the partnership as they are given the opportunity to meet and identify potential recruits. This approach is one of the vehicles for minimising the job skills mismatch in the labour market, thus addressing the current problems of underemployment and unemployment in the Philippines.

\section{Note}

1. Each agency has a plantilla and they could only hire a certain number of people provided that there is an item in the plantilla.

\section{References}

Bataan School of Fisheries (BSF) (2011), "A case study on skills training and industry exposure through strong linkage with industries and universities", BSF, Bataan, Philippines.

Siniloan National High School (SNHS) (2011), “A case study: on-the job training (OJT) with industry for the STVEP: key to linkages in entering higher education, world of work and entrepreneurship", SNHS, Laguna, Philippines.

Subangdaku Technical and Vocational High School (SVHS) (2011), "A case study on the advocacy and partnership with local government and industry sector for skills and resource generation", SVHS, Mandaue City, Phillipines.

Techvoc Task Force Office, DepEd (2008), "Brochure on the Strengthened Technical and Vocational Program (STVEP)”, DepEd, Manilla, Philippines.

UNESCO-ILO (2001), "Report on the revised recommendations on the technical and vocational education and training", UNESCO-ILO. 


\title{
Chapter 8 Vocational training in large companies and SMEs in Korea
}

\author{
by \\ Kyetaik Oh
}

\section{Skill gaps in large and medium to small companies}

Wide gaps in skills exist among the Asian countries as shown by their differing occupational compositions. However, in Korea, such a gap is observed and becoming clearer between large companies and medium and small sized companies. In order words, Korean large companies may be on its road to the high skill equilibrium, while medium and small sized companies are more likely to be in the low skill equilibrium. Such a widening gap may indicate a possibility of double equilibrium within the same country. Large companies have more professionals, technicians, and production workers, while medium to small companies have more services and sales workers and elementary occupations.

Figure 8.1. Compositions of occupations by firm size

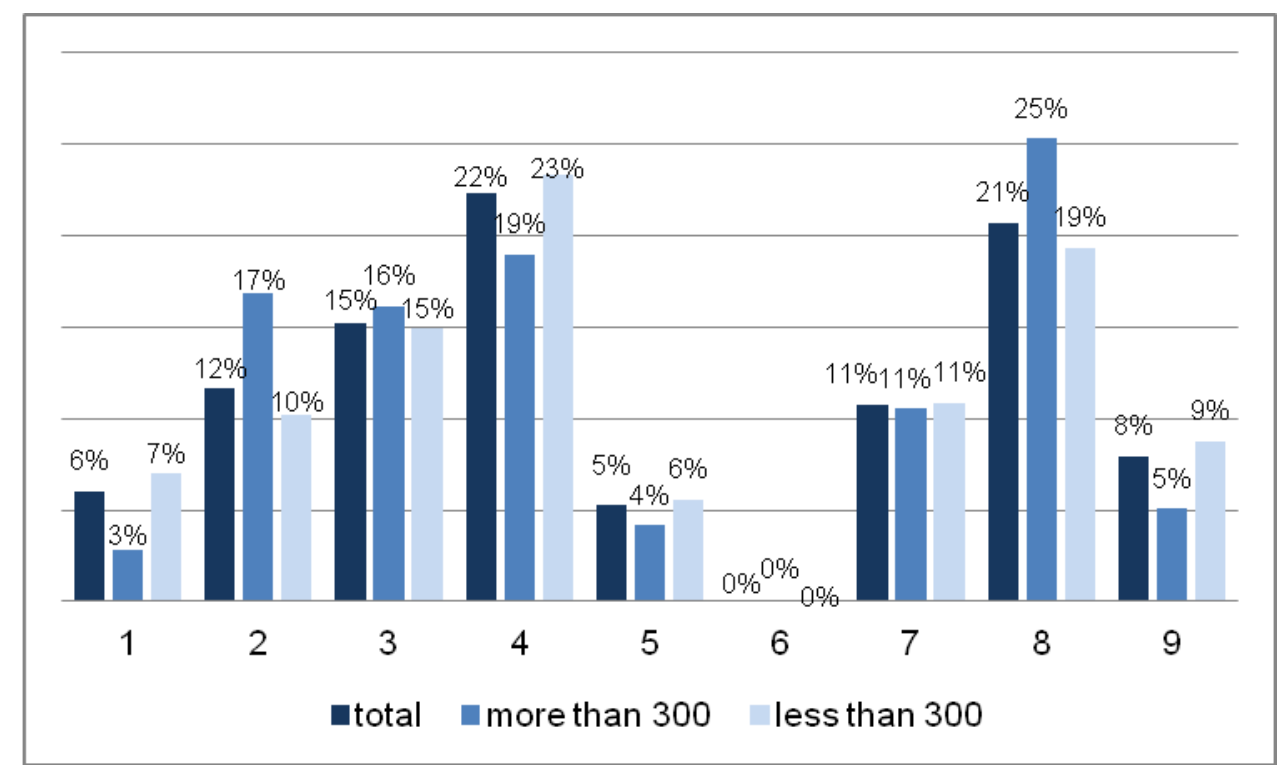

Note: Occupations by categories are as follows: 1(managers), 2(professional and associate professionals), 3(clerks), 4(services workers), 5(sales workers), 6 (agriculture workers), 7(trades and craft workers), 8(assemblers, operatives, and production workers), 9(elementary occupation).

Source: Workplace workforce survey by occupation, 2008, Korea Ministry of Employment and Labor. 


\section{Korea's skill training system}

Korea's training system can be viewed from the supply and demand sides. On the supply side, Korea has a training account system. The unemployed, with and without previous work experience, are entitled for an individual training account as job seekers. Through this training account, job seekers could enroll for training programs and cover the cost of training. Therefore, the system provides the right to be trained and to select the programs at their own disposal to the unemployed in search of jobs in the labor market. In this way, they would be more likely to find the training programs that better serve to their own purpose.

On the demand side, that is, for the companies, Korea has a training cost reimbursement system as a part of its employment insurance system. Companies contribute employment insurance premiums and they can be reimbursed up to a maximum amount proportional to this contribution from the employment insurance fund. If and only if the companies have implemented training, they can receive the reimbursement from the fund. Thus, companies have an incentive to provide training for their own employees since otherwise they would waste the training fund. However, the problem among SMEs under the system is that they do not have the time and resources needed for providing training. Therefore, some SMEs form a training consortium among them, in order to practice trainings more efficiently, utilizing the economy of scale.

However, the Korean system needs more active involvement from SMEs, and its TVET should be made more demand oriented., First of all the authorities should try to figure out the companies' needs and endeavor to align training program to the demands of companies. Further instructors should be properly trained and compensated whose remuneration is relatively low currently in Korea.

\section{Skills and employment creation in Korea}

There are some new findings in the patterns of employment creation in Korea. According to Lepak \& Snell (1999), employment systems can be categorized into four types in Figure 8.2. In Korea, Quadrant 1 is close to the employment system in large companies where value creation and job quality are both high. Quadrant 2 applies to regular worker in most subsidiaries and the $1^{\text {st }}$ level subcontractor companies. Quadrant 4 applies to the professionals, but this labour market has a relatively small share in the Korean economy so far. Lastly, Quadrant 3 is close to the employment system in medium and small sized companies in which both value creation and job quality are poor. The implication of this framework is that job creation in the specific industry would be intertwined with one another if they are linked up by subcontracting relationships. Large companies may retain Quadrant 1 type jobs and transfer Quadrant 2 type jobs to subsidiaries and to the $1^{\text {st }}$ level subcontractors, but the companies may transfer lower quality jobs again to even lower stage companies in the subcontracting hierarchy. 
Figure 8.2. Summary of the HR architecture

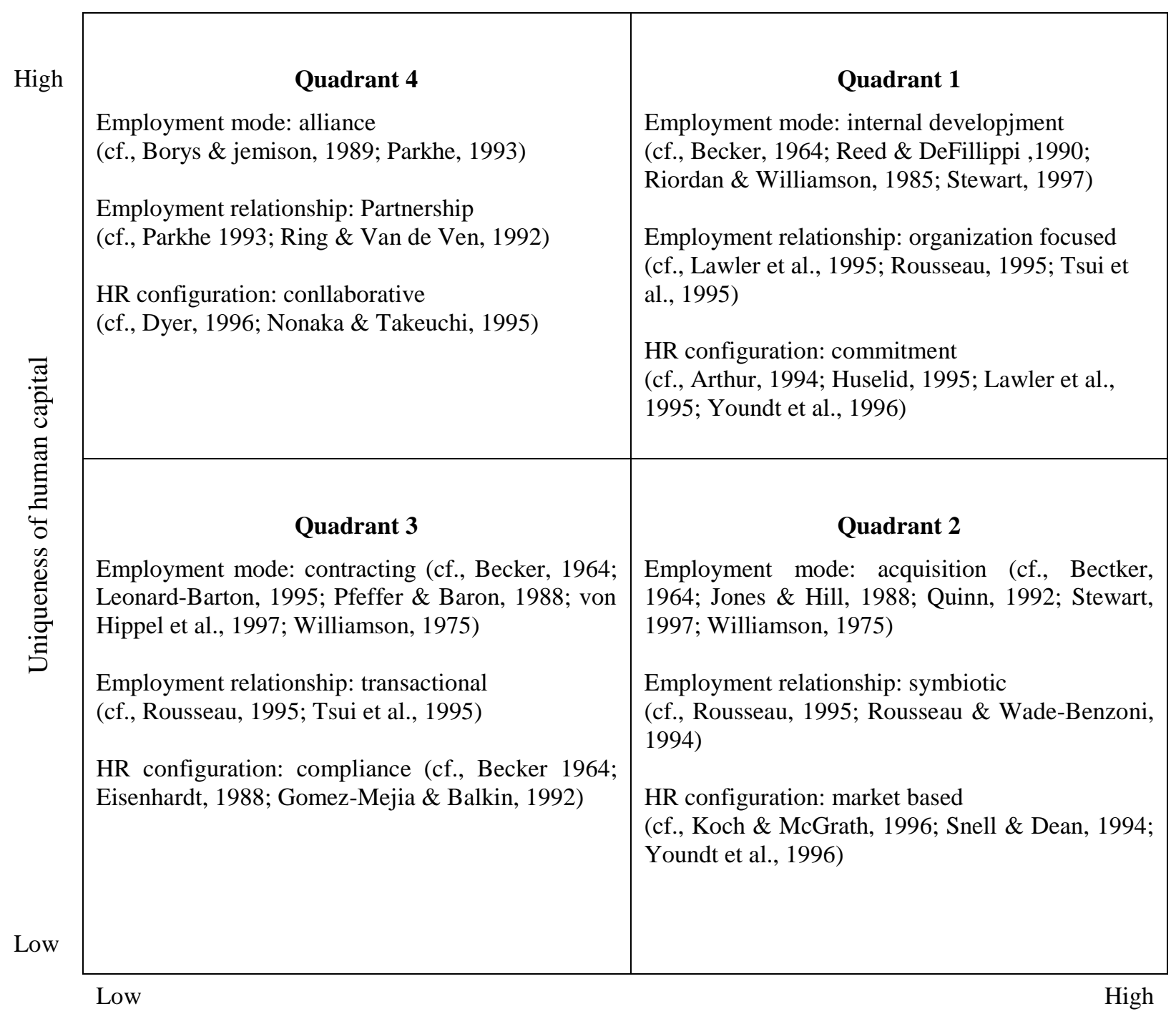

Value of human capital

Source: Lepak \& Snell (1999), p37, Figure 2.

Figure 8.3 and 8.4 show employment pattern changes in mobile phone and automobile industries respectively. When large companies decide to transfer more jobs to subsidiaries and to the $1^{\text {st }}$ level subcontractors, job creation at these levels becomes quite active. The same pattern is repeated at the next level in the subcontracting hierarchy. Therefore, job creation in specific industries in Korea is dependent upon the strategic decisions of large companies and it would be misleading if this mechanism is ignored in setting up a job creation strategy in Korea. The implication of these phenomena is that this job creation mechanism should be taken into account in predicting companies' skills demands and planning vocational and educational training. Otherwise, a labor market mismatch can be incurred due to the misunderstanding on the level of job creation in the labor market. Since the major determinant of job creation is the ecosystem of industries, 
the mechanism in the ecosystem rather than the individual company would be more important in these areas. Therefore, labor market policies should pay more attentions on what is happening in the ecosystem and policy decisions should be based on the understanding the mechanisms.

Figure 8.3. Employment change pattern in mobile phone industry

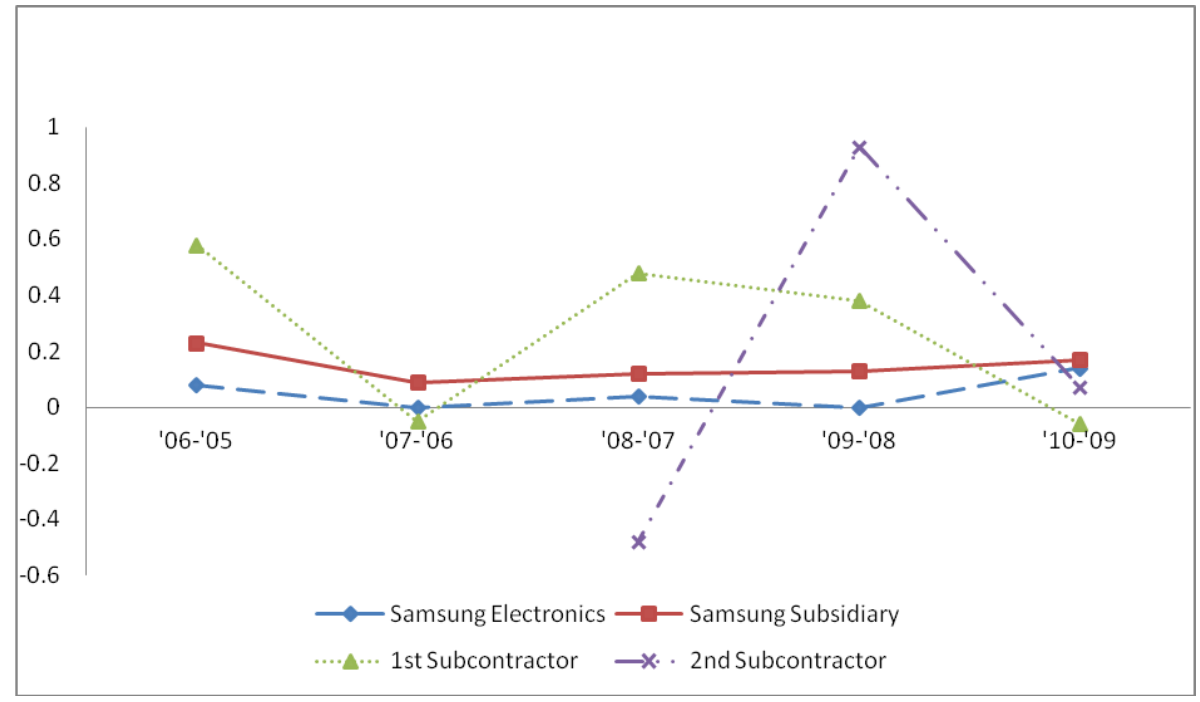

Source: $\operatorname{Kim}(2011)$, p277, Figure 5.5.

Figure 8.4. Employment change pattern in automobile industry

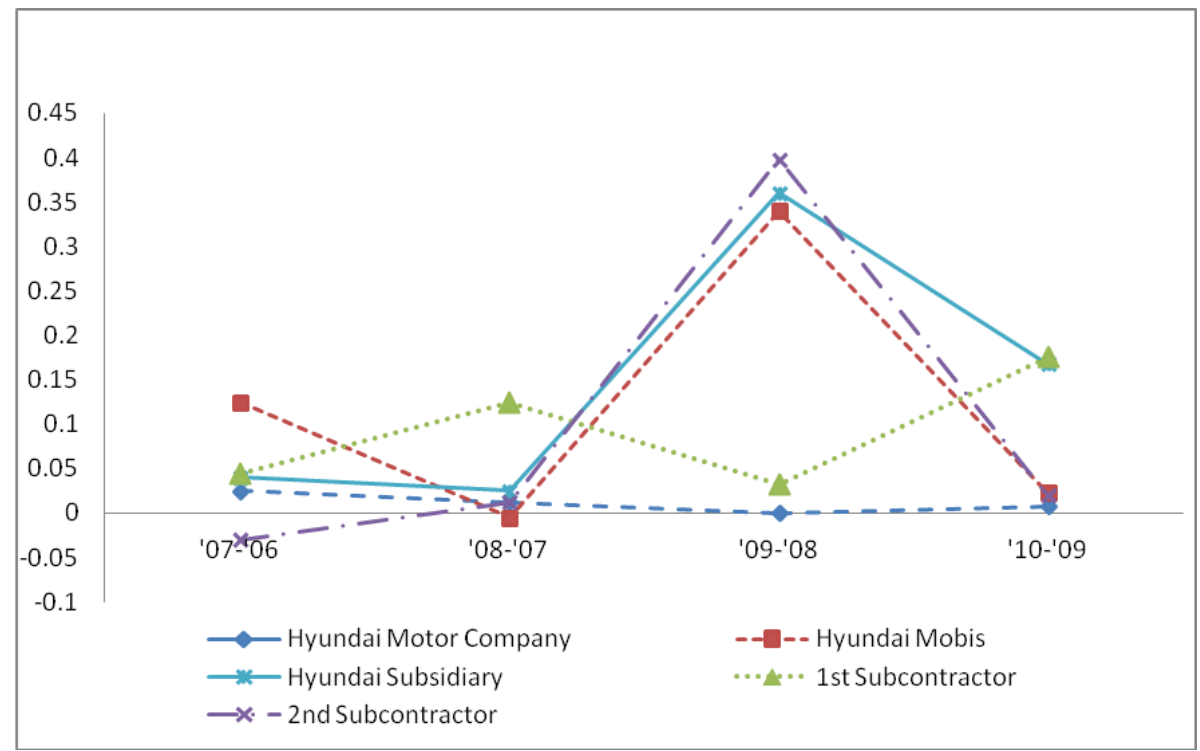

Note: Hyundai Mobis is a subsidiary company, but the company is differntiated from other subsidiaries as it provides large modules for Hundai Motor Company.

Source: $\operatorname{Kim}(2011)$, pp284. Figure 5.8. 


\section{References}

Lepak and Snell (1999), "The Human Resource Architecture: Toward a Theory of Human Capital Applocation and Development," Academy of Management Review, 24(1), 3148.

Kim, Y. (2011), The Case Study of Best Job Creation Companies, Korea Research Institute for Vocational Education and Training. 



\title{
Chapter 9
}

\section{Measures for skills development and employment in Viet Nam}

\author{
by \\ Hoang Ngoc Vinh
}

\section{Introduction}

Foreign investment to Viet Nam has been promoted for decades. Since the implementation of the "open-door" policy 20 years ago, the economy of Viet Nam has grown by approximately $7.5 \%$ per year. Starting from a poor country with persistent food shortages, Viet Nam has become one of the world's leading rice exporters. Viet Nam had a population of approximately 87 million in 2010 with annual population growth close to 1 million people. The working-age population (15 to 64 years old) constitutes $68 \%$ of the population; however, around 33 million of them are unskilled. Most of these unskilled workers live in rural areas and many of them have suffered from the process of urbanisation and industrialisation that has recently taken place.

Although industrialisation and urbanisation took place at a relatively quick pace, Viet Nam still remains an agricultural country with over $72 \%$ of its total population living in rural areas. Although the economic structure has changed over 24 years, with industry and services sectors contributing more to GDP (with an increase of approximately 5 million jobs between 2005 and 2009), the transition has been relatively slow. The production structure of GDP has not significantly changed during the last ten years (currently it is comprised of approximately $20 \%$ agriculture, $42 \%$ industry and $38 \%$ services). The population employed in agriculture-forestry-fishing changed little over the last 5 years, remaining at around 24 million.

Viet Nam joined the WTO and became an official member in late 2006. Shortly after this, the world economy fell into a financial crisis, with a negative influence upon the Vietnamese economy. Many investors stopped investing or limited the scale of production and services. As the Vietnamese economy relies on exports, the global financial crisis resulted in an increase in unemployment (hundreds of thousands people became unemployed as export contracts were cancelled). The GDP growth rate declined from over $6.2 \%$ in 2008 to $5.3 \%$ in 2009 , while trade deficits widened and inflation increased. Most of the manufacturing sector, business and social life were impacted by inflation.

To deal with the risks of the unstable economy, the government has adopted various measures to curb inflation, money supply and credit have been restricted and public spending has been cut. Economic stimulus packages were enacted to enhance industrial production and service, and policies focused on agricultural production. Administrative 
procedures related to export activities were reformed to reduce costs for businesses and to improve the competitiveness of exports. Along with supporting production, human resource training and employment for the unemployed and social security policies were enacted. As a result, economic growth rates remained high in 2008, 2009 and 2010 at $6.2 \%, 5.3 \%$, and $6.7 \%$ respectively. Although the economy suffered from the global financial crisis, the political and social environment is still stable and FDI continues to flow into Viet Nam.

\section{Viet Nam's skills strategy}

\section{Skills and employment background}

Policy on skills development and employment in Viet Nam has been regarded as one of the most important policies for sustainable development for several decades. With unskilled workers amounting to over $65 \%$ of total labour force, shortages of skilled workers, managerial workers (middle managers), law professionals, technologists, and engineers are a challenge for sustainable development. Workforce training is therefore a key approach for dealing with the economic downturn.

The government has approved targeted vocational programmes aimed to train 1 million people annually; vocational training programmes to create jobs for the youth; human resources development programmes for the textile and garment industry (labour in this industry suffered heavily from the global economic downturn); and vocational training programmes to create jobs for women between 2010 and 2015.

The government's three-year programmes of reforming higher education management and improving its quality are considered to be major measures for developing a high-quality workforce. Reforms include enhancing the legal framework of higher education by offering more autonomy to and seeking more accountability from universities, and improving financing for higher education (funding mechanism, tuition fees, faculty salaries), accreditation, and training 20000 personnel with a doctoral qualification by 2020 .

Besides measures for workforce development, the government has implemented employment policies such as the establishment of the labour market (under the General Agreement on Trade in Services - GATS), the creation of the National Centre for Forecast and Labour Market Information, and the development of networks of employment service centres in cities. The government continues to restructure the economy towards promoting industry and service sectors in order to create more jobs.

Human resource training and job creation are presently the most urgent tasks in Viet Nam. The Congress of the Communist Party of Viet Nam confirmed that rapidly training high-quality human resources is one of the three strategic solutions to sustainable growth in Viet Nam in the coming decades. This chapter will address a number of policies and strategic human resource training policies, some of the lessons learned and recommendations for the future.

\section{Outcomes of vocational training in Viet Nam}

Along with the transition of the economy into a market mechanism, vocational training in Viet Nam has made significant adjustments such as: moving from supply-driven to demand-driven vocational training for the labour market, thereby gradually meeting the demands for human resources for economic development towards 
industrialisation, modernisation and integration, which contributes to economic growth and stregthens human capital endowments. This is reflected in:

1. Pursuant to the Law on Education (amended) and the Law on Vocational Training, a regular vocational training system was established with three levels (elementary, middle, and higher vocational training levels) alongside the "frequent vocational training" (irregular), with different forms and modes.

2. A network of vocational training institutions was developed rapidly in Viet Nam. By June 2011, there were 128 vocational colleges, 308 middle vocational schools, 902 vocational training centres and more than 1000 institutions providing vocational training, including nearly 200 private vocational training enterprises.

3. The number of trainees has increased significantly. In 2010, enrolment in vocational training reached 1748000 people (an increase of 3.32 times compared to 1998), in which vocational training at the college and secondary levels increased by 4.77 times (from 75600 to 360000 ); increasing the ratio of trained labourers to $30 \%$ in 2010 .

4. Skills training has gradually been aligned with the demand for human resources in the economy. Introducing training for new occupations that the labour market demands will facilitate the transition from an agricultural and rural economic structure and help create more jobs for labourers. The state orders vocational training from colleges and secondary schools to supply trained labourers based on job positions required by enterprises. Over the years there has been an initial linkage between vocational training institutions and enterprises' needs.

5. The quality and efficiency of vocational training have had positive results: more than $70 \%$ of students found or created jobs immediately following graduation and in some fields of training and vocational training institutions, this rate attained $90 \%$. Vocational training in some occupations has reached the level of the advanced world's standards. Initially providing high-quality human resources based on labour market demands for industrial zones, export processing zones, key economic sectors, FDI enterprises and labour export. Upon completion of the training, $80 \%$ of rural labourers became employed in occupations corresponding to their training.

6. Conditions for ensuring the quality of vocational training have improved and are better adapted to the requirements of enterprises and the labour market. Vocational training programmes have been reformed in accordance with production techniques and technology and with an emphasis on learning skills. They have been developed based on advanced methods used throughout the world, with positive participation of enterprises. Teaching staff has been developed both in quantity and quality, especially occupational skills improvement.

7. Accreditation of the quality of vocational training and skills assessments of labourers are being initiated. In the last three years, accreditation has been piloted in 56 vocational colleges, secondary vocational schools and 12 vocational training centres. National occupational skills standards have been outlined for 130 occupations. Some centres for national occupational skills assessment are being established on a pilot basis. 
8. The structure of vocational training has been improved. Many organisations, enterprises and individuals have invested in the establishment of vocational training institutions; $33 \%$ of vocational training institutions are non-public. The number of students in non-public vocational training institutions accounts for $31 \%$. Many mechanisms and policies have been developed for vocational learning opportunities for specified occupations. Social policies in vocational training have been a priority, especially for ethnic minorities, the poor, and the disabled and policies have been in place to support vocational training for former soldiers, labourers in areas with changing land-use patterns, and rural labourers.

\section{Vocational training for rural labourers}

Rural labourers, who are mainly agricultural workers, account for $75.4 \%$ of the labour force. Rural workers are faced with low labour productivity in agriculture, while agricultural land is in danger of shrinking due to urbanisation. The educational level of the population in rural areas is generally lower than that in urban areas so skills training and job transition are harder. To address the problems for agriculture, farmers and rural associated workers and promote the industrialisation and modernisation of the country, it is necessary to upskill.

Skills training for rural workers has become urgent. On 27 November 2009, the Prime Minister approved the project 1956/QD-TTg for vocational training for rural workers for a total of VND 25900 billion (about USD 1.4 billion in 2009) with specific objectives for each four-year phase to 2020 :

- continue vocational training for approximately 800000 rural workers under the "Strengthening Vocational Training" programme;

- $\quad$ pilot models of vocational training for rural workers for approximately 18000 people in 50 fields and contract-based vocational training for approximately 12000 poor families, ethnic minorities, and rural workers facing economic difficulties. The rate of finding a job after training in these models is at least $80 \%$;

- $\quad$ strive to complete the "Plan for Training and Retraining of Cadres and Civil Servants in Communes".

Between 2011 and 2015, skills training is to be provided for 5200000 rural workers, including:

- approximately 4.7 million rural workers are to be trained (1 600000 trainees in agriculture, 3100000 trainees in non-agricultural sectors), including contract-based vocational training for 120000 people from poor families, ethnic minorities, the rural labour force facing economic difficulties. The rate of employment after training in this stage is at $70 \%$;

- training and retraining civil servants in communes whose population sizes are approximately over 500000 people.

In the following stage (2016-2020), skills training for 6000000 rural workers is to be provided, including:

- About 5.5 million rural workers are to be trained (1 400000 in agriculture, 4100000 trainees in non-agricultural sectors), contract-based skills training for 380000 people in poor families, ethnic minorities and the rural labour force facing economic difficulties. The rate of employment after training in this stage is at least $80 \%$. 
- Training and retraining civil servants in communes whose population sizes are approximately over 500000 people.

- To achieve the above objectives, the government has given priority to vocational training policies that covers vocational trainees, trainers and training institutions. The implementation of synchronous solutions for linking skills training to employment, fostering awareness, developing vocational training institutions with teachers, administrators, programmes, textbooks and learning materials.

- To implement the above scheme a Central Steering Committee has been established with the participation of key ministries as well as similar steering committees at local provincial, district and commune levels. Each level of the administration has to develop a plan to implement the scheme. The scheme has mobilised participation from Communist Party organisations, all levels of government, political and social agencies such as the Farmers' Association, Women's Association, and Youth Association.

- The Central Steering Committee, headed by the Deputy Prime Minister, meets every six months to check the progress and implementation of the scheme. The Central Steering Committee has developed criteria and indicators to evaluate and monitor the implementation of the scheme.

Vocational training for rural workers has had some initial accomplishments so far. First, communication has been enhanced through mass media. The government's TV channel VTV16 provides information to farmers on skills training policies, which are experience based and a valid training model. In addition, local TV stations have training programmes for employees in rural areas. Trainees need information about vocational training institutions, where to learn, where to obtain a job upon completion of the course, and the preferential policies of the state. Local authorities must ensure the four "haves":

1. have plans to train manpower;

2. have a list of vocational training providers;

3. have information on vocational training;

4. have support for employment.

Skills training is provided applying the following model principles:

- model of "one village, one product";

- vocational training for areas specialising in agricultural production;

- $\quad$ skills training and creation of employment;

- $\quad$ skills training for co-operations, companies, businesses.

Skills training is provided using a voucher system. There are different types of vouchers depending on the priority of the subject. Trainees are given vouchers and use them to enroll in vocational training courses according to their needs. The state pays the training institutions for the number vouchers obtained. Higher quality vocational training institutions and ones which meet the needs of many learners will receive higher revenue. The state voucher system has created competition among training institutions for quality and efficiency, thereby giving trainees more options and making them more accountable for their own training. 


\section{The Human Resource Development Plan for 2011-2020}

Ministries and localities are directed to produce a human resource development plan for 2011-2020, which will be used as the basis for developing workforce training as well for deploying solutions for management, labour market, education and training, international co-operation and the mobilisation of resources for training needs.

The objective is to increase the share of trained and skilled personnel from $40 \%$ in 2010 to $70 \%$ in 2020 . The proportion of trained workers in agriculture, forestry and fishery would increase respectively from $15.5 \%$ to $50 \%$; in industry from $78 \%$ to $92 \%$; in construction from $41 \%$ to $56 \%$; and in services from $67 \%$ to $88 \%$. The plan's aim is to develop a workforce with higher quality skills in all areas, giving priority to focus areas to provide Viet Nam with a competitive advantage. Importantly is the development of a cohort of high-quality teachers to train highly skilled personnel.

Human resource development planning in Viet Nam for 2011-2020 has identified needs in terms of quantity, quality and structure of industries in each economic sector. Specifically, the objective is to achieve a total number of trained personnel by 2015 of approximately 30.5 million people (about $55 \%$ of the projected 55 million people working in the economy) and by 2020 to approximately 44 million people (about $70 \%$ of thenearly 63 million people forecast to be working in the economy). Specific sectors are targeted for training and skills development (see Table 9.1). In addition, the plan also refers to skilling the workforce of other sectors including transport, natural resources, environment, tourism, banking, finance, information technology, nuclear energy, and personnel to work abroad.

Table 9.1. Trained personnel for 2010,2015 and 2020 and percentage of labour force

\begin{tabular}{lccc}
\hline \multicolumn{1}{c}{ Sector } & 2010 & 2015 & 2020 \\
\hline Industry and construction & 10.8 million $(22 \%)$ & 15 million $(27 \%)$ & 20 million $(31 \%)$ \\
Services & 13 million $(27 \%)$ & $15-16$ million $(27 \%-28 \%)$ & $17-19$ million $(27 \%-29 \%)$ \\
Agriculture, forestry, fishery & 24.9 million $(51 \%)$ & $24-25$ million $(45 \%-46 \%)$ & $22-24$ million $(35 \%-38 \%)$ \\
\hline
\end{tabular}

Besides determining the labour demand in each economic sector, the plan also identifies human resource needs for each economic area (midland and northern mountainous areas, the Red River Delta, North Central and Central Coast, Central Highlands, Southeast and Mekong Delta). An additional 158 institutions (70 universities and 88 colleges) will be established between 2011 and 2015. According to the plan, it is expected that by 2020, there will be 573 institutions, including 259 universities and 314 colleges.

By 2015, the network of vocational training institutions will include 190 higher vocational colleges (60 non-public schools), 300 vocational secondary schools (100 non-public schools) and 920 vocational training centres (320 non-public centres). By 2020 , there will be 230 vocational colleges ( 80 non-public schools), 310 vocational secondary schools (120 non-public schools) and 1050 vocational training centres (350 non-public centres). 
The preliminary total investment needs for human resource development (including education/vocational training, health-care and other costs for staff development) for the period 2011-2020 is estimated at VND 2135 trillion, accounting for 12\% of the total social investment capital. In particular, the total direct investment in education/vocational training is expected around VND $1225-1300$ trillion.

\section{Orientations and measures for vocational training development in Viet Nam through 2020}

Pursuant to the 2011-2020 Socio-economic Development Strategy, Viet Nam will become an industrial country by 2020. The share of labourers working in agriculture is forecast to drop to $30 \%$ of the total workforce, which means that the demand for technical workers will significantly increase. To meet this demand, between 2010 and 2020, vocational training must fulfil two strategic tasks: $i$ ) training high-skilled technical workers who are directly employed in business and production; and ii) widening the scope of vocational training for rural labourers.

In order to carry out these two tasks, numerous comprehensive measures have been proposed. The major ones are discussed below.

\section{Developing strong vocational training systems to satisfy development requirements of key economic sectors}

The plan for a nationwide network of vocational training institutions is based on the Sociao-economic Development Strategy and country, sectors', regions', sub-regions', and localities' plans by 2020 to meet requirements for training technical workers and improving qualifications for labourers with appropriate occupational structure and vocational training levels. Developing a vocational training institution network is based on:

- Establishing vocational colleges and secondary vocational schools with the capacity for high-quality vocational training (some vocational colleges are capable of training certain occupations in accordance with regional or even international standards) to satisfy the requirements of key economic sectors and to further promote industrialisation and modernisation.

- Developing vocational colleges and secondary vocational schools with sufficient training capacity to satisfy the demand for technical workers by different sectors and localities in a shifting economic and labour structure.

- Developing vocational training centres at district level to create universal access to vocational training for occupational change, employment, better income and living standards for labourers, especially in rural areas and for specific target groups such as former soldiers and ethnic minorities.

- Diversifying the forms and types of vocational training, such as full-time, regular, vocational training in enterprises and trade villages with suitable training programmes and courses, with special attention contracts and agreed orders between vocational training institutions and labour-using enterprises to help meet the skills demands, especially for rural labourers, who strive for universal access to vocational training for adolescent labourers. 


\section{Improving learning conditions for ensuring quality vocational training}

- Keeping goals up-to-date and improving contents, programmes and methods so as to continually improve trainees' competencies.

- Developing institutions' infrastructure to ensure a good conditions for vocational training. Special attention should be given by vocational colleges and secondary vocational schools that apply international or regional standards. Standardising and modernising schools' infrastructure and equipment.

- Developing college and secondary vocational skilled teaching staff with qualifications and vocational skills equivalent to regional and international standards and developing capacity for vocational training managers. This is an important measure for improving the quality of vocational training in Viet Nam.

- Developing curricula to facilitate articulation between training levels in vocational training; in some instances using foreign vocational training curricula that are suitable to the requirements of Viet Nam.

- Strengthening the monitoring of the quality of vocational training by:

- Accreditation of the quality of training institutions and curricula and training accreditation staff for quality.

- Setting up a network of centres for national skills assessment based on popular occupations by region. In the short-term, centres for national skills assessment will be established at vocational colleges for occupations meeting national, regional and international standards. And,

- Implementing skills assessment for labourers based on the national skills standards; striving to recognise skills for labourers among regional countries, with the objective of increasing the competitiveness of human resources and creating conditions for Vietnamese labourers to take part in regional and international labour markets.

\section{Developing vocational training for fostering standardisation and modernisation}

- Setting standards in the vocational training sector such as: occupational skill standards; vocational teachers standards; and standards on infrastructure, equipment, institutions and workshops

- Completing investments in training materials and equipment in accordance with occupational needs. These should be modern and suitable for the techniques and technologies in businesses. This is a significant measure.

- Using information technology and online accessibility in vocational training. Providing English skills for business apprentices and offering vocational training for high-level and key occupations in English on a pilot basis.

\section{Building mechanisms and policies to create conditions for enterprises to become important actors in vocational training}

- Developing mechanisms and policies to create conditions for enterprises to participate in vocational training activities. 
- Mobilising the private sector to directly participate in the vocational training process, such as: setting goals, contents and methods of vocational training; defining a list of occupations and their standards; participating in teaching and assessing skills for labourers.

\section{Continuing to improve vocational training mechanisms, especially financial} policy

- Improve vocational training within the legal system especially in relation to legal regulations (Labour Code, Law on Education, Law on Vocational Training, Enterprise Law, Investment Law).

- Amend policies (such as financial policy) to ensure the best benefits for vocational teachers, apprentices and labourers (salary, awards), and policies for enterprises participating in vocational training, thereby creating motivation for vocational training and teaching.

\section{Ensuring resources for developing vocational training}

The state budget should be focused on investing in key vocational training institutions and occupations, especially in remote areas. Budget resources should also focus on training teachers and managerial staff; developing curricula; training for rural labourers and for beneficiaries of social policies and vulnerable groups; universalising occupations for labourers, thereby gradually closing the gap between regions in the availability vocational training. There is a need to attract international resources through vocational training development programmes and projects while simultaneously mobilising domestic and international enterprises, organisations, individuals and apprentices to promote vocational training.

\section{Strengthening international co-operation in vocational training}

- Increase international co-operation to promote the exchange of ideas and experiences in developing successful vocational training networks and institutions.

- Encourage domestic institutions to co-operate with vocational training institutions from developed countries to exchange and share training programmes, teachers and experts and to transfer technology and teaching methods. Continue to implement ODA (Official Development Assistance) projects in the field of vocational training. Strengthen co-operation in the field of scientific research and apply advanced scientific and technological achievements to increase the quality of vocational training.

The General Department of Vocational Training has developed different concepts that have been approved by the Government of Viet Nam and that reflect the above-mentioned tasks, measures and activities, including, for example, the Vocational Training Concept for Rural Labourers in the period of 2010-2020 and the Vocational Training Renovation and Development Concept in the period of 2010-2020.

\section{Establishing a recognition system for national occupational skills standards and assessment and issuing a national occupational skills certification}

The establishment of a recognition system for national occupational skills standards and assessment, and a national occupational skills certification for workers in Viet Nam aims to: 
- create a link between vocational training and the job market;

- $\quad$ provide businesses with valuable information about the skills level of potential workers;

- improve the status and salaries of employees;

- $\quad$ support the implementation of regulations (old and new) in training;

- improve the career development and employability of skilled workers;

- create favourable conditions for the mobility of workers with skills levels across the country and new opportunities for individuals to seek employment to increase their income;

- implement an assessment to evaluate the quality of vocational training programmes;

- better prepare and improve the quality of the workforce.

In 2008, the Ministry of Labour, Invalids, and Social Affairs (MoLISA) issued Decision No. 09 Prescribed Principles and Processes for the Development and Promulgation of National Occupational Skill Standards (NOSS). MoLISA agreed with ministries, in co-ordination with professional associations, other agencies and related organisations, to develop NOSS for 130 occupations using the funds from the National Target Programme. In 2011, MoLISA issued Circular No. 15 defining the organisation and management assessment, issuing certification of national occupational skills. This circular prescribes the implementation of a skills evaluation of workers in occupations which have national occupational skills standards.

With the purpose of carrying out the above-mentioned strategic tasks, a recognition system for national occupational skills standards and assessment, issuing a national occupational skills certification for workers will be implemented as follows:

1. The first strategic task: training a sufficient number of highly skilled technical workers who are directly employed in business and production with the appropriate high-level qualifications, and producing quality personnel for economic sectors, especially key economic sectors and focal economic zones.

This task is reflected in the project "Renovation and Development of Vocational Training in Viet Nam up to 2020". This project was approved in 2011 under the National Target Employment programme. The government allocated VND 1350 billion to implement this project. One of the important aspects of this project is "Investment focused" - a package of quality assurance in vocational training (including programmes, teachers and administrators, facilities, material and equipment) for vocational training colleges, and secondary vocational schools which have key national trades, especially regarding high competitive trades and high-technology trades to attain the level of vocational training programmes of developed countries in the region and the world.

To implement the above objective, there is a need to define the key occupations at three levels (international, national and regional) and the vocational schools. The MoLISA has chosen 107 key occupations that meet these outcomes and the General Department of Vocational training (GDVT) is developing NOSS for them. In June 2011, the GDVT, in collaboration with the Viet Nam National Coal, Minerals Industries Holding Corporation Limited (Vinacomin) established a National Testing Center at Hong Cam Mining Vocational College (Quang Ninh province) and piloted assessment, issuing national occupational skills certification 
for 100 workers working in mining companies of Vinacomin. In the future, vocational schools which have international, national and regional occupations will have national testing centres under them.

2. The second strategic task: broadening the scope of vocational training for rural labourers, in the effort to accelerate the transition from an economy of agricultural and rural labourers, thereby creating more jobs, increasing incomes, reducing poverty and ensuring social security. In the next 10 years, vocational training will be provided for approximately 9 million rural labourers, $60 \%$ of which will work in non-agricultural occupations. This task is stated in the "Vocational Training for Rural Labourers to 2020" project which was approved by the Prime Minister in Decision No. 1956/QD-TTg in 2009.

In order to boost rural labourers' confidence in applying for a job (regardless of the location) with their national occupational skills certification, in 2011, MoLISA intended to pilot assessment and issue national occupational skills certification for rural workers in coffee planting in Dak Ha district, Kon Tum province.

\section{Conclusion}

Workforce training is a key factor for speeding up industrialisation and modernisation and the development of agricultural workers' skills plays an important role in the sustainable development of the country. Innovative thinking in human resource training and participation of the Communist Party organisations, governments and social organisations are of paramount importance for implementing workforce development policies and strategies. Co-ordination between ministries at the central level, as well as between central and local governments, is particularly important.

To develop human resources effectively, comprehensive and systematic solutions need to be implemented based upon proper demand forecasts, by building a system of labour market information, by innovating management in personnel training and by mobilising and allocating resources appropriately. Building public-private partnerships at the central and local levels will help mobilise resources effectively making skills training more relevant for industry demands. 



\title{
Chapter 10
}

\section{Thailand's skills strategy}

\author{
by \\ Dhida Wiwaha
}

\section{Introduction}

Thailand has a population of 65.4 million (NSO, 2010), with the population aged 15 years and over of 53.98 million. It has a workforce of 39.12 million and the size of employment is 38.88 million. The agriculture sector accounts for $41.5 \%$ of the workforce; the industry sector for $19.5 \%$; and the service sector for $39 \%$. Unemployment is low, at only 0.163 million $0.4 \%$ of the workforce). Most of the unemployed are new graduates (0.085 million) (NSO, June 2011). The agriculture sector workforce increased by 1.8 million from a year ago but the workforce in retail and wholesale and manufacturing decreased by 0.5 million. This could be a sign of the beginning of a period of manufacturing adjustment for labour-intensive industries; the government should support higher technology skills training in order to avoid labour shortages in the future.

A lack of social security is not an issue for Thailand. The entire labour force is insured under the social security system: 9019343 persons in 399168 enterprises (Social Security Office, 2011). In May 2011, the Ministry of Labour enacted the social security system for the labour force between 15 and 60 years of age, who can apply to the social security system for a fee of THB 100 per month. Benefits include up to two days' hospitalisation, one month's salary in the case of illness or injury, 15 years' salary for disability, and compensation of THB 20000 in case of death.

SMEs account for the largest proportion of employment with 2848256 enterprises (99.68\%), with the number of employees reaching $76.05 \%$ of total employment. However, their share of GDP is only $38.9 \%$. Only by diversifying their productivity can they be upgraded and properly developed. The future workforce needs to be equipped with better management skills and higher levels of literacy and numeracy. 
Figure 10.1. Small, medium and micro enterprises

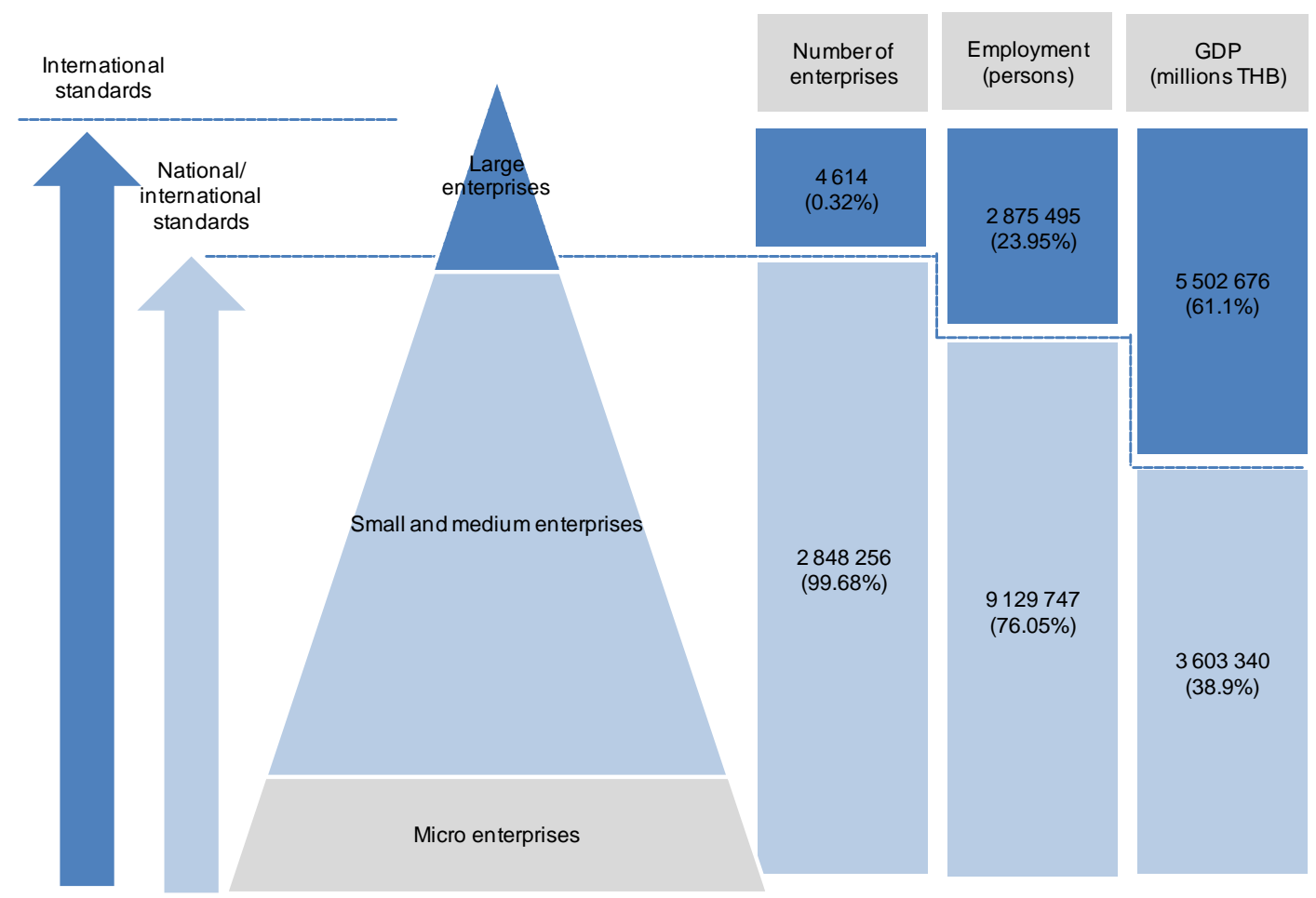

\section{Initiatives on skills training in Thailand}

Thailand has launched two groups of skills strategies. The first is in education and is managed by the Ministry of Education. The government supports the budgets of all programmes, ensures pre-elementary education to higher education (for 12 years). It also manages vocational education, graduate education and post-graduate education. In 2011, there were 26083 schools, 415 vocational colleges and 92 universities accounting for a total of 14337146 students (as of 2007). The second group of skills strategies is authorities from several ministries and more than 20 government organisations that provide training for their specific target groups. The Ministry of Labour, the Ministry of Agriculture and Co-operatives, the Ministry of Industry Thailand, the Ministry of Social Development and Social Security, the Ministry of Transportation, the Ministry of Justice, the Ministry of Public Health, the Ministry of Commerce, the Ministry of Education (training activities only) and Bangkok Metropolitan. The total size of annual training was 7114520 persons.

Table 10.1.Thailand's skills training initiatives (persons)

\begin{tabular}{lr}
\hline Total & 7114520 \\
Ministry of Labour* (2009) & 4614461 \\
Ministry of Education (2007) & 1546008 \\
Others (2006) & 995051 \\
\hline
\end{tabular}

Note: * Department of Skill Development: 4946528 persons and the Department of Employment: 5400 persons. 
The private sector provided $74.05 \%$ of total training. However, the capacity of the business sector needs to be enhanced. The business sector, which is an energetic dynamic sector of the country, should assume a leadership role in meeting skills challenges.

Table 10.2.Public and private sector skills training (persons)

\begin{tabular}{ll}
\hline Total & 7114520 \\
By government sector & 1846000 \\
By business sector & 5268520 \\
\hline
\end{tabular}

In 2009, the Department of Skill Development - which is the core training organisation - in the Ministry of Labour, provided training to 4946528 persons. The areas of training are shown in Table 10.3.

Table 10.3.Composition of the Department of Skill Development's training areas

\begin{tabular}{lc}
\hline 1.Service & $46.18 \%$ \\
2.Electical/electronics/computer & $13.16 \%$ \\
3.Construction & $13.06 \%$ \\
4.Industrial art & $11.98 \%$ \\
\hline 5.Mechanic & $9.29 \%$ \\
6.Automobile & $5.40 \%$ \\
7. Agro-industrial & $0.94 \%$ \\
\hline Total & $100 \%$ \\
\hline
\end{tabular}

The Skill Development Promotion Act of 2002 grants an income tax exemption to enterprises for training. Income tax returned to enterprises totalled THB 1294.44 million and THB 936.71 million in 2009 and 2010 for training 3.287 million and 2.387 million people.

Table 10.4.Enterprise training in 2009 and 2010

\begin{tabular}{|c|c|c|c|c|c|c|c|c|}
\hline \multirow[b]{2}{*}{ Area } & \multicolumn{4}{|c|}{2009} & \multicolumn{4}{|c|}{2010} \\
\hline & Enterprises & Enrolment & Graduate & $\begin{array}{l}\text { Training } \\
\text { budget }\end{array}$ & Enterprises & Enrolment & Graduate & $\begin{array}{l}\text { Training } \\
\text { budget }\end{array}$ \\
\hline \multicolumn{9}{|l|}{ Bangkok } \\
\hline \multicolumn{9}{|l|}{ Central } \\
\hline \multicolumn{9}{|l|}{ North } \\
\hline \multicolumn{9}{|c|}{ East-north } \\
\hline \multicolumn{9}{|l|}{ South } \\
\hline Total & & & & & & & & \\
\hline
\end{tabular}

Source: Ministry of Labour (2010).

The aforementioned Skill Development Promotion Act, which defined the workplace training concept, combines the incentives and compulsory measures to stimulate and promote workplace training, thus encouraging enterprises to establish themselves as training providers and conduct skills development in the workplace. They must of course be registered with the DSD. The incentives include:

1. Income tax exemption of up to $200 \%$ of the training costs. 
2. Assistance from the Department of Skill Development in providing training for trainers, skills standard testing providers, supervisors and others as well as on curriculum and equipment development.

3. Consultation service from the Department of Skill Development on skills development activities.

4. Other privileges indicated in the Ministerial Regulation.

5. Exemption on import duty and value-added tax (VAT) for tools and machinery brought into the country for training purposes.

6. Deduction on utility charges for electricity and water bills up to two times the amount of the training expenses.

These policies need to be integrated with other policies. The government is trying to encourage its employees to improve working targets by:

1. setting the medium term period of the national strategy planning to five years;

2. setting a KPI (key performance indicator) for budgeting outcomes of the government officers and increasing their salaries according to the results of these KPI since 2010;

3. trying to change the new generation of government officers with the Good Governance Rule;

4. changing the rules for work evaluations with KPI;

5. using technology;

6. increasing stakeholders' awareness.

The government is trying to overcome risks, allow more choices and promote integration among stakeholders, by planning, implementing, and sharing data. Integration between government sectors and business sectors is becoming successful more rapidly. The best way to begin is for the business to share its technology and for the government to provide legal framework.

The National Vocational Training Co-ordination Committee (NVTCC) is the national body in charge of issuing policy and planning on HRD in order to avoid the duplication of training and eliminate target group overlaps as well as for sharing training resources. The committee is chaired by the Prime Minister, and the Director General of DSD is the secretary of the committee. The committee is composed of representative members from the private sector and the permanent secretaries of ten ministries. The NVTCC is an important body for facing the following challenges:

1. the diversity of SMEs, SMEs' share of GDP;

2. strengthening private sector co-operation in training based on priorities set by the government;

3. making the skills development programme and the Protection Act parallel;

4. allocating the centred skill development based on data;

5. the local network, which is the most important one, must function properly. The workforce needs better management skills and higher skills levels in the future. 
Strategic planning processes and partnerships have been developed to implement local initiatives such as:

1. DSD's work processes have been overseen by ILO for more than 40 years. Regional offices could take responsibility for designing the curricula, adapting them to different groups or individuals.

2. Empowering offices to take decisions would save time, money and resources. Thus each regional office is given as a lump sum by the general regulations of the Comptroller Authority.

3. The most important responsibilities of offices are setting rules, controlling, and steering.

4. Increasing efficiency would allow officials to focus on more creative and analytic tasks.

5. All feedback should be reviewed by headquarters.

6. Network Strategy: the first priority is aligning it with the organisation's other strategies. The second priority is to establish a training roadmap. The third is to brainstorm with clients and stakeholders. The fourth is to carry out consultations on the programmes. The fifth is to meet the expectations of the different groups.

\section{References}

Ministry of Labour (2010).

National Statistical Office (2010), Population Census, NSO, Bangkok, September.

National Statistical Office (2011), "Employment Survey Report”, NSO, Bangkok, June.

Social Security Office (2011), April. 



\title{
Chapter 11
}

\section{Cambodia's technical education system in high schools}

\author{
by \\ Vuthy Va
}

\section{Technical education in high schools}

Cambodia considers technical education one of the means for the development of the country by integrating its growing number of young people, especially in rural areas and poor city suburbs to labour market. Technical education also prevents school dropouts, who are likely to take part in risky activities like gambling, prostitution and crime. It is also a way to fight poverty. The Educational Strategic Plan of the Ministry of Education, Youth and Sport for 2009-2013 proposes expanding Technical Educaiton (TE) services into secondary education. It is believed that the expansion of strong and relevant technical and vocational education programmes with solid links to the labour market will contribute to social stability and inclusion, poverty reduction, and sustainable economic growth. It is proposed to expand programmes to introduce skills and technical competencies at the high school level since many young people, particularly the poor, are starting to work too early without having developed the basic skills that could make them marketable to employers. Students are completing primary and secondary school without acquiring skills that will allow them to adapt to changes in the labour market. A large number of graduates are unable to find jobs, while business and manufacturing sectors are unable to find qualified workers. As many unemployed and uneducated youth from rural areas migrate to cities in search of better jobs, urban social and economic structures are strained. At the same time, many rural communities are left without some of their most productive members.

Fully recognising the role technical education plays on the social and economic development of the country, in 2009 the Royal Government of Cambodia (RGC) agreed to create the Vocational Orientation Department (VOD) under the Division of General Education (DGE) of the Ministry of Education, Youth and Sport (MoEYS). MoEYS' responsibility for technical and vocational education has re-emerged, five years after having taken over the Ministry of Labour and Vocational Training (MoLVT). The new department is basically organised to make technical and vocational education programmes available in the formal secondary education schooling system. It envisions providing students with alternative options to the traditional academic choices, such as technical and vocational programmes. The introduction of technical and vocational education programmes in high schools is still in its infancy. A pilot project, relying on external support, has been introduced. 
The pilot project, Kampong Chheu Teal High School, has support from the princess of Thailand. It is the only high school that provides both general and vocational education programmes. Teachers have been retrained to teach electronics, electricity, agriculture and animal husbandry. Curriculum materials and teaching equipment related to the proposed subjects have also been supplied. The government partly contributed to the recurrent costs to school operation through programme-based budgeting (PB). The PB budget is in addition to the salary of teaching staff.

\section{Strategies to expand technical and vocational education}

Investment in technical education (TE) is costly since facilities, materials, equipment and maintenance are expensive. Technical education facilities can quickly become obsolete due to industries' and businesses' adaptation to changing markets. MoEYS has considered appealing to external donors to share the costs of expanding TVE programmes to high schools. It could potentially be expanded to include those who have less opportunity in academic streaming and are at risk of dropping out. Statistics show that the net enrolment rate (NER) is $94.8 \%$ in primary level, only $31.9 \%$ and $19.4 \%$ in lower and upper secondary levels. The dropout rate is estimated to be $8.3 \%$ in primary, about $18.8 \%$ in lower secondary and $11.3 \%$ in upper secondary. Providing technical and vocational skills to this group is a top priority.

In the context of budgetary constraints, further expanding the technical edcucation programme in post basic education could be carried out through private provision and employer investment or multilateral involvement. Investment expansion in individual TE programmes is critical. However, considering the embryonic stage of TE programmes necessitates, the expansion of programmes need to be minimized so that capacity and quality can be improved before the scope of the programme's services can be scaled up. The poor quality of basic education at primary and lower secondary stagesfurther constrains skills formation in the TE programme. The general low perception of TE as a second-class education could limit the enrolment rate. The TE orientation programme aims to design a policy to improve the public's perception of TE and increase the demand for it. This includes steps such as institutional capacity building, formulation of a qualification framework, programmes for teachers' training, improvement in curriculum and teaching methods, and labour market data analysis.

In summary, the MoEYS faces many challenging issues for expanding the technical education orientation programme to secondary schooling, ranging from sharing responsibility for th $\mathrm{e}$ programmes with other providers including states, nongovernmental organisations and the private sector, to the financial sustainability of the programmes as well as prospects for enhancing the programme. As technical and vocational education has the potential for contributing to the short- and long-term development of the country, MoEYS should consider investing in expanding the programme, starting with formulating a TVE policy; improving the governance of the TVE system including developing capacity in the administration and management of TVE; setting standards of practice, implementing a monitoring and evaluation system; suggesting strategies to increase participation; giving support for TVE curriculum review; and delivering training to teachers. 
Figure 11.1. Cambodia's schooling system

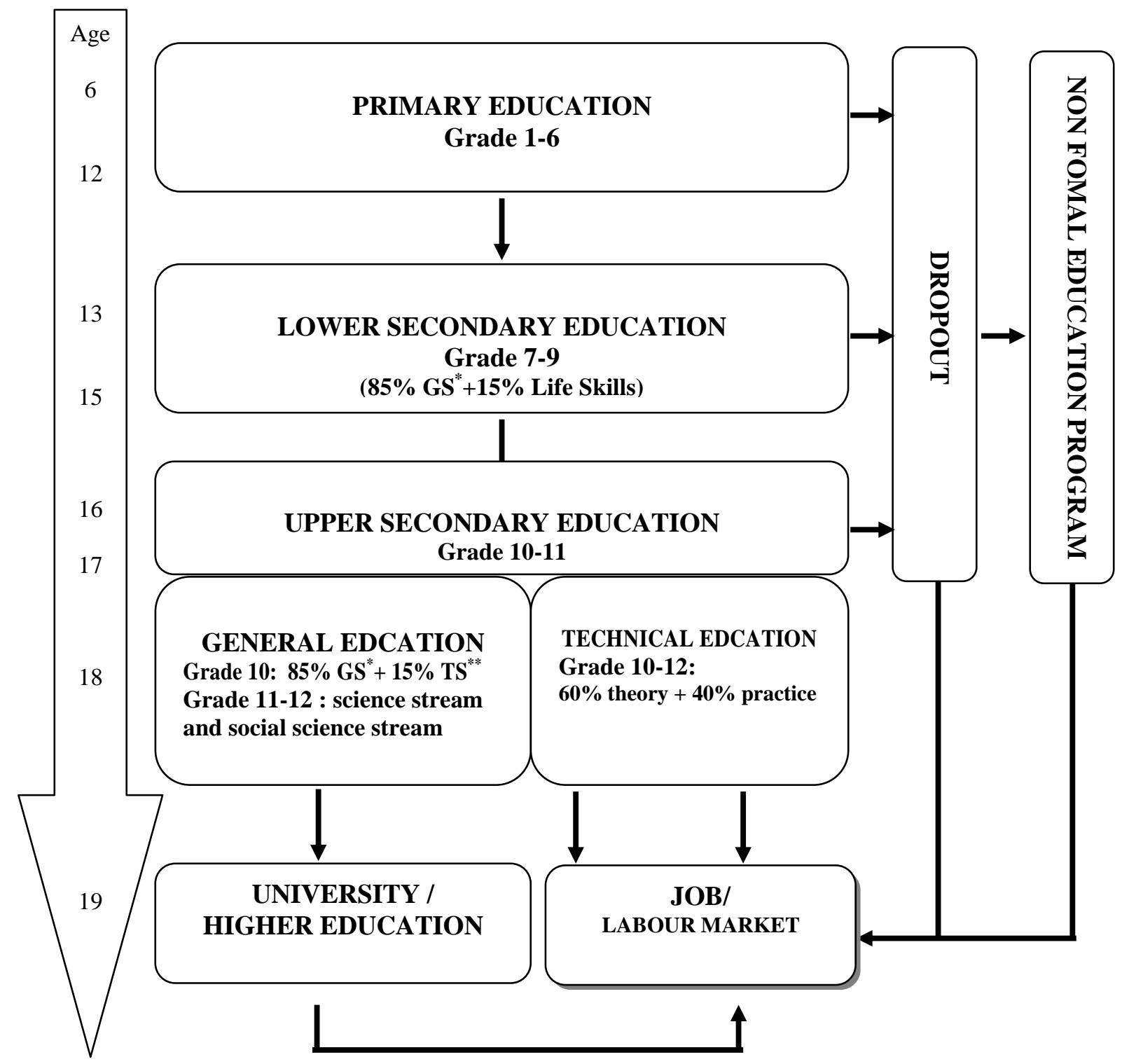

Notes: *GS: General Subject education

** TS: Technical Subject.education 



\title{
Chapter 12
}

\section{Skills policy framework for the next decade in China}

\author{
by \\ Jing Dong
}

\section{Introduction}

Skilled workers, as an indispensable and core part of human resources in China, play a very important role in accelerating economic development, upgrading the industrial structure, improving enterprises' competitiveness, promoting technological innovation and the commercialisation of research findings.

Guiding and administering skills policy is one of the core functions of the Ministry of Human Resources and Social Security. Its main responsibilities are:

- formulating the vocational training policy and planning the outline for urban and rural labourers;

- formulating policies related to highly skilled workers;

- formulating and developing an outline, management rules and institutions for skilled worker schools and vocational training providers under the national education policy framework, while providing instructions on teacher management and teaching materials development;

- improving the national occupational skills qualification system;

- issuing job definitions, conducting job classifications and developing national occupational skills standards and industry standards.

\section{The current status of skilled workers}

In the past decade, the human resources and social security departments at all levels and other related departments such as education and federations of trade unions, provided vocational training of various types and levels separately and jointly. Now, an initial stage of the vocational education and training system has been established, roughly satisfying the employment needs for different groups. Great progress has been made in this area. By the end of 2009, the number of highly skilled workers ${ }^{1}$ reached 26 million, an increase of 7 million from the end of 2004. They accounted for $24.7 \%$ of total skilled workers. 
The policy environment of highly skilled workers has been improved significantly, while many local governments have issued enabling policies for skilled workers. At the central government level, the highest skilled workers can be granted the Special State Allowance. The training system for skilled workers has been gradually improved. The involvement of the private sector in skilled workers' training has been increasing regularly. Co-operation on training skilled workers has increased between skilled workers schools and the business sector.

An evaluation mechanism for skilled workers was developed progressively. Professional ethics and performance as well as occupational skills and competence, are the main criteria for evaluating highly skilled workers. A multiple subject evaluation mechanism has been innovated. ${ }^{2}$ Various types of vocational skills competitions have flourished and are an important channel for discovering and selecting highly skilled workers. Public recognition of the role highly skilled workers play in economic and social development has increased. An enabling social atmosphere is taking shape.

\section{The policy framework for skilled workers in the next decade}

The period from 2011 to 2015, which is also the period of the Twelfth Five-Year Plan for National Economic and Social Development, is a critical stage for industrialisation and urbanisation. During this period, the demand for skilled workers will keep growing. It is predicted that in 2015 and 2020, the demand for skilled workers will increase by nearly 19 million and 32.9 million respectively compared to 2009, which includes an increased demand for highly skilled personnel by about 5.4 million and 9.9 million respectively.

In order to speed up industrialisation and the upgrading of traditional industries, it is urgent to upskill on-the-job skilled workers. To accelerate the development of the tertiary industry, especially the modern service industry, a large number of labourers need to be trained with skills such as IT, household management, tourist guides, equipment repairs, etc. There is also an urgent need to train a group of skilled workers in fields related to the development of a low-carbon economy and the green industry.

The policy framework for the next decade has the following objectives:

- First, steady growth in the number of skilled workers, a more rational age and industry structure, and improved quality is expected in the future. By 2015, the total number of skilled labourers will reach 125 million, including more than 34 million highly skilled workers, accounting for $27 \%$ of skilled labourers. And by 2020, demand for skilled workers will be 140 million, including more than 39 million highly skilled workers, or $28 \%$ of total skilled labourers.

- Second, the management of skilled workers will be more efficient. More social resources will be integrated and a lot of public advanced demonstration and training centres will be established. By the end of 2020, it is estimated that 1200 public training centres and 1000 skill-master studios will be set up.

- Third, the policy and legal environment for skilled workers will be significantly improved. The rights and obligations of different stakeholders, such as skilled worker schools, enterprises and related institutions, will be clearer and more determined.

The main tasks are to: $i$ ) continue improving the vocational training system and strengthen the role of enterprises for establishing specific training standards, developing training content, and implementing skills training; ii) encourage industries and businesses to upskill workers in new knowledge, new materials and new technologies; iii) optimise 
the skilled worker evaluation system and improve to a scientific and standardised operation and management system; iv) construct a skilled worker post-engagement mechanism to encourage enterprises to increase skilled workers' salaries based on upskilling training and to provide a convenient social security transfer service to facilitate inflow of highly skilled workers; and v) strengthen co-operation among the Ministry of Human Resource and Social Security with other government departments, enterprises and industry as well as other stakeholders such as international and regional organisations.

\section{The way forward}

According to the National Industrialisation Plan, more skilled human resources need to be developed. By the end of 2020, a new supply of 3.5 million technicians and 1 million senior technicians is needed. In order to establish a vocational training system to meet the needs of various types of labourers, and to give priority to skills training for the youth and upskill training for employed workers, at least one skills training should be provided to every new entrant into the labour market with public financial support. More channels need to be explored to discover and select outstanding skilled workers, and representative skilled workers should be sent abroad to take part in international skills competitions.

Specifically, the government should construct skill-master studios and make the best possible use of such high-valued human resources; have highly efficient and good quality public job agencies and social security to promote the rational allocation of skilled workers; strengthen the technical support and the related legislation; and accelerate the formulation and modification of national occupational standards.

To support this strategy, there is a need to increase the government's financial input and private investment to the development of skilled workers and to establish and improve the government's, employers', social and individual multi-channel input mechanism for skilled workers. Different levels of governments should actively participate in implementing the related policies and measures. A target responsibility system for related works should be implemented and task performance should be used for evaluating the performance of relevant and responsible persons. A set of implementation indicators needs to be developed to stregthen the monitoring and reporting system.

\section{Notes}

1. Highly skilled workers are skilled labourers whose skill level is equal to or above the skill of level III, such as senior skilled worker, technician and senior technician.

2. There are three types of subjects for skills appraisal: public occupational skills evaluation centre, enterprises and schools. 



\title{
Chapter 13
}

\section{"Skilling Pakistan": National Skills Strategy}

\author{
by \\ Sajid Manzoor Asadi
}

\section{Introduction}

Human resource development (HRD) is a pre-requisite for sustainable economic growth and for meeting the challenges of global competitiveness. The prevailing structure of technical and vocational education and training (TVET) in Pakistan is fragmented and supply oriented. It has remained neglected in terms of policy level directions, area of implementation and budgetary provisions compared to those allocated to general education. Most of the workforce is unskilled and informally skilled. Skill standards are not recognised internationally and have no linkages with industry demands. Therefore, the portability of the workforce is limited, further compounded by inadequate labour market information systems.

In order to address the aforementioned issues, the government has accorded high priority to skills development, acknowledging the supply of a skilled labour force as mandatory input to the growth process. Therefore, a national regulatory body, the National Vocational and Technical Education Commission (NAVTEC) was created under the direction of the President of Pakistan on 30 December 2005 followed by Ordinance No. XXXIV of 2006.

All matters pertaining to the policy and administration of the commission and its affairs vests in the NAVTEC Board. The Executive Director is the Principal Accounting Officer and is also a member/secretary of the NAVTEC Board. The board is an apex body consisting of 18 members from the public and private sectors. Four regional offices in the provinces have been established along with an office in the federal capital to cater to AJK (Azad, Jammu and Kashmir), Northern Areas and three sub-offices in Multan, FATA (Federally Administered Tribal Areas) and Larkana.

The following broad mandate has been assigned to NAVTEC:

- review and formulation of policies, strategies and regulations;

- development of skills standards and curricula;

- accreditation and certification systems;

- $\quad$ training needs assessment and programmes;

- regulation and quality assurance standards;

- co-ordination among provinces and boards; 
- promotion of public-private partnerships;

- labour market information system (LMIS) and National TVET Database;

- $\quad$ trade testing and certification;

- training of trainers;

- national and international linkages.

\section{National Skills Strategy: 2008-2013}

The NAVTEC addresses all of the aforementioned challenges in the National Skills Strategy 2008-2013. This flagship strategy emphasises a shift from curricula-based to competency based training and the creation of a demand-driven training system which is responsive to industry needs. It seeks to institutionalise various segments of the TVET sector and will adopt corrective measures during its implementation.

The strategy is meant to build a skills development system that can be benchmarked against international standards and to achieve the following mandate defined by the government:

1. Streamlining policy making: presently, an overlap in roles, mandate and strategies is hindering NAVTEC's progress in achieving the target set in MTDF (2005-2010). In the past, some institutions were established with the objectives to formulate and implement vocational training policies and to facilitate the training of skilled workers to meet domestic and overseas labour requirements. However, no long-term policy or plans were developed due to lack of vision, capacity and maladministration.

2. Centres of excellence: the government proposes to promote and facilitate the establishment of sector-specific centres of excellence, which will be located in proximity to relevant industry and will be linked with reputed industry specific training facilities abroad. The British Council and NAVTEC signed a Memorandum of Understanding in May 2008, under which seven Pakistani institutes have been twinned with UK institutes. They share best practices, staff training, develop industry-led curricula and training materials and assure quality standards. NAVTEC has also signed an MoU with JICA, for converting GCT Railway Road, Lahore into a centre of excellence. NAVTEC, by extending its co-operation with provincial governments, has taken over the Government Advance Technical Training Centre, Hayatabad, and Peshawar as a centre of excellence for the FATA.

3. Promoting the role of the private sector: institutionalising industry's role in policy making, training design, setting standards, assessment and accreditation is one of the priority areas.

4. Apprenticeship training: Apprenticeship Ordinance 1962 has not been reviewed since its promulgation and has become outdated; the system is therefore not operating effectively. It is coercive and provides little choice to industry in the selection of apprentices/trainees in structuring the training.

5. Entrepreneurship training: a large part of the workforce in the informal economy is self-employed, and self-owned enterprises are an important source of earnings for families. They need to be well structured/managed in order to be successful. 
6. Geographical provision: regions such as Balochistan, FATA/FANA have relatively limited provision of TVET institutes, especially compared to other provinces. This disadvantage stems from the limited industrial spread and scattered population living in remote, difficult to access areas.

7. Flexible training delivery: most vocational learning takes place in fixed-time, teacher-led, classroom environments and for those living in remote regions, rigid time stipulations for access to skills development opportunities becomes limited.

8. Skills training for the vulnerable groups:

- Women: training available to women and girls is narrow and conventional. Courses have poor linkages with the formal labour market. The strategy proposes strengthening the training of women not only in traditional areas, but also in new and emerging areas.

- Disadvantaged groups: the physically challenged, orphaned girls and boys, people living in remote or troubled regions, religious and ethnic minorities, craftspeople, and informal economy workers are neglected in mainstream policies and do not have equal access to opportunities for skills development

- Informal economy workers: informal economy workers are skilled workers, but their skills are not recognised. The strategy addresses ways to cover skills deficits and recognise and certify skills according to nationally recognised qualifications. This learning should be validated through recognition of prior learning (RPL).

- Migrant workers: Pakistani workers earn less compared to other countries because of their lack of skills. The international job market is changing and so is the skills requirement. It is therefore necessary to conduct a skills needs analysis and introduce internationally recognised, certified courses to increase workers' mobility.

9. Career guidance and placement services: career guidance services are almost non-existent in Pakistan, and many workers are unaware of the possible training opportunities and career choices.

10. Vocational education in schools: general education should incorporate aspects of vocational education, so that students are aware of the range of career choices and employment. The strategy proposes to determine the level at which to introduce VET, develop qualifications that combine vocational and academic skills in emerging trades, establish pathways between vocational and general education.

11. Image of TVET: TVET is accorded little social status, and is often regarded as a last resort. The strategy proposes to improve the system, aims to launch motivation campaigns through the use of media, exhibitions, competitions, etc. to increase awareness about skills and employability, disseminate success stories and introduce role models.

12. National qualification framework: progression within the vocational/technical stream to secondary education to TVET and from TVET to higher education is limited or non-existent. There are no systems to transfer credit nor formal links between apprenticeship and national qualification. 
13. Registration and accreditation: programmes and institutions will be accredited by regional accrediting bodies to facilitate the mobility of skilled workers and allow credit transfers for further education abroad.

14. Management reforms of training institutes: lack of administrative autonomy hampers the performance and responsiveness of public sector TVET institutions. This will be made more flexible and institutions will be allowed to take decisions on key issues such as curricula, financial and personnel management.

15. Training of trainers: the quality and quantity of TVET teachers and trainers is insufficient and out-dated due to a lack of instructor training facilities, ill-equipped badly maintained training facilities, and facilities that are not relevant to the industry. There are no well-defined standards. In addition, budgetary support for professional development is very low.

16. Research: capacity to conduct research and facilitate other organisations in conducting research is very low. There is a need for an information management system for collecting and analysing information related to skills development and making it available to policy makers.

\section{Innovative programmes for TVET}

Under the presidential directive "Funni Maharat Programme", NAVTEC is establishing 130 new vocational training centres/institutes in 79 uncovered tehsils of Sindh, Punjab, NWFP, Baloschistan, AJ\&K and FANA, where no TVET institute exist. ${ }^{1}$ This programme costs PKR 1.17 billion under which 47765 trainees will be trained.

NAVTEC, in the light of the Prime Minister's "Hunarmand Pakistan Programme," has taken the initiative of offering short-term (mostly up to six months) skills development programmes in collaboration with public sector training institutes. It covers four priority sectors including: construction, agriculture, dairy and livestock, IT and telecommunications and services (hospitality and tourism). The other sectors being addressed are light engineering, services (oil and gas, childcare, transport, financial, paramedics), traditional trades (cottage crafts, etc.) and textiles. Courses utilise the idle vacant capacity of the existing TVET infrastructure in public and private sector training institutes. The geographic spread covers Islamabad, Punjab, NWFP, Sindh, Balochistan, AJK, FATA and the Northern Areas. The major partners are provincial TEVTAs, federal ministries, public sector universities, defence establishments and reputed public and private sector institutes and organisations.

NAVTEC is planning to start mobile training units to broaden the accessibility of training to remote areas. NAVTEC is co-ordinating this initiative with the Small Industries Development Board (SIDB), Ministry of Industries (Government of NWFP) and the Ministry of Youth Affairs (Government of Pakistan).

For the first time in Pakistan, NAVTEC has become a UNEVOC centre by which it will join, and draw on, the international network of technical and vocational education and training.

Under Section 20 of the NAVTEC Ordinance, NAVTEC is mandated to regulate, co-ordinate and process TVET in the entire country. As an apex body at national level, the above-mentioned section envisages "the provision of this Ordinance shall have effect notwithstanding anything to the contrary contained in any other law for the time being in force." Organisations like the National Training Bureau (Ministry of Labour) and the 
National Institute of Science and Technical Education (Ministry of Education) are performing activities which are mandated exclusively to NAVTEC, hence creating an overlap/duplication which is seriously hampering its regulatory functions. In order to remove this duplicity, both NTB (National Training Bureau) and NISTE (National Institute of Science and Technical Education) should be placed under administrative control of NAVTEC. This arrangement would enhance the efficiency and effectiveness of both organisations, which in practice at present are not playing the role assigned to them.

\section{Note}

1. In Pakistan, tehsils are the second administrative division. A tehsil is similar to a county. 



\title{
Chapter 14
}

\section{Integrating skills, employment and economic development: the south Asian context}

\author{
by \\ Ranabhat Baburam
}

\section{Background}

South Asia, also known as Southern Asia comprises the countries of Afghanistan, Bangladesh, Bhutan, the Maldives, Nepal, Pakistan, and Sri Lanka. South Asia, home to over one-fifth of the world's population, is the most populous geographical region in the world. In the past, many South Asian countries were suffering from conflict, poverty, high rates of unemployment and slow economic growth. However, in recent years, the region has been drawing international attention for its rapid economic growth and substantial poverty reduction. Compared to $3.7 \%$ growth per year between 1960 and 1980, South Asia's GDP expanded by 5.7\% from 1980 to 2000; growth accelerated further to $6.5 \%$ in 2000-2007 (United Nations, n.d.). India experienced 9\% GDP growth in 2007, close to that of China. Other South Asian countries like Bangladesh, Pakistan and Sri Lanka have also achieved high economic growth rates compared to the past.

Although substantial improvements have been made in the areas of poverty reduction, employment generation and economic growth, South Asia still remains the home of the world's largest number of poor people. Regional data on South Asian countries is presented below.

As illustrated in Table 14.1, South Asian countries are quite different from each other in terms of their size, population and per capita income. But they do have several things in common, including:

- high percentage of poverty ( $23 \%$ to $42 \%$ ) and illiteracy;

- largely rural-based population (65\% to $85 \%)$;

- main occupation is agriculture (except the Maldives);

- large proportion of population in the informal sector;

- increasing unemployment and underemployment;

- many youths of Bangladesh, India, Nepal, Pakistan and Sri Lanka are engaged in foreign employment;

- unemployment and illiteracy is higher among women. 
Table 14.1. Statistics on South Asian countries

\begin{tabular}{|c|c|c|c|c|c|c|}
\hline Country & $\begin{array}{l}\text { Population in } \\
\text { millions (2009) }\end{array}$ & $\begin{array}{l}\text { Per capita income } \\
\text { in USD (2009) }\end{array}$ & $\begin{array}{c}\text { Literacy } \\
(15 \text { years }+)(\%)\end{array}$ & $\begin{array}{l}\text { Population below } \\
\text { poverty }(\%)\end{array}$ & $\begin{array}{c}\text { Urban } \\
\text { population (\%) }\end{array}$ & $\begin{array}{c}\text { Labour force } \\
\text { participation by } \\
\text { occupation (\%) }\end{array}$ \\
\hline Afghanistan & 33.6 & 486 & 34 & 42 & 24 & $\begin{array}{l}\text { Agriculture: 82, } \\
\text { industry: } 8 \text { (2002) }\end{array}$ \\
\hline Bangladesh & 162.2 & 573 & 53 & 36 & 26 & $\begin{array}{l}\text { Agriculture: } 45, \\
\text { industry: } 30, \\
\text { services: } 25 \text { (2008) }\end{array}$ \\
\hline Bhutan & 0.697 & 1880 & 53 & - & 31 & $\begin{array}{l}\text { Agriculture: } 63 \text {, } \\
\text { industry: } 10, \\
\text { services: } 27 \text { (2004) }\end{array}$ \\
\hline India & 1190.0 & 1030 & 66 & 37 (2010 est.) & 29 & $\begin{array}{l}\text { Agriculture: } 52, \\
\text { industry: } 14, \\
\text { services: } 34 \text { (2009) }\end{array}$ \\
\hline Maldives & 0.396 & 3932 & 97 & - & 34 & $\begin{array}{l}\text { Agriculture: } 11, \\
\text { industry } 24, \\
\text { services: } 59 \text { (2006) }\end{array}$ \\
\hline Nepal & 29.3 & 451 & 57 & 31 & 16 & $\begin{array}{l}\text { Agriculture: } 81 \text {, } \\
\text { industry: } 3 \text {, } \\
\text { services: } 16\end{array}$ \\
\hline Pakistan & 180.0 & 1016 & 54 & 23 (2007) & 35 & $\begin{array}{l}\text { Agriculture: } 43, \\
\text { industry: } 20, \\
\text { services: } 36 \text { (2005) }\end{array}$ \\
\hline Sri Lanka & 202.3 & 2041 & 91 & 23 & 15 & $\begin{array}{l}\text { Agriculture: } 32.7 \text {, } \\
\text { industry: } 26.3 \text {, } \\
\text { services: } 41\end{array}$ \\
\hline
\end{tabular}

Source: Wikipedia (2011), "South Asia”, http://en.wikipedia.org/wiki/South_Asia.

\section{Youth employment situation in South Asia}

It is often said that the youths are the drivers of economic development. But in the current context of economic crisis, the youth unemployment rate is increasing. The ILO report "Global employment trends for youth" stated that at the end of 2009, there were an estimated 81 million unemployed young people in the world. That was 7.8 million more than the number in 2007 at the start of the global crisis (ILO, 2010). The situation of unemployed youth in South Asian countries is (United Nations, n.d.):

- youth unemployment in South Asia reached all-time high of 15.3 million in 2009;

- more than two-thirds of unemployed youth in Egypt and Nepal emigrated for employment purposes;

- $\quad$ out of the 2.5 million unemployed people in Nepal, 1.5 million are youths;

- 400000 youths enter the job market annually in Nepal;

- unemployed, poor and disadvantaged youths were on the frontline during the Maoist Conflict;

- youth generally do not get a job due to a lack of experience. 
Considering the negative consequences that the unemployed youth can have on the national economy, society, and families, many countries have given due focus to youth employment programmes.

\section{Challenges for the government and policy makers}

The major challenges that the governments of South Asian countries are facing in view of the current situation include:

- to provide relief to all those affected by conflict (Afghanistan, Nepal, Pakistan, Sri Lanka);

- to include regions, backward communities and ethnic minorities in the mainstream of development;

- to eliminate poverty and unemployment.

\section{The way forward and policies for employment generation}

South Asian countries face daunting problems of unemployment and poverty. The majority of the labour forces of these countries are still in the agricultural sector, which provides only seasonal employment. To create employment opportunities, the Government of Nepal has introduced youth employment programmes targeting unemployed youth. The National Skill Development Corporation of India and Afghanistan's Skill Development Project provide different types of skills development training for self-employment. But despite government and donor agencies' efforts, unemployment continues to be a major problem in these countries.

The experience of developed countries demonstrates that rapid and sustained economic growth is essential for generating employment opportunities. However, due to the lack of peace and security (Afghanistan, Nepal, Pakistan) and political stability, many South Asian countries are unable to create a conducive business environment for industrial development. Due to limited employment opportunities, dependence on employment abroad, particularly in the Middle East, remains high in Bangladesh, Nepal, Pakistan and Sri Lanka. These countries need to focus on the following areas:

- making education and training accessible to all men and women;

- making linkages between formal and informal sectors, rural and urban;

- developing the capacity of technical trainers;

- investing in infrastructure (electricity, road) and industrial enterprise development;

- focusing on inclusive economic growth;

- $\quad$ area-based participative planning.

Although there is a need to focus on the different sectors for creating employment opportunities and inclusive economic growth, two approaches exist: one for generating employment at the national level and the other for employment abroad.

\section{Employment generation at the national level}

Generally, it is believed that there is a mismatch between skills development training and the needs of business communities/sectors. Therefore, it is essential for government 
(central/local level) to work with business communities/employers and skills development training providers to develop a plan. Participative planning organised at the central or local level between these organisations will contribute to developing marketable skilled human resources. Figure 14.1 presents a conceptual framework for participative planning.

\section{Figure 14.1. Conceptual framework for participative planning}

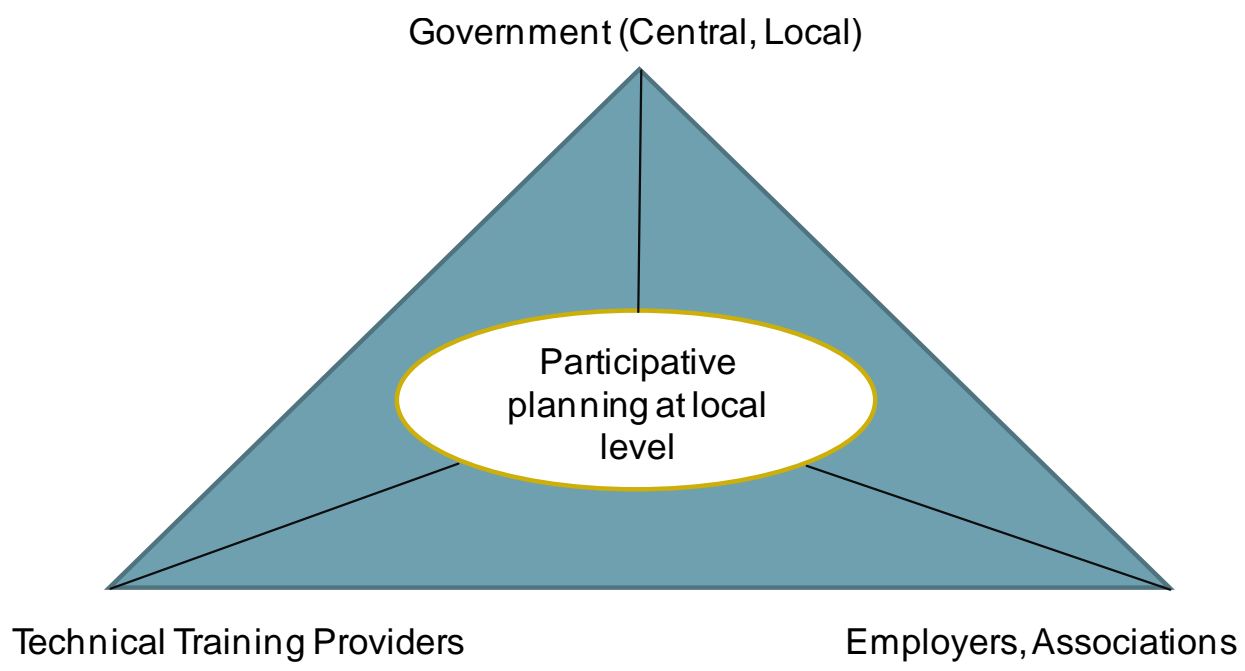

\section{Workforce development for employment abroad}

Since domestic labour markets are too small to absorb the growing labour force, many South Asian countries are dependent on overseas employment. But due to a lack of appropriate skills, a majority of them are in low-paid jobs. Therefore, considering the demand of skilled manpower in many countries such as Korea, Malaysia, Singapore, Thailand and others, it is proposed to develop a skilled labour force targeting the unemployed youth. Figure 14.2 presents a framework for achieving this.

As Figure 14.2 illustrates, there is need to devise a systematic planning to develop skilled manpower for foreign employment. This will be possible if a needs assessment survey is conducted in the existing and/or potential job market, if the results of survey are provided to technical training providers, if needs are identified and if government provides support services during this process. 
Figure 14.2. Workforce development for foreign employment

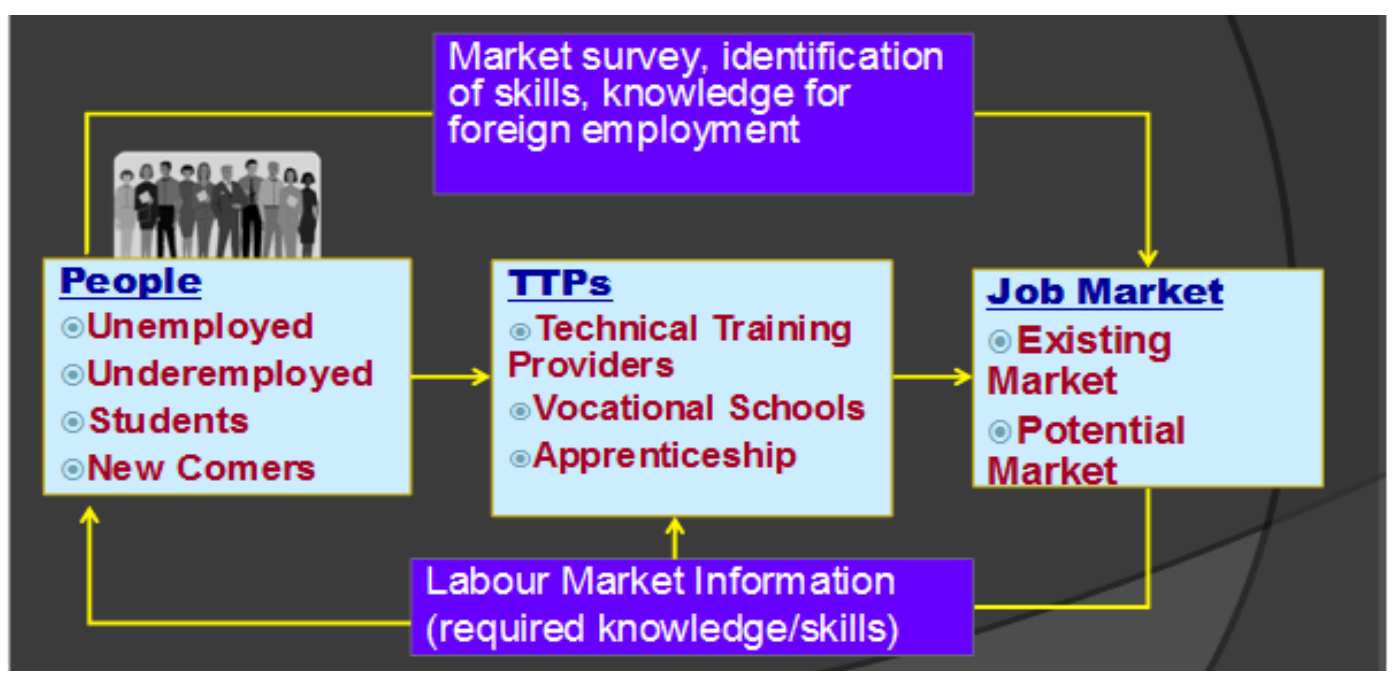

\section{References}

Central Bureau of Statistics (2008), "Labor Force Survey", Government of Nepal, Kathmandu.

Ghani, Ejaz and Sadiq Ahmed (ed. 2009), Accelerating Growth and Job Creation in South Asia, Oxford University Press, World Bank Group, New Delhi.

http://www.medlibrary.org/medwiki/south_asia.

http://en.wikipedia.org/wiki/southeast_asia.

http://web.worldbank.org/wbsite/external/countries/southasiaext.

International Labour Office (2010), "Global employment trends for youth", ILO, Geneva, August.

Wikipedia (n.d.), "United Nations geoscheme", http://en.wikipedia.org/wiki/United_Natio ns_geoscheme. 



\title{
Chapter 15
}

\section{Public Vocational Training Framework in Japan}

\author{
by \\ Doui Yasuhiro
}

\section{Introduction}

A high quality labour force is the source of national power and the foundation of economic and social development as Japan has limited natural resources. That is the reason why the Japanese government puts a great effort into its vocational training policy. The National Level Human Resources Development Basic Plans have been drawn up every five years since 1971 by the Minister of Health, Labour and Welfare on the principal direction of human resources development such as vocational trainings and vocational ability tests under the Human Resources Development Promotion Act. The Ninth Basic Plan is for the period from FY2011 to FY2015 and acts as the mid-term principal direction of Japanese vocational training policy in line with the New Economic Growth Strategy approved by the Cabinet in June 2010.

The Basic Plan has three parts. The first part is an evaluation of the current labour market situation and other related issues. The second part sets up the principal direction for the measures that will be taken to tackle such issues. The third part describes clearly the areas of vocational training where the Japanese government expected people to be hired and toward which the training will be geared up. The third part also describes the targeted people who need vocational training such as non-regular workers.

\section{Evaluation of current situations}

An aging population combined with a fertility drop is still a serious problem in Japan. Figure 15.1 shows the total fertility rate is lower than 1.4 since the late 1990s. The total population (Figure 15.2) peaked out in the year 2004 and transitioned to a declining phase. The ratio of people aged 65 or older to the total population will be over $30 \%$ in 2025 .

Changes in industrial structure affect the distribution of employees by industry. Figure 15.3 shows that employees in medical, health care and welfare sector (dark green line in Figure 15.3 Panel B) increased significantly while the employment of manufacturing (red line) and construction (yellow line) sector decrease significantly during the period from 2002 to 2010. It means that the structure of the supply and demand in the labour market has changed in the context of social and economic environment shifts caused by factors such as the aging society and globalisation. 
Figure 15.1. Trend of the Total Fertility Rate in Japan

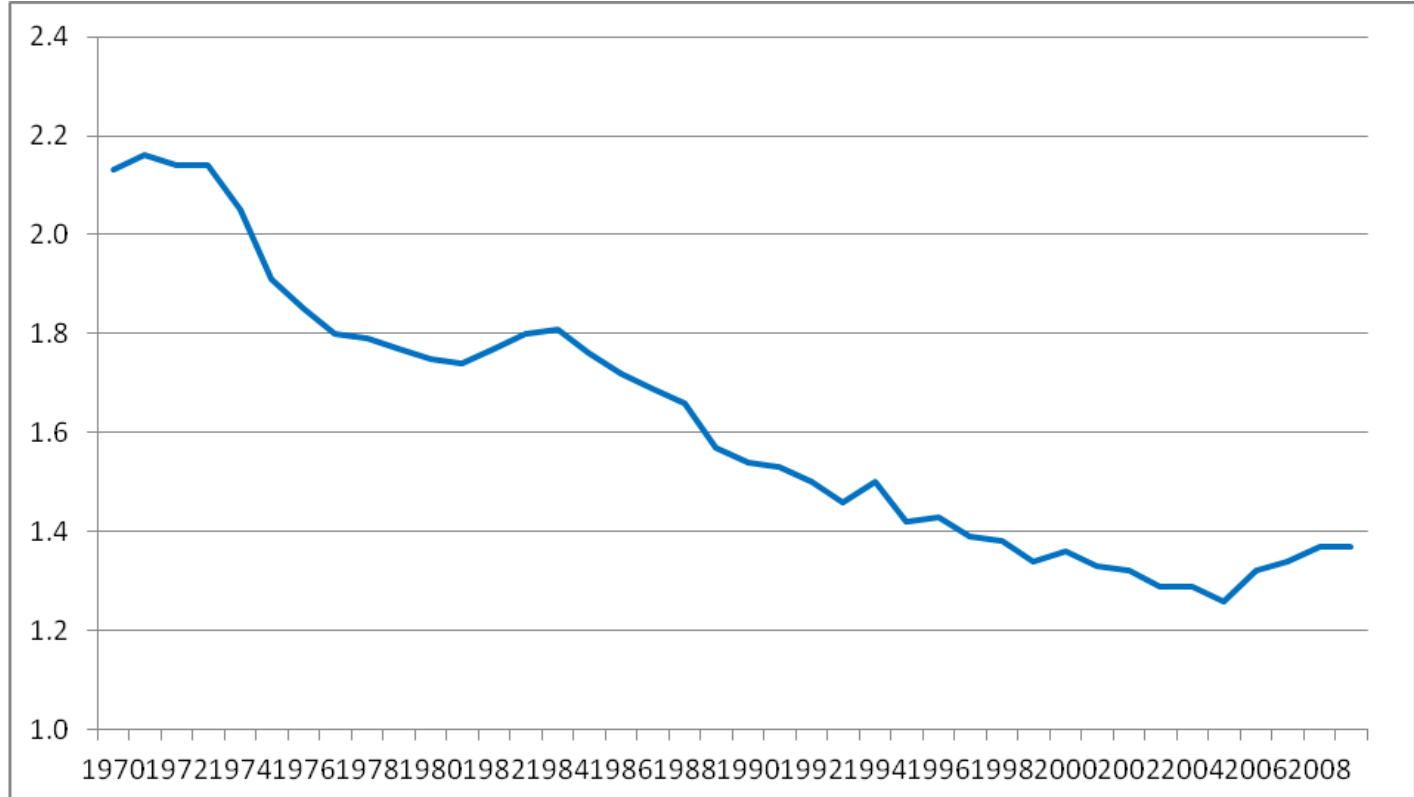

Source: Ministry of Health, Labour and Welfare (2010), Specified Report of Vital Statistics, Japan.

Figure 15.2. Actual and Projected Population in Japan

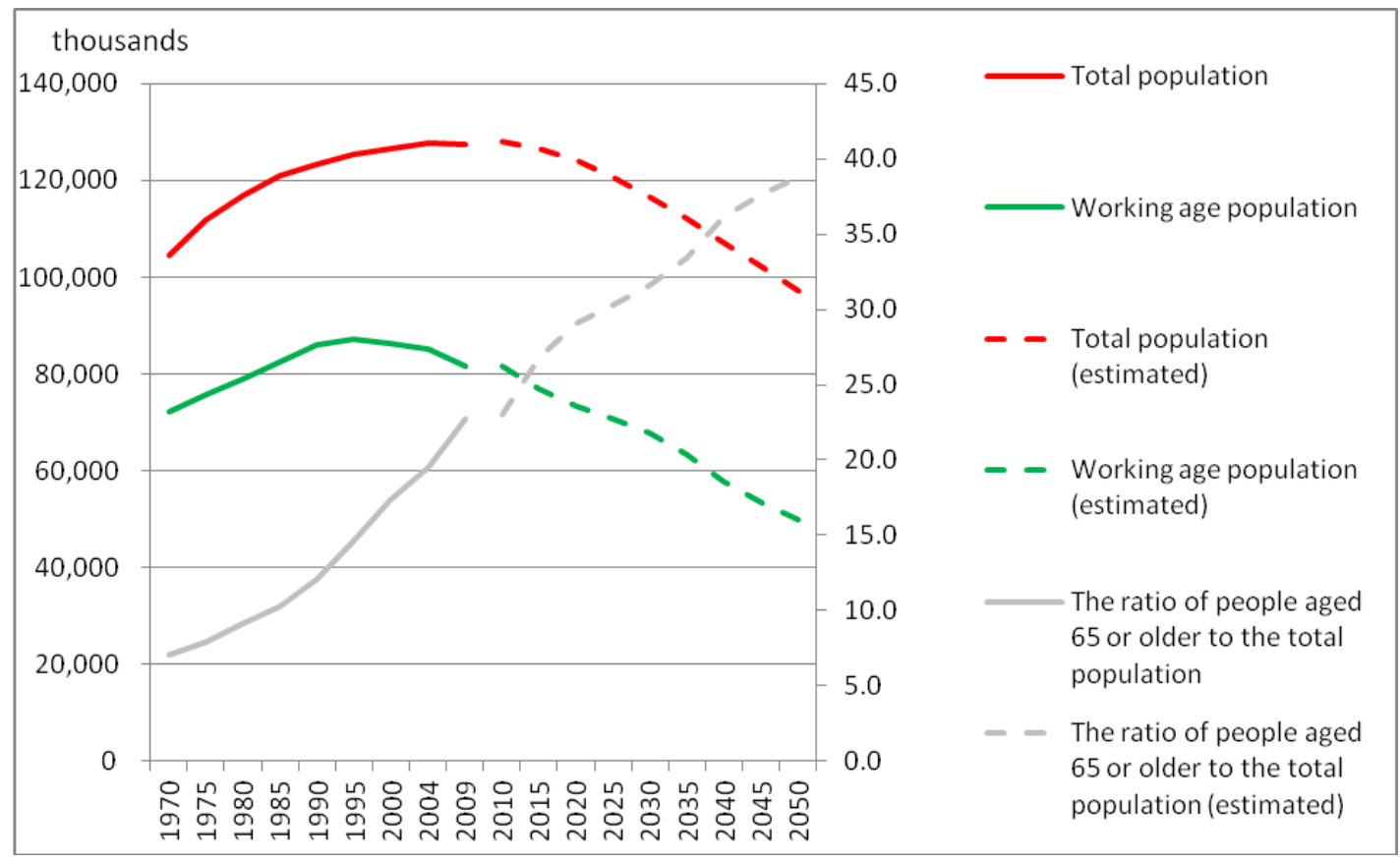

Source:Ministry of Internal Affairs and Communications (2012), Statistics of Japan 2012, Japan. National Institute of Population and Social Security Research (2012), Population Projection for Japan: estimated in January 2012, Japan. 


\section{Figure 15.3. Employees by Industry}

A. $1970-2002\left(10^{\text {th }}\right.$ revision industrial classification $)$

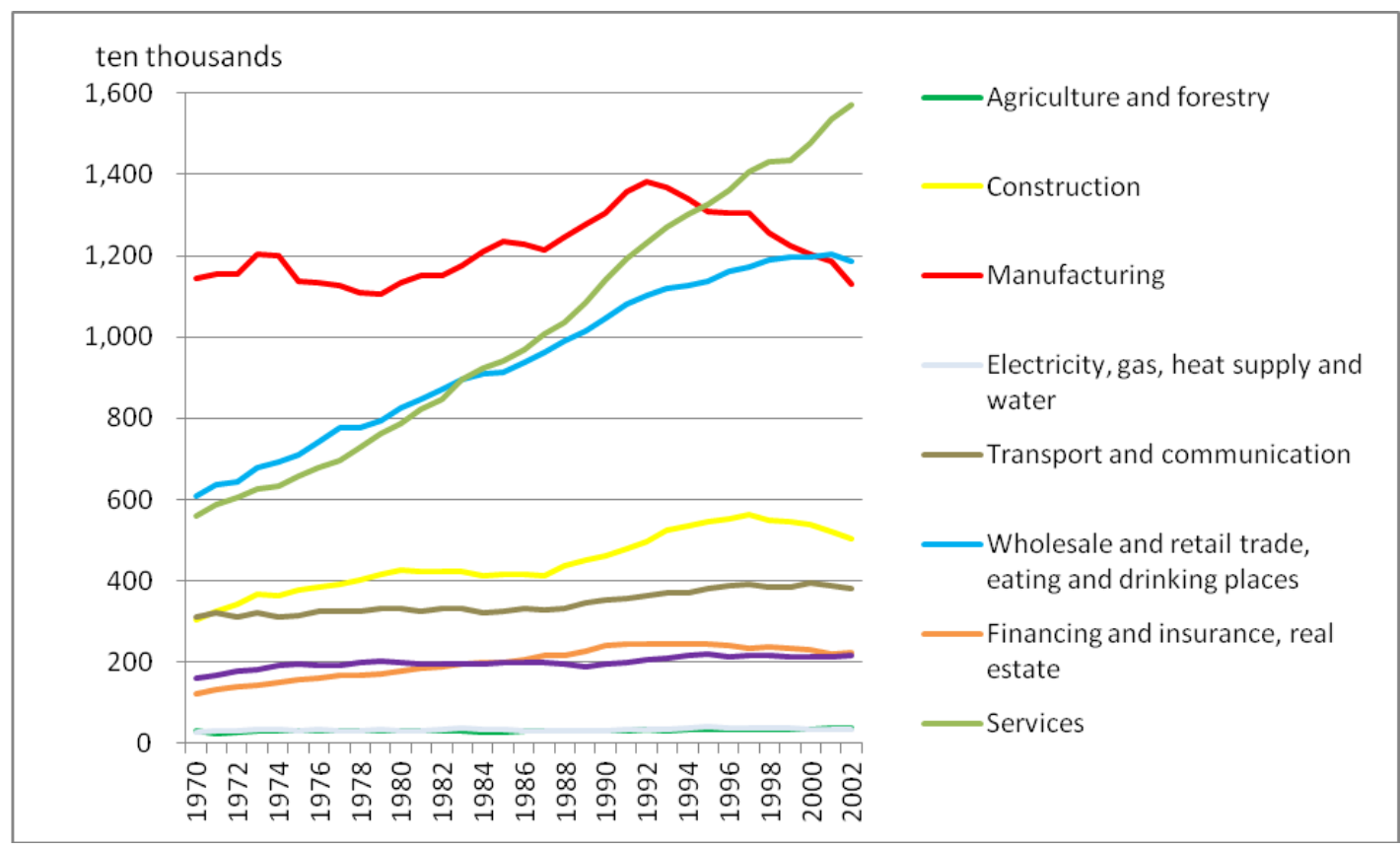

B. $2002-2010\left(12^{\text {th }}\right.$ revision industrial classification $)$

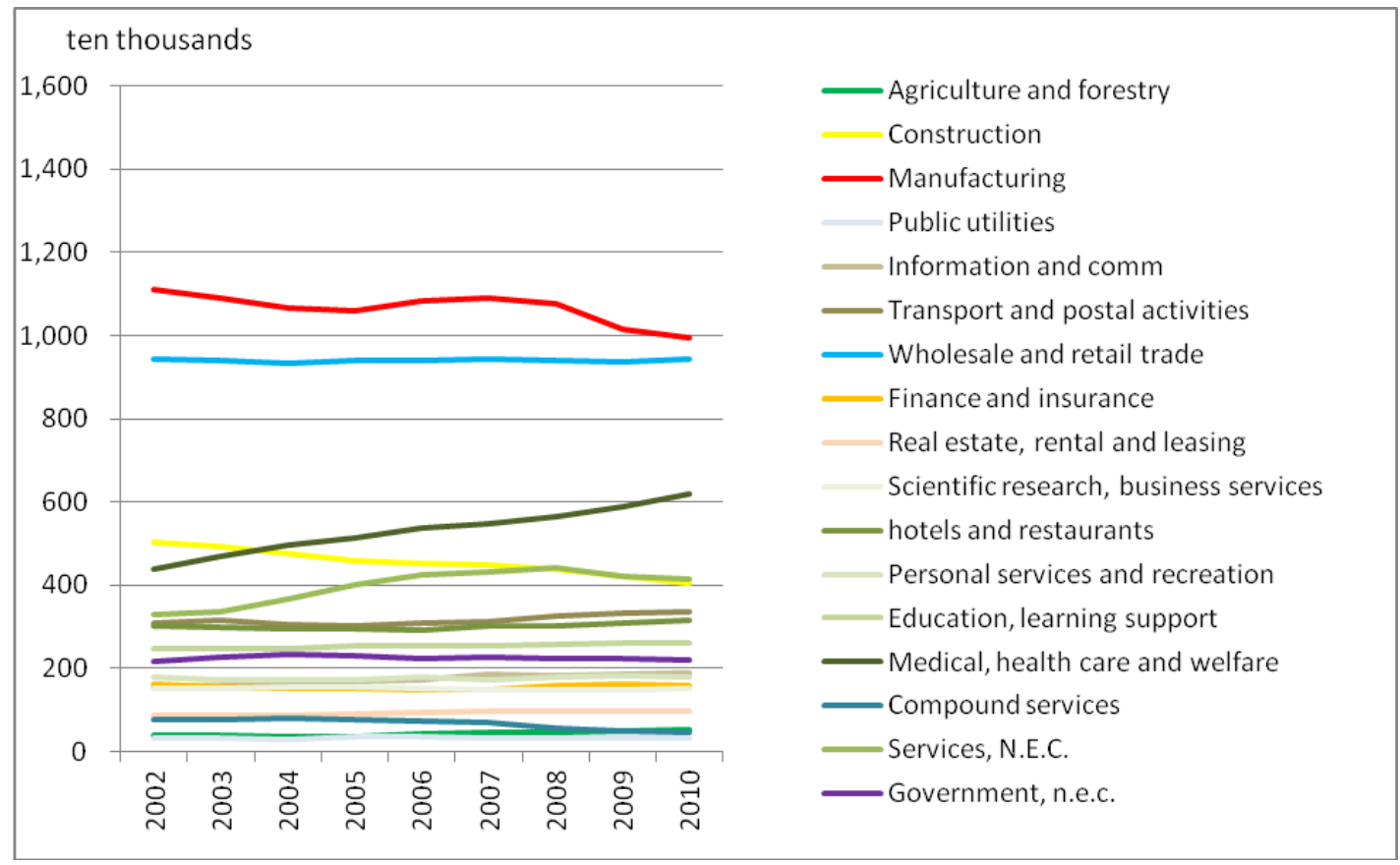

Source: Ministry of Internal Affairs and Communications (2012), Labour Force Survey: long term time series data, Japan. 
Figure 15.4 shows that the number of non-regular workers who tend to find few opportunities to develop their vocational skills is continuously increasing and their proportion in whole employees has surpassed the one-third mark in 2010.

Therefore, it is important that all the members of the society including the young, women, the elderly, the disabled and non-regular workers should pull up their productivity through their own effort such as receiving vocational trainings to build a sustainable and vibrant economy.

Figure 15.4. Employees by Employment Types

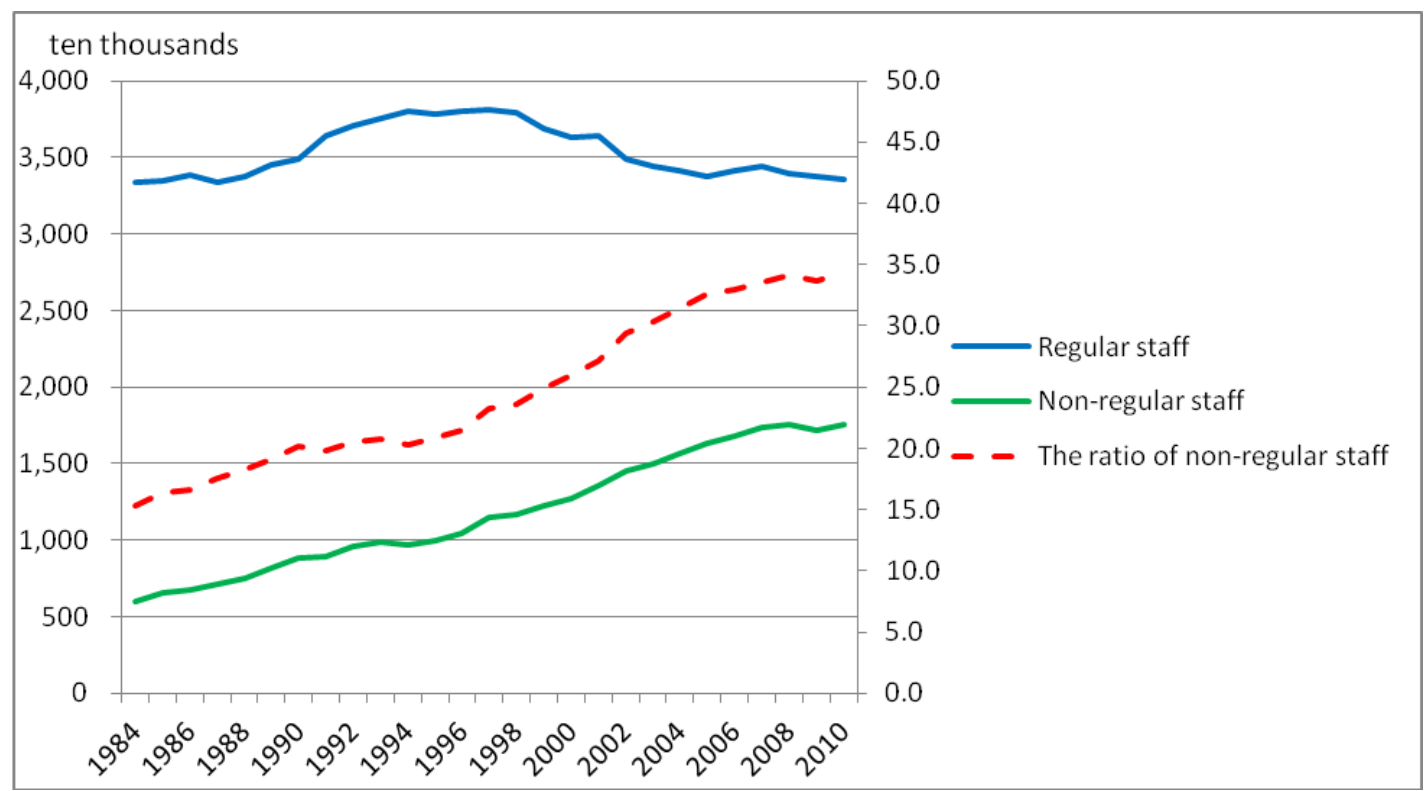

Source: Ministry of Internal Affairs and Communications (2012), Labour Force Survey: long term time series data, Japan

\section{Principal directions}

The Japanese government drives forward its national vocational training policy during the period of the plan with the following objectives:

- Put an emphasis on human resource development for the sectors which are expected to grow up rapidly and for the manufacturing sector whose competitiveness as the key industry is considered as one of most urgent issues.

- Set up a system that allows people who are not eligible for the unemployment insurance to be able to receive vocational training as a safety net.

- Prepare the certificate system for vocational qualification in conjunction with the vocational training system to contribute to the formation of an ability-based labour market.

- Support vocational trainings by individuals themselves proactively and by employers.

- Provide the necessary vocational trainings which could cover the training needs of the country as a whole in the light of needs of the employer and the community 
by various players, such as central government, municipalities, private vocational training companies and employers, with appropriate allocation of roles between them.

\section{Elemental measures}

Drive forward vocational trainings for the sectors which are expected to grow up rapidly and for the manufacturing sector which is considered as a competitive and key industry

Human resource development for the sectors which are expected to grow up rapidly:

- Drive forward human resource developments which are required in the domains of long-term care and welfare, medical care, child care, information and communication technology, tourism and the environment.

- Understand needs for vocational abilities which are required of job applicants or are difficult to develop by On the Job Training provided by employers, as well as research and develop training curriculums and pedagogy.

- Utilise further private vocational training companies for entrusted vocational training programmes, following previous successful experience of such programmes for long-term care.

- Strengthen collaboration with universities and colleges for developing effective vocational training programmes using their expertise and for providing employers with training opportunities for their employees using their functions.

- Human resource development for the manufacturing sector which is considered as a competitive and key industry:

- Provide advanced vocational training programmes including leading programmes by central government which employers, especially SMEs, or private vocational training companies could not provide. Also, provide programmes for basic techniques and skills which are in line with needs of local industries by each prefectural government, of which Japan has 47, which is gathering relevant information on it includes those of SMEs.

- Expand training programmes not only for traditional manufacturing but also for environmental and energy domains such as building up a solar power generation system.

\section{Enhance vocational trainings as a safety net for non-regular workers}

Enhancing roles and functions of vocational trainings as a safety net:

- Draw up a plan on vocational training by consulting the vocational training council at national and prefectural level every year.

- Provide public vocational trainings with job seekers and strengthen further cooperation with job-placement assistance provided by the public employment service offices.

The second safety net: 
- Turn the temporary "Job-Seeker Support System" into a permanent system. The system provides a job seeker, who has no job experience, no unemployment benefits because of frequent non-regular jobs, or who is not able to find a new job after receiving unemployment benefits, with free vocational training and benefits during the training period as the second safety net.

Promoting the Job Card System:

- Apply the Job Card System not only to training courses where the trainee is hired directly by the company which provides the training, but also to ordinary public vocational training and free vocational training for job-seekers who are not eligible for unemployment insurance as one of the measures for the recent economic crisis.

- Pull up the management of local Job Card Steering Offices from private organisations which are entrusted with local Job Card Centre to central government to beef up the system with closer cooperation among national level organisations.

- Expect the Job Card to be utilised in the Job-Seeker Support System with career counseling and by the certificate system for vocational qualifications in conjunction with a vocational training system as an effective tool.

\section{Prepare the certificate system for vocational qualification in conjunction with a vocational training system}

Expanding the labour market for specialists by giving them marketable skills through building the new certificate system for vocational qualification in conjunction with a vocational training system named "the Career Ranking System." Also, the system should be built for "long-term care and life care", "environment and energy" and "food, restaurant and tourism" first because they are directly related to marketable skills.

Improving "the Vocational Ability Evaluation Standards," which outline not only knowledge, techniques and skills for each occupation, but also job performance skills, evaluated from entry-level to management level, thorough analysis of why particular sectors do not use them and understanding their needs.

Matching "the National Trade Skill Testing System" to the needs of applicants and employers periodically through reducing categories, entrusting examinations to private institutions, and updating examinations.

\section{Support career development through working life further}

Support for vocational ability development by individuals themselves proactively:

- Improve availability and quality of career counseling at any time when needed through preparing the evaluation, such as "the Skill Examination" for career counselors and "the Career Consulting Ability Evaluation Examination," and the training to upgrade a skill of career counselor.

Support for vocational training of employees by their employers:

- Support employers who work actively on skills and career development of their employees through using subsidies for promoting career development and bringing up mentors for career development within their management staffs. 
Promoting career education:

- Be involved actively with promoting designed career education in lower secondary education and also higher education as the Japanese government labour policy administration, increase the number of specialists such as career counselors who could contribute to the education with using a working experience programme and the Job Card, and provide people with opportunities to re-study after graduation in view of lifelong learning.

\section{Promote trade skills}

Highlighting the importance of skills through skills competitions.

Encouraging skill acquirement by young people through exchange opportunities with veterans.

\section{Enhance vocational trainings for the people who need special support}

For the young, especially for NEET, applying "the Job-Seeker Support System" to the long-term unemployed and job seekers who have no job experience, leading them to a self-reliance support programme for the young by visiting support, and using a support programme for young trainees including follow-up support such as daily life guidance.

For single parents, especially mothers, providing vocational trainings with a pretraining programme and a child care service during the training.

For people with disabilities, providing tailored vocational training which depends on each trainee's characteristics, by the vocational skills development centres for disability which provide specialised trainings, and by private companies which provide various entrusted vocational trainings.

\section{Promote international cooperation on vocational training}

Supporting vocational trainings in developing counties by dispatching vocational training instructors.

Disseminating a Japanese skill evaluation system widely across the world by helping to build the system in developing countries.

Implementing the revised technical interns training programme properly.

\section{Enhance overall coordinating functions on human resources development in Japan as a whole}

Setting prospects on vocational training and drawing up a plan on it:

- Set medium and long term prospects on human resources development to establish its overall direction in Japan as a whole in terms of efficiency and effectiveness, especially concerning human, financial and facility resources.

- Draw up a plan on vocational training at national and prefectural level by consulting the vocational training council at each level which consists of stakeholders such as representatives of employers' organisation and trade unions, training institutions, academics, relevant ministries and agencies, and local governments at the local level.

Upgrading infrastructures for vocational training: 
- Analyse job contents and required vocational abilities in the sectors which are expected to develop rapidly and encourage vocational trainings for them which include detailed training curriculums, and pedagogy and job-placement assistance techniques.

- Ensure quality of a public vocational training includes entrusted vocational training programmes provided by private vocational training companies through an improvement of information provision to trainees such as contents of the training and number of trainees who could find jobs after training, and a support for voluntary efforts by the private vocational training companies to improve their programmes in light of ISO29990.

- Bring up vocational training instructors by providing trainings for candidates who have various vocational experiences and for existing instructors to fill the gap in their teaching ability as high level instructors.

- Prepare an evaluation system for vocational ability.

- Share responsibility among central government, prefectural governments, and private vocational training companies for enhancing the vocational training system in Japan as a whole. Central government provides advanced vocational training programmes for the manufacturing sector and vocational trainings as a part of an employment safety net. Central government and prefectural governments provide vocational training programmes for employees of SMEs. Private vocational training companies provide entrusted vocational training programmes and central government promotes this framework to promote their utilisation.

\section{Conclusion}

The Ninth Basic Plan aims to develop human resources in the sectors which are expected to grow rapidly, such as long-term care and welfare, medical care, childcare, information and communication technology, tourism, environment and manufacturing. The plan also seeks to enhance vocational trainings as a safety net for non-regular workers since their number has significantly increased in Japan, and to improve the vocational ability evaluation system in cooperation with the education and training sector.

\section{References}

Ministry of Health, Labour and Welfare (2011), "The ninth National Level Human Resources Development Basic Plan," Japan 


\title{
Chapter 16
}

\section{Introduction to employment and social welfare policies and programmes in Mongolia}

\author{
by \\ Amartugs Tsenddavaa
}

\section{Introduction}

In 2009, the population of Mongolia reached 2.7 million and the working age population amounted to 1.7 million. The labour force participation rate was $61.4 \%$ while unemployment was $12.8 \%$.

Mongolia has the following policy framework:

1. Long-term policy papers:

- National Development Concept for Mongolia;

- National Policy of Mongolia on Informal Employment.

2. Medium-term policy papers:

- Economic Growth Support and Poverty Reduction Strategy Paper;

- Social Security Sector Strategy Paper 2006-2015;

- Government Action Plan for 2008-2012.

- Master Plan to Develop the Education Sector of Mongolia in 2006-2015.

3. National and sub-programmes:

- National Program for Employment Promotion.

4. Legal frameworks:

- Law on Education;

- Law on Employment Promotion;

- Labour Law;

- Law on Vocational Education and Training. 


\section{Skills development issues and policies}

The Government of Mongolia places importance on creating a favourable legal environment for employment promotion. In 2001, the Parliament of Mongolia passed the Law on Employment Promotion and approved the National Program on Employment Promotion. In 2002 it passed the Law on Vocational Education and Training and in 2003 the "Strategy document on social welfare". These documents have contributed to establishing a better legal environment for regulating labour relations and employment and to implementing policies to support employment.

Prior to economic transition, public training institutions were the main providers of skills development programmes in Mongolia. Today, the government, enterprises and workers are aware that public and private training institutions are encountering severe difficulties in providing the level of skills training needed for modern enterprises.

Moreover, the mismatch between the training provided by existing training institutions and the skills requirements of the labour market is widening. The effects of globalisation, rapid changes in technology, and the way in which work is now organised have contributed significantly to this widening skills gap. Public training institutions have difficulties securing budget, equipment, material and appropriately trained human resources to enable them to provide relevant skills training for today's workplace. In fact, many state-owned enterprises have been partially or fully privatised, their equipment has been upgraded, requiring their employees to be knowledge workers.

Furthermore, there is a disparity between the way in which training providers conduct skills training and the way in which enterprises contribute to the skills development of their workforce. Larger enterprises frequently invest in training, whereas medium and small enterprises are often unable or unwilling to. Thus, it is essential to bring together government, public and private training providers, enterprises and employees in order to develop policies and strategies that: $i$ ) address learning within training institutions and the workplace to meet the skills development needs of large, medium and small enterprises; and ii) encourage a flexible and quick response to skills training for a competitive and rapidly changing market environment.

As the private sector continues to grow and more and better jobs are created, it is critically important that vocational skills are improved in order for Mongolian workers to be able to fill these new vacancies. An educated and skilled workforce is crucial if private sector enterprises are to be productive and competitive. Workplace learning and training is an area that can be very cost effective and efficient, if training within the workplace is correctly targeted and implemented. Therefore, the Minister for Social Welfare and Labour approved sub-programmes for on-the-job training in 2009 in the construction, road and transport sector funded by the Employment Promotion Fund. The sub-programme involved 3000 unemployed people in training activities at 94 economic entities in the road, construction and mining sectors, and provided $80 \%$ of them with a job. Consequently, given the importance of the on-the-job-training, it was decided to prolong this pilot activity for another two years.

Order No.96 of the Minister of Social Welfare and Labour on 13 September 2007 sets the quotation on "the maximum expenditure of training at production site" and financing was made available by the Employment Promotion Fund. 
Training at the production site of the energy, mining, construction and maintenance service industries, which are in great demand in the Mongolian labour market, lasts four months. There is a system of payment, amounting MNT 420-550 000 for the training expenditure, based on a labour contract. Up to $50 \%$ of the transport and subsistence expenses for the trainees are compensated to the employer, depending on the labour contracts and sustainability of the workplace. The costs of retraining and qualification training should not exceed one-third of the maximum expenditure per a trainee. If an employer organises professional and qualification training and employs a registered unemployed citizen for more than three months, the training course can be reimbursed to the employer if the citizen earns a state recognised certificate pertenent to the occupation.

Also with a view to facilitate employment promotion, self-employment and entrepreneurship training activities on entrepreneurship and business skills are conducted through 11 business incubation centers, 25 business development centers, and 9 entrepreneurship centers.

The Government of Mongolia created the National Council on Vocational Education and the National Employment Council to ensure the balanced participation of the public and private sectors, effective consultation on policy and decision making, and effective implementation of vocational skills development policies. Major concerns include the balanced provision of opportunities to enhance skills and the competitiveness of enterprises for flexible and effective implementation and greater impact. 



\title{
Chapter 17
}

\section{SMEs' important role in creating jobs in the post-crisis}

\author{
by \\ Yasuhiko Yoshida
}

\section{Importance of SMEs for job-rich growth}

Though several years have passed since the global financial crisis unfolded in 2008, it is still casting uncertainty on the global economy. Under these circumstances, it is important to make sure that government policies are devoted to making the recovery jobrich and sustainable. In considering the strategies for employment, skills, and social protection in Asia, due attention should be paid to the role of small and medium-sized enterprises (SMEs).

SMEs are a source of economic growth, innovation and employment for most countries. SMEs and entrepreneurs play a significant role in all economies and are the key generators of employment and income, as well as the drivers of innovation and growth. In many countries, SMEs employ more than half of the labour force in the private sector and they account for an overwhelming majority of all enterprises. For example, SMEs employ $74.2 \%$ of all employees in the Japanese manufacturing sector (small and medium business establishment basis) and they account for $99.6 \%$ of all manufacturing firms in Japan.

Among those SMEs, high-growth SMEs (top 5\%-10\% of all growing firms in terms of the number of jobs created) especially account for a disproportionate share of gross job gains. According to an OECD study (OECD, 2002) which used data from the late 1980s and early 1990s, in France, Greece, Italy and the Netherlands, between 50\% and 60\% of employment gains for the whole economy could be associated with high-growth firms while in Spain it reached more than $90 \%$. In this context, focusing on SMEs' growth stage should be very important while policy makers tend to mobilise more resources for start-ups.

In addition, SMEs tend to be less affected by crisis, so SMEs could serve as an important initial driver for job creation in recovery.

\section{Challenges for SMEs during the crisis}

\section{The crisis and SMEs' limited access to finance}

Just after the financial crisis hit the world, most countries witnessed an evaporation of liquidity for financing SMEs' business activities. Therefore, securing access to financing (investment capital as well as working capital) for SMEs is very important. In the past, to 
facilitate growth and innovation, government policy aimed at supporting SMEs' access to financing tended to focus on investment capital, especially in normal times. However, not only investment capital but working capital as well is essential for their survival during the current crisis.

While the financial system needs to be fixed in terms of pro-cyclicality, improving the credit-worthiness of SMEs remains very important.

\section{Compounded impact of the crisis on SMEs}

As private industries increasingly employ sophisticated production management, which achieves more timely production planning and advanced inventory management, it can multiply the impact of the adjustment to demand shock on suppliers including subcontractors, which are mostly SMEs. In this context, for example, the Japanese Index of Industrial Production (IIP) dropped by 36\% due to the 2008-2009 recession.

\section{Today's global business environment}

\section{Global value chain}

When reviewing the current global business environment, it should be taken into account that sophisticated global value chains helped by information technology (IT) and free trade agreements (FTAs), including economic partnership agreements (EPAs), have increasingly influenced not only large multinational corporations (MNC) but also local SMEs.

Many MNCs are looking for FDI destinations where there are reliable supporting industries, which are mostly made up of SMEs. In such a case, specialised SMEs can relatively easily make up a part of global value chains (GVCs).

\section{Rapidly growing middle-class market}

In response to the rapidly growing middle-class market in Asia and some other emerging economies, product specifications need to be strategically defined. For example, the Tata Nano was introduced to the Indian market at about USD 3000 (Tata initially intended to sell the automobile at about USD 2 000, which was before the price hikes of natural resources.)

\section{Skills development needs in the current context}

First of all, in developing countries, skills development has to be supported by a solid basic education starting from literacy and simple math.

More specifically, and as mentioned above, the current crisis revealed that SMEs need to secure financing, especially working capital once the financial crisis arrives. In this context, SMEs need to be capable of understanding and utilising financial knowledge so the scope of skills needed for SMEs should include those of financing. SMEs tend to lack reliable financial documentation, not to mention detailed business plans, projections, etc.

With regard to the tools which might be used to promote skills development, skills standard setting and testing may be useful. It is necessary to make sure that they are in accordance with these needs and lead to improved labour force performance. 


\section{Box 17.1. Tata Nano's low-cost features}

- Luggage space is only accessible from inside the car, as the rear hatch does not open.

- Single windscreen wiper.

- No power steering.

- Three lug nuts on the wheels.

- Only one side door mirror.

- No radio or CD player.

- No airbags.

- $623 \mathrm{cc}$ engine with only 2 cylinders.

Source: Tata Motors website (2010), http://tatanano.inservices.tatamotors.com/tatamotors/index.php?optio $n=$ com_whynano\&task=experience \&Itemid $=303$, accessed on 16 December 2010; Wikipedia website (n.d.), “Tata Nano", http://en.wikipedia.org/wiki/Tata_Nano, accessed 16 December 2010.

\section{References}

OECD (2002), High-Growth SMEs and Employment, OECD, Paris. 



\section{Part III}

Workplace training and local ecosystems 



\title{
Chapter 18
}

\section{Shanghai's talent development strategy for becoming an international financial centre}

\author{
by \\ Kouqing $\mathrm{Li}$
}

\section{Shanghai as an international financial centre}

In 1992, the Chinese Government took a major strategic decision to speed up the process of developing Shanghai into an international financial centre in response to economic globalisation and the new scenario of global financial competition. However, due to the short supply of competent financial talents in Shanghai, the city is faced with a serious obstacle for achieving its goal. To solve the problem, the Shanghai municipal Government has made tremendous efforts to co-ordinate many relevant parties and numerous types of resources to develop and implement the Financial Talent Development Strategy, encourage the recruitment of high-level overseas financial talents, strengthen the cultivation of local financial talents, improve and optimise the development environment for financial talent to bring their role into full play.

\section{Nurturing local financial talents}

In accordance with the growth nature of financial talents, the Shanghai municipal Government has embarked on educating and training local financial talents: $i$ ) building a sound system for financial talent development; ii) boosting the construction of a platform for integrating and sharing financial education resources; iii) training financial talents in line with international standards; and $i v$ ) conducting classified training for different financial talents. Concrete measures are discussed below.

\section{Building a sound system for financial talent development}

1. For educating and training students majoring in finance, higher education institutions have taken measures to improve curriculum design and reform teaching methods by strengthening faculty team-building to better cater to the needs of the market.

2. The Shanghai municipal Government encourages training institutions specialised in finance-related training to carry out high-quality certification training and high-end professional training.

3. Financial institutions are encouraged use various means to train their employees, including internal training, on-the-job exchange, mentoring, etc. 


\section{Boosting the construction of a platform for integrating and sharing financial education resources}

1. In 2010, four higher education institutions including Fudan University, Shanghai University of Finance and Economy, Shanghai Advanced Institute of Finance and Shanghai National Accounting Institute ${ }^{1}$ were designated by the Shanghai municipal Government as the training bases for training skilled financial professionals in Shanghai.

2. Financial institutions are encouraged to co-operate with each other and share education and training resources, such as faculty, courses, venues, etc.

\section{Training financial talents in line with international standards}

1. Shanghai quickened its steps to build high-level financial talent training bases in line with international standards, relying on the large number of famous international financial institutions in Shanghai and high-level universities and research institutions in China and abroad.

2. Shanghai is also developing outbound training programmes, promoting personnel training and exchange with governments, financial institutions, and finance associations in other international financial centres such as New York, London and Hong Kong, China and sending financial talents with great potential to those cities for further training.

3. Firms are encouraged to train employees during their co-operation with famous foreign financial institutions in areas of capital management, operations management, product development and technological innovation. They are encouraged to send employees abroad to prestigious international financial institutions to learn the advanced managerial philosophies and experience in the financial sector.

\section{Conducting classified training for different financial talents}

1. Executives working in financial institutions are encouraged to enhance capacity building and sharpen their managerial expertise by participating in executive MBA programmes at famous business schools, as well as thematic trainings, overseas trainings and internships. Taking advantage of the various training opportunities, they can master advanced financial management philosophies and improve their capability of harnessing the market and managing modern financial enterprises.

2. Skilled financial persons adept in financial technology are encouraged to sharpen their skills by participating in project co-operation, outbound programme training, and knowledge updates to meet international standards in terms of knowledge structure and competency.

3. Skilled financial professionals are encouraged to take part in career development trainings in various formats, such as on-the-job training, short-term training, and taking various exams to obtain professional qualifications, and by doing so, to further improve their working ethics as well as their vocational skills. 


\section{Recruiting overseas financial talents}

To accelerate the recruitment of high-level overseas talents, the Shanghai municipal Government launched the Program of Attracting 10000 Overseas Chinese Talents in 2003, the Shanghai Pujiang Talent Program in 2005 and the Young Talent Returning Program in 2008. In addition, the Shanghai municipal Government exerted more efforts to recruit high-level overseas financial talents that the city is in urgent need of and to better use those talents so that they can play more effective roles in developing Shanghai as a global financial centre.

\section{Recruiting overseas financial talents}

- The Shanghai municipal Government uses various recruitment methods to attract excellent overseas financial talents, including government-organised recruitment, online recruitment, job market recruitment and head hunting.

- The government co-operates with many Chinese organisations overseas such as the Chinese Finance Association and the Canadian-Chinese Finance Association to recruit financial talents.

- The government has built a database to collect information on the flow of excellent overseas financial talents.

\section{Encouraging enterprises to make good use of the recruited overseas talents}

- The government supports financial institutions to explore a system of talent development, management, evaluation and motivation that is suitable for high-level overseas financial talents.

- The government encourages local enterprises to recruit overseas talents for senior management positions or other key positions, to build up a working platform and provide necessary resources for the recruited talents.

- The government proposes that enterprises nurture a healthy environment for career development and value creation for recruited overseas talents so as to strengthen their sense of belonging.

\section{Improving services for the recruited overseas financial talents}

To better meet the needs of the talents, the government visits and communicates with them regularly. With the establishment of a knowledge sharing platform and information service platform as well as various professional training programmes, the talents can more quickly adjust to the domestic environment. The government builds recreational, cultural and living facilities with local characteristics that are suitable for the overseas talents and offers quality service to them with regard to their children's education, medical treatment and care for their retired parents.

\section{Improving the development environment for financial talents in Shanghai}

By providing opportunities for career development, preferential policies, services and cultural and living facilities, the Shanghai municipal Government is devoted to create a comfortable living and working environment for the financial talents. 


\section{Opportunities for career development}

By establishing a sound financial market system and a financial institution system, the Shanghai municipal Government invites large-scale Chinese or foreign financial institutions with operations in China to locate their headquarters or regional headquarters in Shanghai, so that the talents have more opportunities for career development.

\section{Preferential policies}

The government issued many preferential policies for the financial talents in terms of healthcare, children's education and credentials handling procedures, such as a household register, Residential Certificate and Foreign Expert Certificate. Financial talents who make tremendous contributions to establish Shanghai as an international financial centre will also be rewarded. In addition, the government created taxation policies that suit both domestic situations and international practices for Shanghai as an international financial centre.

\section{Service platform establishment}

The government has built the Shanghai Finance Human Resources Network. The network has become a service platform for the government, enterprises and the public to exchange information on financial talents. Meanwhile, the Shanghai Financial Development Service Center, the Shanghai Financial Association, the Shanghai Financial Youth Federation and the Financial Industry Association are important agencies which provide services for the financial talents. The government organises various events, such as salons, parties, high-level expert fora and seminars, for financial entrepreneurs, senior financial experts and young financial talents to exchange knowledge and information.

\section{Living environment and cultural environment}

The government promotes the construction of apartments for the financial talents. The government also makes a lot of efforts to improve the living and cultural functions of concentrated financial areas such as the Lujiazui area and the Bund. The government actively promotes the publicity of relevant policies, excellent financial talent and innovative teams and promotes honesty, innovation and good practices so as to create an open, relaxed and tolerant environment for the financial industry.

\section{Conclusion}

Through the above-mentioned measures, Shanghai has made remarkable achievements in nurturing financial talents in recent years. By the end of September 2010, the number of people working in the financial industry had reached 231900 , an increase of 130000 from 2000. The classification of the financial industry now covers not only banking, which used to be the dominant category, but securities, insurance, futures and trust as well (Shanghai Municipal Office for Financial Services at Shanghai Futures Exchange, 2010). The development of financial talents satisfactorily meets the needs of financial industry in Shanghai and effectively contributes to the development of Shanghai as an international financial centre. According to the global financial centres ranking in 2011 issued by the Chinese Academy of Social Sciences, Shanghai and Tokyo were both ranked the fifth most competitive among the 75 global financial centres, following London, New York, Hong Kong, China and Singapore (Institute of Finance of China Academy of Social Sciences, 2011). 


\section{Note}

1. The Shanghai National Accounting Institute (SNAI) is also the training base for the Asia-Pacific Finance Development Center (AFDC).

\section{References}

Human Resources Development Plan for the Financial Industry of Shanghai in the $12^{\text {th }}$ Five-year Period, 2011.

Outline of Medium and Long-term Human Resources Development Plan in Shanghai (2010-2020).

Shanghai’s Urgently Needed Financial Talents Development List, 2010.

Suggestions on Further Optimizing the Human Resources Development Environment in Shanghai, 2009.

Regulations on Converging Financial Resources to Improve Financial Services for Financial Industry Development in Shanghai, 2009.

Administrative Measures on Shanghai Pujiang Talent Program, 2008.

Some Suggestions on Implementing the Program of Attracting 10,000 Overseas Chinese Talents in Shanghai, 2003.

Institute of Finance of China Academy of Social Sciences (ed. 2011), "Finance Blue Book 2011: annual report on China's financial centers development (2010-2011)", Social Sciences Academic Press, November.

Working Conference on Shanghai’s Financial Talent held in September 2010. 



\title{
Chapter 19
}

\section{Hong Kong Qualifications Framework: A platform for skills development and responding to changing market needs}

\author{
by \\ Bing Hung Pang
}

\section{Background}

The advent of globalisation and rapid technological advances have triggered fundamental changes to the economic structure of Hong Kong, China. In fact, over the past two decades, Hong Kong, China has been making the transition from an industrial society to a knowledge-based one in order to maintain its competitiveness. By the turn of the century, Hong Kong, China was geared towards the provision of knowledge- and information-based products and services such as financial and professional services, as well as high-tech manufacturing and design. As a result, the workforce is required to demonstrate continuously improve its capacity, quality and specific skills and competencies.

Like many other countries and regions, Hong Kong, China has been experiencing a sizeable mismatch between job requirements and employees' qualifications over the last ten years. More specifically, there is a shortage of manpower at "post-secondary" and "first degree and above" levels while a surplus supply exists at the "upper secondary" and "lower secondary and below" levels. Indeed, the demand for more and higher vocational and professional qualifications is increasingly important in the job market. There is an apparent need to upgrade the quality of the workforce and to provide individuals with opportunities to optimise their potential if Hong Kong, China is to meet the changing demands of the economy. In this respect, a common platform conducive to skills development and enhancement for employees in different sectors and lifelong learning for members of the public at large is considered a viable solution to the local manpower challenges ahead. The Qualifications Framework (QF) in Hong Kong, China was established based on this context.

\section{Establishment of a unitary qualifications framework}

In 2004, the Education Bureau of the Hong Kong SAR Government announced the establishment of a unitary and cross-sectoral QF and its associated quality assurance mechanism with a view to promoting lifelong learning. The QF in Hong Kong, China is a seven-level hierarchy covering qualifications in the academic, vocational and continuing education sectors. It is designed to be applicable to all sectors to facilitate the interface 
between academic and vocational sectors. Each level is characterised by a set of generic level descriptors which describe the common features of qualifications at the same level. All qualifications recognised under the $\mathrm{QF}$ are quality assured.

The government has been working closely with relevant stakeholder groups, including employers, employees, trade associations and unions, professional bodies, and education and training providers, to establish the infrastructure for the QF. It also introduced legislation in 2008, namely the Accreditation of Academic and Vocational Qualifications (Cap. 592), to provide legal backing to the quality assurance mechanism to underpin the QF. The new Ordinance empowered the Hong Kong Council for Accreditation of Academic and Vocational Qualifications (HKCAAVQ) as the accreditation authority and qualifications register authority. All qualifications and the associated learning programmes have to be accredited by the HKCAAVQ in order to be registered on the QR and become recognised under the QF. With this framework in place, learners can draw their own road maps to acquire quality assured qualifications to upgrade their skills and pursue lifelong learning at different stages and through different channels.

\section{Developments to date}

As regards the vocational education and training sector, which is primarily concerned with continuing skills development and enhancement for the workforce, the Education Bureau of the Hong Kong SAR Government has commissioned the Qualifications Framework Secretariat (QFS) to assist various industries and trades in setting up respective industry training advisory committees (ITACs) to implement QF on an industry basis. ITACs are tasked to draw up specifications of competency standards (SCSs) for the relevant sectors, which set out the skills, knowledge and outcome standards required of employees at various levels under different functional areas of the respective industry sectors. SCSs are task- or function-based, with competency requirements and assessment criteria to serve various purposes, including the development of competency based training programmes, human resources development and management, as well as vocational skills assessment and recognition.

ITACs have so far been set up for 17 sectors, ${ }^{1}$ covering over $40 \%$ of the total labour force. The ITACs have made good progress in drawing up SCSs of their respective industries. As of September 2011,, 12 ITACs have already completed their SCSs for adoption by different stakeholder groups in various applications as follows:

- development of vocational education and training programmes by training providers;

- development of in-house training programmes by enterprises;

- development of in-service competency based certifications by specific trades;

- development of competency based job specifications by enterprises;

- development of recruitment specifications by enterprises;

- basis for the conduct of recognition of prior learning (RPL) mechanism.

The recognition of prior learning (RPL) mechanism under the $\mathrm{QF}$ is designed to encourage and facilitate employees to pursue further education and lifelong learning. The RPL mechanism is a process that enables employees of various backgrounds to receive formal recognition under the $\mathrm{QF}$ by virtue of their knowledge, skills, and experience 
already acquired in the workplace. It is therefore most beneficial to those skilled workers with low educational attainment to determine their own skills level through RPL and then to pursue further training on the basis of the recognised RPL qualifications so obtained. The RPL will not only help enhance employees' opportunities for further learning and training, it will also ensure that they do not need to start from scratch or repeat training. The establishment of the RPL mechanism under the QF is an important milestone in the development of the QF in Hong Kong, China.

\section{Conclusion: the way forward}

The development and implementation of the QF in Hong Kong, China is a long-term endeavour to upgrade the quality of the labour force and hence economic strength through continuous skills development. The Education Bureau and the QFS will continue to enhance the QF infrastructures in a progressive and step-by-step manner. Continued efforts will be made to increase public awareness of the QF, and to promote a wider application of its deliverables in the education and training sector as well as in the workplace.

\section{Note}

1. Printing and publishing, watch and clock, Chinese catering, hairdressing, property management, electrical and mechanical services, jewellery, information and communications technology, automotive, beauty, logistics, banking, import and export, insurance, retail, testing, inspection and certification, and manufacturing technology (tooling, metals and plastics). 



\title{
Chapter 20
}

\section{Skills development for SMEs and micro enterprises in the Philippines}

\author{
by \\ Marissa Grasparil Legaspi
}

\section{MSMEs in the Philippines and the impact of the crisis}

\section{Overview of MSMEs in the Philippines}

In the Philippines, micro, small and medium-sized enterprises (MSMEs) are the backbone of the economy. They play a vital role not only in wealth creation but also in dispersing new industries to the countryside and stimulating gainful employment. They also contribute to the equitable distribution of income and poverty alleviation.

Based on a survey conducted by SERDEF/UP-ISSI, there were 783065 business enterprises operating in the Philippines as of 2006. Of these, 99.7\% (780 469) were micro, small, and medium-sized enterprises (MSMEs) and the remaining 0.3\% (2 596) were large enterprises. Of the total number of MSMEs, 92\% (720 191) were micro enterprises, 7.3\% (57 439) small enterprises, and 0.4\% (2 839) medium-sized enterprises. The same survey also showed that MSMEs contributed 70\% (or 3.3 million jobs) of the total jobs generated during the period, $30 \%$ of the total valued-added in the manufacturing sector and accounted for $25 \%$ of the total exports.

MSMEs in the Philippines are categorised as follows:

- $\quad$ By asset size:

- micro: Up to PHP 3000 000;

- small: PHP 3000001 - PHP 15000 000;

- medium: PHP 15000001 - PHP 100000 000;

- large: above PHP 100000000.

- Alternatively, MSMEs may also be categorised based on the number of employees:

- micro: 1-9 employees;

- small: 10-99 employees;

- medium: 100-199 employees;

- large: more than 200 employees. 


\section{Impact of the global crisis on MSMEs}

MSMEs in the Philippines still face key issues and challenges which include those relating to competitiveness, productivity and structural limitations, financing and access to markets.

The recent global financial crisis did not spare the enterprises in the Philippines. A World Bank study confirmed that small and medium-sized export enterprises in the Philippines were hit hardest by the decline in trade financing during the 2008-2009 global crisis. This was the result of the survey conducted during the first quarter of 2009 on trade and trade finance developments among 425 firms and 78 banks in 14 developing countries across 5 regions.

In the case of the Philippines, salient findings of the study include:

- small exporters lost their credit lines as demand for their products sharply declined and no orders were received;

- affected cash flow of SMEs as orders were cancelled, payments for delivered orders delayed and shorter maturity imposed by suppliers;

- firms that rely to a large extent on the banking system for trade finance suffered from more risk-averse and selective local banks;

- $\quad$ small and medium-sized enterprises (SMEs) were most affected by high increases in the cost of trade finance instruments;

- firms operating in global supply chains experienced a drop in export revenues and buyers' liquidity;

- banks made lending standards and guarantee requirements more stringent.

Enterprises' financial losses ultimately result in job losses. According to the Department of Labor and Employment (DOLE), from October 2008 to December 2009, a total of 1836 establishments reported job displacements affecting 213417 workers as a consequence of the financial crisis. Most of the workers (58.1\% or 124 006) were placed under flexible working arrangements in the form of job rotations and reduced working hours. Around 24\% (50 855 workers) were terminated while the rest (18.1\% or 38556 workers) were laid off temporarily.

Workers in export-oriented industries were hit the hardest. The crisis affected 149 companies in the electronics industry who were forced to displace a total of 77026 workers. They accounted for over $36 \%$ of the total number of workers reported as having been affected by the crisis. Another $32.9 \%$, or 70307 workers, employed in the manufacture of garments, furniture, metal components, and mineral products for export were also displaced.

\section{Responses to the global crisis}

The Philippines was among one of the first Asian countries to respond to the crisis by adopting a stimulus package called the Economic Resiliency Program (ERP). The aim of the programme was to mitigate the impact of the global crisis on the local economy and ensure sustained growth, to save and create as many jobs as possible, to protect the most vulnerable sectors consisting of the poorest of the poor, returning overseas workers, and workers in the export sector, ensure low and stable prices and improve industrial competitiveness in preparation for economic recovery. These goals were to be attained by 
stimulating domestic demand through expansionary monetary and fiscal policies, promoting employment through public works and skills training, and insulating the most vulnerable sectors of society from its worst effects through more focused implementation of existing social protection programmes.

A number of programmes were implemented as a response to the crisis, one of which is the training and retraining of the labour force. Skills training can play a critical role in promoting employment and alleviating poverty not only during but more so in the aftermath of an economic crisis. For workers who lose their jobs or are forced into underemployment, training helps them to acquire skills they will need to find new and perhaps even better employment opportunities. For others that were laid off from industries facing an irreversible structural decline in demand, retraining provides them with new skills to replace existing skills that have become obsolete. It is most crucial for a country like the Philippines which can no longer compete in low-skilled labour-intensive industries and must now shift production to more skill-intensive high-productivity industries.

\section{Skills development system in the Philippines}

The global integration of markets has important implications for skills development throughout the world. Countries like the Philippines, for instance, have found it increasingly difficult to compete in the production of low-skill, labour-intensive manufactures and have seen the need to shift production to more skill-intensive, higher value-added manufacturing and service industries. Structural changes and intense competition have made it difficult for low-skilled workers to find gainful employment.

Modern economic growth is also driven by the rapid pace of innovation and technological change, especially in the area of information and communication technology and biotechnology. These innovations have brought about new products, services, equipment, and methods of production that require specialised skills. The lack of relevant skills, however, may be a major impediment to the ability of a country to restructure its economy and industries, exploit emerging opportunities, and undertake technological innovations.

The Philippines has always placed a high premium on its human resources as it is a source of competitiveness in a globalised environment. The new administration has placed human resource development as a top priority in its labour and employment agenda with an over-arching goal of investing in human resources and making it more competitive and employable while promoting industrial peace based on social justice. This is reflected in the increasing public investments in human resources development and redirecting these investments to where they are needed most and addressing the education needs of the vulnerable.

The priority given to skills development has been maintained, whether in times of economic crisis or prosperity.

\section{The technical vocational education and training system}

Technical vocational education and training (TVET) is one of the key measures to equip workers with employable and productive skills needed by the industry and the economy in the Philippines. The Technical Education and Skills Development Authority (TESDA) is the lead government agency that is responsible for managing this sector. It 
was established to provide direction and formulate policies, programmes and standards to promote quality technical education and skills development in the country.

The Philippine technical vocational education and training (TVET) system can be characterised as competency based, accessible and open, flexible and responsive to industry requirements and quality-assured. The network of public and private TVET institutions provides massive training opportunities, particularly in the light of local and global demand for qualified and highly skilled workers for enhancing productivity and global competitiveness of industries as well as in addressing displacements of workers. TVET provision is delivered by the network of public and private institutions through the following modes: school-based; centre-based, enterprise-based, and community based technology training programmes.

- School-based programmes: these refer to the direct delivery or provision of TVET programmes by public and private providers, including TESDA administered schools. These school-based programmes include post-secondary course offerings of varying duration depending on the Training Regulation.

- Centre-based programmes: these refer to training programmes being undertaken in the 16 TESDA regional training centres (RTC), 45 provincial training centres (PTC) and specialised centres such as the TESDA Women's Center, TESDA Training Center Taguig Campus Enterprise (TTCTCE), Korea-Philippines Training Centers as well as private training centres. Programme offerings in the centres are also qualification- or TR-based similar to the TVET schools.

- Enterprise-based programmes: these programmes are implemented within companies/firms and can be any of the following:

- Learnership Program: practical on-the-job training for approved learnable occupations for a period not exceeding three months. Only companies with TESDA approved and registered learnership programmes can hire learners. Learners are absorbed by the companies after training.

- Dual Training System (DTS): an instructional delivery system that involves two venues of learning $-30 \%$ in the school/training centre and $70 \%$ in the company/establishment. The training is based on a training plan collaboratively designed and implemented by an accredited dual-system educational institution/training centre and accredited dual system of agricultural, industrial and business establishments.

- Apprenticeship Program: enterprise-based training undertaken within the company which involves a contract between a trainee and an enterprise on an approved apprenticeable occupation. The programme serves as a bridging mechanism to enhance the government's skills development and employment facilitation programmes and provides new entrants to the labour force with the opportunity to acquire basic skills and work experience, which are of prime importance to employers in hiring new employees.

- Community-based training: these are TVET programmes conducted in the communities, mostly in partnership with local government units (LGUs) and NGOs. Programmes are usually based on the local skills requirements and resources available in the area. 
All TVET programmes offered by public and private technical institutions are required to get prior approval from TESDA through a mandatory process of programme registration.

In partnership with industry, TESDA draws up competency standards which are officially promulgated by the TESDA Board as training regulations.

The training regulations include the minimum training standards by which programmes are qualified and registered. The process takes into consideration four essential components of training delivery: curriculum, trainers' qualifications, available tools and equipment, and training facilities.

The same competency standards become the basis for competency assessment which has been declared by the TESDA Board as mandatory. All trainees who pass the assessment are given a certificate of competency which serves as a trade credential.

The total capacity of the TVET system is more than 1 million training seats per annum in more than 4000 private and public training institutions, including enterprise-based training centres. The training or skills development programmes can be classified into three types: pre-employment training programmes for workers without skills and which are conducted by formal or institution-based delivery systems; retooling or retraining programmes to equip displaced workers with new skills to enable them to shift to new jobs within the enterprise or in other industries or occupations; and upgrading programmes to enhance the skills of a worker in an enterprise or occupation.

The enhancement of matching of TVET outputs with jobs available is being addressed by TESDA through the "Seek-Find-Train, Certify = Employability" (SFTCE) paradigm. Essentially, this involves the following: $i$ ) seek the job opportunities in the local and overseas markets through labour market intelligence; $i$ ) find the right people fit for the jobs; and iii) train the right people for the available jobs using quality standards developed in consultation with industry, iv) certify the qualified workers as a proof of competence; and $v$ ) facilitate the absorption of graduates into employment through post-training assistance such as referral and placement.

This approach is aimed at addressing the lingering problem of job-and-skill mismatch. The Project Jobs Fit 2020 initiated by the Philippine Department of Labor, which identified the labour market requirements, including shortages and surpluses of key employment generators or those sectors that have the potential for high growth and subsequently job creation, now serves as a basis of TESDA in prioritising and directing technical vocational education and training programmes, including scholarships.

TESDA's Training for Work Scholarship Program (TWSP) is one of the major programmes to provide the training interventions and employment opportunities for domestic and overseas Filipino workers affected by the global financial crisis.

The programme had a budget of only PHP 0.5 billion when it started in 2006, which was increased to PHP 1.35 billion in 2008 then to PHP 5.66 billion in 2009. Aside from free training, scholars from poor households are given PHP 60 a day for transport and meals thus ensuring $100 \%$ attendance in all trainings. Workers who were displaced during the crisis enjoy a much bigger allowance amounting to about half of the minimum wage per day while in training.

Training is delivered by private and public providers, through partnership agreements with industry associations or their training centres, and in partnership with an enterprise that has training facilities. To ensure that quality standards are met, TESDA has adopted a 
strict monitoring and evaluation process. At least $60 \%$ of graduates of a training programme should have found employment within a year. Failure to achieve these targets for three batches of training is ground for delisting the training provider. TESDA also requires graduates of the programme to undergo a competency assessment. The performance of graduates in these competency assessments is also used as a basis for renewing or extending the accreditation of the training providers.

The TWSP proved to be an effective strategy to direct training provision to where the demands are and to encourage the participation of enterprises/industry in skills development.

\section{Technical vocational education in high school}

Technical vocational education has also been introduced in selected public high schools through the Strengthened Technical-Vocational Education Program of the Department of Education. This is aimed at giving high school students a relevant education and certifiable foundation skills that will enable them to pursue higher learning, entrepreneurship ventures and/or employment opportunities either in the formal or informal sectors. The tech-voc components of the curriculum are aligned with TESDA's training regulations such that the graduates who successfully met the standards through assessment and certification can be awarded the National Certificate for the qualifications they achieved in high school. These vocational high school graduates (who are of legal age) join the pool of skilled workers available for employment.

\section{Skills development programmes for MSMEs}

An array of programmes and services provided by various government and non-government organisations, including local government units and chambers of commerce, are available for MSMEs in the Philippines. The programme and service areas include product development, technology/production, marketing, training and human resources development, regulations/incentives and institutional development.

In the area of training and human resources development, focus is given to providing existing and potential entrepreneurs with the necessary skills and knowledge to become competitive in the local and global market, particularly in the areas of financing, marketing, technology, human resource development and advocacy. Training for MSME workers, on the other hand, involves skills acquisition for technology-intensive industries and improving productivity.

Despite these programmes, however, most MSMEs are still suffering, including from the lack of appropriate skills and capabilities to make their products and services globally competitive. The smaller the SME, the more they find it difficult to afford a skilled workforce and their competitiveness is severely affected.

Furthermore, training conducted by employers of MSMEs is on a limited scale. Many studies have indicated that in most countries, both developing and industrialised, the incidence of formal training rises with firm size. MSMEs, therefore, are more constrained in training than their larger counterparts. Poor access to finance is the number one constraint cited by employers in offering training to their workers. Other important constraints included poor information on training needs, and the perception that existing worker skills and informal on-the-job training provided by supervisors and co-workers was more than adequate. Lack of training capacity is also cited, mostly by exporters (World Bank, 2010). 
The difficult economic circumstances of enterprises, especially MSMEs and particularly in the light of the global financial crisis, coupled with the presence of surplus labour, contribute to the reluctance of many MSMEs to invest in training activities.

In the Philippines, therefore, the government and the educational and training institutions, both public and private, remain the major providers of the skilled manpower requirements of MSMEs and the industry and the economy, in general.

\section{Conclusion and recommendations}

The pursuit of job-rich and inclusive growth should be central in the development agenda. An inclusive growth policy supports economic growth along with the opportunity for all workers to obtain gainful employment leading to productive careers. This necessitates creating productive and decent work opportunities with high and sustainable economic growth and strengthening social resilience through investment in education, training and social protection. This also involved structural and policy reforms to place job creation at the centre of macroeconomic policies.

The recent fiscal crisis also highlighted the need to address human resource concerns, including the need for an appropriately trained workforce for economic recovery and the emerging skills requirements of the future.

From past experiences and the issues and concerns on implementing skills development programmes in the Philippines, including those for MSMEs, several recommendations can be forwarded.

\section{Strengthen the industry-education and training linkage, including enterprise-based training}

The involvement of industry/employers is essential to link training supply with demand. As the end-user of skilled manpower, the industry is in the best position to determine what type of skills and competencies have to be developed. Its involvement in training provision as well as in the development of competency standards and in the design of curricula has to be strengthened and sustained.

More importantly, given the fact that skills are better learned in the workplace, enterprise-based training such as apprenticeship, dual training, on-the-job training and other related schemes need to be intensified and realigned to suit industry requirements.

To fully harness the participation of industry/employers in the delivery of skills training, they need to be included in skills development planning and governance bodies at the local and national levels.

The provision of incentives for enterprises who engage in training should be pursued and expanded.

\section{Improve labour market information and address the labour demand and supply gaps and matching problems}

Strong labour market intelligence and a functional labour market information system are critical to address the jobs and skills mismatch. This means ensuring the availability and accessibility of the relevant labour market information, anytime, anywhere to the industry, students, parents, educational institutions and other stakeholders. 
The industry/employers play a very crucial role in making this a reality since they provide the information on jobs and skills in demand. TVET is directed towards employment and the availability of timely and relevant information on where and what jobs will contribute significantly to make TVET provision more pertinent thereby enhancing graduates' chances of finding employment.

The DOLE's PhilJob Net and the Public Employment Service Offices (PESOs) as well as other public and private job boards are essential elements of the country's labour market information system.

TESDA's efforts to address the job-skills mismatch include the Job Bridging and Referral programme. This programme is aimed at shortening the job search period and assisting TVET graduates to find immediate employment, particularly TVET scholars. This is implemented through the establishment of Blue Desks in all TESDA regional and provincial/district offices, TTIs and private TVIs and the conduct of jobs bridging events all over the country. The Blue Desks served as one-stop shops for TESDA information and services to include, but not limited to, job referral and placement assistance services, career profiling and coaching.

\section{Continuing quality improvement in skills development provision}

Training programmes need to continuously adjust and adapt to technological changes and advancement. Training inputs such as curriculum, facilities, equipment, tools and materials need to be regularly upgraded. Trainers' have to be qualified and their competencies continuously upgraded. Institutionalising quality assurance mechanisms in all modes of training provision is an imperative. In the Philippines, TVET institutions' programme offerings comply with the minimum standards prescribed by industry as contained in the training regulations, through a quality assurance mechanism called the Unified TVET Program Registration and Accreditation System (UTPRAS). TVET graduates must also complete a mandatory assessment. Assessment and certification ensures that the TVET graduates and skilled workers have the necessary competences to perform the tasks consistent with the required standards in the workplace.

\section{Institutionalise the Philippine national qualifications framework and a system of skills/qualification progression/career shifts and lifelong learning}

The national qualifications framework (NQF) is an instrument for the development and classification of qualifications according to a set of criteria for levels of learning achieved.

Most countries have their own formally promulgated national qualifications frameworks (NQFs), whether in unified form for all levels (e.g. Australia, Scotland, South Africa) or for specific sectors (e.g. Singapore only has NQF for the technical education level).

Currently, NQFs are the starting point for comparing qualifications among countries. The PNQF was developed to establish a coherent national and internationally benchmarked structure for all qualifications awarded in the Philippines. The PNQF covers all levels of formal education from pre-school levels to doctoral degrees. Each level has specific descriptors in terms of learning outcomes. All qualifications listed in the PNQF are quality assured so that there is confidence not only in their academic standards and vocational relevance but also in the quality of teaching, assessment and the awarding of credentials. 
The PNQF may be used to:

- unify the three sectors of Philippine education;

- ensure that all qualifications have a purpose and relation to one another that the students and the public will understand;

- improve access to lifelong learning;

- improve quality standards;

- foster more innovation, improve relevance and responsiveness;

- be comparable with international benchmarks and international recognition.

\section{Expand access and equity to skills development opportunities}

Scholarships, student financial assistance and free training in public training institutions serve as mechanisms for expanding access and equity to skills development opportunities. Sustainable and adequate financing is crucial to address this concern.

Alternative modes of delivery in education and training such as online and blended learning, facilitated by ICT can also help expand access to skills development opportunities.

Education and training are recognised as tools for alleviating poverty. They serve as the common man's ticket to upward social and economic mobility. These opportunities must be made accessible and available to a broad range of clientele, particularly the poor and the marginalised sectors. Empowering the poor by providing them with employable and productive skills will help them get out of poverty.

\section{Increase and sustain investment in education and training}

The development of a strong skills base is critical to the country's economic growth and development. Education and training should be given top priority in the allocation of government resources. Quality training to produce competent and qualified workers requires adequate and sustainable financing.

\section{References}

World Bank (2010), "Philippine skills report: skills for the labor market in the Philippines", World Bank. 



\title{
Chapter 21
}

\section{An area-based approach to skills development in Australia}

\author{
by \\ Caroline Alcorso
}

\section{Post-school education participation and government targets}

In November 2008, the Council of Australia Governments (COAG) signed a National Skills and Workforce Development Agreement that sets out commitments to increase the skill levels of all Australians, including Indigenous Australians. It noted the need for action to:

- address gaps in foundation skill levels for the working age population to enable effective educational, labour market and social participation;

- $\quad$ ensure the working age population has the depth and breadth of skills and capabilities required for the $21^{\text {st }}$ century labour market;

- ensure the supply of skills provided by the national training system responds to meet changing labour market demand; and

- ensure skills are used effectively to increase labour market efficiency, productivity, innovation and ensure increased utilisation of human capital.

The agreement has targets for people with vocational and university qualifications, and commits to monitoring the literacy levels of working age people.

Current government targets are as follows (followed by a 2008 comparison):

- $40 \%$ of all 25-34 year-olds to have at least a bachelor's degree by 2025 (up from 32\%);

- $20 \%$ of higher education enrolments to be from students from low socio-economic backgrounds by 2020 (up from 16\%);

- halve the proportion of 20-64 year olds who do not have a qualification at or above Certificate III by 2020 (over 3 million more people with qualifications);

- double the number of higher qualification completions (diploma and advanced diploma) by $2020(+32000)$. 


\section{Skills development in small businesses}

\section{An ageing workforce implies increasing the training participation for older workers, the existing workforce and people in small businesses}

Small business becomes a key focus. Most larger companies already provide extensive training and make considerable use of the national qualifications system. Small businesses do not. They are less likely to use formal (nationally accredited) and structured training, and more likely not to train their staff at all.

Table 21.1. Use of the VET system and provision of training in the last 12 months by employer size, 2009

\begin{tabular}{lccc}
\hline & $1-9$ employees & 10-99 employees & 100+ employees \\
\hline Apprentices/trainees employed & 26 & 41 & 68 \\
Nationally accredited training used & 20 & 40 & 78 \\
Unaccredited training used & 44 & 72 & 95 \\
Informal training used & 72 & 88 & 93 \\
No training provided & 12 & 1 & 0 \\
\hline
\end{tabular}

Source: National Centre for Vocational Education Research (NCVER) (2010), "Employers' use and views of the VET system, 2009”, Tables 4 and 6, NCVER, Adelaide, South Australia.

SMEs are half as likely as medium-sized firms to use nationally accredited ${ }^{1}$ training, and also much less likely to engage apprentices or trainees.

\section{In Australia, most people work in small businesses}

In any case, the vast majority of businesses in Australia are small businesses, as classified by employment size $(<20$ employees $)$. Nearly two-thirds are very small or micro-businesses.

Table 21.2. Number of businesses by employer size, 2008

\begin{tabular}{lcc}
\hline & Number of businesses & \% of all employing businesses \\
\hline $1-4$ employees & 527450 & 63 \\
$5-19$ employees & 228310 & 27 \\
$20-199$ employees & 78300 & 9 \\
$>200$ employees & 5876 & 1 \\
Employing businesses & 839940 & 100 \\
Non-employing businesses & 1171830 & \\
\hline
\end{tabular}

Source: Australian Bureau of Statistics (ABS) (2010), "Innovation in Australian business, 2008-09", ABS.

Small businesses collectively employ nearly half the workforce (48\% in June 2009), with another $23 \%$ of employed people working in medium-sized businesses (less than 200 people). Twenty-nine per cent of the workforce work in the few large businesses that employ more than 200 people. 


\section{Why don't small businesses provide formal training?}

Small businesses are more likely than large ones to say their staff already have adequate skills or more skills than are needed, indicating many small businesses may not be seeking growth or change. Employer initiation of training is, however, often associated with innovation, growth or restructuring. Another reason could be that small businesses have less ability to make full use of their employees' skills, although the data on skill use suggests otherwise.

Table 21.3. Adequacy of employee skills by employer size, 2005*

\begin{tabular}{lccc}
\hline & $1-9$ employees & $10-99$ employees & $100+$ employees \\
\hline Skills of my workforce are above what is required & 40 & 30 & 24 \\
Skills of my workforce are adequate & 55 & 64 & 66 \\
Skills of my workforce are below what is required & 5 & 6 & 10 \\
\hline
\end{tabular}

Note: Employers were asked how adequate their employees' skills were relative to the needs of the organisation.

Source: NCVER (2006), "Employers use and views of the VET system, 2005”, unpublished data.

Informal learning, on-the-job learning and the use of business networks satisfy the needs of many small businesses. Not all identified business needs require a training solution: in many cases, timely technical and financial advice suffices. Not all small businesses employ people: many are sole operators. Not all small businesses want to grow: some people go into small business for lifestyle and work-style reasons, and growing bigger is at odds with these reasons.

Small business are generally less engaged with the formal training system and are less satisfied with it when they do use it. As well as not seeing the need for training, many small firms lack the financial resources, time and expertise to organise it. They dislike the bureaucracy it entails, and Australian research suggests many small businesses do not feel that training relevant to their business is actually available (Townsend et al., 2005). In a UK study, small firms reported that the most common routes to employee development were from "learning by doing" and through "discussions with their manager" (Green and Martinez-Solano, 2011).

There is also the awareness/information issue given SMEs may find it hard to locate training that suits them. The consultations undertaken by Skills Australia in preparation for the development of Workforce Futures (Skills Australia, 2009) elicited comments such as:

...many employers, particularly small and medium-sized enterprises, still find the VET system opaque, mysterious and inflexible. (Construction and Property Services Industry Skills Council)

...Methods of engaging small and micro-businesses are essential - they do not have [human resource management] departments to help them navigate this area. A programme to assist them will be important - this will need to allow for the full range of variables that can impact on SMEs, that is, not be narrow in concept. (Queensland Consultation Session) 


\section{Strategies that small businesses favour in Australia}

The findings of a systematic review of Australian and overseas research on training and small business undertaken in the mid-2000s (Dawe and Nguyen, 2007) drew some clear conclusions. Small businesses express positive views about training that:

- has a clear focus on business-specific needs;

- involves flexible and customised provision that carefully individualises content and delivery to their needs.

The review also concluded that small businesses are more inclined to take up training if the approach is personal, for example by a recognised local facilitator or organisation.

\section{Box 21.1. Ten factors contributing to successful strategies for small business}

This review found ten factors which contribute to strategies that work for small business:

1. Providing opportunities to share skills, knowledge and experience with other business people.

2. Linking training to business performance - increased profit, growth or survival.

3. Linking training to specific stages in the business cycle (start-up, crisis and/or survival, growth and/or expansion, and export and/or internationalisation).

4. Contacting small business managers personally to analyse their business needs.

5. Providing ongoing business-specific support through a business service organisation.

6. Minimising time spent away from the workplace.

7. Integrating formal training and learning with informal learning processes in the workplace.

8. Lowering costs of training by collaborating with other businesses or through financial incentives, such as a government subsidies or interest-free loans.

9. Ensuring that facilitators and trainers have the appropriate networks and experience to enable them to be trusted and respected by all business participants, especially in the case of Indigenous Australian small business operators.

10. Planning the strategy with small businesses and business service organisations.

\section{Focus on innovating businesses - linking training and innovation}

The Australian Government also has goals for industry innovation. Innovation is the major source of productivity growth in Australia, as wage levels are relatively regulated. In 2009 , it committed to a $25 \%$ increase in the proportion of businesses engaging in innovation in the ten years to 2019 and the improvement of innovation skills and workplace capabilities.

Weak innovation performance in Australian industry is largely the product of the weak innovation performance of small businesses, which, as shown earlier, make up the majority of firms. Large firms (200+ employees) are twice as likely to innovate as micro-enterprises $(<5$ people). 
Table 21.4. Innovation activity by business size, 2008-2009

\begin{tabular}{lcc}
\hline & Business size & \% of businesses that are innovation-active \\
\hline $0-4$ employees & 33 \\
$5-19$ employees & 48 \\
$20-199$ employees & 58 \\
$>200$ employees & 67 \\
Average & 40 \\
\hline
\end{tabular}

Source: Australian Bureau of Statistics (ABS) (2010), "Innovation in Australian business, 2008-09”, ABS, Cat no. 8158.0.

\section{Skill shortages hamper innovation more in small businesses}

During the early stages of the last growth cycle (2002-2003), when skill shortages were starting to be reported, small and medium-sized innovating businesses were more likely to report this as a factor hampering innovation than large ones. The issue was linked, in part, to whether the innovating businesses were foreign or domestically owned. As small businesses are more likely to be locally owned, they are not as able as larger ones to source talent overseas and within internal global labour markets (DITR, 2007).

Today, small and medium-sized innovating firms are reporting more difficulties with accessing suitable skills compared to larger firms. The gap between small and large firms on this issue is larger than for any of the other barriers canvassed in the survey; the next biggest gap comes in the extent to which access to funds hampers innovation.

Table 21.5. Barriers to innovation by business size, 2008-2009

\begin{tabular}{lcc}
\hline \multicolumn{1}{c}{ Business size } & Lack of skilled people in the business or the labour market (\%) & Lack of access to additional funds (\%) \\
\hline $0-4$ employees & 34 & 30 \\
$5-19$ employees & 31 & 30 \\
$20-199$ employees & 31 & 26 \\
$>200$ employees & 21 & 18 \\
\hline
\end{tabular}

Source: Australian Bureau of Statistics (ABS) (2010), "Innovation in Australian business, 2008-09", ABS, Cat no. 8158.0.

The gap appears to have widened over the six years between 2003 and 2009. In 2009, skill shortages were reported to be hampering around one-third of small and medium-sized businesses, compared to around one-quarter in 2003; there was a smaller rise in large businesses reporting that skills shortages hampered innovation from $19 \%$ to $21 \%$.

\section{Larger firms can better draw on expertise from outside the business}

The survey also suggests that larger firms have readier access to new sources of expertise, including new employees, graduates, external contractors, and higher education and research organisations, compared to smaller firms. 
Table 21.6. Sources of innovation by business size, 2008-2009

\begin{tabular}{lcc}
\hline \multicolumn{1}{c}{ Business size } & New employees (\%) & External expertise (\%) \\
\hline $0-4$ employees & 15 & 16 \\
$5-19$ employees & 29 & 19 \\
$20-199$ employees & 27 & 25 \\
$>200$ employees & 40 & 39 \\
\hline
\end{tabular}

Source: Australian Bureau of Statistics (ABS) (2010), "Innovation in Australian business, 2008-09", ABS, Cat no. 8158.0.

Where small firms operate in clusters or hubs, their ability to collaborate can be enhanced. The National Skill Ecosystem Program undertaken in the early 2000s was based on firms in an industry or region working together on skill and workforce issues that they collectively faced. The programme encouraged businesses to take more responsibility for solving their skills issues, but also encouraged them to work with outside experts (such as research institutes) that offered new ideas and approaches. Employer responsibility for the training and development of their own workforces was also required. Employers had to consider whether they as employers were offering people opportunities to access learning within their workplace, and how the skills that workers had were being used in the business, as well as the external training or new skills that their workers might need. ${ }^{2}$ Figure 20.1 is used in the National Skill Ecosystem Program to discuss this broader approach to skills.

Figure 21.1. National Skill Ecosystem Program: a broader approach to skills collaboration between wide range of parties needed

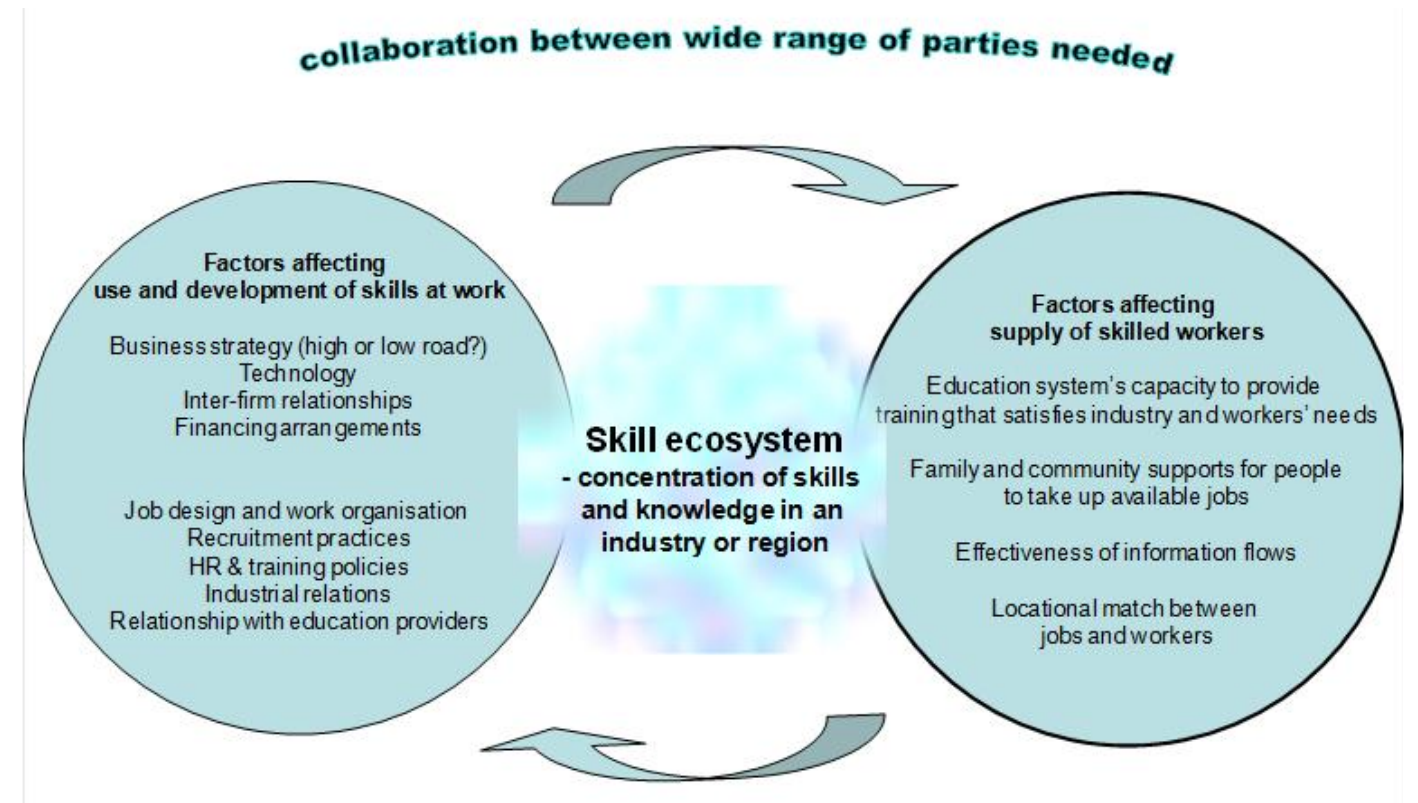




\section{How can we better connect small businesses with formal and structured training?}

Lessons for trainers from the National Skill Ecosystem Program include the following:

- Think of education and skills as just one ingredient in a matrix of factors that support economic growth, i.e. start with a business issue or opportunity and address training needs along the way.

- The work context is crucial in understanding skill formation - consider how to create more expansive learning environments and how skills will be used, as well as focusing on training outputs such as qualifications, i.e. ask how people are recruited, managed and developed in their work with the company.

- Alignment with business needs is also important: if employers and workers are involved in the design or training, it is more likely to be relevant and useful, while still leading to recognised qualifications.

- Take into account the effects of labour market fragmentation and changing industry structure - how can contingent workers and different workforce groups such as women and migrants be reached? i.e. consider the needs of casual, part-time and contract workers, and spell out the firm's responsibility to include them in skill development activities.

- Work with business clients in terms of their relationships (as industry sub-sector networks, supply chains and regional groupings), i.e. address the issues that enterprises within an industry can agree to work on together; build the industry's capacity to solve its own issues.

- Integrate VET policy into labour market, employment, social and industry policy, i.e. establish programmes where trainers work alongside business advisers, industry consultants or community development agencies.

\section{Notes}

1. Nationally accredited training is training that leads to part or all of a nationally recognised qualification.

2. A guide to the skill ecosystem approach can be downloaded at www.training.nsw.gov.au/forms_documents/industry_programs/workforce_developm ent/skill_ecosystem/skills_in_context.pdf while additional material can be located at www.training.nsw.gov.au/businesses/training_options/managing_workforce/skill_eco system.html. 


\section{References}

Australian Bureau of Statistics (ABS) (2010), "Innovation in Australian business, 200809", ABS.

Dawe, Susan and Nhi Nguyen (2007), Education and Training that Meets the Needs of Small Business: A Systematic Review of Research, NCVER, Adelaide, South Australia.

Department of Industry, Tourism and Resources (DITR) (2007), "Aspects of skill shortages and innovation in Australian businesses: An analysis of the 2003 Innovation Survey data".

Green, A. and L.E. Martinez-Solano (2011), "Leveraging training skills development in SMEs: an analysis of the West Midlands, England, UK", OECD Local Economic and Employment Development (LEED) Working Papers, No. 2011/15, OECD Publishing, Paris, http://dx.doi/10.1787/5kgOvststzr5-en.

National Centre for Vocational Education Research (NCVER) (2006), "Employers use and views of the VET system, 2005", unpublished data.

NCVER (2010), "Employers' use and views of the VET system, 2009", Tables 4 and 6, NCVER, Adelaide, South Australia.

New South Wales Department of Education and Training (2008), "Skills in context: a guide to the skill ecosystem approach to workforce development", Sydney, Australia, www.training.nsw.gov.au/forms_documents/industry_programs/workforce_developme $n t / s k i l l \_e c o s y s t e m / s k i l l s \_i n \_c o n t e x t . p d f$.

New South Wales Department of Education and Communities (n.d.), "Skill ecosystems", State Training Services, NSW Department of Education and Communities, Sydney, Australia, www.training.nsw.gov.au/businesses/training_options/managing_workforce /skill_ecosystem.html.

Skills Australia (2009), "Consultations on workforce Futures, the National Workforce Development Strategy", Commonwealth of Australia, Canberra, www.skillsaustralia.gov.au.

Townsend, Ray, Peter Waterhouse and Marg Malloch, (2005), Getting the Job Done: How Employers Use and Value Accredited Training Leading to a Qualification, NCVER, Adelaide, South Australia. 


\title{
Chapter 22
}

\section{Challenges and strategies in the local partnership approach to training in Japan}

\author{
by \\ Yoko Nitta
}

\section{Introduction}

Japan needs an innovative local approach for building effective local partnerships. Self-support is imperative and effective co-ordination a must.

There are many stakeholders involved in local partnerships and each one must be given due credit for the role they play in order to avoid conflicts. It is important to let the locals take the initiative if they have sufficient management capacity. How can consensus building efforts in local partnerships be facilitated? How can the project leader ensure that the partnership remains sustainable after s/he leaves? Sustainability, partnership, paradigm shift and real democracy are keys to making it happen.

\section{Critical issues}

\section{Funding}

There is a funding dilemma. Including as many learners as possible results in high dropout rates among participants in the hardest to reach groups, resulting in a lower return on investment and decreased interest on the part of agencies or sponsors in providing further funding.

The funding mechanism it is therefore hampered by including the most problematic groups. Business investment is, however, necessary and incentives can include businesses' PR strategy and seeking business opportunities.

\section{Barriers}

Funding is distributed on a project basis, which affects continuity and the sense of direction of the initiatives. Changes in the allocation of the funds that accompanies changes in the number of members or of national governments tend to cause similar discontinuities. The nature of the centres and partnerships changes whenever a new sources of money come into play. This also seems to indicate that the initiative still remains too much in the hands of the authorities and not enough of the people themselves. 


\section{Partnership model}

To some extent, models for local partnerships depend on national traditions and culture. But in general, more traditional systems tend to be more centralised and government-driven, whereas more developed systems have more diversified partnerships and provision. It is important for the government first to develop its own position on the issue and then to take into account the preferences of all parties involved.

It must be kept in mind that young people should be approached using different methods and instruments than those used for other learners, with a focus on work and employment, while training for elderly people should be more focused on learning ICT skills, basic skills and social cohesion.

\section{Discussions}

There may be some divergence in trying to make learning attractive and the effects it policy makers expect it to have on employment. Should the focus be on learning first, hoping employment perspectives will come with it? Or should the focus be on employment issues from the start? Stakeholder involvement is necessary for local partnerships. Does too much involvement from government organisations in the funding of initiatives discourage other actors - employers, sponsors, clients, participants and stakeholders - from becoming involved? Initiatives that involve a wider variety of partners are more dynamic and creatine and are better able to cope with changes. Therefore, multiple sources of funding means greater continuity, more partners often implies a multi-disciplinary approach - which may enhance the transfer of learning to a work situation.

\section{In-company training or staff development}

Both companies and workers benefit from fostering social relations and improving social well-being. Creating opportunities for the unemployed to take part in in-company learning projects would be beneficial to the trainees as they would acquire qualifications/skills as well as for the companies who would establish a pool of potential new employees. Various other activities aimed at supporting adult learning within work or other aspects of life may offer more, yet unknown, opportunities. If employment is a goal of training, it is wise to involve employers in partnerships with the community and/or political parties.

\section{Organising local learning centres and partnerships}

Bottom-up developments, grass-root movements, and incidental initiatives tend to lead to partnerships in which training providers co-operate and seek funding from other sources. Those who provide funding form the core of the partnership and the decision-making unit. When the local authorities take the initiative, a partenership structure is set up but they tend to keep the decision making for themselves, sometimes letting those who should be partnership facilitators assume the role of deliberations, negotiations and co-operation between partners. 


\section{The way forward}

The following problems need to be solved in the future:

- co-ordinating vocational training;

- involving industries;

- improving placements. Placement services should take into account of incentives effectively;

- responding to the market/meeting employers' demands. 



\section{Part IV}

\section{Green growth and local transition}





\title{
Chapter 23
}

\section{Green job creation in Korea: issues and policies}

\author{
by \\ Seung Teak Kim \\ and Kyungsoo Choi
}

\section{Introduction}

On 15 August 2008, at a national speech commemorating the $60^{\text {th }}$ anniversary of Korea, President Lee Myung-Bak announced the "low-carbon, green growth strategy" as a new vision for the country's sustained economic growth. Six months later, in January 2009, the Korean Government set up an economic stimulus package amounting to USD 28.1 billion to mitigate the deepening recession. Eighty percent of the total budget for the stimulus package was allocated to environment-related projects such as freshwater, waste management, energy efficient buildings, renewable energy, low-carbon automobiles, and railroad networks. This is the largest comparable stimulus programme in G-20 countries. On 6 July 2009, the government announced a "Five-Year Green Growth Plan", which is meant to be a medium-term guideline to put the green growth strategy into practice. With total funding of USD 83.6 billion, amounting to $2 \%$ of GDP, this five-year plan aims to substantiate the strategy with concrete and operational policy initiatives in order to achieve green growth over the period from 2009 to 2013.

By extending the temporary recession measure, named the "Green New Deal", to a full five-year plan, the Korean Government showed that it views green growth as a strategy well beyond the current economic recession and as its economic future. The government has committed itself to moving away from the traditional "brown economy" and growth-at-any-cost model to a "green economy" model with long-term prosperity and sustainability as its key elements. Korea's commitment may potentially create a domino effect on the other Asian economies.

The Korean economy has higher fossil fuel dependence than any other economy and is hence very vulnerable to external energy shocks, whether price hikes or resource shortages. Korea's dependence on imported fossil fuel in its total energy consumption is as high as $97 \%$, and thus oil price shocks as well as its secular rise as a consequence of the peak of world oil production has long been threatening the economy's sustained growth in the long term. The economy has been seeking a transition to a technological progress and innovation-led growth path to spur new and sustained growth. 
One of the most important commitments that the Korean Government has made is its voluntary adoption of a mid-term green-house gas (GHG) reduction goal, although Korea is not among the Annex I countries of the United Nations Framework Convention on Climate Change (Kyoto Protocol) and therefore it is not required to commit to such a GHG emission reduction goal. On 17 November 2009, it announced to voluntarily adopt a mid-term GHG reduction goal to reduce GHG emissions by as much as $30 \%$ from the business-as-usual (BAU) level by 2020. The goal is the most ambitious among the Non-Annex I countries. The initiative has been applauded by UNEP who recommended aiming for an even higher target for Korea's future energy security in view of its own green growth strategy and plans (UNEP, 2010). By setting a voluntary reduction goal, the Korean Government wanted to advance two agendas: first, Korea can join the leading group and grasp the opportunities created by an early transition to a green economy. Second, the government can send a strong signal to domestic industries and consumers, and urge them to make the necessary transition.

\section{Korea's National Green Growth Strategy}

The Green Growth Strategy sets out Korea's goal to become one of the seven largest economies in green industries by 2020, and one of the five largest economies by 2050 . The strategy consists of three pillars: reduction of greenhouse gas (GHS) emissions and raising energy security; creation of new growth industries through green technologies and innovations; and transition to a more environmentally sound and sustainable lifestyle.

\section{Figure 23.1. Korea's National Green Growth Strategy}

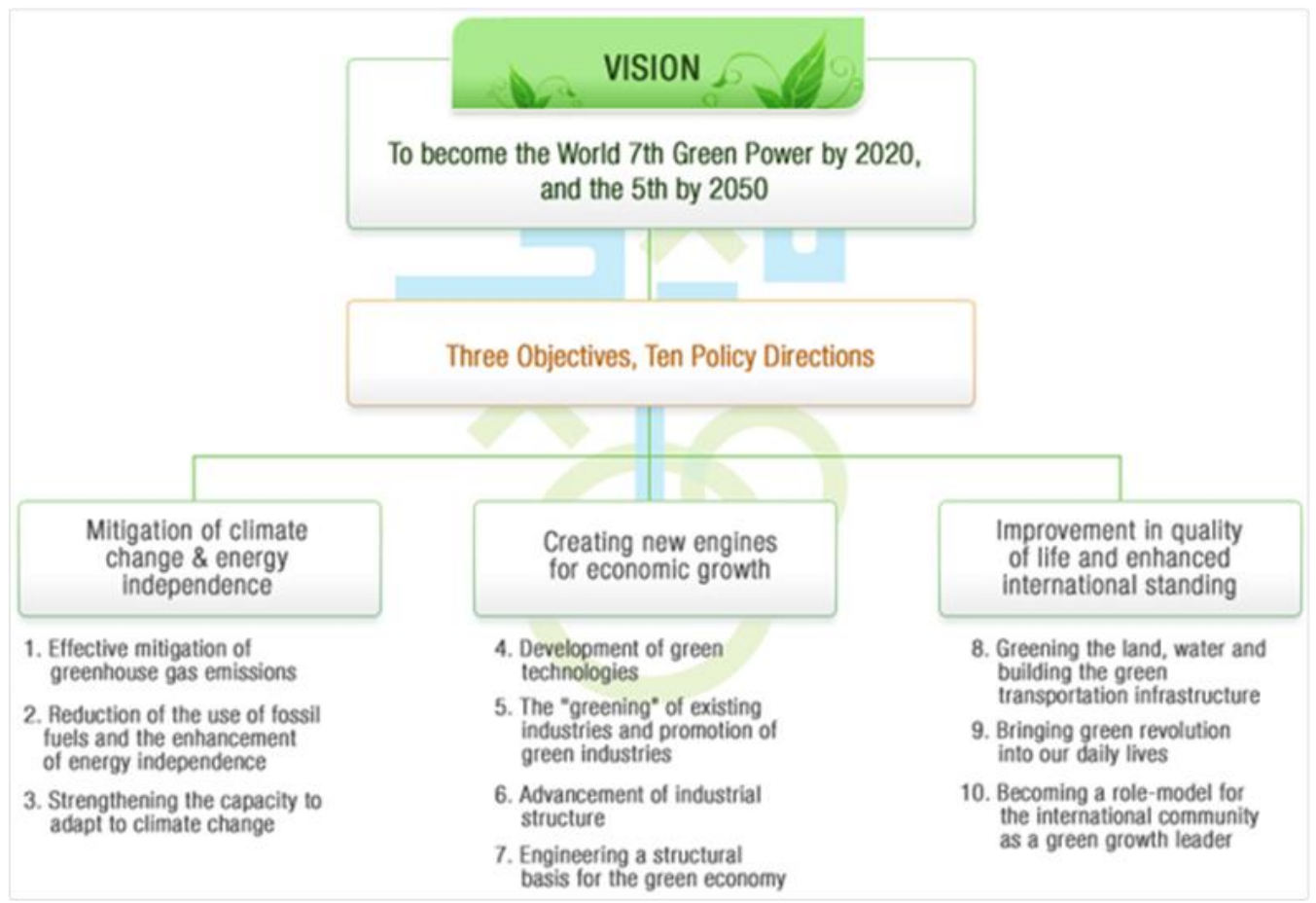

Source: www.greengrowth.go.kr/english/en_policy/en_strategy/en_strategy.cms. 
Korea's Green Growth Strategy aims to achieve the 30\% reduction goal using technological and regulatory means. Technological means include green buildings and highly energy-efficient buildings. A low-carbon transport system will replace the existing system. The share of new and renewable energy in total power generation will be raised from $2.4 \%$ in 2007 to $4.3 \%$ in 2015 and to $6.1 \%$ in 2020 and to $11 \%$ in 2030 . Twelve new nuclear power plants will be added to the existing 20 by 2030 to decrease coal consumption. The government will expedite development of Smart Grid system and Carbon Capture and Storage (CCS) technology as well as the next-generation green autos, opening new technological opportunities via strong demand-side management (DSM) measures.

Regulatory policy means include a target management system (TMS), an emissions trading system (ETS), and carbon tax measures. Under the target management system, large carbon dioxide emitter factories will be targeted and regulated. A large amount of subsidies, in the form of loans and tax breaks, will be extended for the installation of energy-efficient and low-carbon facilities. An emissions trading system (ETS) is planned to be introduced in steps starting from 2015. Under the ETS system, GHG emissions will be traded among the emitter companies. The introduction of a carbon tax has been under consideration for several years but no definite schedules have been set yet in the face of strong resistance from industries. The share of new and renewable energy in total energy consumption stood at $2.7 \%$ in Korea as of 2009, a much lower level compared to those of the EU, the United States (5.7\%), and Japan (3.4\%). The government has set a goal of raising this share to $4.3 \%$ by $2015,6.1 \%$ by 2020 , and $11 \%$ by 2030 .

\section{Job creation in green growth}

Korea views the transition to a green economy both as a challenge and an opportunity. Faced with the declining job creation potential of industries, the country seeks in green industries a new job creation engine and an opportunity to move up in the value chain of global production, as it seized the opportunity and benefited from the transition to the information and communication technology revolution a decade ago.

To evaluate the employment impact of the green growth initiative in Korea, one needs to set the definition of green jobs appropriately. But green jobs are defined in various ways. The existing literature defines green jobs as follows:

- In the narrow sense, green jobs are "low-carbon, green industry" jobs in new energy industries (renewable energy, substitute energy development, and energy saving) and in environmentally friendly industries (organic agriculture, recycling, environmental services).

- In the broader sense, green jobs are those jobs created by the transition to an environmentally friendly economy. Included under this definition are all the jobs related to green growth and the jobs created by transformation of the economy to a green economy (UNEP, 2008).

Difficulties in identifying green economy-specific jobs from the national statistics data forces us to adopt the second, broader definition, and the estimates reported below are the size of employment induced by the investments for a green economy. 
On 11 September 2008, Korea's newly inaugurated Growth Planning Board announced an investment plan in new industries for five years amounting to KRW 102 trillion (which is roughly equal to USD 102 billion). The areas of investment are:

- $\quad$ energy and environment: KRW 30.5 trillion (29.6\%);

- transport: KRW 2.0 trillion (2.0\%);

- new information technology: KRW 28.3 trillion (27.5\%);

- convergence technology industries: KRW 34.5 trillion (33.5\%);

- bio-industry: KRW 0.9 trillion (0.9\%);

- $\quad$ knowledge services: KRW 6.6 trillion (6.5\%).

An input-output analysis can be applied to compute the implication of this investment plan on employment, showing that the investment would bring about 1.43 million jobs, of which roughly 1 million (70\%) are wage and salaried worker jobs. Out of the total KRW 102 trillion investment, KRW 60.3 trillion (58.6\%) can be categorised into environment-related industry investment with a job creation effect estimated at 800000 jobs. Among the remainder, KRW 2.8 trillion (2.7\%) are in green energy industries, with job creation effect estimated at 0.04 million jobs. By occupation, among the 1.43 million jobs, the largest increase is among clerical jobs ( 0.25 million $)$, followed by operatives ( 0.18 million), labourers ( 0.17 million), and assemblers ( 0.10 million). Among professionals, 90000 engineers, 30000 scientists, and 20000 computer-related professionals are additionally needed.

\section{Policy issues}

The employment effects outlined above is not the net increase but the total increase induced by investments. For example, in McEvoy and Longhurst's (2000) study on job creation effects from the United Kingdom's renewable energy investment, if all the displacement effects are properly accounted for, the size of net job creation is one-fifth of the total job creation size. Figure 23.2 is a flowchart of green job creation and explains the labour movement that should be taken into account in measuring the net job increase. Thus, one should expect that in Korea's case too, the size of net job creation would be a small portion of what has been presented in the previous section.

Table 23.1. Expected employment effect from the United Kingdom's renewable expenditure, 1995-2005

\begin{tabular}{lc}
\hline \multicolumn{1}{c}{ Type of impact } & Employment change \\
\hline Gross employment & +44800 \\
"Conventional" displacement in the sector & -15200 \\
"Subsidy" displacement in other sectors (opportunity cost) & -16200 \\
"Waste disposal" displacement in the complementary sector & -4500 \\
Net impact & +8900 \\
\hline
\end{tabular}

Source: McEvoy, D. and J.W. Longhurst (2000), "Assessing the employment implications of a sustainable energy system: a methodological overview”, Geographical \& Environmental Modelling, 4(2): 189-201. 
Figure 23.2. Green job creation flowchart

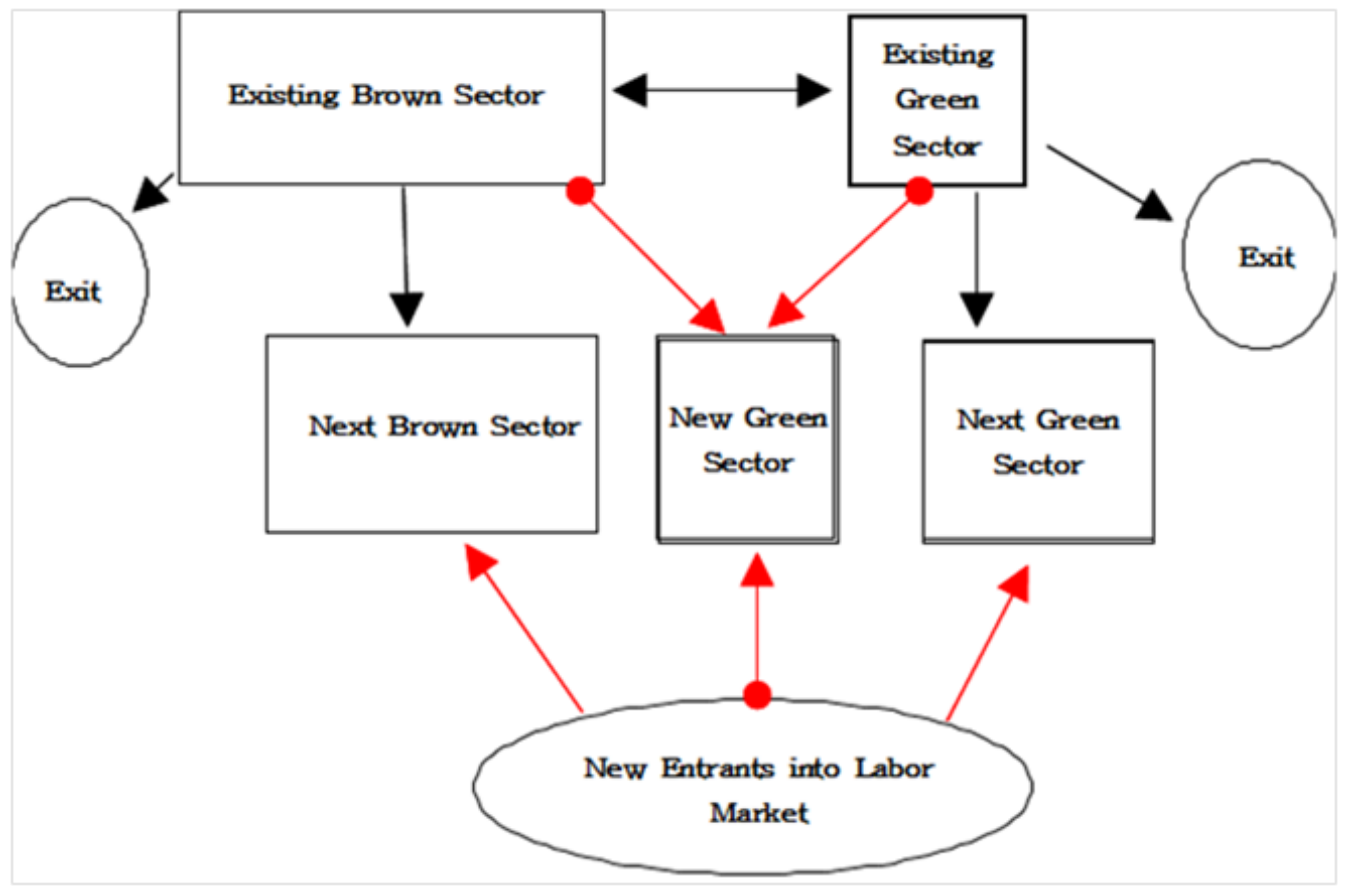

Source: McEvoy, D. and J.W. Longhurst (2000), "Assessing the employment implications of a sustainable energy system: a methodological overview”, Geographical \& Environmental Modelling, 4(2): 189-201.

However, Korea is faced with falling potential economic growth rates and employment coefficients, which are the ratio of jobs per output in economic sectors. Hence, the economy's job creation potential has dropped, leading to "jobless growth". Given the low feasibility for creating additional job creation in the existing sector, new industries and new businesses are viewed as important sources of additional job creation. Back in the 1990s, the IT industry was a new industry then but the industry eventually emerged as a leading industry in Korea.

For the green sector to lead job creation in the future, Korea needs new research and policy design in the area. More efficient and effective ways to create jobs through green growth need to be developed. And eventually, stronger green skills would lower the cost for the green industries and ultimately boost green growth.

The transition to a green growth strategy puts forward the following questions and issues to employment policy authorities:

1. What is its implication on employment?

2. What is the state of current manpower for green growth?

3. How large is the training demand for a green economy? 
On the labour supply side, authorities need to set up:

- Training programmes:

- education programmes for $\mathrm{R} \& \mathrm{D}$ specialists for green technology development;

- training programmes to facilitate the transition of the existing workers to green workers.

- ALMPs:

- job attachment programmes for disadvantaged job-seekers;

- ALMP in green sectors: invent new ALMPs in green sectors.

- Social safety net for displaced workers.

\section{References}

Kim, Seung-taek (2009), “Green Growth Job Creation Strategy”, Korea Labor Institute.

McEvoy, D. and J.W. Longhurst (2000), "Assessing the employment implications of a sustainable energy system: a methodological overview", Geographical \& Environmental Modelling, 4(2): 189-201.

United Nations Environment Programme (UNEP) (2008), Green Jobs: Towards Decent Work in a Sustainable, Low-Carbon World, UNEP, Nairobi, Kenya.

UNEP (2010), Overview of the Republic of Korea's Green Growth National Vision, UNEP, April.

www.greengrowth.go.kr/english/en_policy/en_strategy/en_strategy.cms. 


\title{
Chapter 24
}

\section{Skills development for green jobs in Singapore}

\author{
by \\ Bhavani Prakash \\ and Patrick Chan
}

\section{Introduction}

The island of Singapore, barely $710 \mathrm{~km}^{2}$, has achieved a high per capita income of SGD50 134 (USD 40 000) for its 5.18 million inhabitants (Straits Times, 2012). Accompanying this rapid economic progress, which has been deservedly earned through high governance standards, economic policies to attract investments and the hard work of the populace over the decades, is a large carbon footprint - one of the highest in the Asia-Pacific region on a per capita carbon emissions basis, according to World Wildlife Fund (WWF) (Straits Times, 2012).

The move towards a low-carbon economy is essential not only for reasons of moral leadership, but also for the practical imperative of ensuring the sustainable development of an interconnected region, from which Singapore imports a bulk of its resources. Becoming a hub for green technology and innovations, and the concomitant development of skills, are areas which will benefit not only green growth for Singapore, but also for the rest of Asia.

Green growth and green jobs creation could become an important factor in creating resilience in the labour market. Asia Business Council's report (2008) "Addressing Asia's new green jobs challenge" highlights:

Demographic structures in Asian economies vary, presenting different labour challenges. Japan, Taiwan, Korea and Singapore already face an aging population pyramid and will see an absolute decline in working age populations by 2025 . These economies will become relatively 'labour-poor' over time. The main challenge will be to employ workers in higher value-added jobs in order to ease growing dependency burdens, as well as find workers with the right skills for new, technologydriven industries.

To provide the context for skills development for green jobs in Singapore, it would be useful to look at the overall national targets for carbon emissions reduction and sustainable development. Singapore's national target is to reduce emissions by $7 \%$ to $11 \%$ below business-as-usual levels by 2020 . This will be raised to $16 \%$ in 2020 if there is a global agreement on climate change (National Environment Agency, 2010). 
In 2008, Singapore set up an Inter-Ministerial Committee on Sustainable Development (IMCSD) to develop a "national framework" and key strategies for sustainable development. A Lively and Liveable Singapore: Strategies for Sustainable Growth (IMCSD, 2009), which is also called "The sustainable Singapore blueprint", encompasses strategies to "improve resource efficiency in energy, water and waste management", "to be more cost effective and efficient in the long run" and "to enhance our physical environment through controlling pollution and beautifying natural bodies." The targets outlined in the document give an indication as to the country's priority areas for green growth such as the "aim to increase energy efficiency by $35 \%$ from 2005 levels by 2030 , "reach a recycling rate of $70 \%$ by 2030 and "aim to reduce domestic water consumption to $140 \mathrm{~L}$ per person from $156 \mathrm{~L}$ by $2030 . "$

Though green jobs creation has not as yet been identified in detail by way of a holistic national strategy filtering down to sectoral job creation targets, as recently as 1 March 2012, Deputy Prime Minister Teo Chee Hean said in Parliament, "We can create high-value jobs for Singaporeans and enable our economy to benefit from a green growth trajectory if we continue to strengthen and attract investments in green industries." $\mathrm{He}$ added that Singapore was "well-positioned to tap on the opportunities in this transition to a clean energy future" ( $\mathrm{Ng}, 2012)$.

An integrated national strategy on green growth and green job creation is a possibility in the future but at the moment, only fragmented sectoral data and information are available in the public domain. Some sectoral initiatives, however, are well established, and they can be traced back to a strong policy push and agenda.

\section{Roles of government agencies in green growth}

\section{Energy efficiency and the role of the National Environment Agency (NEA)}

A viewpoint often echoed by polity is Singapore's "limited ability" to tap into renewable energy (like wind, solar or tidal), hence the emphasis on "energy efficiency as the key strategy to reduce $\mathrm{CO}_{2}$ emissions" as highlighted by the National Climate Change Strategy (Ministry of the Environment and Water Resources, 2008).

This is a sector where there is a clear top-down mandate, and the emphasis on skills development is quite evident. As mentioned in the Singapore sustainability blueprint (IMCSD, 2008), the objective is to increase energy efficiency 35\% from 2005 levels by 2030. The Energy Conservation Act is expected to take effect in 2013, which "will require companies that use more than 15 giga watt-hours of energy per year, to appoint a trained energy manager to monitor and report energy use to the National Environment Agency (NEA) and submit improvement plans to improve energy efficiency" (Government of Singapore, 2012).

The National Environment Agency (NEA) is the government agency under the Ministry of Environment and Water Resources (MEWR) that is responsible for maintaining public health through environmental services including overseeing recycling and waste management.

According to the NEA Annual Report 2010-2011 (NEA, 2011):

The Singapore Certified Energy Manager (SCEM) programme offers formal training and certification in the area of energy management. Designed for engineering professionals who intend to build their careers as energy managers, the programme gives a thorough understanding of the key energy issues either in the building or 
industry sector. It also helps participants develop the technical skills and competencies needed to manage energy services and perform management work within their organisations. Jointly administered by NEA and the Institution of Engineers, Singapore (IES), it has two certifiable levels - the Associate and Professional Levels.

It is interesting to note that the government agency for business development - the Economic Development Board (EDB) - and the National University of Singapore (NUS) had already started the skills development process back in 2006, when the SCEM programme was instituted. NEA started offering training grants for the SCEM programme in 2008 in anticipation of the requirement for trained managers by the time the Energy Conservation Act comes into force in 2013. NEA aims to train 1000 managers. About 250 have already received their certification.

The importance of strategic knowledge transfers cannot be understated. To this end, the Singapore Environment Institute (SEI), the training division of NEA, invites leading practitioners and expertise globally into Singapore with regular courses and talks for industry and the public. Knowledge areas include waste management, pollution control, resource conservation, energy efficiency, environmental governance and climate change.

\section{Green building and the role of the Building and Construction Authority (BCA)}

The World Wildlife Fund's (WWF) "Asia footprint report", which is due to be released in June 2012 (Straits Times, 2012), mentions Singapore's high per capita carbon footprint in Asia-Pacific, pointing to the country's construction industry as one of the reasons for high emissions. However, even though data is not available as to the target emissions reduction for this sector, or whether the objectives of the strategy policy document called the "Green Building Master Plan" will achieve this, an important point to note is that the Building and Construction Authority's (BCA) efforts have enabled a lot of progress in the area of skills development in Singapore. The BCA is a statutory board under the Ministry of National Development, with the objective of developing a high-quality, safe and sustainable built environment in the country.

The Green Building Master Plan sets out specific initiatives to green the built environment in Singapore. The aim is to green $80 \%$ of buildings in Singapore by 2030, by meeting the Green Mark building certification standards (Building and Construction Authority, 2009).

BCA's Annual Report 2010/2011 (2011) estimates that at least 18000 to 20000 "green specialists" are required by 2020 in the building sector. To achieve this, BCA has created various courses for Green Mark managers and professionals, and has already trained more than 700 Green Mark professionals, managers and facilities managers.

BCA is addressing skills development at the executive level too. For example, it has conducted 23 courses on sustainability including the Master of Science programmes in collaboration with the University of Nottingham and University College London. Its executive development courses include BCA-HFT Stuttgart Executive Development Programme on Innovations in Sustainable Design \& Technology, and BCA-Carnegie Mellon University Executive Development Programme on Leadership in Environmental Sustainability conducted in Pittsburgh (Pennsylvania), United States. 
Building Information Modelling (BIM) is one of the key technologies identified under BCA's SGD 250 million Construction Productivity and Capability Fund (CPCF). BCA sees technology as an essential tool for enabling the design and innovation of sustainable buildings by enabling better communication and collaboration between architects, engineers and contractors. It also helps designers save valuable resources through energy analysis on virtual building models.

The clear strategic direction in this area is evident from the funding and skills development thrust. About SGD 6 million has been earmarked under CPCF to help companies with training, consultancy, and software and hardware implementation, with a target to get $80 \%$ of industry to use BIM by 2015 .

To accelerate the adoption of technology, BCA is also introducing a Specialist Diploma in BIM. It is building up a core team of BIM specialists within its Centre for Construction IT (CCIT) to guide newbies in industry on BIM projects. In addition, BCA is engaging universities to introduce BIM into the curriculum.

BCA's roadmap includes creating a "smarter construction workforce". BCA has worked closely with the Ministry of Manpower (MOM) to implement a tiered-levy framework to encourage and incentivise companies to retain and upgrade their skilled employees. Class 1 general builders undertaking projects valued at SGD 20 million and above are required, under law, to deploy registered personnel to the projects. These personnel are certified under the Construction Registration of Tradesman (CoreTrade) scheme which results in qualified, skilled and experienced supervisors and tradesmen in the construction industry.

\section{Sustainable water solutions and the Environment and Water Industry Programme (EWI)}

Given the strong desire for Singapore to become less reliant on imported water from Malaysia, it comes as no surprise that the country regards water as a strategic resource. It also flows that there is a lot of emphasis being placed on developing a robust water ecosystem, with encouragement being given to research and industry-university tie-ups, for testing and commercialisation of technologies.

Singapore aims to become self-sufficient by 2060. Desalination and NEWater (reclaimed water) are targeted to provide $80 \%$ of Singapore's water needs by 2060 . The Environment and Water Industry Programme Office (EWI), an agency led by the PUB Singapore's National Water Agency, the Economic Development Board (EDB) and International Enterprise (IE) Singapore has an allocation of SGD 470 million to promote research and development in the water sector as well as to develop manpower, and the commercialisation of technology.

This investment is expected to create 5500 jobs in 2003 to 11000 in 2015 as well as to raise the water sector's contribution to the economy from SGD 0.5 billion in 2003 to SGD 1.7 billion by 2015. According to PUB, "Investments by water companies between 2006 and 2010, when fully realised, will add SGD 590 million of annual value-add to our economy and generate 2300 professional and skilled jobs" (Prakash, 2011).

Against this background, it is interesting to have an idea of skills development taking place in the water sector. Through the initiative of the National Research Foundation (NRF) under the Prime Minister's Office, research and innovation in environment and water technologies is supported as one focus area. As a result, the Singapore-Delft Water Alliance (SDWA) has been set up as an inter-disciplinary research centre involving PUB 
Singapore, National University of Singapore (NUS) and Deltares (Netherlands). NUS and Delft University of Technology (TUD) have developed a double Master's programme in Hydraulic Engineering and Water Resources Management (HEWRM DDP) to train professionals with technical expertise in the area (Singapore Delft Water Alliance, n.d.).

Another corporate-academia partnership in this sector is that of the National University of Singapore (NUS) and General Electric (GE) which together launched the Singapore Water Technology Centre (SWTC) in 2009 to deliver effective water technology solutions. The focus of the centre is on low energy desalination. It will also look into developing safe drinking water systems for developing countries such as China and India and for the Middle East.

To develop the capabilities of the water industry workforce at the technician level, the Singapore Workforce Development Agency (WDA), the PUB, and the Singapore Water Association (SWA) have piloted a "Workforce Skills Qualifications (WSQ)" training programme called "Used Water Treatment Technician Programme" for the water industry" (WDA, 2010).

Given Singapore's ambition to become a global hydrohub (Prakash, 2011), it is to be expected that a lot of attention will be given to skills development, research and technological innovation in this area, and this could, through the sharing of expertise and governance standards, benefit the rest of Asia where acute water shortages are expected in the future.

\section{Certified Sustainability Professional and Green Collar Worker Programmes by Singapore Business Federation (SBF)}

As sustainability becomes an increasingly important business imperative, there is an increasing trend for setting up a sustainability office to co-ordinate and drive sustainability strategies and initiatives across diverse corporate functions at the highest level.

Whether it is a sustainability director of a property company or consultancy firm, or a sustainability officer of a manufacturing company, there is a growing proliferation of sustainability related roles across different levels and corporate functions in different types of organisations across a diverse spectrum of sectors. In Singapore, for instance, the CEO of Keppel Integrated Engineering is also the Head of Sustainable Development for Keppel Corporation.

There is an increasing market demand for sustainability professionals like engineering or audit professionals. The sustainability professional will need to combine sustainability domain knowledge such as engineering and environmental expertise with business and financial acumen to address sustainability opportunities and challenges that cannot be addressed by technical or business skills alone.

The Singapore Business Federation, the apex business chamber in Singapore, is working with institutes of higher learning partners such as the National University of Singapore and Temasek Polytechnic to produce Certified Sustainability Professional Training and the Green Collar Worker training programmes.

A training roadmap is expected to be charted out, with a range of training programmes developed for mass workers in the green economy right up to the level of chief sustainability officer. 


\section{Other sectors}

There are skills development processes in place in other sectors. In the waste management domain, according to the Singapore Workforce Development Agency (WDA, 2011), a government body to enhance the competitiveness of the workforce, "6000 local workers including public waste collection workers will be the primary beneficiaries of training and skills upgrading over the next five years through the Singapore Workforce Skills Qualifications (WSQ) programme for the Waste Management Industry". These include workers such as waste collection truck drivers, fleet and route co-ordinators, waste recycling workers, plant technicians and managers.

In 2009, the "Singapore sustainability blueprint" highlighted that the country aims to develop the clean technology or "cleantech" sector. Almost SGD 700 million (USD 470 million) has been set aside for R\&D and manpower training. Some SGD 3.4 billion (USD 2.4 billion) is expected to boost Singapore's economic output along with the creation of 18000 "green collar" jobs by 2015 (Singapore Economic Development Board, 2009).

Even though Singapore's land area is small, with limited scope for generating electricity from solar power, the government is ambitious in its plans to develop the country as a solar energy hub. A key initiative is a pilot project by the Housing and Development Board (HDB), the government body which builds public housing. It has set up the largest solar test-bed programme in the country, costing SGD 31 million (USD 31 million), and aims to install solar panels in 30 HDB projects by 2015 (Singapore Economic Development Board, 2009). A new national solar research institute was set up in 2008. The Solar Energy Research Institute of Singapore (SERIS) aims to develop critical solar technologies, and build skills in this area by training specialist manpower. SERIS has been established with the National University of Singapore (NUS), in partnership with the multi-agency Clean Energy Programme Office (CEPO), managed by the Economic Development Board (EDB) National University of Singapore, 2008).

Other areas are also emerging such as the Singapore Certified Green IT Professional (SCGP) by the Singapore Infocomm Technology Federation, an industry association for the ICT industry in Singapore (Prakash, 2012). The Singapore Manufacturing Federation and the Sustainable Supply Chain Centre of Asia Pacific are organisations that also have courses for industry on sustainable manufacturing and greening the supply chain respectively. There are also a few private educational and training institutes offering training in different domains such as energy efficiency and corporate social responsibility.

Various universities and polytechnics have gradually been increasing their offerings of environmental and sustainability courses over the years. Interdisciplinary courses are also emerging, such as the Master of Science in Environmental Management (MEM) programme of the National University of University of Singapore (NUS) which is a joint initiative of the Faculty of Arts and Social Sciences, NUS Business School, the Faculties of Engineering, Law, Medicine, Science and the School of Design and Management (National University of Singapore, n.d.).

\section{Conclusion}

It is encouraging to see various skills development initiatives in Singapore even though they are more pronounced in some sectors versus others. Where there are clear national targets, it is evident that investments in skills development have been channelled 
in those areas. However, these initiatives need to be integrated within a holistic, national strategy on green jobs creation. Such an integrated strategy is vital to link back to Singapore's commitment to its national target of carbon emissions reductions. This will then lead to a more holistic plan for all sectors for skills development, and the possibility of inter-sectoral linkages.

There are many questions that can be used as pointers for further study and policy action, a few of which are outlined below:

- How can a national strategy on green jobs creation be created, linking to the overall carbon emission reduction goals, and how will this translate to skills development in the green jobs sector?

- Are there other missing areas or opportunities which could help position Singapore as a regional hub for developing technology prototypes and best practices for it to become a regional hub for green skills development?

Examples are food security and sustainable sourcing of inputs for manufacturing. Food security is an important issue for Singapore as it imports over $90 \%$ of its food requirements. As it sets up contracts for food sourcing from other countries like China, India, Malaysia or Africa, can it develop or invest in skills in sustainable farming practices that actually bring benefits both up and down the supply chain? Sustainable development of these food sources will become critical for future food supply for Singapore, and the countries concerned. This will go hand in hand with Singapore's growing expertise in water technologies that can assist with sustainable farming. Another area is sustainable sourcing of inputs for greening the manufacturing supply chain. Singapore imports most of the materials needed for the building sector from overseas. Can it establish best practices for its sub-contractors and develop or invest in skills that create a ripple effect down the supply chain, both in terms of environmental sustainability and social equity?

- Which is more effective, mandatory pressure or a voluntary approach for fostering skills development? In the case of the Singapore Exchange (SGX), it has not yet mandated sustainability reporting for companies in Singapore. Is this an example where trainers are leading the way, before demand builds up from the industry, or will a government mandate accelerate the process? What are the challenges in either approach and how can they be overcome?

- What role does the private sector play? There are many examples of private sector participation in skills development in Singapore. Is this being nurtured and encouraged adequately and across sectors? Can industry be engaged more actively to see if there are skills that are hard to obtain currently? How can these gaps be addressed?

- Is there a need for more interdisciplinary courses and interdisciplinary professionals with a focus on "systems thinking" and a holistic look at problem solving? Is there sufficient cross-sectoral industry interaction, and industry-government interaction to brainstorm on problem solving in critical sustainability issues?

- How does green growth and green job creation address social equity issues in Singapore?

Hopefully the process of answering some of these key questions will not only help Singapore accelerate its skills development process, but also play a critical role in imparting these skills across the region. 


\section{References}

Asia Business Council (2008), “Addressing Asia's new green jobs challenge”, Asia Business Council, Hong Kong, China, www.asiabusinesscouncil.org/docs/GreenJobs. $p d f$.

Building and Construction Authority (2009), "The Green Building Master Plan", Building and Construction Authority, Singapore, www.bca.gov.sg/GreenMark/others/ gbmp2.pdf.

Building and Construction Authority (2011), Building and Construction Authority Annual Report 2010/2011, Building and Construction Authority, Singapore, www.bca.gov.sg/AboutUs/others/arl1.pdf.

Government of Singapore (2012), Energy Conservation Act, http://app.mewr.gov.sg/data/ ImgCont/1386/2.\%20Factsheet_Energy\%20Conservation\%20Act\%20\%5Bweb\%5D.p $d f$.

Inter-ministerial Committee on Sustainable Development (2009), A Lively and Liveable Singapore: Strategies for Sustainable Growth, Ministry of the Environment and Water Resources and Ministry of National Development, Singapore, http://app.mewr.gov.sg/data/ImgCont/1292/sustainbleblueprint_forweb.pdf.

Ministry of the Environment and Water Resources (2008), "National Climate Change Strategy", Government of Singapore, Singapore, March, http://app.mewr.gov.sg/web/ Contents/ContentsNCC.aspx? ContId $=456$.

National Environment Agency (2010), Singapore's Second National Communication: Under the United Nations Framework Convention on Climate Change, November, National Environment Agency, Singapore, p. 20, http://app.mewr.gov.sg/d ata/imgCont/1439/singapore_snc2010.pdf.

National Environment Agency (2011), Safeguard, Nurture, Cherish: National Environment Agency Annual Report 2010-2011, National Environment Agency, Singapore, www.nea.gov.sg/cms/ar2011/NEA-AR-2010-2011.pdf.

National University of Singapore (n.d.), "Master of Science in Environmental Management", National University of Singapore, Singapore, www.sde.nus.edu.sg/acad/mem.

National University of Singapore (2008), "New Solar Institute at NUS to conduct world-class R \& D and train specialist manpower", News Hub: NUS' Newsportal, NUS, Singapore, 21 February, http://newshub.nus.edu.sg/pressrel/0802/080221.php.

$\mathrm{Ng}$, Esther (2012), "More measures being considered to tackle climate change", Today Online, 2 March, MediaCorp Press, Singapore, www.todayonline.com/Singapore/EDC 120302-0000050/More-measures-being-considered-to-tackle-climate-change.

Prakash, Bhavani (2011), "Drivers of the hydrohub", Green Purchasing Asia, Issue 6, November, www.greenpurchasingasia.com/pdf/GPA_NOVEMBER2011_Digital.pdf.

Prakash, Bhavani (2012), "Mok Chee Hong: Singapore certified green IT professional", Green Collar Asia, 6 March, www.greencollarasia.com/2012/03/02/mok-chee-hongsingapore-certified-green-it-professional-scgp. 
Singapore Delft Water Alliance (n.d.), "Master's programme overview”, Singapore Delft Water Alliance, Singapore, www.sdwa.nus.edu.sg/index.php?option=com_content\&vi $e w=$ article $\& i d=52 \&$ Itemid $=76$.

Singapore Economic Development Board (EDB) (2009), "S\$1 billion environmental blueprint to make Singapore a clean technology and urban solutions hub", EDB, Singapore, 3 September, www.edb.gov.sg/content/edb/sg/en_uk/index/news/articles/s_ 1_billion_environmental.print.html.

Singapore Workforce Development Agency (WDA) (2010), "Water industry courses with WSQ for greater productivity and sector competitiveness", 1 February, http://app2.wda.gov.sg/Web/contents/Contents.aspx?ContId=1033.

Singapore Workforce Development Agency (WDA) (2011), "Singapore waste management industry to get $\$ 5$ million WSQ training boost to raise productivity levels", WDA, Singapore, 12 August, http://app2.wda.gov.sg/web/contents/contents.a spx? yr $=2011$ \& contid $=1252$.

Straits Times (2012), "Singapore top carbon emitter in Asia Pacific: WWF", 5 March, www.straitstimes.com/BreakingNews/Singapore/Story/STIStory_773974.html. 



\title{
Chapter 25
}

\section{Educating for sustainability: Australian green skills initiatives and employment services}

\author{
by \\ Sally Sinclair
}

\section{Australia's green growth policy}

Green skills are referred to as skills for sustainability as they support environmental sustainability and better environmental outcomes, enable organisations to address changed operating environments and compliance frameworks, support improved business practices through the elimination of waste and inefficiency, and create natural and synthetic conditions that protect and preserve business continuity.

Australia's commitment to building a stronger, greener economy has seen the development of policies that will grow green collar jobs including energy efficiency strategies for households, industry and commercial buildings; rapid expansion of clean energy infrastructure; structural reform of emission-intensive industries; a cleaner vehicle fleet and public transport infrastructure plan, and targeted regional investment and industry planning.

Beneficial outcomes resulting from the development of these policies are the opportunities that green collar jobs bring to communities, and this is particularly important for communities that are deemed to be at high risk and vulnerable.

Subsequently developing a stronger, greener economy will require the re-skilling, cross-skilling and upskilling of new work practices and workers. This creates a window of opportunity, especially for disadvantaged and Indigenous groups, and to take advantage of this opportunity, educating communities early through the integration of the school system, VET system, trade colleges and universities is paramount in ensuring candidates, especially the disadvantaged and Indigenous groups, acquire the training necessary to gain the skills required to obtain sustainable employment in the green collar sector.

The achievement of a green economy requires a diverse range of workers with broad skill sets. In a number of cases, the move towards this achievement will have a minimal impact on a job role, for example building cleaners using environmentally friendly products. In other cases, the move will require a new set of skills that will necessitate additional training, such as plumbers installing rainwater tanks and grey water recycling systems. 
Studies conducted by the Australian Council of Trade Unions, the Australian Conservation Foundation and the Australian Commonwealth Scientific and Research Organization (CSIRO) on the impact of moving to a more sustainable economy have shown that it offers productivity benefits for Australia through the creation of thousands of extra jobs, as well as the re-creation of hundreds of thousands of existing jobs.

The National Green Skills Agreement between the federal, state and territory governments seeks to build the capacity of the vocational education and training (VET) sector to deliver the skills for sustainability required in the workplace and to enable individuals, businesses and communities to adjust to, and prosper in, a sustainable, low-carbon economy.

Included in the agreement are a number of important elements contributing to its advancement including the review and revision of training packages to incorporate skills for sustainability, the development of national standards of sustainability practice and teaching in vocational training, the upskilling of vocational education and training practitioners so they can offer quality instruction in skills for sustainability and the implementation of strategies to re-skill vulnerable workers in the transition to a low-carbon economy.

There are a number of barriers to the uptake and utilisation of sustainable knowledge and skills in the workplace with management playing a key role in promoting sustainability. The results from a survey conducted by the Australian Industry Group and Deloitte in 2009 of 500 CEOs in the manufacturing, construction and services sector, revealed that mangers are struggling with the concept of green skills.

Also, many small to medium-sized enterprises remain unconvinced by the arguments for sustainability, so it is important to link sustainability products, services and advice to a clear business case.

\section{The role of employment services providers}

Employment services providers play an important role in helping industry and business address emerging skills challenges in green collar jobs as their influence across the job market is significant. They have established systems, processes and tools to help mobilise suitable green collar job-ready candidates.

Employment services providers are able to advise their candidates on the prospects of green collar jobs. Then, by directing them to the appropriate training, the employment services provider not only assists in establishing a vocational career path for their candidates, they also facilitate the availability of job-ready labour.

As Australia works towards building a stronger, greener economy, it is evident that skills and training are central to building the capacity of businesses to work sustainability and that the focus is on useful, relevant and applicable knowledge about sustainability that candidates and employees can utilise.

Employment services providers are well placed to be a key participant in taking a lead role with vulnerable, "at risk" communities and workers exposed to de-carbonising transformation. 


\title{
Chapter 26
}

\section{Skills for low-carbon growth: an Indian perspective}

\author{
by \\ Sunita Sanghi \\ and Jeevan Sharma
}

\section{Introduction}

The rapid technological changes in general, and those associated with climate change in particular, along with the integration of a national economy in the world economy have an impact on the dynamics of economic growth and the international labour market. This labour market shift has implications for skills development policies for sustainable development. The "Green Job Report" (UNEP, ILO, IOE and ITUC, 2008) has estimated that efforts to tackle climate change could result in the creation of millions of new green jobs requiring new skills. The transition to greening requires an available workforce with skills that help in effective and efficient uses of natural resources and sustainable environment. The transition would open up ample opportunities both in existing (through greening) and new occupations. The creation of new jobs/greening of existing ones requires changes in public policies relating to economic, social, labour, skills and the environment for sustainable growth. In fact, the environmental aspect is to be an integral part of all policies.

Sustainable development has found a place in India's development strategy and has emerged as a focus area in the $12^{\text {th }}$ Five-Year Plan (2012-2017). The Government of India has formulated a low-carbon strategy with focus on agriculture, waste management, energy, transport and services sectors. The main challenges to be addressed for sustainable development include mapping skills, creating a registry of skills, infrastructure for skills development (both physical and human), involvement of the private sector and civil society, etc. It is thus urgent to put the necessary governance structure and co-ordination at the policy planning stage in place to achieve the objective making skilled manpower available for the existing as well as the new emerging occupations for a low-carbon economy.

The chapter is divided into three sections: the first section discusses the challenges and priorities for low-carbon growth and policy responses including skills at the local level; the second section analyses the challenges for skills development to meet the needs of the green growth strategy and the government's skill development strategy in general, and for meeting the requirement for sectors relevant for low-carbon growth in particular. the last section suggests a way forward for meeting the skills requirement of the green economy and for sustainable development. 


\section{Challenges and priorities for low-carbon growth and skills response}

India is one of the lowest greenhouse gas (GHG) emitters in the world, with emissions of 1.18 tonnes, which is nearly one-fourth of the global average of 4.38 tonnes and less than one-fifth that of the United States and China. India has announced its intention to reduce the emissions intensity of its GDP by $20 \%-25 \%$ of 2005 levels by 2020 by pursuing proactive policies while maintaining its growth process for inclusive growth (Planning Commission, 2011b). The low-carbon growth requires efficiently using resources in order to minimise the environmental degradation and conservation of natural resources. However, this needs to be supported by development policies and actions to ensure that outcomes are inclusive (UNCTAD, 2011). India has formulated a low-carbon inclusive growth strategy focusing on sectors which have an implication for sustainable environment viz. agriculture, transport, energy, waste management, etc. The strategy assumes that climate change mitigation policies differentially affect development objectives which include poverty alleviation, improvement in quality of life, distributive justice, job creation, competitiveness, industrial growth and improving the quality of the local environment (Planning Commission, 2011b). This needs to be achieved by policy coherence between developmental and environmental policies at all levels.

\section{Priorities and challenges for green growth}

The priorities for green growth include managing environmental degradation by improving activities in the economic sectors viz. agriculture, forestry, transport, energy efficient buildings, sufficient energy supply, waste management, improved health and sanitation facilities, etc. which would have impact on employment generation. These economic sectors are important in terms of greenhouse gas emissions, the use of natural resources as well as their contribution to the economy and employment. In a country the size of India, the challenges have different impact on different areas depending on location. The maintenance of environment and gainful employment is key for green growth (ILO, 2011). The key priorities and challenges for green growth can be summarised as:

- Managing environmental degradation in terms of controlling water, land and air pollution and restricting the loss of bio-diversity.

- Improving the well-being of the more than $30 \%$ of the Indian population living below poverty level and improving the working conditions of the $94 \%$ of the workforce working in the unorganised/informal sector ${ }^{16}$ with negligible or no social security.

- Sustaining agricultural growth and improving production to support livelihood and food security by addressing problems of soil degradation, drought, floods, excessive use of fertilisers, etc. There is huge pressure on cultivable land as $2.3 \%$ of world land supports $17.5 \%$ of the world population; $75 \%$ of land is dependent on monsoon ${ }^{17}$ and $68 \%$ of sown area is subject to drought in varying degrees affecting more than 50 million people.

- Managing water security with $4 \%$ of the world's water resources to support $16 \%$ of the world's population and $15 \%$ of livestock. Ground water ${ }^{18}$ is overexploited due to the unsustainable consumption pattern and unregulated extraction of ground water and contamination due to a discharge of toxic waste, inefficient irrigation and farming practices and overuse of chemical fertilizers and pesticides. 
- Loss of forest cover due to the conversion of forests to agriculture, settlement, infrastructure, illegal extraction grazing of cattle, etc. This leads to soil degradation, flood, droughts, etc.

- The contribution of the transport sector in India to greenhouse gas emissions increased from 6.4\% to 7.5\% between 1994 and 2007 (Planning Commission, 2011b). Reducing greenhouse gas emissions from the transport sector requires a shift away from road and air towards rail and water, in addition to improving the efficiency of individual modes of transport.

- The increase in solid waste and waste water output and its rudimentary disposal method is a cause of concern. There is urgency to treat waste and use it for energy and other products. ${ }^{19}$

- The use of alternative sources of energy and energy efficiency measures to meet shortages (2008/2009) of approximately $11 \%$ in energy terms and $12 \%$ in peak energy, with over 400 million people without access to electricity and $90 \%$ of rural India dependent on traditional fuels for cooking (ILO Conference, 2010).

\section{Policy and skills response at the local level for green growth}

The adoption of greener technology in the sectors identified by the low-carbon strategy would bring about a change in the occupational structure and associated skill sets of the labour market. The quantity and quality of jobs, as well as the availability of skills to access those jobs, affects the transformation to the green economy at the local level, particularly when a large part of the workforce is engaged in the informal sector and does not have any skill training (ILO, 2011). Green growth requires enhancing ecological sustainability. For this, India unveiled a National Action Plan on Climate Change with eight core national missions in 2008 (Table 26.1). State governments are also preparing state action plans in line with the national plan for sustainable environment.

Table 26.1.India's National Action Plan on Climate Change

\begin{tabular}{|c|c|c|}
\hline Mission & Objective & Responsible entity \\
\hline National Solar Mission & $20000 \mathrm{MW}$ of solar power by 2020 & $\begin{array}{l}\text { Ministry of Non-renewable Energy } \\
\text { Sources }\end{array}$ \\
\hline $\begin{array}{l}\text { National Mission for Enhanced Energy } \\
\text { Efficiency }\end{array}$ & $\begin{array}{l}10000 \text { MW of energy efficiency savings } \\
\text { by } 2020\end{array}$ & Ministry of Power \\
\hline $\begin{array}{l}\text { National Mission for Sustainable } \\
\text { Habitat }\end{array}$ & $\begin{array}{l}\text { Energy efficiency in residential and } \\
\text { commercial buildings, public transport, } \\
\text { solid waste management }\end{array}$ & Ministry of Urban Development \\
\hline National Water Mission & $\begin{array}{l}\text { Water conservation, river basin } \\
\text { management }\end{array}$ & Ministry of Water Resources \\
\hline $\begin{array}{l}\text { National Mission for Sustaining the } \\
\text { Himalayan Ecosystem }\end{array}$ & $\begin{array}{l}\text { Conservation and adaptation practices, } \\
\text { glacial monitoring }\end{array}$ & Ministry of Science and Technology \\
\hline National Mission for a Green India & $\begin{array}{l}6 \text { million hectares of afforestation over } \\
\text { degraded forest lands by the end of the } \\
12^{\text {th }} \text { Plan }\end{array}$ & Ministry of Environment and Forests \\
\hline $\begin{array}{l}\text { National Mission for Sustainable } \\
\text { Agriculture }\end{array}$ & $\begin{array}{l}\text { Drought proofing, risk management, } \\
\text { agricultural research }\end{array}$ & Ministry of Agriculture \\
\hline $\begin{array}{l}\text { National Mission on Strategic } \\
\text { Knowledge for Climate Change }\end{array}$ & $\begin{array}{l}\text { Vulnerability assessment, research and } \\
\text { observation, data management }\end{array}$ & Ministry of Science and Technology \\
\hline
\end{tabular}

Source: Ministry of Environment and Forests, "National Action Plan on Climate Change", Government of India. 
In addition to the above missions, a comprehensive approach to reduce emissions from deforestation/forest degradation with a focus on conservation, afforestation ${ }^{20}$ and the sustainable management of forests has also been initiated. The initiatives under these missions would create a large number of jobs. The policies adopted at national level and diverse methods used under them to address different challenges at local level have implications for employment and skills.

Sustaining agriculture through use of micro irrigation, national water management, pest management technologies

The government has been implementing a large number of programmes for increasing agricultural productivity with active involvement from all stakeholders' viz. farmers, scientists, research institutes, local bodies, NGOs, civil society. The development of location-/area-specific cost-effective, eco-friendly conservation and management technologies for better input efficiency, irrigation/water efficiency, micro-nutrient efficiency, fertilizer use, organic farming and dry farming are helping to sustain agricultural production and creating additional direct and indirect employment opportunities. The Government of India has a number of training programmes for training extension workers, farmers, etc. ${ }^{21}$

The use of traditional methods of micro-irrigation ${ }^{22}$ at the local level to mitigate the impact of droughts has revived the use of traditional water harvesting systems in various ecological zones in India. They have made check dams, johads, and other structures to harvest every drop of rain. Some of them have even harvested rooftop runoffs. In many places, these efforts have withstood the effects of recurring drought.

The development of the simple irrigation facilities has created jobs for local masons, illiterate and semi-literate village people, and extension workers. It has improved the availability of water on the one hand and income to the people and contributed to sustainable development. These projects do not require special skills and can be implemented with the help of the existing local workforce. There is not much investment involved in creating new technologies. The skill sets required are the same. The same is true for pest management (Meghalaya use of crabs): simple hands-on training for constructing and positioning the traps, and the principles of agronomic practices such as the number of traps to be placed in the field based on the level of infestation are needed to be imparted to the traditional farmers for protecting the crops from damage from pests. It emerges that the replication of the green technology in similar agro-ecological areas at the individual as well as the entrepreneur level through awareness generation and mobilisation can result in sustainable production. The Krishi Vikas Kendra is helping farmers.

\section{Recycling and waste management for livelihood security}

The different waste management processes involving manpower include collection, source separation, storage, transport, transfer, processing, disposal and recycling. Waste management creates direct and indirect employment and involves an array of low and high skills depending on the activity. It serves a twin purpose of generating employment and improving health conditions. The government has put in place the regulatory infrastructure as well as campaigning to generate awareness. ${ }^{23}$ NGOs play a critical role in motivating the rag pickers and promoting the three "Rs" (reduce, recycle, reuse), that is essential for preventing global warming and protecting the environment. NGOs are providing training to these waste pickers to convert waste into useful items. SEWA, in the 
Ahemdabad city of Gujarat, is playing a catalytic role in mobilising more than 30000 waste pickers.

The different waste treatment interventions are generating large employment in new occupations, in existing jobs, additional jobs in terms of numbers viz. waste collector, segregators, drivers, loaders, workers for treatment and processing, disposal, packers, and different occupations in recycling and energy generation and to sustain environment. Drivers, loaders and segregators are available. However, recycling waste for energy generation and composting requires skilled manpower. The Government of Delhi has set up plants for composting, producing energy from waste and recycling waste to produce products. There is a skills gap for processing and recycling waste to energy as well as for composting.

\section{Using alternative sources for energy supply and improving energy efficiency}

Strong emphasis has been placed on using alternative sources of energy to meet the growing energy requirements. Emphasis is placed on making India's development energy efficient based on non-fossil sources viz. solar, wind, hydro, biomass, etc. The rapid growth in the sector requires a pool of competent manpower to design, install and maintain the renewable energy system. For this, relevant courses at all levels of the skill pyramid to cater to the demand for a skilled workforce in new and existing occupations is necessary (Confederation of Indian Industry, Ministry of New and Renewable Energy and Government of India, 2010). It is estimated that renewable sources of energy would produce 3.5 million direct and indirect employment involving different tiers of government. There are training programmes initiated for solar and wind energy. Jobs in renewable energy cut across a wide spectrum of specialists and skills, including some generic (communication, engineers, community outreach, marketing, planning, finance, accounts, and IT skills) and some specialists. The key occupations in renewal energy include high-, medium-, and low-skilled occupations. However, in the Indian context, illiterate or semi-illiterate women are trained to take up these activities. The Barefoot College provides them with training in the assembly of solar lamps, lanterns and charge controllers, testing of their parts, fabrication of these parts, unit installation and maintenance. A large number of technicians is trained in these sectors. By the year 2015, it is estimated that in a high growth scenario, employment would be in the order of about 0.7 million and in the long term about 1.4 million in different occupations (Confederation of Indian Industry, Ministry of New and Renewable Energy and Government of India, 2010). There are skill gaps in both generic and specialist skills.

\section{Availability of clean drinking water and safe environment}

The availability of clean drinking water and safe environment is a must for a healthy life. The government has initiated many programmes using the community model. Community mobilisation has not only helped in achieving the objective but has also helped in generating employment using local sources. Village communities and NGOs play an important role in achieving these objectives. This also helps to empower local groups. This is supported by a large number of studies across India. The water and sanitation-related activities can be grouped into three categories, namely hardware operation, maintenance and monitoring, and social mobilisation. It requires master masons, village masons, mechanical fitters, caretakers, trainers, and motivators. It was found that for hardware, women were engaged with the help of trained village masons for safe drinking water. Operation, maintenance and monitoring has been the responsibility of the village community, trainers and caretakers. The village people had no previous 
experience but acquiring the masonry skills was not difficult. A strong emphasis was given on intensive, area-specific and time-bound social mobilisation activities for demand generation involving different skills sets. The training was provided to women involved in hardware management by village masons and training for operation and maintenance was provided by NGOs (Vipin Kumar, 2010).

\section{Restoring forests for sustainable environment}

Afforestation contributes to socio-economic development, employment generation, and infrastructure development. Intervention under the Mahatma Gandi National Rural Employment Guarantee Act, like water harvesting, recycling, installation of solar water heaters, tree plantations, composting, sustainable harvest of forest produce not only have direct employment benefits but in the process create green jobs. These activities have significant socio-economic benefits as they employ poor, unskilled and semi-skilled workers who are generally be able to do this type of work with minimal or limited training. Under this programme, jathropha and pongamia plantations are encouraged, which is helping to substitute diesel/ethanol with bio-fuels thereby reducing greenhouse gas emissions. This is creating direct and indirect employment on the one hand, and protecting the environment on the other.

\section{Energy management for a green economy}

The government is the key player in promoting and implementing energy conservation technologies. The Energy Conservation Act, Energy Conservation Building Code and Bureau of Energy Efficiency are facilitating the optimisation of energy consumption. The emphasis is placed on the construction of green buildings and greening existing buildings. A green building encompasses features such as sustainable site planning, optimum energy efficiency, use of renewable forms of energy, water and waste management strategies, use of fly ash bricks, etc. It provides direct, indirect and induced employment. Municipal corporations are providing incentives for the construction of green buildings. New technologies and a new management system gave rise to new skills as a result of green restructuring and to new occupations viz. energy auditing and efficiency services.

\section{Restoring eco balance through mass rapid transport and adoption of cleaner technology - Delhi Metrocompressed natural gas}

India is poised for rapid economic growth, which as per the approach to the $12^{\text {th }}$ Five-Year Plan, will largely come from manufacturing and service sectors. Since economic activities in these sectors are largely concentrated in urban areas, the environmental conditions of these towns and cities are important for India's growth. For cities and towns to be able to support the required level of activities, they must provide for easy and sustainable flow of goods and people. The availability of a fuel efficient and low emission transport system is necessary for maintaining eco-balance. Pollution from vehicles is hazardous to health and needs to be addressed by adopting suitable modes of transport using energy efficient clean technology, namely compressed natural gas (CNG) and a mass rapid transport system. The introduction of CNG and the metro has resulted in greening existing occupations and created new occupations as well. The Indian Institute of Technology (IIT) Delhi has initiated a course for the Delhi metro. The change in the economic activity for green growth requires government to play a catalytic role in terms of investment in innovation and devlopment of new technologies as well in an 
educational system to produce people with the right skills. The UNDP referred to environmentally friendly investment that can create employment for the poor, providing income on the one hand and rehabilitating/conserving the environment on the other hand (UNDP, 2009).

\section{Challenges for skills development and skills strategy}

The above analysis indicates that the transition to green growth has implications for employment generation and skills development. In Indian context, the skill response varied from sector to sector. While lower level skills such as masons, segregators, drivers, loaders, collectors, general mechanics, etc. were available locally, skills related to new green occupations were not available viz. processors, managers, etc. In some sectors, such as energy efficiency in buildings, agencies like the Indian Green Building Council and the Bureau of Energy Efficiency are conducting training programmes and a national certification examination for energy managers and energy auditors respectively. While the Ministry of Road and Surface Transport is organising training programmes for drivers and conductors of the CNG buses, courses have been introduced in ITIs to train mechanics for CNG buses and attendants on the CNG filling stations. Agricultural universities are offering degree courses in different agricultural-related disciplines. In addition, there are training institutes providing training on plant protection, pest management, and locust controls. Needs-based training programmes in new and emerging areas such as organic farming are organised by the Indian Council of Agricultural Research. Agricultural extension workers are providing timely information and advice to Indian farmers.

In the renewable energy sector also, there are a large number of sectoral training and research institutes, including for solar power (Solar Energy Centre for Development of Solar Energy Technologies); wind power (Centre for Wind Energy Technology; National Institute of Renewable Energy; Alternative Hydro Energy Centre). They are promoting power generation as well as providing some training facilities. In addition, the government has created the Indian Renewable Energy Development Agency which provides term loans for renewable energy and energy efficiency projects. The key challenges include:

- Increasing the capacity and capability of the existing system to ensure the availability of requisite skills and access to all.

- Promoting lifelong learning, maintaining quality and relevance, according to the changing requirements, particularly of emerging knowledge and green economy.

- Creating effective convergence between school education, various skill development efforts of government and between government and private sector initiatives.

- Capacity building of institutions for planning, quality assurance and involvement of stakeholders.

- Creating institutional mechanisms for research development quality assurance, examinations and certification, affiliations and accreditation.

- Increasing the participation of stakeholders, mobilising adequate investment for financing skills development, attaining sustainability by strengthening physical and intellectual resources. 
India is enjoying a demographic dividend vis-à-vis ageing countries. The government has set up a Co-ordinated Action on Skills Development with a three-tier governance structure for creating the necessary infrastructure to train a skilled workforce for the growing economy. The National Skill Development Policy (2009) envisaged the creation of 500 million skilled workers by 2022. Skills development has been taken in mission mode both at the federal and provincial levels. Various federal and provincial ministries/departments are running skills training programmes for generic and sector-specific skills. The 9000 plus industrial training institutes and more than 3500 polytechnics, in addition to the 8000 engineering/other degree institutions, are providing training for different skill levels. The course curriculum in ITIs is basically designed to provide basic skills in about 200 trades. Through the World Bank assistance, the Government of India has created 500 centres of excellence in specified trades. Efforts are also made to improve the training and development of the university faculties to increase the placement of trained workers and to arrange on-the-job training. The private sector has also been involved in the training efforts through National Skill Development Corporation to train people based on the market requirements. Therefore, industry is directly involved in the creation of skilled manpower. The current training capacity (about 4.5 million per annum) is not sufficient to meet the skills requirements of the growing economy. Sector skill councils are constituted for mapping the skills requirement of different sectors. A National Qualification Framework is proposed for the mobility of the trainees.

Although India has a National Skill Development Strategy and a Co-ordinated Action Plan for Skills,, there is no comprehensive strategy for promoting skills for a green economy in particular. In fact, the industry linkages with the training institutes for all skills are at a very nascent stage. The education and training system faces a number of challenges in meeting the skills requirement of the green economy. For example,e.g the system needs to be flexible to respond to the changing market environment, adequate availability of quality teachers; continuous revision of curriculum and upgrading of teacher's skills are important aspects. There is focus on upscaling the initiatives through setting up of sector skills councils which aims at complementing existing sectoral vocational education system to make available skilled manpower both in terms of quality and quantity for value chain requirements. So far 11 Sector Skills Councils have been set up in high growth sectors which are expected to generate employment.

\section{Policy recommendations}

India's low-carbon growth strategy would create millions of green jobs in different sectors requiring different skill sets and competency levels which may or may not be available in the current skill structure. The greening of the economy is generating a demand for new skills as new activities and new markets emerge. This also raises the demand for new competencies. Various central ministries working in the area of skills development are working in silos, although their initiatives have an impact on each other. The availability of an adequately trained workforce is becoming a key limiting factor in meeting the requirement of a transitory economy. Key recommendations are:

- Effective co-ordination, convergence and policy coherence at all levels among different central ministries/departments and educational levels for properly assessing the potential of green jobs/occupations and associated competency levels, thereby meeting the skills requirements appropriately. 
- Creating a labour market information system at national and state levels to get a clear picture of the skills requirements. This would help create adequate capacity for training in relevant sectors.

- Sensitising different stakeholders about environmental concerns in different spheres of economic activities through media campaigns, street plays, art forms, school curricula, etc. Educating workers, employers, civil society and policy planners would help in protecting the environment.

- Involving all of the social partners in skills development. India has a sound tripartite system where workers, employers and the government discuss all proposed changes to labour-related regulations. Since a large number of activities for the transition to a green economy are likely to be carried out in the informal sector, it is necessary to strengthen the regulatory framework. The current need is for effective dialogue at all levels to mobilise all stakeholders for a smooth transition and integrated policy response.

- Restructuring syllabi and curricula in training institutes to suit the green economy. A start has been made with the implementation of the Modular Employable Skills programme. However, in the absence of a detailed database on skills requirements, it has not been possible to design a curriculum for the skills required for green jobs.

- The training of trainers is important. The new skills needs should be identified early so that trainers are available and curricula is developed.

- Strict enforcement of the administrative and legal framework.

- Scaling up investment in green technology; the government should assume a catalytic role. The investment in clean development and green jobs has been growing fast in India in recent years as is evident from the government expenditure in some of the key ministries responsible for promoting a green economy. Such investment in clean technology has also created employment in green jobs. However, there is need is to scale up such investment both at state government and private level.

- Strengthening the ability of local enterprises and local training providers to develop innovative solutions for filling skills gaps.

- At the local level, interaction between employers and training providers is necessary for moulding training systems to new demands. The cluster approach as is followed in Gujarat can help in co-ordination and shared learning. 


\section{Notes}

The views presented herein are the authors' and do not reflect the views of the organization they are working for.

1. Unorganised sector and informal sector are used interchangeably in India. It is charecaterised by casual employment with minimal or no protection of employment and social security and absence of bargaining power.

2. South West Monsoon is showing an erratic pattern recently (Rainfall is erratic in 4 out of 10 years.), exposing farmers to many risks including droughts, floods, disease in both crops and animals and unpredictable market irregularities.

3. Ground water is overexploited in about $15 \%$ of the assessment blocks and about $14 \%$ of the assessment blocks fall in the category of critical and semi-critical blocks.

4. India waste generation stands at 0.2 to 0.6 Kilogram per person per day. In most cities waste disposal involve dumping it in the landfill. According to Energy Research Institute it would require $1400 \mathrm{Sq}$. Km area by 2047 for waste disposal.

5. India has launched a National Mission for a Green India in 2010 with the objective of doubling the area to be taken up for afforestation/eco restoration in India in the next 10 years, taking the total area to be afforested or eco restored to 20 million ha.

6. Indian Council of Agricultural Research conducts research on different aspects of improving the agricultural production, pest management, input efficiency horticultural products, organic farming, natural resource mangement band dissemination of information at the field level through krishi vigyan kendras. (http:// icar.org.in)

7. For micro irrigation Federal Government provides funds to the provincial governments through a Programme Called Accelerated Irrigation Benefit Programme. Besides this Ministry of Water Resources also provides support.(http://wrmin.nic.in)

8. See http://jnnurm.nic.in for information of waste management in urban areas. 


\section{References}

Barefoot College Website, (http://www.barefootcollege.org).

Confederation of Indian Industry, Ministry of New and Renewable Energy and Government of India (2010), "Human resources development strategies for Indian renewable energy sector", (http://mnre.gov.in/file-manager/UserFiles/MNRE_HRD_ Report.pdf)

Central Rice Research Institute (CRRI) Website, (http://www.crri.nic.in)

Government of India (2009), National Policy on Skill Development, Government of India.

ILO (2011), Skills for Green Jobs: A Global View, , ILO, Geneva.

ILO Conference (2010), ILO National Conference on Green Jobs.

Indian Council of Agricultural Research (ICAR) Website, (http://www.icar.org.in)

Ministry of Agricultural and Co-operation, Annual Report of Ministry of Agricultural andCooperation, Government of India, New Delhi, various years.

Ministry of Environment and Forests, Annual Reports of Ministry of Environment \& Forests, Government of India, New Delhi, various years.

Ministry of Environment and Forests (2008), "National Action Plan on Climate Change", Prime Minister's Council on Climate Change, Government of India, New Delhi.

Ministry of New and Renewable Energy, Annual Reports of Ministry of New \& Renewable Energy, Government of India, New Delhi, various years.

Planning Commission (2008), $11^{\text {th }}$ Five Year Plan 2007-2012, Government of India, Oxford University Press, New Delhi.

Planning Commission (2011a), "Approach to the Twelfth Five Year Plan 2012-2017", Government of India, New Delhi.

Planning Commission (2011b), Expert Group on Low Carbon Strategy on Inclusive Growth, Government of India, New Delhi.

Planning Commission (2011c), Mid-term Appraisal: $11^{\text {th }}$ Five Year Plan 2007-2012, Government of India, Oxford University Press, New Delhi.

Planning Commission (2012), "Working Group Report on Skill Development for $12^{\text {th }}$ Five Year Plan", Government of India, New Delhi.

Ram Krishna Mission Lok Sikha Parishad Website (http://www.rkmnpur.org)

UNCSD NGO Steering Committee (1999), "Sustainable tourism: a non-governmental organization perspective". 
UNDP (2009), Climate Change: Perspectives from India, United Nations Development Programme, India, New Dehli.

UNEP, ILO, IOE and ITUC (2008), "Green job report, Policy messages and main findings for decision makers", UNEP, Nairobi.

Vipin Kumar (2009), Energy Imperative for developing World: Case study Brazil, China and India

Vipin Kumar, Kasturi Mandal, Naresh Kumar, Taposik Banerjee (2011), Skills for Green Jobs in India: Unedited Background Country Study, ILO Skills and Employability Department, ILO, Geneva. 


\title{
Chapter 27
}

\section{Skills development and green jobs in Thailand}

\author{
by \\ Silpa-Archa Nakorn
}

\section{Introduction}

Climate change has impacts on people and their employment, massively destroying jobs, reducing income and placing human and animals at risk. Figures compiled by the ILO indicated that $43 \%$ of the world labour force, 1.3 billion people, are working poor and 190 million are unemployed. What is even more staggering is that there will be 500 million young people seeking jobs in the next 10 years. There are 1.6 billion people who do not have access to energy, and 1 billion who are slum dwellers. Today, 180 million people are facing food shortages and by 2080 the figure will increase to 660 million.

Half of wild marine fisheries have been fully exploited more than a quarter of which are considered to be over exploited. It is speculated that 1.8 billion people will face water shortages and over 50 million will become environmental refugees. The last but not least of these alarming figures is that 262 million people are affected by climate change disasters. Skills development, therefore, needs to equip people to effectively respond to uncertainties and risks that negatively affect their employment and hinder their pursuit of a better life.

What factors need to be considered when developing skills plans for green growth? First, we have to clearly establish that "green growth" is the development issue. Secondly, constant poverty and employment insecurities are caused by "failed development". Another important factor is that economic growth and stability do not guarantee more jobs or increased security. Economic growth from previous decades came at the expense of environmental deterioration. However, green growth can also generate green jobs, like in Brazil where the introduction of bio-fuel generated 500000 jobs or the introduction of solar thermal in China which has created 1000 manufacturers and over 600000 jobs.

Green growth is, after all, a development issue. Therefore enhancing and sustainably educating people on the right approaches are critical. The provision of knowledge must go in hand in hand with instilling wisdom into the people. Economic crisis and recession can be seen as opportunities because people become more aware and consider the sufficient economy. New approaches to skills training and learning must be improved and enhanced when developing skills plans. Training must be learner-centred, reinforce employability and based on the concept of lifelong learning. 
What are the implications of transforming economies into low carbon? It must be borne in mind that green growth takes time and is more difficult than the introduction of massive production. Moreover, food and related commodity prices may go up as bio-fuel uses the same crops. Greening economies requires broad-based proactive policy and public-private investments; in order words, ways to overcome impediments to green jobs through knowledge and tools to assess, close the skills gap and monitor progress. Foreign direct investment may decrease. The impacts of climate change are caused by human ignorance and require sufficient time to allow ecosystems to naturally adapt to change. In the meantime, some measures and mechanisms can provide a safety net for people affected by the change.

\section{Green growth in Thailand}

In Thailand, the royal projects are outstanding examples of sufficiency economy. These projects are initiated by King Rama IX and have widely been practiced as part of rural development. Royal Projects have demonstration community based centres located in every part of Thailand.

The sufficiency economy is an approach to life and conduct of practice which is applicable at every level from the individual through the family and community to the management and development of the nation. Sufficiency in this sense has three major components which are moderation, reasonableness and self-immunity.

- Moderation meaning enough in the sense of not too little and enough in the sense of not too much.

- Reasonableness refers to being able to evaluate the reasons for any action and also understanding its full consequences - not only on oneself, but on others, the community and society as a whole as well as the environment.

- Self-immunity means having built-in resilience and the ability to withstand shocks and being able to adapt to changes and cope with unpredictable occurrences.

The sufficiency economy offers certain guidelines for approaching environmental problems within the framework of moderation, insight and resilience. Therefore royal projects seek solutions offered by nature in a traditional way while considering the impact they may have on other parts of the ecosystem. Moreover, the solutions are self-sustaining and economical. One outstanding example is Inpaeng Model (see Box 24.1).

The sufficiency approach is not confined to the agriculture sector; another example of the sufficiency economy and the environment also exists in the service business at Chumphon Cabana, a resort located on the east coast of Thailand's peninsula. This resort suffered financial difficulties like other businesses in the economic crisis of 1997 and the owner took inspiration from the sufficiency approach to keep the business running.

In terms of green jobs policy, since there has been growing awareness in Thailand of the fragility of the environment, the public sector as well as the private sector, have been combining their efforts to strengthening environmental sustainability. More specifically, Thailand has signed many important international environmental agreements covering a wide array of issues such as climate change, endangered species and nuclear test bans, and has been working very closely with international organisations like the United National Environment Program (UNEP). 


\section{Box 27.1. Inpaeng model}

\section{From cash crop to agro-forest}

Serm Udomna was one of the founders of the Inpaeng network. He started growing cassava in 1979 on a loan of THB 5 000, and by 1986, his debt had grown to THB 30000 . He decided: "We should grow what we can eat and use for our own consumption first. Then we may sell the surplus to our neighbours or process it to add value."

He gradually replaced cash crops with rice, vegetables and fruit trees. On his sloping land, he grew some trees from seed, and brought many other varieties from the nearby Phuphan forest to reproduce the forest's bio-diversity. This idea earned him a reputation. "Serm moved the Phuphan forest to his home." He soon found he had everything he needed including food, medicinal herbs, timber and firewood for his own family and neighbours. "I grow everything I want to eat and use in this forest. I don't need chemical fertilizer. In the natural forest there are no chemicals but the trees still grow very well. Trees with deeper roots get their food from deeper down. As they grow, their leaves fall, rot, and become nutrients for smaller trees and plants with shallower roots."

He had a daily income from the produce of his forest, rice field, fish ponds and poultry. After a few years, he stopped growing cash crops completely, and was able to pay back most of his old debts. Now he has about 260 kinds of trees in his forest and plans to increase it to 300 kinds within 2 years. He also raises a few cows which he regards as a savings bank. When he needs extra money such as fees for his children's higher education, he sells his cows. "My life today is much better. My own garden gives me safe food and medicinal plants which keep me healthy and free of sickness. I believe that prevention is the best solution to health care. As they say, you are what you eat."

Other people came to learn from him. His forest became a model widely copied through the Inpaeng network. He bought some more degraded land with plans to turn it into an agro-forest where children of the area could learn the practice. "It's not an easy job. I know I'll have to work harder. People who don't understand will laugh at me. But I have a strong will to do it. I was born a farmer and I've lived most of my life in this forest area. Besides learning the modern knowledge which they study from schools, I'd like the children to learn how to live in harmony with nature."

\section{Learning by doing and sharing}

In 1986, Tong Chaipanha visited the Royal Development Study Centre in Phuphan to learn about the King's model farm. His land was on a slope and not at all suited for rice. With the help of a loan of THB 38000 , he divided his 5 hectares into 8 areas for rice, fruit, fish ponds, vegetables, tree nursery, mushroom nursery, chicken runs, cattle grazing, and house. He grew rice mainly for home consumption. His orchard yielded lychees, grapes, longans and mangoes for his family's consumption and sale in the local market. In his four fish ponds he cultivated Nile tilapia, common carp, catfish and barb, which supplied his family with protein, and made some income from sales to neighbours. He used natural herbs for pest and weed control.

He found his income steadily grew, while his expenses - especially on chemicals - were being eliminated. The soil on the plot improved, and there were other benefits too: "Many kinds of insects and birds which I had not seen for years now come back to this area because it is free of chemicals which are harmful to them." Fifteen years after Tong had converted his farm, it became a demonstration site for interested farmers from every region in Thailand, including communities within the Inpaeng network. He provides training free of charge because he believes in the spirit of mutual support and generosity. Most visitors buy some fresh products from his farm.

Source: UNDP (2007), Thailand Human Development Report 2007: Sufficiency Economy and Human Development, UNDP, Bangkok. 
At the national level, green jobs and green growth were envisaged and incorporated within the $10^{\text {th }}$ National Economic and Social Development Plan. Under this plan, which was effective until 2011, the focus was on creating a good environment for quality of life and sustainable development through:

1. modification of patterns of production and consumer behaviour which reduce the impacts on the natural resource base and environment;

2. use of public policy and economic mechanisms to create a market for environmentally friendly goods and services;

3. reduction of pollution and activities that impact on the quality of life;

4. assessment of health and social impact of the government's development projects.

The primary mission of the Department of Skill Development is promoting skills development in the workplace, be it in the public or private sector. While its primary focus is on decent jobs, the department has increasingly attached more importance to the promotion of green jobs in all sectors, by considering that green trainings are, in fact, crucial human resources development activities.

In this context, the department has been using the Skill Development Promotion Act 2002 extensively to promote green workplace training and learning. Under this act, private enterprises can benefit from certain tax privileges if they undertake qualified human development training.

- Exemption on corporate income tax to $100 \%$ of the actual training expenses in training institutes authorised by the Ministry of Finance.

- Exemption on corporate income tax to $100 \%$ of the actual expenses for in-house training as approved by the Ministry of Labour.

One formidable example of "green training" is the project which materialised through a partnership between the Department of Skill Development, the Department of Industrial Works and UNEP. The main objective of this project is to help those providing refrigerator and car air conditioner repair and maintenance services to reduce the use of CFCs, as required by the Montreal Protocol. The scheme consisted of a series of seminars for trainers and workshops for service operators and mechanics.

The Ministry of Labour has been playing a pivotal role in promoting green jobs and green growth in Thailand and will continue to do so in the future. It will continue to work through tripartite co-operation among ministries, government agencies, private sector, with both employers and employees organisations. It hopes that through close co-operation it will be able to offer the following training programmes in the near future: green business (with the chamber of commerce), ecotourism (with the Ministry of Tourism and Sports), solar cell installation (with the Department of Industrial Works), biodiversity loss (with the Ministry of Natural Resources and Environment).

\section{References}

UNDP (2007), Thailand Human Development Report 2007: Sufficiency Economy and Human Development, UNDP, Bangkok. 


\section{Annex A}

\section{Note on contributors}

Caroline Alcorso is responsible for workforce development at State Training Services, at the NSW Department of Education and Training, Australia. Her unit develops and co-ordinates industry partnership programmes and innovation projects that address industry requirements for skilled workers, social and economic objectives, and individual needs for quality, sustainable employment opportunities. It combines policy development and programme management functions and has produced the 2011-2013 NSW Strategic Skills Plan. Programmes include the NSW Green Skills and Energy Efficiency Strategy as well as a range of regional initiatives that engage industry in employment and training partnerships. In 2009, Caroline worked for the federal government advisory body, Skills Australia, developing Australian Workforce Futures: A National Workforce Development Strategy. She has a Bachelor of Arts from the University of Tasmania and a Master of Arts from Cambridge University, England. In 2006 she completed a Doctor of Philosophy at the University of Sydney on immigrants and labour management in the information technology and hotel industries.

Sajid Manzoor Asadi is Deputy Director (Monitoring \& Evaluation) at the National Vocational \& Technical Education Commission (NAVTEC), Prime Minister's Secretariat, Pakistan. He is in charge of monitoring the implementation of the National Skill Strategy "Skilling Pakistan" and skills development programmes in close collaboration with the private sector. Previously he served as a Section Officer in charge of the Establishment Division, Cabinet Secretariat; and worked on projects related to civil servants' career planning. Mr. Asadi is currently undertaking a Master's degree in International Development Studies at the National Graduate Institute for Policy Studies (GRIPS), Tokyo. His research thesis is entitled "Gender wage disparities: a cross-section analysis in four regions of Pakistan".

Paul Barker is currently a senior Manager in the New Zealand Ministry of Education with responsibility for the education budget and key cross-cutting work streams. Paul has been extensively involved in the development of employment, education and training, and labour market policy. One of his current priorities is to better link the education system to wider social and economic goals - particularly through integrated skills development strategies. He has worked for the OECD and Australian Commonwealth Government and represented New Zealand at both the OECD and ILO. Previous roles in New Zealand have included the Prime Minister's Department and Department of Labour.

Milagros Campos Valles is the Director of the Technical-Vocational Education Task Force Office. Prior to her appointment as Director II in 2009, she was the Officer-in-Charge/Chief of Staff Development Division, Bureau of Alternative Learning System, Department of Education, Philippines. Under a "secondment contract/basis", she also served as Deputy Director for Professional Cum Training Manager of the Southeast Asian Ministers of Education and Training (SEAMEO VOCTECH), Brunei Darussalam. 
Currently she is the Research Co-ordinator of the SEAMEO VOCTECH's Philippine chapter. She is also a reviewer and writer of the SEAMEO VOCTECH Journal for Vocational and Technical Education and Training. Dr. Valles has conducted numerous research projects on various topics related to education and enhancing skills development. She is actively involved in capacity building programmes on TVET for administrators and implementers. Dr. Valles received an AB Journalism Degree from Quezon University, Manila. She also holds an M.A.Ed. in Educational Management and $\mathrm{PhD}$ in Educational Management. She pursued other graduate certificate courses in different international institutions.

Patrick Chan heads industry development at the Institute of Certified Public Accountants of Singapore (ICPAS), responsible for industry development of accountancy as a financial and business services sector under the auspices of the Ministry of Finance to develop Singapore into a global hub for accountancy services for Asia Pacific by 2020 . Prior to ICPAS, Patrick was the Director of Industry Development at Singapore Business Federation (SBF), the apex business chamber in Singapore with more than 17000 companies. Prior to SBF, Patrick was the Assistant General Manager at Corporate Brokers International, an investment and private equity company and co-chairman of Start-Up@Singapore and held various management and leadership positions across NUS Enterprise, KPMG Consulting's Banking \& Finance and Web/Wireless Enterprise Solutions Consultancy and Singapore Airlines (SIA) where he started as an SIA scholar.

Kyungsoo Choi is a Senior Fellow, Korea Development Institute (KDI), a government-sponsored research institute based in Seoul, Korea. He is currently on secondment to the LEED programme at the OECD. Mr. Choi received his Ph.D in economics from the University of Chicago in 1992, and M.A. and B.A. degrees from Seoul National University. He joined the KDI in 2000 and served in the macroeconomics and social policy divisions. He served as a Senior Policy Advisor to the Minister of Budget and Planning from 2006 to 2008, and a member of the Presidential Committee of Economic Advisors in 2009-2010. His research interest is in labour economics and social policies.

Jing Dong is the Deputy Division Director of Occupational Skill Testing Authority, Ministry of Human Resources and Social Security, China, which she joined in 2009. Ms. Dong previously worked in Wuhan Engine Factory and later joined the China Association of Worker's Education and Vocational Training. Ms. Dong earned her Bachelor's degree in Foreign Trade and her Master's degree in Management both from Wuhan University of Technology, China.

Yasuhiro Doui is Deputy Director, International Affairs Division, Ministry of Health, Labour and Welfare, Japan. He is in charge of international affairs related to the OECD work on health, labour and welfare, including the LEED programme. He joined the Ministry in 1992 and made contributions to the 1996 and 1997 editions of a white paper on labour. He worked for Embassy of Japan in Singapore as a labour attaché from 2001 to 2004.

Randall Eberts is President of the W.E. Upjohn Institute for Employment Research, an independent non-profit research organisation that conducts and supports research on policy-relevant employment and regional economic issues. Before joining the Institute in 1993, Dr. Eberts was Assistant Vice President and Economist at the Federal Reserve Bank of Cleveland. During 1991-1992, Dr. Eberts served as Senior Staff Economist on the President's Council of Economic Advisers. He was also Associate Professor of Economics at the University of Oregon and Visiting Assistant Professor at Texas 
A\&M University. Dr. Eberts' current research examines the role of local partnerships in workforce and economic development. He has worked with the OECD/LEED on several projects related to this topic. He has also prepared reports for the European Commission on the United States' experience with early identification of worker needs and the potential of service jobs to stimulate economic growth in Europe. He also works closely with federal and state governments to develop management tools using statistical analysis to help improve the performance of workforce programmes. He has published extensively in academic journals and has also authored and edited several books, the latest two being Labor Exchange Policy in the United States and Targeting Employment Services.

Noela Eddington is Director of the VET Strategy and Research, Department of Education and Training in Queensland, Australia where she works at developing policy and strategy to support the government's sustainability goals. Her current interests include the relationships between skills, workplaces and sustainable industry development. She has professional research and working relationships with colleagues in a number of countries, and has undertaken various projects for the WHO and United Nations in the Western Pacific region including Australia. In other capacities, Noela has served as a member of Australian Standards Committees, represented the Queensland Government on various national committees, prepared comprehensive environmental legislation, and represented TAFE Queensland International in Asia. She has organised conferences in Australia, edited conference proceedings, published widely in Australia and overseas, piloted new education and training programmes in Queensland, lectured in Queensland universities, and held senior positions in educational administration. She is a Major Groups delegate and member of the Education Caucus to the United Nations Commission for Sustainable Development, New York, and a working NGO delegate at meetings of the United Nations Framework Convention on Climate Change where her major interests relate to emerging issues around "green jobs".

Ghazlan Ghazali is currently Director of the Centre for Instructors and Advanced Skill Training (CIAST), Department of Skills Development, Ministry of Human Resources, Malaysia. Previously he held high positions in the Ministry of Human Resources as an Assistant Director of CIAST, Principal Assistant Director of the Technical Control Unit, Manpower Department, and Director of the Advanced Technology Training Centre. His expertise includes planning, implementation and management of all matters related to curriculum, equipment, and staff development involving high technology courses. He holds a Master's degree in Computer Science/Information Technology from MARA University of Technology, Malaysia, and a Bachelor's degree in Engineering from Concordia University, Canada.

Shanti Jagannathan joined the ADB in May 2010 as Education Specialist in the Poverty Reduction, Gender and Social Development division of the Regional and Sustainable Development Department. She is a member of the ADB's Education Community of Practice and works on ADB education sector policy and strategy, provides support to education operations in the field and is engaged in developing knowledge products for the education sector within $\mathrm{ADB}$ and with external partners in the sector. Prior to joining the ADB, she worked with the European Union as Development Adviser on education and social sector reform programmes in South Asia and on gender issues, democracy and human rights programmes and poverty alleviation and livelihood projects.

Seung Teak Kim is Director-General of the Human Capital Research Division at the Korea Labor Institute (KLI). Prior to joining KLI in October 2000, he worked for the Korea Institute for Industrial Economics and Trade (KIET) as a Research Fellow from 
1997 to 2000. He was a member of the Nation Strategy for Green Growth TFT of the Presidential Committee on Green Growth in 2009 and a member of sub-committees of Economic and Social Development Commission from 2007-2010. He has authored and co-authored several research papers on labour market and labour policies in Korea.

Graham Larcombe is Director of the Strategic Economics Group and one of Australia's leading industry and labour market economists. His expertise includes: extensive research and policy experience in urban planning and regional development ranging from metropolitan and regional development strategies to community economic development strategies; extensive research and policy experience in economic development and industry development including high value-added engineering, construction, education, finance and business services, cultural and creative industries etc.; management of large projects entailing analytical, negotiating, data evaluation, and strategic and project management and leadership skills in both the public and private sectors; specialist analyst of education and training planning, urban planning, infrastructure and transport. He has a broad international experience in Asia and Africa.

Marissa Grasparil Legaspi is currently Chief of Staff of the Office of the Director General and Director-in-Charge of the Project Management Office for the Training in the Technical Education and Skills Development Authority (TESDA), the lead government agency in the Philippines for technical-vocational education and training (TVET). Prior to this, she was the Executive Director of the Planning Office. She rose from the ranks in government service to planning division chief and a provincial director from an economic background. She has done extensive research in the areas of technical-vocational education and training, policy and planning, management, leadership, quality and productivity, and participated in numerous international seminars and conferences. She received a B.S. degree in Statistics in 1980, a Certificate in Development Economics in 1989 from the University of the Philippines, and an M.A. in Development Management from the Asian Institute of Management.

Kouqing $\mathbf{L i}$ is the Deputy Director-General of Asia-Pacific Finance and Development Center (AFDC), Vice-President of Shanghai National Accounting Institute (SNAI), and Deputy Secretary of SNAI's Party Committee, professor. Born in 1965, Mr. Li received his Master's degree in Economics from Shanghai University of Finance and Economics (SUFE) in 1988 and PhD in Business Administration from the School of International Business Administration at SUFE in 2001. In 1988 he joined the Department of Economics in Shanghai University of Finance and Economics as a faculty member. From 1996 to 1997 he was a visiting scholar at the American Graduate School of International Management (Thunderbird). In 1998-2000 he served as Chinese administrator of Sino-US Joint MBA Program at SUFE.

Yongtang Ma is Director of the Overseas Labor and Employment Division in the Institute for International Labor and Social Security, Ministry of Human Resources and Social Security, China. He has more than 20 years of working experience in different research and academic institutions for labour studies, such as the Chinese Academy of Labor and Social Security, the International Institute for Labor Studies in ILO, and the Institute for International Labor and Social Security. Professor Ma is the author of about 40 books and monographs related to labour studies. He is also a member of many professional bodies such as the Professional Evaluation Committee of the Chinese Academy of Labor and Social Security, Academic Committee of the Institute for International Labor and Social Security, and Special Invited Expert of the China Employment Promotion Association. 
Cristina Martinez-Fernandez is a Senior Policy Analyst on Employment and Skills, Green Growth and Southeast Asia at the Organisation for Economic Co-operation and Development (OECD), Local Economic and Employment Development (LEED) programme. She works on issues related to the challenges of skills and training systems for SMEs, entrepreneurial and innovation activities; industrial policy, climate change and the transformation of labour markets into the low-carbon economy; the challenges of demographic change and an ageing society for skills and employment development. Cristina also manages the OECD/LEED initiative on Employment and Skills Strategies in Southeast Asia (ESSSA). Before joining the OECD she was an Associate Professor at the Urban Research Centre, University of Western Sydney in Australia where she led the Urban and Regional Dynamics Programme which analyses industry change, urban performance and socio-economic development within the frameworks of innovation, globalisation and the knowledge economy.

Silpa-Archa Nakorn is Director-General of the Department of Skill Development, Ministry of Labour, Thailand. In 2008 he was Deputy Permanent Secretary, Ministry of Labour and previously appointed Director-General of the Department of Employment, Ministry of Labour in 2002. He holds a Bachelor's degree in Law from the Thammasat University and served as a Lawyer at the Office of the Council of State in 1983 and afterwards as Provincial Chief State Attorney of the Attorney General Office, Office of the Attorney General until 1995 when he entered the then Ministry of Labour and Social Welfare.

Yoko Nitta is currently Associate Fellow of the Research Institute of Science and Technology for Society (RISTEX)/Japan Science and Technology Agency (JST). She has been intensely involved in science diplomacy in Japan and is an official member of the Science and Technology Diplomatic Circle in Tokyo building bridges in many international co-operative activities. She has been a professional researcher in various fields including global affairs related with the Ministry of Foreign Affairs. She previously served as an international negotiator at RIKEN. Thus, she is well-acquainted with global affairs and negotiation strategies with interdisciplinary knowledge. Ms. Nitta has organised the OECD workshop "Transforming Innovation to Address Social Challenge" and its approach is incorporated into OECD Innovation Strategy including Ministerial Conclusions in 2010. She currently oversees an ambitious effort to foster innovation to address social challenges. She has global responsibility of shaping its agenda. In this role, she manages an exclusive list of top industry leaders, top knowledge experts, civil society leaders and government and public figures in pursuit of changing the state of the world. Thus, she has broad responsibilities for developing global bridges through her mission. Currently she is co-writing a book on Japan Science and Technology Policy for Social Innovation.

Kyetaik Oh is an associate research fellow at Office of Research in Employment and Skills Development, Korea Research Institute for Vocational and Educational Training (KRIVET) based at Seoul, Korea. He received his Ph. D in Industrial Relations from the University of Wisconsin at Madison, and M.A. and B. A. degrees from SungKyunKwan University. He joined Korean Research Institute for Vocational and Education Training this year and served as a research fellow in Korea Labor Institute in 2007, and an assistant professor in ChungAng University between 2009 and 2010. His research interests include Strategic Human Resource Management, Human Resource Management practices, compensation program, foreign worker policies, non-regular worker policies, the interaction between HRM and labor market, and job creation in the ecosystem of companies. 
Bing Hung Pang is General Manager of the Qualifications Framework Secretariat (QFS) set up in 2009 by the government of Hong Kong, China for workers' skills development policies. He is one of the few pioneers of the programme. Previously he was appointed Deputy Executive Director of the Employees Retraining Board and served as Labour Officer of the Labour Department in the SAR Government. He currently leads a team of staff serving 17 Industry Training Advisory Committees (ITACs), which steer the development of a full set of competency requirements and standards for the industries, as well as a recognition of prior learning mechanism under QF.

Bhavani Prakash is a Singapore-based recruiter, trainer, speaker and writer in the environment/sustainability sector. She set up Green Collar Asia in 2011 with the objective of integrating, simplifying and bringing into the public domain various green jobs-related trends and data in Asia. In addition, the portal is designed to share the expertise and experiences of various green professionals and entrepreneurs that would be of value to those embarking on a similar journey. She has been writing regularly on green industry topics for local online publications. She has an MBA in Finance from the Indian Institute of Management Calcutta, India and an MSc in Financial Economics from the University of London. She also holds a certificate in EQ coaching from Six Seconds.org

Baburam Ranabhat is Executive Director of the Industrial Enterprise Development Institute (IEDI) of Nepal. Prior to joining IEDI in January 2005, he worked for the Centre for Business Development (CEBUD) as Managing Director from 1998 to 2004, as Director of the Entrepreneurship Development Centre from 1997 to 1998. He also worked as a trainer/consultant in various national and international agencies including ILO, UNDP, GTZ, SDC, ADB and others. He has conducted various entrepreneurship development training programmes and studies in India, Sri Lanka, Pakistan and Afghanistan.

Sunita Shanghi, an officer of the Indian Economic Service, works at a senior management level as an Adviser in the Planning Commission, Government of India. She has more than 25 years of experience in different ministries of the Government of India. At present she is looking after the work relating to preparation of National Five Year Plans and issues pertaining to labour, employment and manpower. She has been deeply associated with the Co-ordinated Action on Skill Development and other labour matters. She has a Master's degree in Economics from Delhi University, India and a Master's degree in Development Studies from University of East Angila, United Kingdom.

Jeevan Sharma is an officer of the Central Secretariat Service. She has worked in different capacities in the central Government of India. Presently she works in the Labour Employment and Manpower Division of the Planning Commission. She has a Master's degree in English.

Sally Sinclair is CEO of the National Employment Services Association, the peak body for the Australian employment and related services industry. Sally has extensive expertise in the design, development and delivery of employment and related services and has been instrumental in informing key stakeholders on addressing Australia's employment and inclusion challenges. Sally is currently a representative on the Minister's Consultative Forum on Mature Age Participation, the Minister's Indigenous Employment and Enterprise Action Group, the Workforce Development Supply and Demand Principal Committee, the Employment Services Industry Reference Group and the Minister's Disability Employment Reference Group. Sally is a board member of the OECD LEED programme's Forum on Partnerships and Local Governance. 
Amartugs Tsenddavaa is Deputy Director of the Information, Monitoring, and Evaluation Department, Ministry of Social Welfare and Labor, Mongolia. She is in charge of economic policies analysis and forecasting employment and labour market trends. She actively co-operates with different international organisations such as various UN agencies. Amartugs has a Bachelor's degree in Labor Economics from the Institute of Mongolia, an MBA from the National University of Mongolia, and an MPA from the Flinders University of Australia.

Hoang Ngoc Vinh is the Director-General of Department of Vocational and Technical Education, Ministry of Education and Training, Viet Nam. Mr. Hoang is in charge of developing a national policy in the fields related to vocational and technical education. Mr. Hoang is also Chief Secretary of the National Steering Board for Training Workforce towards Demand-driven Growth. He authored several research papers published in Viet Nam and abroad. He received a Bachelor's degree in Mechanical Engineering from Hanoi Agricultural University and Master's degree in Education focused on TVE from Sydney University, Australia. Mr. Hoang has also attended a number of international training courses on TVET.

Va Vuthy is the Director of the Vocational Orientation Department, Ministry of Education, Youth and Sport, Cambodia. He was a Team Leader and Deputy Director of the Curriculum Development Department. He was selected to this position from a pool of high school biology teachers and lecturers from rural high schools of Cambodia and also from the Regional Teacher Training Centre. He jointly published several biology textbooks for high school students. Mr. Vuthy holds a Master's degree in Educational Management from the National University of Malaysia, where he conducted a critical review on the development of basic education in Cambodia for a period of about two and half decades while the country underwent three governments. Firstly, the Government of the People's Republic of Kampuchea (PRK) ruled the country after the collapse of genocidal regime in 1979 to 1989, secondly, the government of the State of Cambodia (SOC) which ruled from 1989 to 1993, and lastly the Royal Government of Cambodia (RGC) which ruled the country from 1993 to the present.

Tamara Weyman works as a contracted expert for the OECD, working on various projects involving employment and skills, SMEs development, Southeast Asia, territorial development policy, and demographic change and sustainability. Tamara worked as a Research Associate at the Urban Research Centre, University of Western Sydney (UWS) and completed her $\mathrm{PhD}$ on Spatial Information Sharing for Better Regional Decision Making in 2007 at UWS. Since 2009, Tamara has been involved in the COST Action TU 0803 "Cities Regrowing Smaller".

Dhida Wiwaha is the Director of the Planning and Technology Division, Department of Skill Development (DCD), Ministry of Labour, Thailand. She has more than 30 years of professional experience in skills development. She started her career as Senior Officer in the Labor Office in Kanjanaburi Province, Thailand. Later she served as Chief of Training Co-ordination of DCD offices in various provinces of the country. Prior to her current appointment, Ms. Wiwaha held high rank positions at executive level in different divisions of DCD of the Ministry of Labor. She received her Bachelor's degree in Political Science from Thammasat University and also holds a Master's degree in Social Welfare.

Yasuhiko Yoshida is Senior Fellow at the Research Institute of Economy, Trade and Industry (RIETI), which is an incorporated Japanese administrative agency located in Tokyo. He also serves as Director of International Co-ordination and Public Relations. 
Prior to joining RIETI in August 2010, he worked as a Principal Administrator at the OECD where he carried out analytical work on SMEs and entrepreneurship, especially in the field of access to finance, innovation, globalisation and high-growth SMEs from 2007 to 2010. He has extensive experience in planning as well as research of economic policies, mainly industrial, trade and energy policies (including those on technical assistance to Asian countries, response to the Asian financial crisis, trade liberalisation and manufacturing industry promotion) in the Ministry of Economy, Trade and Industry (METI) of the Japanese Government. 


\section{Annex B}

Figure B.1. Shares of higher-skilled occupations in employment

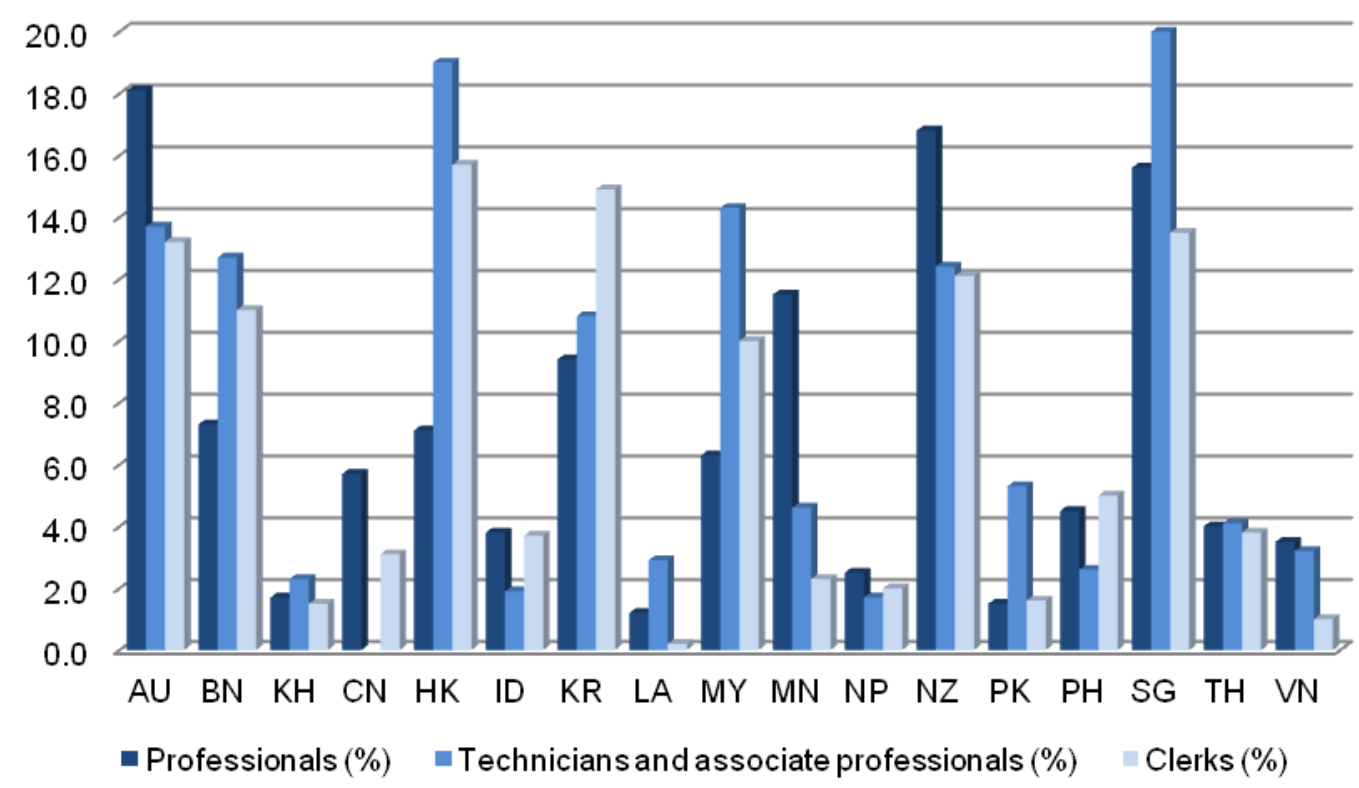

Notes: Australia (AU); Brunei Darussalam (BN); China (CH); Cambodia (KH); Hong Kong, China (HK); Indonesia (ID); Japan (JP); Korea (KR); Lao People's Democratic Republic (LA); Malaysia (MY); Mongolia (MN); Nepal (NP); New Zealand (NZ); Pakistan (PK); Philippines (PH); Singapore (SG); Thailand (TH); and Viet Nam (VN). Data for Brunei Darussalam and Nepal are for 2001; China for 2005; Lao People's Democratic Republic for 1995; Malaysia for 2009; Viet Nam for 2004.

Source: Based on ILO (2011), Key Indicators of the Labour Markets (KILM), $7^{\text {th }}$ edition, ILO, Geneva. 
Figure B.2. Shares of medium-skilled (trade and machine operators/assemblers) occupations in employment

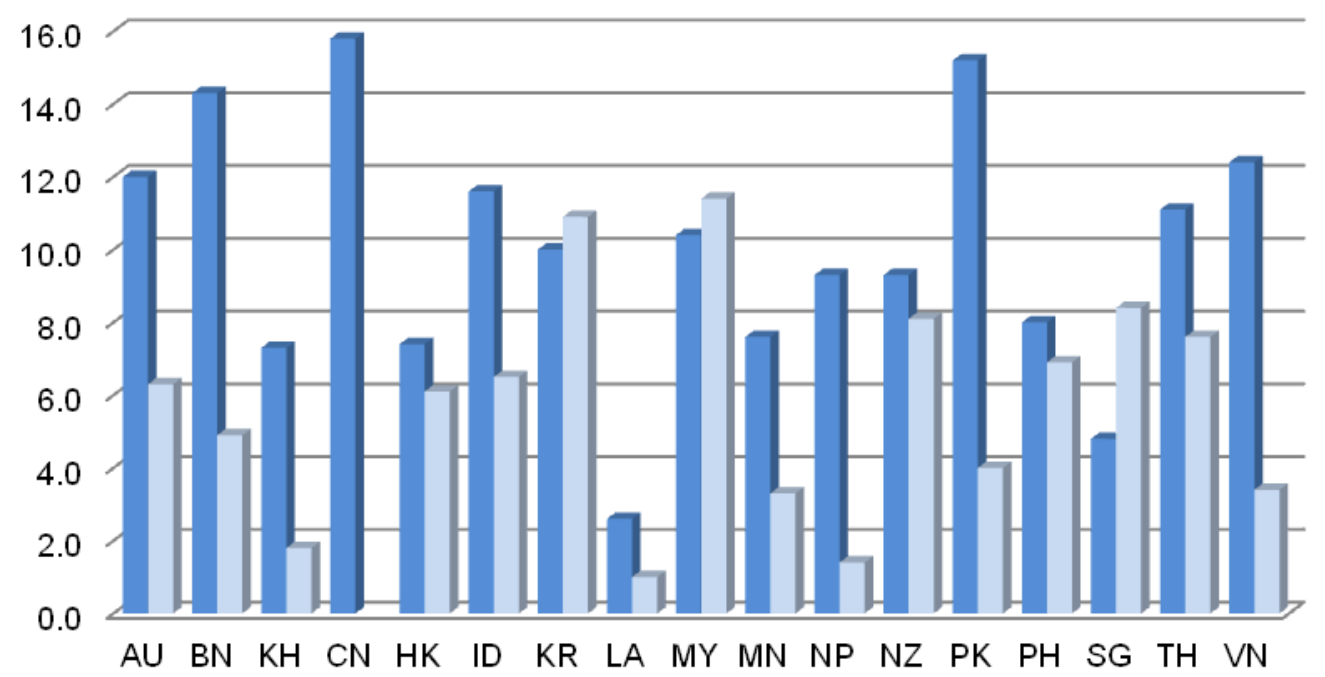

- Craft and related trades workers (\%) $\quad$ Plant and machine operators and assemblers $(\%)$

Notes: Australia (AU); Brunei Darussalam (BN); China (CH); Cambodia (KH); Hong Kong, China (HK); Indonesia (ID); Japan (JP); Korea (KR); Lao People's Democratic Republic (LA); Malaysia (MY); Mongolia (MN); Nepal (NP); New Zealand (NZ); Pakistan (PK); Philippines (PH); Singapore (SG); Thailand (TH); and Viet Nam (VN). Data for Brunei Darussalam and Nepal are for 2001; China for 2005; Lao People's Democratic Republic for 1995; Malaysia for 2009; Viet Nam for 2004.

Source: Based on ILO (2011), Key Indicators of the Labour Markets (KILM), $7^{\text {th }}$ edition, ILO, Geneva.

Figure B.3. Shares of agricultural and elementary occupations in employment

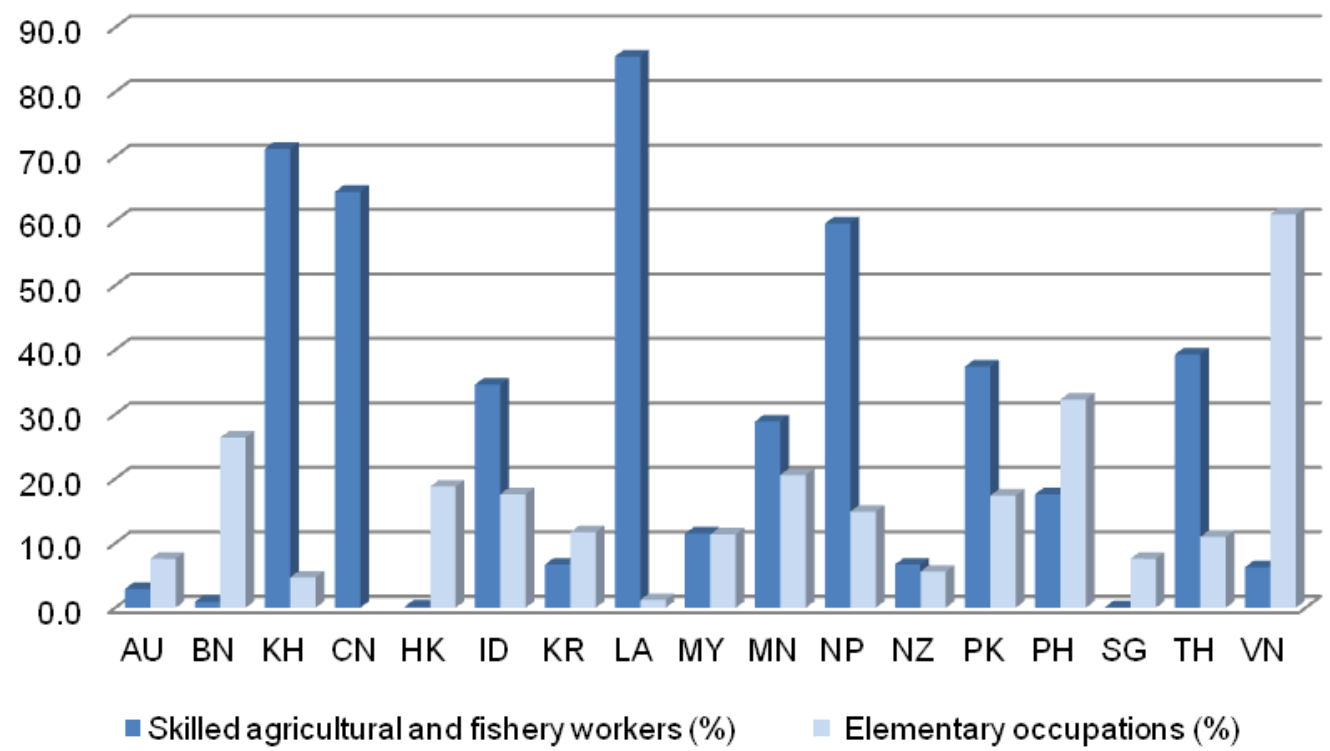

Notes: Australia (AU); Cambodia (KH); China (CH); Hong Kong, China (HK); Indonesia (ID); Japan (JP); Korea (KR); Malaysia (MY); Mongolia (MN); New Zealand (NZ); Pakistan (PK); Philippines (PH); Singapore (SG); Thailand (TH); and Viet Nam (VN). Data for Malaysia is for 2009.

Source: Based on ILO (2011), Key Indicators of the Labour Markets (KILM), $7^{\text {th }}$ edition, ILO, Geneva. 


\section{Annex $C$}

Table C.1. Educational attainment by labour force (age cohort), 2008

\begin{tabular}{|c|c|c|c|c|c|c|}
\hline Country & Age group & Primary (\%) & Secondary (\%) & Tertiary (\%) & $\begin{array}{c}\text { Not definable } \\
\text { by level and level } \\
\text { not stated (\%) }\end{array}$ & Age \\
\hline \multirow{2}{*}{ Australia } & Youth & 26.5 & 47.6 & 25.9 & & $15-29$ \\
\hline & Adult & 27.7 & 35.0 & 37.3 & & $30-64$ \\
\hline \multirow{2}{*}{ Hong Kong, China } & Youth & 12.1 & 52.3 & 35.6 & & $15-29$ \\
\hline & Adult & 34.6 & 41.9 & 23.4 & & $30+$ \\
\hline \multirow{2}{*}{ Indonesia } & Youth & 61.3 & 31.6 & 7.1 & & $15-29$ \\
\hline & Adult & 75.1 & 17.7 & 7.1 & & $30+$ \\
\hline \multirow{2}{*}{ Japan } & Youth & 49.0 & & 51.0 & & $15-34$ \\
\hline & Adult & 62.5 & & 37.5 & & $35+$ \\
\hline \multirow{2}{*}{ Korea } & Youth & 3.3 & 44.0 & 52.7 & & $15-29$ \\
\hline & Adult & 27.5 & 41.5 & 31.0 & & $30+$ \\
\hline \multirow{2}{*}{ Malaysia } & Youth & 11.5 & 63.0 & 25.5 & & $15-29$ \\
\hline & Adult & 28.9 & 52.2 & 18.9 & & $30-64$ \\
\hline \multirow{2}{*}{ New Zealand } & Youth & 18.0 & 47.7 & 29.8 & 4.4 & $15-29$ \\
\hline & Adult & 17.8 & 38.8 & 38.6 & 4.7 & $30+$ \\
\hline \multirow{2}{*}{ Pakistan } & Youth & 59.0 & 14.9 & 25.7 & 0.4 & $15-29$ \\
\hline & Adult & 65.6 & 9.1 & 24.6 & 0.6 & $30+$ \\
\hline \multirow{2}{*}{ Philippines } & Youth & 23.3 & 45.9 & 30.9 & & $15-34$ \\
\hline & Adult & 41.8 & 33.0 & 25.3 & & $35+$ \\
\hline \multirow{2}{*}{ Singapore } & Youth & 5.8 & 65.3 & 28.9 & & $15-29$ \\
\hline & Adult & 28.9 & 46.0 & 25.1 & & $30+$ \\
\hline
\end{tabular}

Notes: Australia (AU); Hong Kong, China (HK); Indonesia (ID); Japan (JP); Korea (KR); Malaysia (MY); New Zealand (NZ); Pakistan (PK); Philippines (PH); Singapore (SG).

Primary level includes ISCED-97 level: 1) basic education and 2) lower secondary education. Secondary level includes: 3) upper secondary and 4) post-secondary non-tertiary. Tertiary includes: 5) fist-stage tertiary and 6) second-stage tertiary education. For Japan "primary" includes the secondary.

Data for Korea is for 2007.

Source: Based on ILO (2011), Key Indicators of the Labour Markets (KILM), $7^{\text {th }}$ edition, ILO, Geneva. 
Table C.2. Ratio of total graduates to labour force by field of education (\%)

\begin{tabular}{|c|c|c|c|c|c|c|c|c|c|c|c|c|c|c|c|c|c|}
\hline \multirow[b]{2}{*}{ Country } & \multirow[b]{2}{*}{ Year } & \multicolumn{2}{|c|}{ Education } & \multicolumn{2}{|c|}{ Humanities and arts } & \multicolumn{2}{|c|}{$\begin{array}{l}\text { Social sciences, } \\
\text { business and law }\end{array}$} & \multicolumn{2}{|c|}{ Science } & \multicolumn{2}{|c|}{$\begin{array}{l}\text { Engineering, manufacturing } \\
\text { and construction }\end{array}$} & \multicolumn{2}{|c|}{ Agriculture } & \multicolumn{2}{|c|}{$\begin{array}{l}\text { Health and } \\
\text { welfare }\end{array}$} & \multicolumn{2}{|c|}{ Services } \\
\hline & & 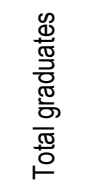 & 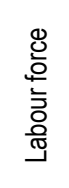 & 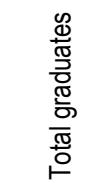 & 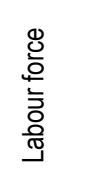 & 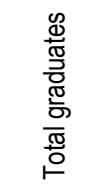 & 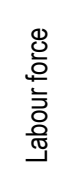 & 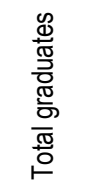 & 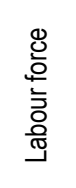 & 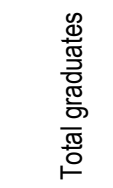 & 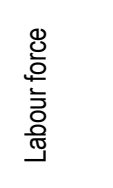 & 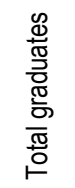 & 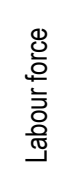 & 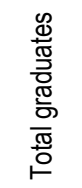 & 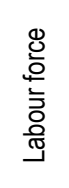 & 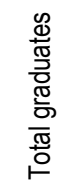 & 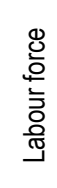 \\
\hline Australia & 2008 & 9.06 & 0.26 & 10.61 & 0.30 & 44.89 & 1.28 & 10.00 & 0.29 & 8.06 & 0.23 & 0.95 & 0.03 & 15.29 & 0.44 & 2.99 & 0.09 \\
\hline Brunei Darussalam & 2010 & 42.27 & 0.36 & 8.78 & 0.08 & 11.76 & 0.10 & 11.52 & 0.10 & 10.39 & 0.09 & & & 10.99 & 0.09 & & \\
\hline Cambodia & 2008 & 2.18 & 0.00 & 13.92 & 0.00 & 66.17 & 0.01 & 9.41 & 0.00 & 3.08 & 0.00 & 2.08 & 0.00 & 3.10 & 0.00 & 0.05 & 0.00 \\
\hline Hong Kong, China & 2006 & 10.97 & 0.13 & 9.63 & 0.11 & 32.74 & 0.37 & 15.14 & 0.17 & 19.53 & 0.22 & & & 4.74 & 0.05 & 1.34 & 0.02 \\
\hline Indonesia & 2010 & 19.52 & 0.13 & 0.48 & 0.00 & 38.98 & 0.27 & 6.04 & 0.04 & 16.73 & 0.12 & 6.25 & 0.04 & 6.17 & 0.04 & & 0.00 \\
\hline Japan & 2009 & 6.91 & 0.11 & 15.03 & 0.23 & 26.55 & 0.41 & 3.05 & 0.05 & 17.50 & 0.27 & 2.41 & 0.04 & 12.99 & 0.20 & 9.26 & 0.14 \\
\hline Korea & 2009 & 8.27 & 0.21 & 17.80 & 0.44 & 20.88 & 0.52 & 7.55 & 0.19 & 23.91 & 0.59 & 1.24 & 0.03 & 14.08 & 0.35 & 6.28 & 0.16 \\
\hline $\begin{array}{l}\text { Lao People's } \\
\text { Democratic Republic }\end{array}$ & 2006 & 20.01 & 0.05 & 25.77 & 0.07 & 10.43 & 0.03 & 1.25 & 0.00 & 11.56 & 0.03 & 11.04 & 0.03 & 2.17 & 0.01 & 4.29 & 0.01 \\
\hline Malaysia & 2009 & 16.61 & 0.33 & 3.56 & 0.07 & 30.70 & 0.60 & 13.94 & 0.27 & 23.78 & 0.47 & 0.54 & 0.01 & 7.73 & 0.15 & 2.52 & 0.05 \\
\hline Mongolia & 2010 & 14.67 & 0.42 & 10.21 & 0.30 & 41.36 & 1.20 & 5.44 & 0.16 & 11.70 & 0.34 & 2.35 & 0.07 & 8.23 & 0.24 & 6.02 & 0.17 \\
\hline Nepal & 2010 & 25.50 & 0.09 & 21.60 & 0.07 & 25.06 & 0.09 & 6.17 & 0.02 & 17.06 & 0.06 & 0.55 & 0.00 & 3.44 & 0.01 & 0.63 & 0.00 \\
\hline New Zealand & 2009 & 12.74 & 0.33 & 15.06 & 0.40 & 34.05 & 0.89 & 14.02 & 0.37 & 6.53 & 0.17 & 1.17 & 0.03 & 14.36 & 0.38 & 4.57 & 0.12 \\
\hline Philippines & 2004 & 20.42 & 0.23 & 2.50 & 0.03 & 33.35 & 0.38 & 10.22 & 0.12 & 14.09 & 0.16 & 3.67 & 0.04 & 8.28 & 0.10 & & 0.00 \\
\hline Viet Nam & 2010 & 27.50 & 0.15 & 3.82 & 0.02 & 32.84 & 0.17 & & & 16.76 & 0.09 & 7.99 & 0.04 & 4.15 & 0.02 & 3.34 & 0.02 \\
\hline
\end{tabular}

Source: Based on UNESCO, Institute for Statistics (graduate statistics); and ILO (2011), Key Indicators of the Labour Markets (KILM), $7^{\text {th }}$ edition (labour force statistics), ILO, Geneva. 
Figure C.1. Broad field of education (tertiary) as a ratio to total graduates

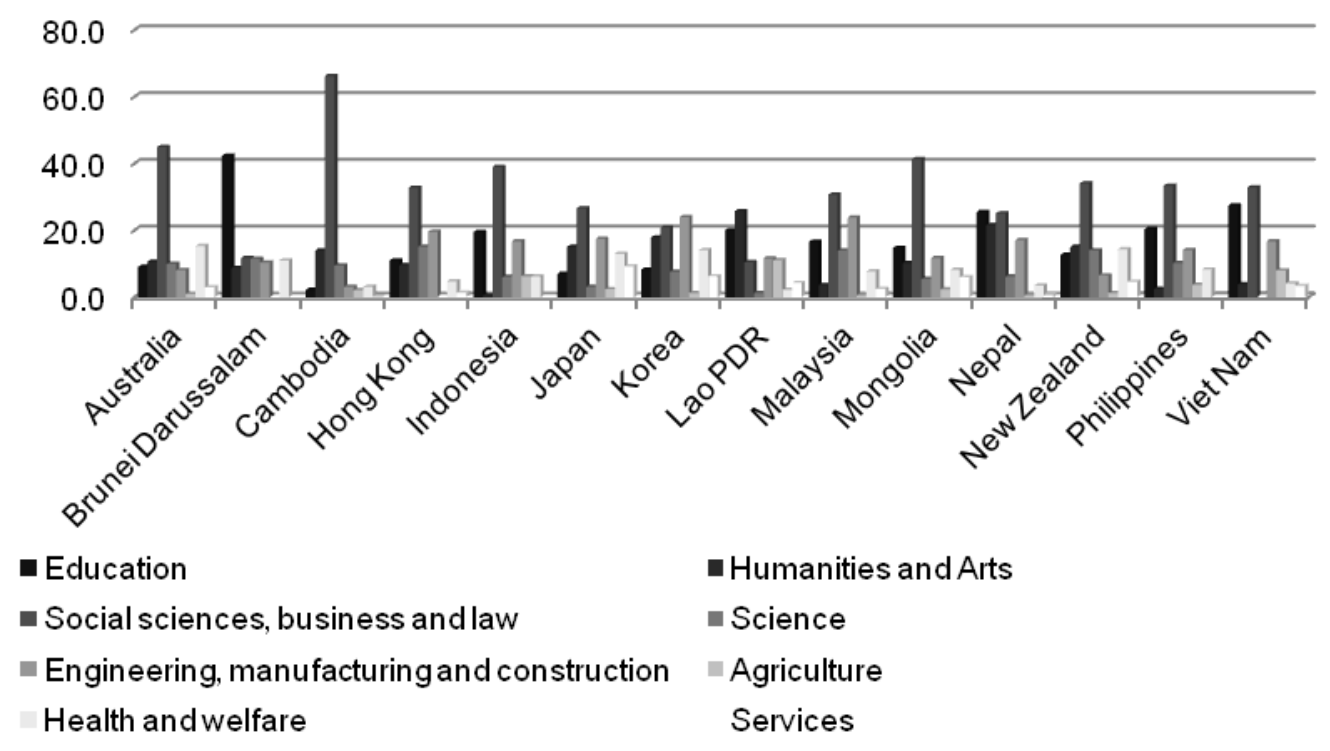

Source: Based on UNESCO, Institute for Statistics (graduate statistics). 



\section{Annex D}

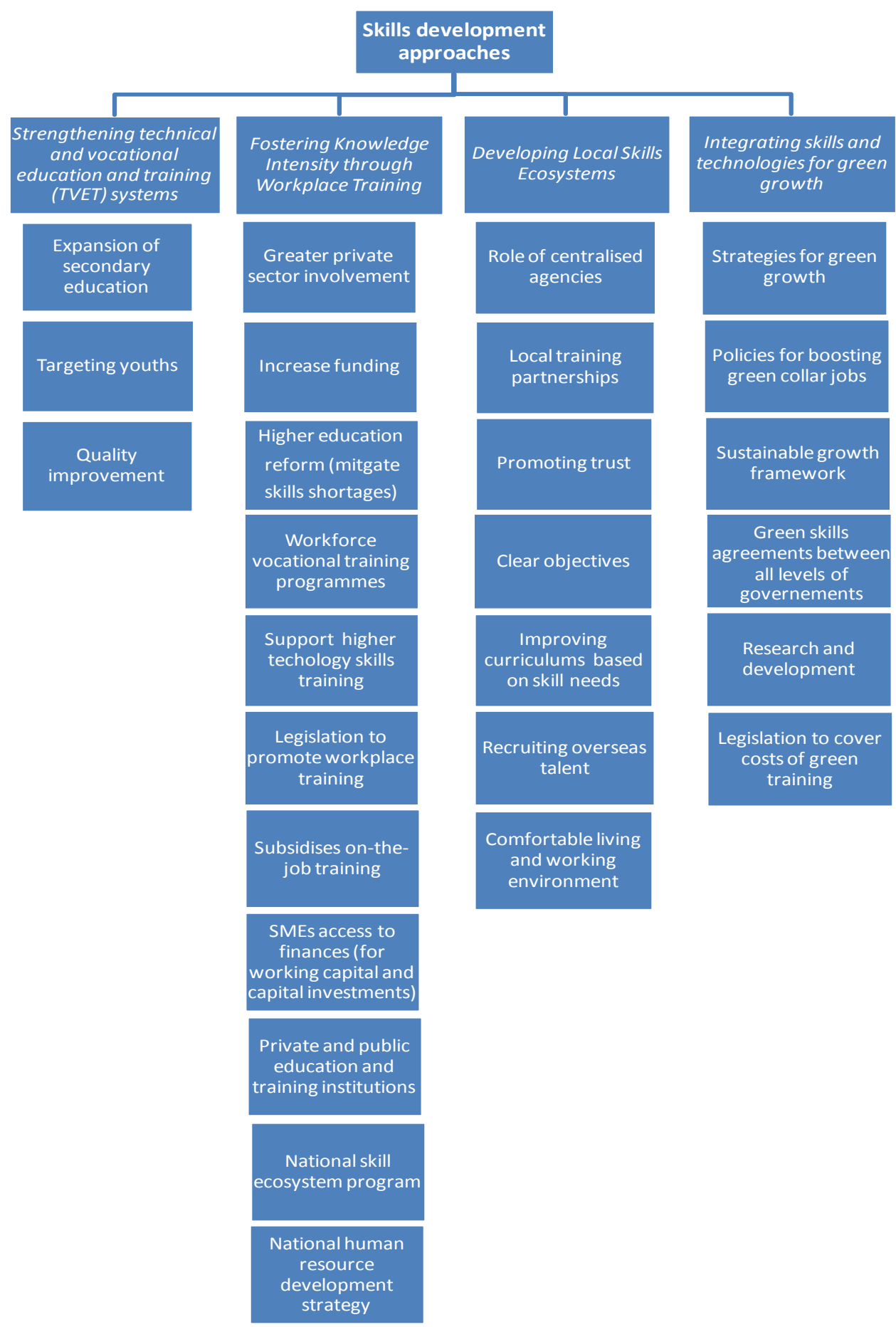






\section{Skills Development Pathways in Asia}

Skills and educational development for inclusive and sustainable growth are becoming significant drivers in OECD countries. Asian countries are not lagging behind on the challenge; on the contrary, they are working towards developing integrated pathways of skills and employment.

This report focuses on current efforts in 15 countries in the Asian region: Australia, Cambodia, China, Hong Kong, China, India, Japan, Korea, Malaysia, Mongolia, Nepal, Pakistan, the Philippines, Singapore, Thailand and Viet Nam. Together, these countries represent one of the most dynamic regions in the world, with steady growth, even during the recent financial crisis.

The initiative on Employment and Skills Strategies in Southeast Asia (ESSSA) facilitates the exchange of experiences on employment and skills development. Its objectives are to guide policy makers in the design of policy approaches able to tackle complex cross-cutting labour market issues; to build the capacity of practitioners in implementing effective local employment and skills development strategies; and to assist in the development of governance mechanisms conducive to policy integration and partnership at the local level.

For more information on the ESSSA initiative, please visit www.oecd.org/cfe/leed/employment/esssa.
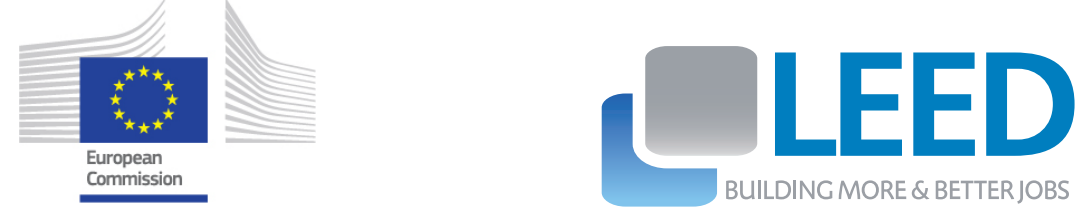